\title{
Mentalization and psychosis
}

Citation for published version (APA):

Weijers, J. (2020). Mentalization and psychosis: trying to understand the un-understandable. [Doctoral Thesis, Maastricht University]. Ridderprint. https://doi.org/10.26481/dis.20201208jw

Document status and date:

Published: 01/01/2020

DOI:

10.26481/dis.20201208jw

Document Version:

Publisher's PDF, also known as Version of record

\section{Please check the document version of this publication:}

- A submitted manuscript is the version of the article upon submission and before peer-review. There can be important differences between the submitted version and the official published version of record.

People interested in the research are advised to contact the author for the final version of the publication, or visit the DOI to the publisher's website.

- The final author version and the galley proof are versions of the publication after peer review.

- The final published version features the final layout of the paper including the volume, issue and page numbers.

Link to publication

\footnotetext{
General rights rights.

- You may freely distribute the URL identifying the publication in the public portal. please follow below link for the End User Agreement:

www.umlib.nl/taverne-license

Take down policy

If you believe that this document breaches copyright please contact us at:

repository@maastrichtuniversity.nl

providing details and we will investigate your claim.
}

Copyright and moral rights for the publications made accessible in the public portal are retained by the authors and/or other copyright owners and it is a condition of accessing publications that users recognise and abide by the legal requirements associated with these

- Users may download and print one copy of any publication from the public portal for the purpose of private study or research.

- You may not further distribute the material or use it for any profit-making activity or commercial gain

If the publication is distributed under the terms of Article $25 \mathrm{fa}$ of the Dutch Copyright Act, indicated by the "Taverne" license above, 


\section{Mentalization and psychosis}

Trying to understand the "un-understandable"

Jonas Gijs Weijers 
Mentalization and Psychosis: trying to understand the "un-understandable" Jonas Gijs Weijers

PhD Dissertation

ISBN 978-94-6416-215-8

(C) Copyright Jonas Gijs Weijers, 2020, the Netherlands

All rights reserved. No part of this thesis may be reproduced or transmitted in any form or by any means, without the written permission of the author.

Cover design by Sjoerd Wenting

Photography by Jeroen Berends

Print: Ridderprint | www.ridderprint.nl 


\title{
Mentalization and psychosis \\ Trying to understand the "un-understandable"
}

\author{
ACADEMISCH PROEFSCHRIFT
}

ter verkrijging van de graad van doctor aan de Universiteit Maastricht, op gezag van de Rector Magnificus, Prof.dr. Rianne M. Letschert volgens het besluit van het College van Decanen,

in het openbaar te verdedigen

op dinsdag 8 december 2020 om 10.00 uur

door

Jonas Gijs Weijers

Geboren op 8 april 1986 te Nijmegen 


\section{Promotores}

Prof. Dr. J.-P.C.J. Selten

Prof. Dr. E.H.M. Eurelings-Bontekoe (Universiteit Leiden)

\section{Copromotor}

Dr. W.V. Viechtbauer

\section{Beoordelingscommissie}

Prof. dr. B.P.F. Rutten (Voorzitter)

Dr. C.E.C. Henquet

Prof. dr. D.E.J. Linden

Prof. dr. P. Luyten (Katholieke Universiteit Leuven, België)

Prof. dr. C.L. Mulder (Erasmus Universiteit Rotterdam)

The research presented in this thesis was conducted at the School of Mental Health and Neuroscience (MHeNS), Department of Psychiatry and Neuropsychology of Maastricht University, Rivierduinen Institute for Mental Health Care and Altrecht Institute for Mental Health Care. 


\section{Table of contents}

\begin{tabular}{|c|c|c|}
\hline PART I & Theoretical outline & 7 \\
\hline Chapter One & General Introduction & 9 \\
\hline Chapter Two & $\begin{array}{l}\text { Mentalization and psychosis: a rationale for the use of mentalization } \\
\text { theory to understand and treat non-affective psychotic disorder }\end{array}$ & 25 \\
\hline PART II & Childhood abuse and psychosis & 47 \\
\hline Chapter Three & $\begin{array}{l}\text { Reported childhood abuse and stress reactivity in psychosis: a } \\
\text { conceptual replication and an exploration of statistical approaches }\end{array}$ & 49 \\
\hline Chapter Four & $\begin{array}{l}\text { The relationship between childhood abuse and severity of psychosis } \\
\text { is mediated by loneliness: an experience sampling study }\end{array}$ & 69 \\
\hline Chapter Five & $\begin{array}{l}\text { Mentalizing impairment as a mediator between reported childhood } \\
\text { abuse and outcome in nonaffective psychotic disorder }\end{array}$ & 87 \\
\hline PART III & Mentalization based treatment for psychotic disorder & 107 \\
\hline Chapter six & $\begin{array}{l}\text { Mentalization-based treatment for psychotic disorder: protocol of a } \\
\text { randomized controlled trial }\end{array}$ & 109 \\
\hline Chapter seven & $\begin{array}{l}\text { Mentalization based treatment for psychotic disorder: a rater- } \\
\text { blinded, multi-center, randomized controlled trial. }\end{array}$ & 133 \\
\hline PART IV & Conclusion & 157 \\
\hline \multirow[t]{7}{*}{ Chapter Eight } & Summary and general discussion & 159 \\
\hline & Addendum & 185 \\
\hline & Summary in Dutch & 186 \\
\hline & Valorization & 212 \\
\hline & List of publications and invited lectures & 216 \\
\hline & Acknowledgements & 218 \\
\hline & Curriculum Vitae & 223 \\
\hline
\end{tabular}





\section{THEORETICAL OUTLINE}

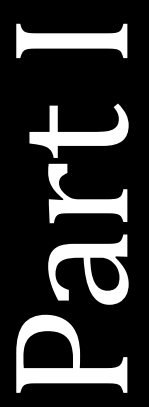





\section{GENERAL INTRODUCTION}

J.G. Weijers 


\section{Psychosis and non-affective psychotic disorder}

This dissertation is the result of a six-year long empirical journey exploring the potential contribution of mentalization theory to the understanding and treatment of Non-Affective Psychotic Disorder (NAPD). Its title - Mentalization and psychosis: trying to understand the "ununderstandable" - rather cheekily refers to this journey, as both psychosis and mentalization are complex concepts that can be difficult to grasp.

Psychosis is a state of mind characterized by a loss of contact with reality. Hallmarks of psychosis are the presence of idiosyncratic, sometimes demonstrably false interpretations of reality, i.e. delusions, and the perception of things that are not really present, i.e. hallucinations. The term 'un-understandability' was first introduced in 1910 by psychiatrist and philosopher Karl Jaspers as a way to differentiate delusion-like ideas that are common to many psychiatric disorders from truly psychotic delusions. According to Jaspers, delusion-like ideas can be understood by others "rationally or emotionally as arising from the situation of the patient and due to the situation and his emotions" (Fish \& Hamilton, 1984). On the other hand, true delusions arise from primary delusional experience (Fish \& Hamilton, 1984) - what today would be referred to as 'aberrant experience' - in which abnormal significance is attributed to normal perception. Therefore according to Jaspers, at their core, psychotic delusions remain incomprehensible in terms of a normal mental process.

About $6 \%$ of the general population has psychotic-like experiences at some point in their lives, although these do not necessarily disrupt life severely. However, a psychotic disorder, which is by definition pathological, tends to severely invalidate the patient. Psychotic disorders comprise a combination of five features according to the DSM-5 (American Psychiatric Association, 2013), including: delusions, hallucinations, disorganized thinking and speech (these are often referred to as 'positive symptoms'), grossly disorganized or abnormal motor behavior, and negative symptoms, such as avolition or flattened affective expression. Within the spectrum of psychotic disorders, clinicians tend to differentiate between affective psychoses, which solely occur in the context of manic or depressive episodes, and the so called 'non-affective psychotic disorders' (NAPD), that do not necessarily co-occur with episodes of affective dysregulation. The umbrella term NAPD includes the DSM-5 categories schizophrenia, schizoaffective disorder, brief psychotic disorder, delusional disorder, schizophreniform disorder, and unspecified schizophrenia spectrum and other psychotic disorder. This thesis solely focuses on NAPD. 


\section{Social functioning and social cognition in NAPD}

Next to the clinical symptoms described above, NAPD tends to involve a significant decline in social functioning, which includes difficulties in self-care, independent living, and the maintenance of relationships and employment. Sadly, whereas the past century has seen the development of effective medication to treat the positive symptoms of psychotic disorders, there has been remarkably little improvement in the treatment of overall social functioning of patients with psychotic disorder (Green, Horan \& Lee, 2015).

The causes of poor social functioning are incompletely understood, but social cognitive deficits have been identified as an important contributor (Fett, Viechtbauer, Penn, van Os, \& Krabbendam, 2011). Social cognition is the multifaceted domain of "the mental processes underlying social interactions" (Fett et al., 2011). It entails the capacity to perceive, interpret, and adequately react to social interactions (Dimaggio \& Lysaker, 2014). A large body of evidence now shows that NAPD is characterized by a range of social cognitive deficits. As a result, interest in the enhancement of social cognition as a treatment target has increased, and the past decade has seen the development of several treatments targeting social cognition (See Lana, Sola Victor \& MartiBonany, 2017 for an overview).

However, issues remain regarding social cognition and its status as a treatment target. Social cognition as a construct lacks specificity, both for clinical and academic purposes. Additionally, there is no general consensus on how to best measure the various aspects of social cognition. Below we will discuss how mentalization theory comes to define social cognition and will highlight the role of childhood abuse in mentalizing and psychosis. Furthermore, we will discuss how mentalization is operationalized for measurement and will provide a short introduction of mentalization based treatment.

\section{Social cognition according to mentalization theory}

In the last three decades, Peter Fonagy and colleagues have popularized mentalization theory as a framework to understand how humans make sense of themselves and others. Mentalizing refers to the imaginative process through which an individual interprets behavior of himself and others in terms of intentional mental states such as desires, needs, feelings, and beliefs. Mentalizing allows us to "put ourselves in another situation and feel ourselves into another's shoes" (Fish \& Hamilton, 1984).

The construct of mentalization in its current usage was the result of a combination of the French psychoanalytic term 'mentalisation' and the empirical term 'theory of mind', which relates to 
the ability to infer the mental states of others (see Dimaggio \& Lysaker, 2014). Contemporary social cognitive research tends to conflate these terms, but such conflation reveals a lack of understanding of the concept's theoretical underpinnings, while also diminishing its conceptual depth and clinical usefulness. The French term mentalisation initially exclusively referred to the capacity to transform sensory-affective experience into organized ideas that could be adapted, reflected upon, and communicated. In other words, mentalisation used to mean 'to make mental' or 'to symbolize' (see Lecours \& Bouchard, 1997). As such, "understandability" also applies to the activity of mentalizing, meaning 'to understand that which has not yet been understood'. However, Fonagy (1991) gave a secondary meaning to mentalisation by arguing that the process through which we come to understand our own mental states, is similar to the process through which we come to understand the mental states of others. He argued that through symbolization of our own sensory-affective experience we develop an increasingly complex, consciously accessible model of our own mental states - a theory of mind - which then can be applied to others as well.

He also argued that, especially in childhood, symbolization is done for us. Central to mentalization theory is the notion that mentalization is a developmental achievement, best established in a secure attachment relationship to caregivers. In infancy, when the capacity to mentalize is still absent, we rely on our caregivers to provide meaning to our yet to be understood, visceral experiences. In secure relationships, caregivers tend to provide such meaning through responsive, sensitive and slightly exaggerated or 'marked' feedback to the infant's sensory-affective experiences, sometimes referred to as 'motherese' (see chapter 2). Providing feedback that accurately reflects the child's sensory-affective experience, allows the child to identify its feelings. Additionally, when the feedback is marked, the child can come to understand that the descriptions used by the caregivers do not apply to their feeling states, but rather to its own feeling states. This allows the child to come into contact with another's view of its inner experiences, which constitutes the cornerstone of mentalizing.

Furthermore, security in early attachment relationships is thought to contribute to mentalizing, as it promotes the ability to co-regulate emotions (Lyons-Ruth, Yellin, Melnick, \& Atwood, 2003). Based on the quality of early attachment interactions, children come to develop expectations of relationships; whether or not others can be trusted to help co-regulate affect, i.e. to offer consolation, and whether or not the self is worthy of such consolation. Such expectations in turn are thought to determine how emotions are regulated and the quality of such regulation, for example by seeking out consolation or solitude (e.g., Berry, Barrowclough \& Wearden, 2007). 
Emotion regulation in turn is key to adequate mentalizing, as the ability to mentalize deteriorates when emotional arousal becomes too high (Fonagy \& Bateman, 2006; Nolte et al., 2013).

\section{Childhood abuse, mentalizing and psychosis}

Childhood abuse, defined as the physical, sexual, or psychological maltreatment or neglect of a child, is viewed to be antithetical to the establishment of a secure attachment relationship and therefore the development of mentalizing. It often involves hostile, uncaring or grossly inappropriate responses to a child's affective states, which may communicate that such states are not acceptable or permissible.

As relatively well functioning adults it may be difficult to understand that anyone would want to perpetrate harm on children. In this sense, "un-understandability" is also applicable to the topic of childhood abuse. Yet, empirical research suggests that a history of childhood abuse is common among patients with NAPD, with estimates ranging between 47.5\% (Alvarez et al., 2011) and 85\% (Duhig et al., 2015; Larsson et al., 2013), exceeding prevalence rates in the general population (e.g. Springer, Sheridan, Kuo \& Carnes, 2007; MacMillan, Tanaka, Duku, Vaillancourt, \& Boyle, 2013).

Childhood abuse is increasingly recognized as an important contributing factor to psychosis (Varese et al., 2012). Although the veracity of self-reported accounts of childhood abuse by psychotic patients has been questioned (Susser \& Widom, 2012), several prospective studies have convincingly shown that children who were abused, were at greater risk of developing psychosis later in life (Cutajar et al., 2010; Bechdolf et al., 2010, Arseneault et al., 2011; Kelleher et al., 2013). Additionally childhood abuse has been shown to contribute to an adverse outcome of NAPD, predicting the severity of positive symptoms, negative symptoms (Longden, Sampson, \& Read, 2015; Schenkel, Spaulding, DiLillo, Silverstein, (2005); Spauwen, Krabbendam, Lieb, Wittchen \& Van Os, 2006; van Dam et al., 2015) and social dysfunction in adulthood (Alameda et al., 2015; Stain et al., 2013). There is currently a wide consensus that childhood abuse plays some part in psychosis (Read, van Os, Morrison, \& Ross, 2005; Howes \& Murray, 2014), although much remains unclear about the way in which it contributes to development and course of NAPD.

Relatively few studies have examined the underlying mechanisms of this relationship, but several hypotheses have been proposed that seem to converge with mentalization theory. Childhood abuse may cause a sensitization of reactivity to stressful situations, i.e. poor emotion regulation, that may contribute to psyschosis (see chapter 3 ). As childhood abuse instills negative expectations of others' abilities to help co-regulate emotion, this may also result in the shunning of 
attachment relationships altogether. A tendency for loneliness may therefore further complicate the co-regulation of emotions, thereby contributing to the development of psychosis (see chapter 4). Lastly, childhood abuse may contribute to psychosis in adulthood through an impaired development of mentalizing (see chapter 5). Childhood abuse is thought to suppress the naturally curious, nonjudgmental attitude needed for mentalizing. Furthermore, thinking about a hostile or uncaring caregiver's mind may be so overwhelmingly painful for a child, that it instills a phobic avoidance of mentalizing (see chapter 5 for more elaboration).

\section{Operationalization of mentalization}

The construct of mentalization has not been without criticism. Some have referred to the concept as "ungainly" and "all-encompassing" (Choi-Kain \& Gunderson, 2008) and it can be argued to be difficult to operationalize for empirical study. Fonagy and Luyten (2009) therefore proposed to deconstruct mentalizing into four interrelated polarities: implicit vs explicit, cognitive vs affective, internal vs external, and self vs other. Lastly, it could be argued that Luyten, van Houdenhove, Lemma, Target, \& Fonagy (2012a) introduced a fifth polarity by introducing the term 'embodied mentalizing'.

Implicit or automatic mentalization refers to the non-consciously directed process of mentalizing. Implicit mentalizing involves reflexive and intuitive 'snap' judgments about internal or external events. In contrast, explicit mentalization involves the slow and deliberately guided process of reflection on one's own and someone else's mental states (Fonagy \& Luyten, 2009).

Cognitive versus affective mentalization refers to the different ways people process information, as well as the different types of information that are processed. According to mentalization theory, social cognition involves both the capability to reason about beliefs and the capacity to detect and process signals on an affective basis, i.e. 'to feel for someone'.

The self-and-other distinction refers to the object of mentalizing; that is to what extent people are able to reflect on their own or others' mental states. Here the two must not be seen as discrete polarities but as dynamically interacting domains. Reflecting on one's own feelings can provide information about how one feels about someone else, whereas the reaction of others to oneself provides information about ourselves as well. Secondarily it also involves the ability to clearly distinguish between one's own mental state and those of others.

The internal/external distinction refers to the material with which one mentalizes. Imbalances on this polarity determine whether one focuses exclusively on inner experiences or on external features, such as looks or behavior. 
Lastly, Luyten and colleagues (2012a) introduced the term embodied mentalizing to signify "the ability to experience the body as the seat of emotions". Specifically, embodied mentalizing pertains to the degree of certainty that is attributed to one's cognitive beliefs or one's sensoryaffective signals as accurate representations of the world (see chapter 2 for more elaboration).

\section{Measurement of mentalization}

Measuring mentalizing capacity can be considered to be in its infancy. To measure mentalizing on the basis of self-report instruments is difficult, as it requires some mentalizing capacity to understand one's mentalizing deficits. Furthermore, the field of social cognition research lacks a general consensus on what measures best capture mentalizing capacity. Commonly used non-selfreport tests are heterogeneous, tend to have poor psychometric properties and lack ecological validity (Green et al, 2008; Horan \& Green, 2019). As such, the measurement instruments of mentalizing used in this thesis deserve some attention.

A recent large-scale study of the psychometric properties of widely used social cognitive measures showed that the Hinting Task (HT) was one of the few instruments considered to be good enough for use in clinical trials (Pinkham et al., 2013). The HT measures the ability to infer another's wishes from indirect speech, i.e. the cognitive, other-oriented aspect of mentalizing or 'theory of mind'. It features ten short passages, with each passage presenting an interaction between two characters that must be interpreted by the respondent. To provide correct answers, respondents must place themselves in the shoes of the characters in order to infer what the other characters are implying. The HT showed adequate test-retest reliability, only small practice effects, a strong relation to social functioning and also enough sensitivity to distinguish patient performance from controls. Furthermore, it is well tolerated by patients, and can be administered relatively quickly (Pinkham et al., 2013). Still no test is perfect; the HT has been criticized for being overly simplistic and having a tendency for ceiling effects (e.g., Roberts \& Penn, 2009).

The second instrument for measuring mentalizing used in this thesis is the Social Cognition and Object-Relations Scale scored on narratives on the Thematic Apperception Test (TAT; Murray, 1943). It is less commonly used because of its time consuming and projective nature. It is therefore often omitted from reviews of measurement instruments (Pinkham et al., 2013; Horan, \& Green 2019). This is unfortunate, because it has adequate and well-studied psychometric properties. The TAT consists of black-and-white pictures of ambiguous social situations to elicit spontaneous responses from participants. Among other things, participants are asked to describe what is going on in the picture and what is going through the minds of the characters in the picture. In the current 
thesis, responses were transcribed verbatim and analyzed using the Social Cognition and Object Relations System (SCORS; Westen, 1991), a scoring system to evaluate TAT narratives. The SCORS assesses four dimensions of social cognition: complexity of representations of people, measuring the respondents' ability to differentiate between their own and another's point of view; understanding of social causality, representing respondents' ability to give a logical and psychologically-minded explanation for another's behavior; affect-tone of relationships, which represents the degree to which others are expected to be benign or malign; and the capacity for emotional investment, which represents the extent to which relationships with others are experienced as inherently meaningful or just as a means to an end.

Importantly, according to Luyten and colleagues (2012b), the SCORS is one of the few tests that takes almost all aspects of mentalization into account, including cognitive mentalizing (measured by the dimensions complexity and understanding of social causality) and affective mentalizing (measured by the dimensions affect tone and emotional investment). Furthermore, the SCORS, has been shown to be a valid and reliable instrument of social cognition (Meyer, 2004), with good internal consistency between pictures (Hibbard, Mitchell \& Porcerelli, 2001) and good (Hibbard et al., 2001) to excellent (Meyer, 2004) inter-rater reliability.

\section{Mentalization based treatment}

The development of mentalization based treatment was inspired by the hypothesis that empirically supported psychotherapies of different psychological schools tend to be equally effective, which was later corroborated by controlled trials (e.g. Messer \& Wampold, 2002). This finding has come to be known as the 'dodo effect' of psychotherapy, in which 'every therapy wins'. Bateman and Fonagy argued that this dodo effect is related to non-specific factors of therapy, i.e. factors that are common to all forms of psychotherapeutic approaches. They argued that 'bonafide' psychotherapies tend to be effective because they all offer a structured view of the human mind, with which patients can organize and make sense of their psychological problems. They also argued that, to differing degrees, all forms of psychotherapy engage the patient's ability to reflect on and verbalize sensory-affective experience, i.e. to mentalize. MBT highlights mentalizing as a way to improve psychopathology and social functioning. Chapter 2 elaborates on how mentalizing is targeted in treatment.

MBT was found to be an effective treatment for borderline personality disorder (Bateman \& Fonagy, 1999; 2001; 2008) but as a transdiagnostic theory of psychopathology and social cognition, mentalization theory has come to inform understanding and treatment of several psychiatric 
disorders, including eating disorders (Robinson et al., 2013), antisocial personality disorder (Bateman et al., 2013), adolescents who self-harm (Rossouw \& Fonagy, 2012), functional somatic disorder (Luyten, van Houdenhove, Lemma, Target, \& Fonagy, 2012a), NAPD (Brent, Holt, \& Keshavan, 2014; Weijers, et al., 2016) and the prodromal states of NAPD (Debbané et al., 2016). However, empirical examination is required to determine its effectiveness for many of these disorders (Malda-Castillo, Browne, \& Perez-Algorta, 2018). Chapter seven reports the results of a randomized controlled trial focusing on the effectiveness of mentalization based treatment for psychotic disorder.

\section{Aims and outline of this thesis}

AIM I: To outline how mentalization theory may contribute to understanding and treatment of NAPD.

Chapter two describes a theoretical framework of NAPD based on mentalization theory. It describes how childhood abuse, insecure attachment, social dysfunction, poor emotion regulation, epistemic mistrust and impaired mentalizing are interrelated and how these may contribute to psychosis. Additionally, it discusses how mentalization based treatment may be used to treat NAPD.

AIM II: To test several hypotheses which have been proposed to explain the relationship between childhood abuse and the severity of symptoms in adult patients with NAPD.

Chapters three, four, and five examine to what extent abuse in childhood contributes to severity of symptoms in adult patients with NAPD and explores mechanisms central to mentalization theory that may account for this relationship, namely: poor emotion regulation, loneliness and impaired mentalizing. More specifically, chapter three examines whether childhood abuse is related to an increased emotional and psychotic reactivity to stress, while also exploring statistical issues relating to skewed data. Chapter four examines whether loneliness accounts for the relationship between childhood abuse and psychotic symptoms in daily life and whether the relation between loneliness and psychotic symptoms in turn can be accounted for by anxious and depressive feelings. Chapter five examines whether impaired mentalizing accounts for the relationship between childhood abuse and functional and clinical outcome in NAPD.

AIM III: To test whether mentalization based treatment for psychotic disorder (MBTp) is an effective addition to treatment as usual regarding social dysfunction and impaired mentalizing. 
Specifically, chapter six outlines the hypotheses and methods in a pre-published research protocol of our randomized controlled trial. Chapter seven describes the results of this trial. We will conclude this thesis with a general discussion of the combined findings as well as directions for future research (chapter eight) and the valorization of our current research (addendum).

\section{References}

Alameda, L., Ferrari, C., Baumann, P. S., Gholam-Rezaee, M., Do, K. Q., \& Conus, P. (2015). Childhood sexual and physical abuse: age at exposure modulates impact on functional outcome in early psychosis patients. Psychological medicine, 45(13), 2727-2736.

Alvarez, M. J., Roura, P., Osés, A., Foguet, Q., Sola, J., \& Arrufat, F. X. (2011). Prevalence and clinical impact of childhood trauma in patients with severe mental disorders. The Journal of nervous and mental disease, 199(3), 156-161.

American Psychiatric Association. (2013). Diagnostic and statistical manual of mental disorders (DSM-5®). American Psychiatric Pub.

Arseneault, L., Cannon, M., Fisher, H. L., Polanczyk, G., Moffitt, T. E., \& Caspi, A. (2011). Childhood trauma and children's emerging psychotic symptoms: a genetically sensitive longitudinal cohort study. American Journal of Psychiatry, 168(1), 65-72.

Bateman, A., \& Fonagy, P. (1999). Effectiveness of partial hospitalization in the treatment of borderline personality disorder: a randomized controlled trial. American journal of Psychiatry, 156(10), 1563-1569.

Bateman, A., \& Fonagy, P. (2001). Treatment of borderline personality disorder with psychoanalytically oriented partial hospitalization: an 18-month follow-up. American Journal of psychiatry, 158(1), 36-42.

Bateman, A., \& Fonagy, P. (2006). Mentalizing and borderline personality disorder. Handbook of mentalization based treatment, 185-200.

Bateman, A., \& Fonagy, P. (2008). 8-year follow-up of patients treated for borderline personality disorder: mentalization-based treatment versus treatment as usual. American Journal of Psychiatry, 165(5), 631-638.

Bateman, A., Bolton, R., \& Fonagy, P. (2013). Antisocial personality disorder: A mentalizing framework. Focus, 11(2), 178-186.

Bechdolf, A., Thompson, A., Nelson, B., Cotton, S., Simmons, M. B., Amminger, G. P., ... \& Sidis, A. (2010). Experience of trauma and conversion to psychosis in an ultra-high-risk (prodromal) group. Acta Psychiatrica Scandinavica, 121(5), 377-384. 
Berry, K., Barrowclough, C., \& Wearden, A. (2008). Attachment theory: a framework for understanding symptoms and interpersonal relationships in psychosis. Behaviour research and therapy, 46(12), 1275-1282.

Brent, B. K., Holt, D. J., \& Keshavan, M. S. (2014). Mentalization-based treatment for psychosis: linking an attachment-based model to the psychotherapy for impaired mental state understanding in people with psychotic disorders. The Israel journal of psychiatry and related sciences, 51(1), 17.

Choi-Kain, L. W., \& Gunderson, J. G. (2008). Mentalization: Ontogeny, assessment, and application in the treatment of borderline personality disorder. American Journal of Psychiatry, 165(9), 1127-1135.

Cutajar, M. C., Mullen, P. E., Ogloff, J. R., Thomas, S. D., Wells, D. L., \& Spataro, J. (2010). Psychopathology in a large cohort of sexually abused children followed up to 43 years. Child abuse \& neglect, 34(11), 813-822.

Debbané, M., Benmiloud, J., Salaminios, G., Solida-Tozzi, A., Armando, M., Fonagy, P., \& Bateman, A. (2016). Mentalization-based treatment in clinical high-risk for psychosis: a rationale and clinical illustration. Journal of Contemporary Psychotherapy, 46(4), 217-225.

Dimaggio, G., \& Lysaker, P. H. (2015). Metacognition and mentalizing in the psychotherapy of patients with psychosis and personality disorders. Journal of Clinical Psychology, 71(2), 117124.

Duhig, M., Patterson, S., Connell, M., Foley, S., Capra, C., Dark, F., ... \& Scott, J. (2015). The prevalence and correlates of childhood trauma in patients with early psychosis. Australian \& New Zealand Journal of Psychiatry, 49(7), 651-659.

Fett, A. K. J., Viechtbauer, W., Penn, D. L., van Os, J., \& Krabbendam, L. (2011). The relationship between neurocognition and social cognition with functional outcomes in schizophrenia: a meta-analysis. Neuroscience \& Biobehavioral Reviews, 35(3), 573-588.

Fish, F. J., \& Hamilton, M. (1984). Fish's schizophrenia. John Wright, Sheffield, United Kingdom. Fonagy, P. (1991). Thinking about thinking: Some clinical and theoretical considerations in the treatment of a borderline patient. International Journal of Psycho-Analysis, 72, 639-656.

Fonagy, P., \& Luyten, P. (2009). A developmental, mentalization-based approach to the understanding and treatment of borderline personality disorder. Development and psychopathology, 21(4), 1355-1381.

Fonagy, P., \& Bateman, A. W. (2016). Adversity, attachment, and mentalizing. Comprehensive psychiatry, 64, 59-66. 
Green, M. F., Penn, D. L., Bentall, R., Carpenter, W. T., Gaebel, W., Gur, R. C., ... \& Heinssen, R. (2008). Social cognition in schizophrenia: an NIMH workshop on definitions, assessment, and research opportunities. Schizophrenia bulletin, 34(6), 1211-1220.

Green, M. F., Horan, W. P., \& Lee, J. (2015). Social cognition in schizophrenia. Nature Reviews Neuroscience, 16(10), 620.

Hibbard, S., Mitchell, D., \& Porcerelli, J. (2001). Internal consistency of the object relations and social cognition scales for the thematic apperception test. Journal of Personality Assessment, 77(3), 408-419.

Horan, W. P., \& Green, M. F. (2019). Treatment of social cognition in schizophrenia: Current status and future directions. Schizophrenia research, 203, 3-11.

Howes, O. D., \& Murray, R. M. (2014). Schizophrenia: an integrated socio-developmental-cognitive model. The Lancet, 383(9929), 1677-1687.

Kelleher, I., Keeley, H., Corcoran, P., Ramsay, H., Wasserman, C., Carli, V., ... \& Cannon, M. (2013). Childhood trauma and psychosis in a prospective cohort study: cause, effect, and directionality. American Journal of Psychiatry, 170(7), 734-741.

Larsson, S., Andreassen, O. A., Aas, M., Røssberg, J. I., Mork, E., Steen, N. E., ... \& Melle, I. (2013). High prevalence of childhood trauma in patients with schizophrenia spectrum and affective disorder. Comprehensive Psychiatry, 54(2), 123-127.

Lana, F., Africa Cruz, M., Sola Victor, P., Marti-Bonany, J. (2017). Social Cognition Based Therapies for People with Schizophrenia: Focus on Metacognitive and Mentalization Approaches. Schizophrenia treatment. SM Groups Open access ebooks.

Lecours, S., \& Bouchard, M. A. (1997). Dimensions of mentalisation: Outlining levels of psychic transformation. International Journal of Psycho-Analysis, 78, 855-875.

Longden, E., Sampson, M., \& Read, J. (2016). Childhood adversity and psychosis: generalised or specific effects? Epidemiology and psychiatric sciences, 25(4), 349-359.

Luyten, P., Van Houdenhove, B., Lemma, A., Target, M., \& Fonagy, P. (2012a). A mentalization-based approach to the understanding and treatment of functional somatic disorders.

Psychoanalytic Psychotherapy, 26(2), 121-140.

Luyten P., Fonagy P., Lowyck B., Vermote R. (2012b). Assessment of mentalization. In Bateman \& Fonagy (2012). Handbook of mentalizing in mental health practice, 43-65. Washington, DC: American Psychiatric Pub. 
Lyons-Ruth, K., Yellin, C., Melnick, S., \& Atwood, G. (2003). Childhood experiences of trauma and loss have different relations to maternal unresolved and hostile-helpless states of mind on the AAI. Attachment \& Human Development, 5(4), 330-352.

MacMillan, H. L., Tanaka, M., Duku, E., Vaillancourt, T., \& Boyle, M. H. (2013). Child physical and sexual abuse in a community sample of young adults: Results from the Ontario Child Health Study. Child Abuse \& Neglect, 37(1), 14-21.

Malda-Castillo, J., Browne, C., \& Perez-Algorta, G. (2018). Mentalization-based treatment and its evidence-base status: A systematic literature review. Psychology and Psychotherapy: Theory, Research and Practice.

Messer, S. B., \& Wampold, B. E. (2002). Let's face facts: Common factors are more potent than specific therapy ingredients. Clinical psychology: Science and practice, 9(1), 21-25.

Meyer, G. J. (2004). The reliability and validity of the Rorschach and Thematic Apperception Test (TAT) compared to other psychological and medical procedures: An analysis of systematically gathered evidence. Comprehensive handbook of psychological assessment, 2, 315-342.

Murray, H. A. (1943). Thematic Apperception Test, Harvard University Press, Cambridge, MA. Nolte, T., Bolling, D. Z., Hudac, C., Fonagy, P., Mayes, L. C., \& Pelphrey, K. A. (2013). Brain mechanisms underlying the impact of attachment-related stress on social cognition. Frontiers in Human Neuroscience, 7, 816.

Pinkham, A. E., Penn, D. L., Green, M. F., Buck, B., Healey, K., \& Harvey, P. D. (2013). The social cognition psychometric evaluation study: results of the expert survey and RAND panel. Schizophrenia bulletin, 40(4), 813-823.

Read, J., van Os, J., Morrison, A. P., \& Ross, C. A. (2005). Childhood trauma, psychosis and schizophrenia: a literature review with theoretical and clinical implications. Acta Psychiatrica Scandinavica, 112(5), 330-350.

Roberts, D.L., \& Penn, D. L. (2009). Social cognition and interaction training (SCIT) for outpatients with schizophrenia: a preliminary study. Psychiatry research, 166(2-3), 141-147.

Robinson, P., Hellier, J., Barrett, B., Barzdaitiene, D., Bateman, A., Bogaardt, A., ... \& Kern, N. (2016). The NOURISHED randomised controlled trial comparing mentalisation-based treatment for eating disorders (MBT-ED) with specialist supportive clinical management (SSCM-ED) for patients with eating disorders and symptoms of borderline personality disorder. Trials, 17(1), 549. 
Rossouw, T. I., \& Fonagy, P. (2012). Mentalization-based treatment for self-harm in adolescents: a randomized controlled trial. Journal of the American Academy of Child \& Adolescent Psychiatry, 51(12), 1304-1313.

Schenkel, L. S., Spaulding, W. D., DiLillo, D., \& Silverstein, S. M. (2005). Histories of childhood maltreatment in schizophrenia: relationships with premorbid functioning, symptomatology, and cognitive deficits. Schizophrenia research, 76(2-3), 273-286.

Spauwen, J., Krabbendam, L., Lieb, R., Wittchen, H. U., \& Van Os, J. (2006). Impact of psychological trauma on the development of psychotic symptoms: relationship with psychosis proneness. The British Journal of Psychiatry, 188(6), 527-533.

Springer, K. W., Sheridan, J., Kuo, D., \& Carnes, M. (2007). Long-term physical and mental health consequences of childhood physical abuse: Results from a large population-based sample of men and women. Child abuse \& neglect, 31(5), 517-530.

Stain, H. J., Brønnick, K., Hegelstad, W. T., Joa, I., Johannessen, J. O., Langeveld, J., ... \& Larsen, T. K. (2013). Impact of interpersonal trauma on the social functioning of adults with first-episode psychosis. Schizophrenia bulletin, 40(6), 1491-1498.

Susser, E., \& Widom, C. S. (2012). Still searching for lost truths about the bitter sorrows of childhood. Schizophrenia bulletin, 38(4), 672-675.

van Dam, D. S., van Nierop, M., Viechtbauer, W., Velthorst, E., van Winkel, R., Bruggeman, R., ... \& Myin-Germeys, I. (2015). Childhood abuse and neglect in relation to the presence and persistence of psychotic and depressive symptomatology. Psychological Medicine, 45(7), 1363-1377.

Varese, F., Smeets, F., Drukker, M., Lieverse, R., Lataster, T., Viechtbauer, W., ... \& Bentall, R. P. (2012). Childhood adversities increase the risk of psychosis: a meta-analysis of patientcontrol, prospective-and cross-sectional cohort studies. Schizophrenia bulletin, 38(4), 661671.

Weijers, J., ten Kate, C., Eurelings-Bontekoe, E., Viechtbauer, W., Rampaart, R., Bateman, A., \& Selten, J. P. (2016). Mentalization-based treatment for psychotic disorder: protocol of a randomized controlled trial. BMC psychiatry, 16(1), 191.

Westen, D. (1991). Clinical assessment of object relations using the TAT. Journal of personality assessment, 56(1), 56-74. 




\section{MENTALIZATION AND PSYCHOSIS: A RATIONALE FOR THE USE OF}

MENTALIZATION THEORY TO UNDERSTAND AND TREAT NON-AFFECTIVE PSYCHOTIC DISORDER

J. G. Weijers, C. ten Kate, M. Debbané, A.W. Bateman, S. de Jong, J.-P.C.J Selten, E.H.M. Eurelings-Bontekoe 


\begin{abstract}
Social functioning can be severely impaired in non-affective psychotic disorder (NAPD). Current models of psychosis pathogenesis do not tend to focus on social dysfunction and pharmacological treatment fails to ameliorate it. In this article, we propose that mentalization theory provides a valuable contribution to the understanding and treatment of NAPD. Impaired mentalizing may contribute to both positive and negatives symptoms as well as social dysfunction observed in NAPD. Furthermore, impaired mentalizing may help explain the relation between childhood abuse, insecure attachment and psychosis. Mentalization based treatment may contribute to the functional recovery of NAPD patients as it targets the social cognitive processes underlying social interaction. The article includes a description of the principles of MBT in general, specific characteristics of using MBT with patients with NAPD and a clinical vignette to illustrate these principles.
\end{abstract}

Keywords: psychosis, schizophrenia, attachment theory, mentalizing, epistemic trust, mentalization based treatment

\title{
Part I: A mentalization based model of psychosis pathogenesis
}

Introduction. A recent, dominant model of psychosis pathogenesis (Howes \& Murray, 2014) suggests that many factors contribute to the etiology of psychosis, such as variant genes, stress, neuroinflammation, dysregulated activity in the hypothalamic-pituitary-adrenal axis, and developmental insults (e.g., pre- and perinatal complications). It is furthermore held that the assignment of aberrant salience (i.e., motivational value) to mundane stimuli due to a sensitized mesolimbic dopamine system is the final common pathway through which these variables increase psychosis risk. Additionally, there is increased consensus that misattribution processes in the form of cognitive biases are also involved in the etiology of psychosis. For example, hallucinations do not solely involve aberrant experience but also involve the misattribution of such experiences to outside sources (Aleman \& Larøi, 2008). Thirdly, evidence suggests that socio-developmental adversity plays a vital role in the development of psychosis through the sensitization of the mesolimbic dopamine system (e.g., Selten, van der Ven, Rutten, \& Cantor-Graae, 2013).

As such, the recent conceptualization of psychosis (Howes \& Murray, 2014) offers a much needed integration of different neurodevelopmental, biological, and cognitive models to account for psychotic or "positive" symptoms, such as delusions or hallucinations. However, non-affective 
psychotic disorders (NAPD'1) like schizophrenia, brief psychotic disorder and schizoaffective disorder, also involve negative symptoms such as lack of initiative or flattened affective expression and social dysfunction (Green, Horan \& Lee, 2019), which are less prominently featured in most current etiological models of psychosis. Because mentalization theory focuses on the development of social cognitive processes, it may offer a valuable contribution to current models of NAPD.

Social dysfunction and social cognition in NAPD. Research shows that premorbid social dysfunction and adversity predict poor clinical and functional outcome in NAPD (e.g. White et al., 2009; Velthorst et al., 2010; Stumbo et al., 2015). Whereas positive symptoms often can be treated adequately with antipsychotic medication, social dysfunction cannot (Pinkham, Penn, Perkins \& Lieberman, 2003), often creating a wide gap between the severity of symptoms and dysfunction in patients with chronic NAPD (e.g., Birchwood et al., 2013). However, a recent review showed that functional recovery is possible, with the rate for recovery of adequate social functioning lying between $14 \%$ and 53\% (Leonhardt et al., 2017). Rather than pharmacological factors however, social factors such as feeling connected (Eisenstadt, Monteiro, Diniz \& Chaves, 2012; Hendryx Green \& Perrin, 2009) and experiencing social support (Norman, Windell, Lynch \& Wachanda, 2013; Thomas, Muralidharan, Medoff, \& Drapalski, 2016) seem instrumental to subjective and objective functional recovery. As a result, the development of nonpharmacological, adjunctive treatments that improve functioning in NAPD has been an important goal in recent psychosis research (e.g., Holthausen et al., 2007).

Social cognition is the multifaceted domain of cognitive and affective processes that underlie social interaction. Given that social cognitive deficits are widely linked to poor social functioning in patients with NAPD (see Fett, Viechtbauer, Penn, van Os \& Krabbendam, 2011), they have garnered increased interest as a treatment target. Many lines of research opt to focus on specific aspects of social cognition such as facial affect recognition or "theory of mind," i.e., the ability to infer mental states of others (Green et al., 2019). However, it can be argued that welldeveloped social cognition comprises the successful synthesis of its different aspects. Increasing the successful recognition of facial affective expression, may help to recognize that someone is angry, but does not necessarily mean that one is better able to interpret why a person is angry. Recent lines of research have therefore taken a more 'holistic' approach, proposing that underlying social cognitive deficits is an impaired ability to think about thoughts and emotions (Semerari et al., 2003) also termed mentalization (Fonagy, 1989) or metacognition (Lysaker et al., 2005). While this article

${ }^{1}$ This paper will focus exclusively on non-affective psychotic disorders (NAPD), because affective psychotic disorders may have a different pathogenesis. 
mainly focuses on mentalizing, we will also touch upon metacognition, given the conceptual overlap of these constructs.

Social cognition, mentalization and metacognition. To understand the constructs of mentalizing and metacognition, we first need to look at theoretical accounts of how people come to understand minds. Until recently, two theories polarized the field of social cognition (Keysers \& Gazzola, 2007). Simulation theory holds that people develop an experiential understanding of others through the simulation of others' experiences, through mirror neurons and shared sensoryaffective circuits (Gallese, 2005). The intended meaning of actions is viewed to be understood implicitly, through shared feeling. 'Theory theory' on the other hand, holds that we come to understand others through the cognitive inference of "rules" from observed social situations, thus attributing theoretical beliefs and intentions to them (e.g. Baron-Cohen, Leslie \& Frith, 1986). These rules are thought to be updated if the models do not precisely predict current situations.

It can be argued that both metacognition and mentalization, bridge the gap between these two positions. Mentalizing - defined as a form of "imaginative mental activity through which behavior is interpreted in terms of mental states like needs, feelings, beliefs and goals" (Bateman \& Fonagy, 2004)—can be understood as the dynamic interplay between implicit, reflexive, affectoriented processes and explicit, reflective, cognition-oriented processes. Metacognition refers to a "spectrum of mental activities by which persons form integrated ideas about their own minds and those of others" (Lysaker \& Dimaggio 2014). Metacognition comprises discrete activities such as affect recognition and more synthetic activities such as the integration of experiences into overarching narratives. Both concepts suggest that we do not just experience another's mental state through shared emotions-this would not differentiate us much from macaques (Gallese, 2005) but that we use higher-order cognitive processes to transform discrete experiences into conscious representations that can be used to improve our understanding of ourselves as well as others. However, the concept of mentalization is anchored in psychoanalytic and particularly attachment theory, specifying particular preconditions for the development of mentalizing ability, namely, a parent's capacity to reflect on the mind of the child. In contrast, metacognition is posited as an integrative model that is not specifically linked to a developmental theory ${ }^{1}$.

Mentalizing impairments and NAPD. A growing body of research has observed a range of deficits in cognitive and affective aspects of mentalizing and metacognition in NAPD. Patients with NAPD tend to have an impaired ability to infer the mental states of others (for overviews see

\footnotetext{
${ }^{1}$ However, it should be noted that attachment theory has received increased attention in recent metacognitive literature, see Aydin et al. (2016) for example.
} 
Harrington, Siegert \& McClure, 2005; Sprong, Schothorst, Vos, Hox, \& Van Engeland, 2007) and understand others' emotional expressions (O’Driscoll, Laing \& Mason, 2014). They also tend to have trouble recognizing their own internal sensory-affective experience (Brunelin et al., 2007) and show difficulty verbalizing such experience (Trémeau, 2006). Frith (1992) was one of the first to suggest that an impaired capacity to experience and represent mental states of self and others is tied to specific clinical symptoms of NAPD. For example, delusions of persecution and reference are, almost by definition, failures to correctly represent the minds of others. Additionally, misunderstanding that certain gestures, expressions, and intonations convey mental states, may cause what clinicians perceive to be flattened affective expression (Frith, 1992). An impaired ability to infer the mental states of others is also likely to severely complicate social interaction, as it leads to difficulty understanding its unwritten mores. This may make social interaction overwhelmingly complex and in turn may lead to withdrawal in patients or ostracism from peers. Indeed, mentalizing deficits seem related to both positive (e.g. Hasson-Ohayon, Goldzweig, Lavi-Rotenberg, Luther, Lysaker, 2018; Mcleod, Gumley, MacBeth, Schwannauer \& Lysaker, 2014) and negative symptoms (Mcleod et al., 2014; Weijers et al., 2018).

Impaired embodied mentalizing in NAPD. Debbané et al. (2016) further expanded upon Frith's hypothesis by suggesting that patients with NAPD suffer specifically from problems with 'embodied' mentalizing. Embodied mentalizing involves the ability to consciously detect and identify sensory-affective signals coming from one's body and to critically think about them. Indeed, NAPD patients tend to make errors in the detection and identification of self-generated events, or 'source monitoring errors' (see Brookwell, Bentall \& Varese, 2013 for an overview). Problems in detecting and accurately representing one's own sensory-affective experience in turn cause problems in mentalizing (Lind \& Bowler, 2009; Kantrowitz, Hoptman, Leitman, Silipo \& Javitt, 2014). When embodied mentalizing becomes unbalanced, one may assign too much certainty to one's sensory-affective experiences as accurate representations of reality. If such experiences are not challenged and regulated by cognitive mechanisms such as reappraisal, they may come to be interpreted as equating with reality. When too much certainty is assigned to prior cognitive beliefs on the other hand, this runs the risk of misconstruing reality if such beliefs will fail to be updated by sensory-affective experience.

Epistemic mistrust and cognitive biases in NAPD. Patients with NAPD not only have difficulty updating their beliefs on the basis of sensory-affective experience but often become unsusceptible to others' viewpoints. Psychosis often coincides with a loss of socially construed meaning ('common' sense in its literal meaning) and 'epistemic trust' (e.g. Pereira \& Debbané, 2018). 
Epistemic trust is defined as the "willingness to consider new knowledge from another person as trustworthy, generalizable, and relevant to the self" (Fonagy et al., 2015). According to the epistemic trust hypothesis, there are two ways in which people may come to accept new views as true: They can try to deduce by themselves whether such new knowledge offers an accurate model of reality, or they can rely on the knowledge of someone they deem both epistemically trustworthy and well-meaning (Fonagy, Luyten, Allison \& Campbell, 2017).

A chronic lack of epistemic trust, sometimes referred to as epistemic hypervigilance, results in treating others as untrustworthy sources of information. It is thought to be pathogenic because it cuts individuals off from easy, interpersonal approaches to updating belief systems. Additionally, epistemic trust plays a central role in the sharing of cultural customs and values, because belonging to a certain cultural group gives rise to the expectation that one construes meaning of behavior in similar ways. Customs and values often have opaque functions but are nonetheless important to "fit in".

Contributors to impaired mentalizing and psychosis. In the previous section, we argued that disruptions in mentalization and epistemic trust may be relevant to the pathogeny of NAPD. Here, we argue that childhood abuse may hinder the development of mentalizing and epistemic trust and thus fosters psychosis.

Many studies have shown that childhood abuse constitutes a significant risk factor to the emergence of psychosis (see Varese et al., 2012; Read, Fosse, Moskowitz, \& Perry, 2014 for overviews). Childhood abuse rates for those at ultra-high risk to develop psychosis may be as high as $86 \%$ (see Kraan et al., 2015 for an overview), and prospective studies show that abused children are more likely to develop psychosis (e.g. Kelleher et al., 2013). Childhood abuse has also been widely shown to hinder the development of mentalizing ability (see Fonagy et al., 2017 for an overview) and impaired mentalizing has been shown to account for some of the relation between childhood abuse and negative symptoms in NAPD (Weijers et al., 2018).

Counter to nativist accounts of social cognition, mentalization theory proposes that mentalizing is initially formed in secure attachment relationships with caregivers (e.g., Kim, 2015). Such relationships are characterized by a genuine interest in the child's mental state that is conveyed through ostensive cues (e.g., eye contact) and 'marked mirroring,' wherein emotions are imitated in a slightly exaggerated fashion, sometimes referred to as 'motherese' (Kim, 2015). In this way, a child has his emotions "re-presented" back to him, which provides him with the opportunity to come into contact with other perspectives on his inner experiences (Fonagy \& Allison, 2014), thus enabling him to begin developing second-order representations of bodily feeling states. 
Although less emphasized, this hypothesis is also present in metacognitive theory, which stresses that the development of self-reflectivity is fostered by 'intersubjectivity', a communicative process between child and parent that revolves around the narration of inner experience (Lysaker et al., 2005). The experience of caregiver abuse on the other hand is thought to lead to a phobic avoidance of mentalizing in children (Kim, 2015) "to protect themselves from acknowledging their caregiver's wishes to harm them" (Fonagy, 1989). Inhibiting mentalizing in this manner may be the only means to negotiate the need for proximity and becoming overwhelmed by psychological pain. ${ }^{1}$

Childhood abuse may also contribute to poor mentalizing through the establishment of poor emotion regulation strategies. Attachment theory proposes that humans have an instinctual need to form close social bonds. In the face of danger or uncertainty, children display attachment behavior to promote safety and to regulate affect (Bowlby, 1980). Especially, when primary caregivers are abusive, they are experienced as both a source of threat and a source of security to the child who is still dependent on them for nourishment and safety. In such cases, stress results in an alternation between strong impulses to escape and to seek care, increasingly escalating the levels of emotional dysregulation. Based on the quality of early attachment interactions a child develops expectations of relationships and how emotions will be co-regulated called 'attachment styles' (e.g., Berry, Barrowclough \& Wearden, 2008).

Perhaps unsurprisingly, attachment styles characterized by a distrust of others predominate in patients with psychosis. Between $70 \%$ and $89 \%$ of NAPD patients (dependent on the classification system used) are dismissing of attachment or attached in a disorganized fashion (e.g., Gumley, Taylor, Schwannauer \& MacBeth, 2014). Estimates in the general population range between $20 \%$ and $25 \%$ for dismissing attachment (Ainsworth, Blehar, Waters \& Wall, 1978; Mickelson, Kessler \& Shaver, 1997) and between 12\% and 15\% for disorganized attachment (e.g., Main \& Solomon 1990). Moreover, greater insecure attachment in NAPD has been linked to greater difficulty regulating emotions (Owens, Haddock \& Berry, 2013).

Mentalizing in turn is vulnerable to excessive levels of emotional arousal (Nolte et al., 2013). Here, it is important to note that mentalizing is viewed as a complex 'higher-order cognitive

\footnotetext{
${ }^{1}$ By stipulating that childhood abuse and insecure attachment play a role in the pathogenesis of impaired mentalizing and psychosis, we in no way advocate a return to the days of the "schizophrenogenic" mother (see Hartwell, 1996 for an overview). The contribution of peers to the development of mentalizing and secure attachment relationships seems substantial (see Choudhury, Blakemore \& Charman, 2006; Sroufe, 2005) and attachment styles are not as immutable as once thought (Mikulincer \& Shaver 2012). Additionally, many forms of social adversity beyond child-caregiver attachment relationships predict risk of psychosis (Selten, van der Ven, Rutten \& Cantor-Graae, 2013). Rather social relatedness throughout life seems crucial for mental health (Fonagy et al., 2017).
} 
process' in which functions of the prefrontal cortex, such as working memory and the direction of attention, are used to integrate pieces of information from different sensory, motor, and affective networks (Fonagy \& Bateman, 2016). ${ }^{1}$ When overly stressed, the orchestration of the brain's activity by the prefrontal cortex is undermined and overtaken by subcortical structures, such as the amygdala, the nucleus accumbens, and the hypothalamus (Arnsten, 2009) at the expense of higher order cognition.

Insecure attachment and epistemic mistrust. Fonagy and Allison (2014) also maintain that epistemic trust, much like mentalizing capacity, is developed in secure attachment relationships. When a child finds himself accurately represented by a caregiver "as a thinking and feeling intentional being", this is thought to engender the secure feeling that the caregiver's intentions are benign, which helps the child more easily accept shared information as true. Indeed, the quality of the relationship between a child and a communicator determines the extent to which such information is accepted as truth (Lane \& Harris, 2015). However, children who repeatedly experience that their internal states are met with distorted or inaccurate caregiver responses, may develop a chronic mistrust regarding others' messages. Indeed, both insecure attachment styles and NAPD diagnoses are related to aspects of epistemic hypervigilance such as resistance to other views when they conflict with pre-existing ones (Bentall \& Swarbrick, 2003) and a tendency for dogmatic beliefs (e.g., Mikulincer, 1997). Please refer to figure 1 for a schematic overview of the model described in this section.

\footnotetext{
${ }^{1}$ Similarly, synthetic metacognition is thought to be the process combining "atoms of experience" into larger, overarching narratives (Hasson-Ohayon et al., 2018).
} 


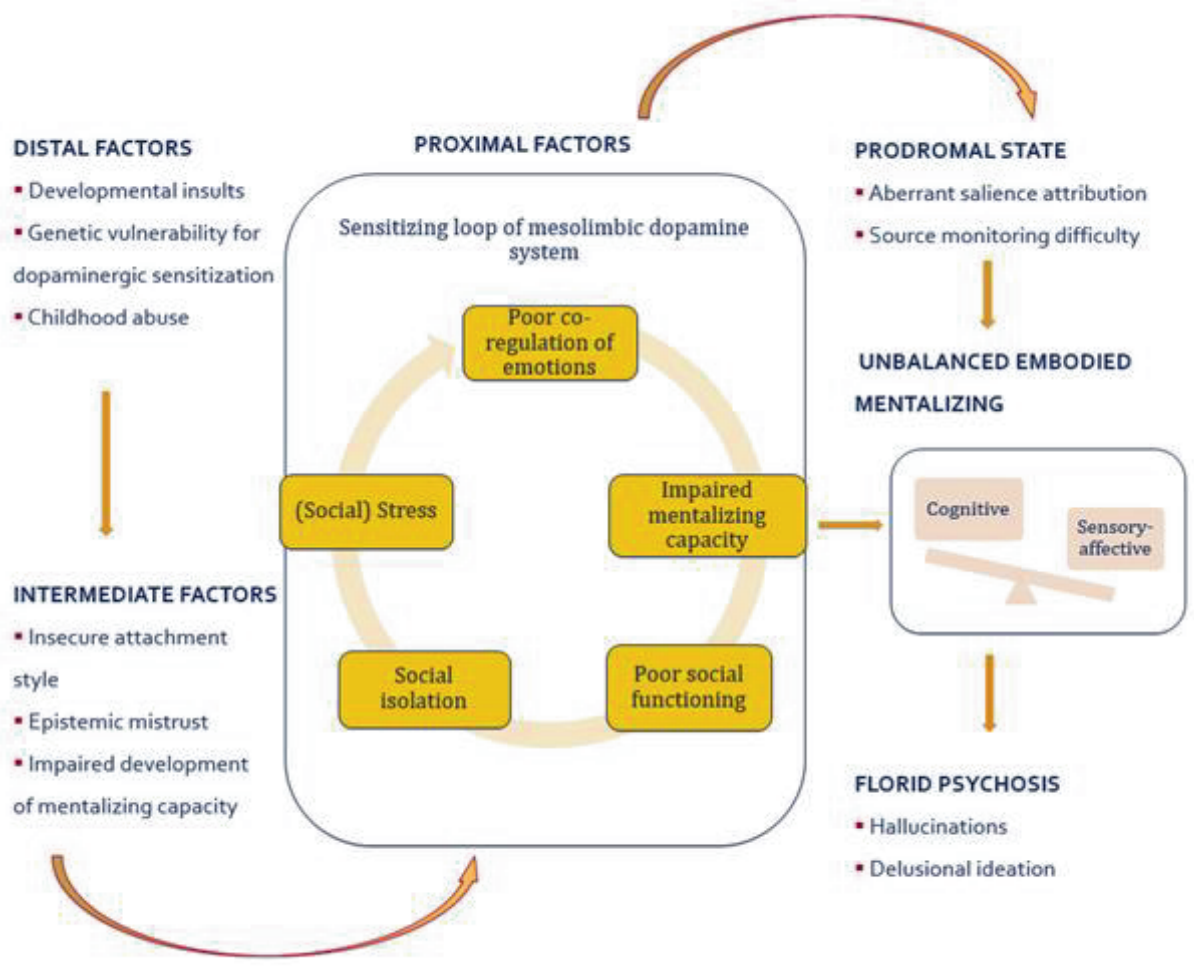

Fig.1 A heuristic, mentalization based model of psychosis pathogenesis.

Together with a constitutional liability caused by variant genes, developmental factors such as childhood abuse and insults, and intermediate factors such as insecure attachment and impaired mentalizing comprise a fertile ground for social difficulties to sensitize the mesolimbic dopamine system. Dismissing or disorganized attachment relationships to caregivers and peers may result in distress and poor co-regulation of emotions when in the proximity of others. This complicates social interaction, and may lead to isolation or withdrawal, and thus more stress and impaired mentalizing. The sensitization of the dopamine system in turn results in aberrant experiences. Due to epistemic mistrust, interpretation of these experiences may become progressively idiosyncratic and tenacious. If individuals attribute extreme certainty to sensory-affective experiences, this results in proper hallucinations. On the other hand, sensory-affective information or the viewpoint of others may not be used to update cognitive beliefs, resulting in delusional ideation. 


\section{Part II: Implementation of mentalization based treatment for NAPD}

Epistemic hypervigilance in NAPD tends to complicate psychotherapeutic interventions because it entails that new perspectives that a therapist offers are seen as irrelevant, or attempts at coercion (Fonagy \& Allison, 2014). Secondly, many patients with NAPD experience difficulty mentalizing under stress, meaning that psychotherapeutic interventions may be at risk of being too complex.

Principles of Mentalization Based Treatment. Mentalization based treatment (MBT) was specifically developed to address impaired mentalizing (Bateman \& Fonagy, 1999) and epistemic mistrust (Fonagy \& Allison, 2014), through four main principles: a 'not-knowing' therapeutic stance, unassuming interventions, a focus on currently felt affect, and careful adjustment to the patient's level of mentalization and arousal.

Firstly, MBT emphasizes that therapists adopt a 'not-knowing stance,' which entails that the therapist actively questions the patient and cultivates a genuine interest in the patient's current experience without forcing any single interpretation upon the patient. When using this stance, the therapist communicates that she is trying to interpret the patient's actions in line with her own subjective experience and that the patient is being treated as an intentional agent (Debbané et al., 2016; Fonagy et al., 2017). Feeling "mentalized about" in therapy is thought to make the patient feel safe enough to think about himself in relation to his social world and how he operates in it (Fonagy \& Allison, 2014), which aids the restructuring of the "organization of thinking into less rigid, delusional and pervasive patterns of reality testing" (Pereira \& Debbané, 2018). Becoming more flexible in one's cognitive beliefs, opens up the opportunity to again learn from experience and other perspectives, which is thought to lead to an improvement of understanding one's self and the social world.

Secondly, interventions are kept unassuming and are aimed at getting the patient to identify and verbalize sensory-affective experiences. As Fonagy and Bateman (2006) underscore, "psychotherapists of many orientations often attempt to provide mentalistic understandings for issues that trigger intense emotional reactions at a time when the capacity for effective explicit mentalization is practically inaccessible." Therefore, MBT de-emphasizes the exploration of 'deep' unconscious motives, often present in psychodynamic treatment, instead focusing on more readily available subjective experience in the here and now.

Thirdly, the focus of both patient and therapist should be on the patient's current affective experience. By helping the patient actively reflect on their currently felt experience, MBT attempts to loosen the dominance of affect-driven modes of information processing on thought and behavior (Pereira \& Debbané, 2018) as verbalizing sensory-affective experience has been shown to 
downregulate the intensity of such affect at neural, physiological, and subjective levels (e.g., Torre \& Lieberman, 2018).

Fourthly, the intensity of interventions, that is, the complexity of mentalization required of the patient, is adjusted to the level of emotional arousal the patient is experiencing. In general, therapists attempt to keep questions and reflections at the maximum level of mentalizing that the patient is able to. Too little arousal provides too little material to actively reflect upon, while too much arousal will reduce a patient's ability to mentalize. At this level only supportive interventions should be uses such as affect validation.

Mentalization based treatment in contrast to other psychotherapies. MBT differs from and shares similarities with other psychotherapies. Of them, Cognitive Behavioral Therapy (CBT) for psychosis, has been the most studied and arguably most prominent intervention in the recent decades. Generally, the main goal of CBT is to correct negative beliefs and thoughts in order to treat symptoms. Both CBT and MBT aim to increase the understanding of how cognitions and emotions affect behavior (e.g. Björgvinsson \& Hart, 2006). However, CBT requires that some level of mentalization capacity is already present, asking patients to critically appraise their thoughts, whereas MBT does not. Furthermore, as a psychodynamic form of therapy, MBT is less directive, mainly aiming to help patients to better represent sensory-affective experience. Additionally, being rooted in attachment theory, MBT tends to be more directly concerned with the therapeutic relationship than CBT. Lastly, CBT takes a less 'holistic' approach to treatment patient, focusing on specific symptoms instead.

More akin to MBT, are the so called 'third wave' cognitive behavioral therapies. Whereas CBT was developed to treat specific symptoms, the third wave cognitive therapies, like MBT, have shifted their focus on the thinking process underlying symptoms rather than on the content of that thinking process (Lana, Sola Victor \& Marti-Bonany, 2017). In other words, they have shifted their focus from what people think to how people think (Björgvinsson \& Hart, 2006). Social cognitive therapies for example tend to focus on specific aspects that underlie other-oriented mentalizing, such as affect recognition, social attribution biases or theory of mind (see Lana et al., 2017 for an overview of different approaches). Such approaches tend to differ from MBT, however, because they are more directive in nature and also tend to focus on just one distinct element of mentalizing. Additionally, such treatments do not target self-oriented aspects of mentalizing.

Perhaps most akin to MBT is Metacognitive Insight and Reflection Therapy (MERIT; de Jong et al., 2018). Ridenour et al. (2019) have previously noted that descriptions and case reports suggest that MBT and MERIT are largely compatible with one another. MERIT, like MBT, focuses on 
the identification of mental states, the differentiation of subjective experiences from objective reality, relating mental states to behavior, and integrating such knowledge into narratives. Similar to MBT, MERIT focuses on higher order cognitive processing by engaging the patient's ability to verbalize their subjective experience. The therapist takes an inquisitive stance towards the patient, searching for the patient's narrative rather than 'the truth'. Lastly, both emphasize that therapeutic questions should be adjusted towards the patient's level of metacognition.

There are however subtle distinctions between MERIT and MBT, however, which have been extensively detailed by Ridenour et al. (2019). Chief of these are that MBT specifically offers psycho-education prior to treatment to elaborate on mentalizing and its relation to attachmentprocesses and emotions. MBT has also been argued to pay more attention to the bodily aspect of emotional experience (Debbané et al., 2016). From the therapist perspective, MBT-training provides specific clinical guides to assess emotional arousal in sessions, as well as how to work safely within the client-therapist relationship (Brent, 2009; Debbané et al., 2016). On the other hand, MERIT arguably focuses more explicitly on the patient's agency, by explicitly making the patient set the agenda for each treatment session. Lastly, group-therapy is an important element of MBT, but this is not the case for MERIT.

Mentalization based treatment for psychotic disorder. Although MBT was originally designed for borderline personality disorder (BPD; Bateman \& Fonagy, 1999), given its focus on impaired mentalizing ability, it may be suitable for patients with NAPD as well. Recent articles have explored the applicability of MBT as a treatment for psychotic disorders or its prodromal states (Brent \& Fonagy, 2014; Weijers et al., 2016; Debbané et al., 2016) and the effectiveness of MBT for psychotic disorders is currently being examined in a randomized controlled trial (Weijers et al., 2016). However, disorder-specific characteristics do warrant some different approaches in MBT when dealing with patients with NAPD.

First, many NAPD patients tend to deactivate attachment-related affect to manage overarousal triggered by social interaction. This may give a false impression of a lack of arousal. Moreover, negative symptoms such as flattened affective expression, can further complicate gauging the level of arousal of the patient and asking the patient to do complex mental work in the context of high arousal is not deemed helpful. MBT therapists must therefore be acutely aware on slight signs of emotional disturbance that are particular to NAPD, such as slowing of speech or decreased coherence.

Second, given their inclination for disorganized or dismissive attachment, NAPD patients do not tend to become very attached to their therapist or group members, at least in the initial phase 
of treatment. This means that attachment bonds tend to remain fragile for a longer time, and patients may find it relatively easy to drop out of treatment. Keeping patients 'in mind' through telephone calls or house visits following missed sessions, helps.

Third, we concur with Gumley and Liotti's (2008) observation that a more severe mentalization deficit distinguishes NAPD from BPD. Mentalizing in BPD seems to be characterized more by an instability rather than a deficit, while patients with NAPD tend to have a more structural difficulty detecting and interpreting sensory-affective experiences. Therapy sessions in the initial phase should therefore focus on elementary levels of mentalizing such as detecting affective experiences and verbalizing them.

Fourth, often antipsychotic medication has a substantial dampening effect on emotions. This may improve mentalizing ability in certain respects, but it can also make it difficult to talk about the emotional significance of events if such emotions are hardly experienced. It is therefore important that antipsychotic medication is attenuated with a specific focus on the ability to still feel affect.

Clinical Vignette. To conclude, we will shortly illustrate the principles of MBT for psychotic disorder with a patient who suffers from paranoid delusions and finds it difficult to relate to others who do not share his beliefs.

Therapist: Hi, how are you feeling? (The therapist immediately focuses on current affect.) Patient: Yeah, I'm good; I've been on holiday with my girlfriend, which was mostly good. T: Mostly good? (The therapist adopts a not-knowing stance)

P: Yeah, we had fun, but I also had a falling-out with her, which is still bothering me. I tried to talk to her about my views on the world. I really wanted her to see my point of view.

$\mathrm{T}$ : In what way is this still bothering you? (Again, the therapist focuses on current affect.) P: I have experiences like this all the time, with friends, for example. I sometimes just feel that if they saw it my way, they would agree with me. (Here, the patient is focused on the 'then and there,' but is not consciously attending his own current affective experience.)

T: How does that make you feel now? (Again focus is shifted to current affective experience.)

P: (The patient starts avoiding eye contact, and begins to talk in an agitated manner.) I have put a lot of research into how the world works. We are being deceived; the evidence is there. (The patient now shows signs of agitation; his answers do not clearly address the questions asked, and he withdraws from contact. In this state it is unlikely that his therapist will reach him. Being asked to think about his current feelings may have been too complex at this time and complexity needs to be scaled back at this point.) 
T: Hey, I see you are getting a bit agitated. This must be difficult for you! (Here, the therapist tries to reduce the level of stress by validating the patient's feelings.)

P: (Shrugs) It's no use talking about this stuff, because you people simply adhere to what we have been fed by the media, like sheep. I get the feeling that you are all against me, but I am used to it. (Here, the patient shows cleat signs of impaired mentalizing. He has lost the ability to distinguish between individuals, lumping everyone in one category, he is now likely unable to consider therapist's perspective as meaningful.)

T: I'm very sorry to hear that you perceive everyone is against you. That must be so difficult to bear, that perception that everyone is against you. (Since the level of stress for the patient is too high, the therapist resorts to supportive interventions, validating his current affective state. By using terms like 'perceive' and 'perception' the therapist also addresses the fact that the patient's view is impressionistic, implying it does not necessarily reflect reality.) P: (Relaxes visibly) I don't necessarily think you are against me, but many people are. (The ability to mentalize seems to return, as he regains the ability to distinguish between people.)

T: Hey, it seems to me that you got a little worked up there, but that now you have also calmed down a bit. Could you help me understand what happened there? (Here, the therapist tries to get the patient to reflect on the affective response he just had.)

P: I get worked up about this stuff, and then I get angry with people for no reason.

$\mathrm{T}$ : Shall we look at what happened there then? It seems like you lumped me together with people you dislike (Here, the clinician considers the interaction that just occurred just as a prototype for interactions with others.)

P: I react to people too quickly because I don't like it when people do not agree with me. I think I get upset, when I have the feeling people do not take me seriously. (Here, through becoming conscious of his affective reaction to the therapist, the patient has developed some insight into the way he relates to others in general.)

\section{Concluding Remarks}

With this article, we attempted to show how mentalization theory may inform understanding and treatment of NAPD, especially regarding difficulties in mentalizing and epistemic mistrust. On-hand experience with mentalization based treatment for psychotic disorder has given the impression that, MBT may help loosen rigid interpretations of aberrant sensory-affective experience and thus improves social interaction. 


\section{Acknowledgments}

None.

\section{Funding}

This research did not receive any specific grant from funding agencies in the public, commercial, or not-for-profit sectors.

\section{Compliance with Ethical standards}

Research was conducted according with the provisions of the World Medical Association Declaration of Helsinki. This study is part of a larger study (Weijers, et al., 2016) for which ethical approval was given by the Medical Research Ethics Committee of the University Hospital Maastricht and Maastricht University (13-3-066.5/ab). Written informed consent to publish data and clinical material was obtained from all subjects, including the individual for whom potentially identifying information is included in this article.

\section{Conflicts of interest}

The authors declare that they have no competing interest.

\section{References}

Ainsworth, M. D. S., Blehar, M. C., Waters, E., \& Wall, S. N. (1978). Patterns of attachment: A psychological study of the strange situation. London, United Kingdom: Psychology Press.

Aleman, A., \& Larøi, F. (2008). Hallucinations: The science of idiosyncratic perception. American Psychological Association.

Arnsten, A. F. (2009). Stress signaling pathways that impair prefrontal cortex structure and function. Nature Reviews Neuroscience, 10(6), 410.

Aydin, O., Balikci, K., Tas, C., Aydin, P. U., Danaci, A. E., Brüne, M., \& Lysaker, P. H. (2016). The developmental origins of metacognitive deficits in schizophrenia. Psychiatry research, 245, 15-21.

Baron-Cohen, S., Leslie, A. M., \& Frith, U. (1986). Mechanical, behavioural and intentional understanding of picture stories in autistic children. British Journal of Developmental Psychology, 4, 113-125. 
Bateman, A., \& Fonagy, P. (1999). Effectiveness of partial hospitalization in the treatment of borderline personality disorder: a randomized controlled trial. American Journal of Psychiatry, 156(10), 1563-1569.

Bateman, A. W., \& Fonagy, P. (2004). Mentalization-based treatment of BPD. Journal of personality disorders, 18(1), 36-51.

Bateman, A., \& Fonagy, P. (2006). Mentalizing and borderline personality disorder. In Allen, J. G. \& Fonagy, P. (Eds.), The handbook of mentalization-based treatment (pp. 185-200). Hoboken, United States: John Wiley \& Sons Inc.

Bentall, R. P., \& Swarbrick, R. (2003). The best laid schemas of paranoid patients: autonomy, sociotropy and need for closure. Psychology and Psychotherapy: Theory, Research and Practice, 76(2), 163-171.

Berry, K., Barrowclough, C., \& Wearden, A. (2008). Attachment theory: a framework for understanding symptoms and interpersonal relationships in psychosis. Behaviour research and therapy, 46(12), 1275-1282.

Birchwood, M., Connor, C., Lester, H., Patterson, P., Freemantle, N., Marshall, M., ... \& Everard, L. (2013). Reducing duration of untreated psychosis: care pathways to early intervention in psychosis services. The British Journal of Psychiatry, 203(1), 58-64.

Björgvinsson, T., \& Hart, J. (2006). Cognitive behavioral therapy promotes mentalizing. Handbook of mentalization-based treatment, 157-170.

Bowlby, J. (1980). Attachment and loss. (vol. 1). New York, United States: Random House.

Brent, B. (2009). Mentalization-based psychodynamic psychotherapy for psychosis. Journal of clinical psychology, 65(8), 803-814.

Brent, B. K., \& Fonagy, P. (2014). A mentalization-based treatment approach to disturbances of social understanding in schizophrenia. In Social cognition and metacognition in schizophrenia (pp. 245-259). Cambridge, MA: Academic Press.

Brookwell, M. L., Bentall, R. P., \& Varese, F. (2013). Externalizing biases and hallucinations in source-monitoring, self-monitoring and signal detection studies: a meta-analytic review. Psychological Medicine, 43(12), 2465-2475.

Brunelin, J., d'Amato, T., Brun, P., Bediou, B., Kallel, L., Senn, M., ... \& Saoud, M. (2007). Impaired verbal source monitoring in schizophrenia: an intermediate trait vulnerability marker? Schizophrenia Research, 89(1-3), 287-292.

Choudhury, S., Blakemore, S. J., \& Charman, T. (2006). Social cognitive development during adolescence. Social cognitive and affective neuroscience, 1(3), 165-174. 
Debbané, M., Salaminios, G., Luyten, P., Badoud, D., Armando, M., Solida Tozzi, A., ... \& Brent, B. K. (2016). Attachment, neurobiology, and mentalizing along the psychosis continuum. Frontiers in human neuroscience, 10, 406.

de Jong, S., van Donkersgoed, R. J. M., Timmerman, M. E., Aan Het Rot, M., Wunderink, L., Arends, J., ... \& Pijnenborg, G. H. M. (2019). Metacognitive reflection and insight therapy (MERIT) for patients with schizophrenia. Psychological Medicine, 49(2), 303-313.

Eisenstadt, P., Monteiro, V. B., Diniz, M. J., \& Chaves, A. C. (2012). Experience of recovery from a firstepisode psychosis. Early intervention in psychiatry, 6(4), 476-480.

Fett, A. K. J., Viechtbauer, W., Penn, D. L., van Os, J., \& Krabbendam, L. (2011). The relationship between neurocognition and social cognition with functional outcomes in schizophrenia: a meta-analysis. Neuroscience \& Biobehavioral Reviews, 35(3), 573-588.

Fonagy, P. (1989). On tolerating mental states. Theory of mind in borderline patients. Bulletin of Anna Freud Centre, 12, 91-115.

Fonagy, P., Luyten, P., \& Allison, E. (2015). Epistemic petrification and the restoration of epistemic trust: A new conceptualization of borderline personality disorder and its psychosocial treatment. Journal of personality disorders, 29(5), 575-609.

Fonagy, P., \& Bateman, A. (2006). Progress in the treatment of borderline personality disorder. The British Journal of Psychiatry, 188(1), 1-3.

Fonagy, P., \& Allison, E. (2014). The role of mentalizing and epistemic trust in the therapeutic relationship. Psychotherapy, 51(3), 372.

Fonagy, P., \& Bateman, A. W. (2016). Adversity, attachment, and mentalizing. Comprehensive psychiatry, 64, 59-66.

Fonagy, P., Luyten, P., Allison, E., \& Campbell, C. (2017). What we have changed our minds about. Borderline personality disorder as a limitation of resilience. Borderline personality disorder and emotion dysregulation, 4(1), 11.

Frith, C. D. (1992). The cognitive neuropsychology of schizophrenia. London, United Kingdom: Psychology press.

Gallese, V. (2005). Embodied simulation: From neurons to phenomenal experience. Phenomenology and the cognitive sciences, 4(1), 23-48.

Green, M. F., Horan, W. P., \& Lee, J. (2019). Nonsocial and social cognition in schizophrenia: current evidence and future directions. World Psychiatry, 18(2), 146-161.

Gumley, A., \& Liotti, G. (2008). An Attachment Perspective on Schizophrenia: The Role of Disorganized Attachment, Dissociation, and Mentalization. In Moskowitz, A., Schäfer, I. 
Martin, J. \& Dorahy, M. J., Psychosis, Trauma and Dissociation. Evolving Perspectives on Severe Psychopathology. Wiley Online Library: 97-116.

Gumley, A. I., Taylor, H. E. F., Schwannauer, M., \& MacBeth, A. (2014). A systematic review of attachment and psychosis: measurement, construct validity and outcomes. Acta Psychiatrica Scandinavica, 129(4), 257-274.

Harrington, L., Siegert, R., \& McClure, J. (2005). Theory of mind in schizophrenia: a critical review. Cognitive neuropsychiatry, 10(4), 24.

Hartwell, C. E. (1996). The schizophrenogenic mother concept in American psychiatry. Psychiatry, 59(3), 274-297.

Hasson-Ohayon, I., Goldzweig, G., Lavi-Rotenberg, A., Luther, L., Lysaker, P.H. (2018). The centrality of cognitive symptoms and metacognition within the interacting network of symptoms, neurocognition, social cognition and metacognition in schizophrenia. Schizophrenia Research, 202, 260-266.

Hendryx, M., Green, C.A., Perrin, N.A. (2009). Social support, activities, and recovery from serious mental illness: STARS study findings. Journal Behavioral Health Service Research, 36(3), 320329.

Holthausen, E. A., Wiersma, D., Cahn, W., Kahn, R. S., Dingemans, P. M., Schene, A. H., van den Bosch, R. J. (2007). Predictive value of cognition for different domains of outcome in recent-onset schizophrenia. Psychiatry Research, 149, 71-80.

Howes, O. D., \& Murray, R. M. (2014). Schizophrenia: an integrated socio-developmental-cognitive model. The Lancet, 383(9929), 1677-1687.

Kantrowitz, J. T., Hoptman, M. J., Leitman, D. I., Silipo, G., \& Javitt, D. C. (2014). The 5\% difference: early sensory processing predicts sarcasm perception in schizophrenia and schizoaffective disorder. Psychological medicine, 44(1), 25-36.

Kelleher, I., Keeley, H., Corcoran, P., Ramsay, H., Wasserman, C., Carli, V., ... \& Cannon, M. (2013). Childhood trauma and psychosis in a prospective cohort study: cause, effect, and directionality. American Journal of Psychiatry, 170(7), 734-741.

Keysers, C., \& Gazzola, V. (2007). Integrating simulation and theory of mind: from self to social cognition. Trends in cognitive sciences, 11(5), 194-196.

Kim, S. (2015). The mind in the making: Developmental and neurobiological origins of mentalizing. Personality Disorders: Theory, Research, and Treatment, 6(4), 356. 
Kraan, T., Velthorst, E., Smit, F., de Haan, L., \& van der Gaag, M. (2015). Trauma and recent life events in individuals at ultra-high risk for psychosis: review and meta-analysis. Schizophrenia research, 161(2-3), 143-149.

Lana, F., Africa Cruz, M., Sola Victor, P., Marti-Bonany, J. (2017). Social Cognition Based Therapies for People with Schizophrenia: Focus on Metacognitive and Mentalization Approaches. Schizophrenia treatment. SM Groups Open access ebooks.

Lane, J. D., \& Harris, P. L. (2015). The roles of intuition and informants' expertise in children's epistemic trust. Child development, 86(3), 919-926.

Leonhardt, B. L., Huling, K., Hamm, J. A., Roe, D., Hasson-Ohayon, I., McLeod, H. J., \& Lysaker, P. H. (2017). Recovery and serious mental illness: a review of current clinical and research paradigms and future directions. Expert Review of Neurotherapeutics, 17(11), 1117-1130.

Lind, S. E., \& Bowler, D. M. (2009). Recognition memory, self-other source memory, and theory-ofmind in children with autism spectrum disorder. Journal of Autism and Developmental Disorders, 39(9), 1231.

Lysaker, P.H., Buck, K.D., Fogley, R.L., Ringer, J., Harder, S., Hasson-Ohayon, I., et al. (2005). The mutual development of intersubjectivity and metacognitive capacity in the psychotherapy for persons with schizophrenia. Journal of Contemporary Psychotherapy, 43(2), 63-72.

Lysaker, P. H., \& Dimaggio, G. (2014). Metacognitive capacities for reflection in schizophrenia: implications for developing treatments. Schizophrenia Bulletin, 40(3), 487-491.

Main, M., \& Solomon, J. (1990). Procedures for identifying infants as disorganized/disoriented during the Ainsworth Strange Situation. Attachment in the preschool years: Theory, research, and intervention, 1, 121-160.

McLeod, H.J., Gumley, A.I., MacBeth, A., Schwannauer, M., Lysaker, P.H. (2014). Metacognitive functioning predicts positive and negative symptoms over 12 months in first episode psychosis. Psychiatry Research, 54(1), 109-115.

Mickelson, K. D., Kessler, R. C., \& Shaver, P. R. (1997). Adult attachment in a nationally representative sample. Journal of personality and social psychology, 73(5), 1092.

Mikulincer, M. (1997). Adult attachment style and information processing: Individual differences in curiosity and cognitive closure. Journal of personality and social psychology, 72(5), 1217.

Mikulincer, M., \& Shaver, P. R. (2012). An attachment perspective on psychopathology. World Psychiatry, 11(1), 11-15. 
- Chapter Two

Nolte, T., Bolling, D. Z., Hudac, C., Fonagy, P., Mayes, L. C., \& Pelphrey, K. A. (2013). Brain mechanisms underlying the impact of attachment-related stress on social cognition. Frontiers in Human Neuroscience, 7, 816.

Norman, R. M., Windell, D., Lynch, J., \& Manchanda, R. (2013). Correlates of subjective recovery in an early intervention program for psychoses. Early intervention in psychiatry, 7(3), 278-284.

O'Driscoll, C., Laing, J., \& Mason, O. (2014). Cognitive emotion regulation strategies, alexithymia and dissociation in schizophrenia, a review and meta-analysis. Clinical Psychology Review, 34(6), 482-495.

Owens, K. A., Haddock, G., \& Berry, K. (2013). The role of the therapeutic alliance in the regulation of emotion in psychosis: an attachment perspective. Clinical psychology \& psychotherapy, 20(6), 523-530.

Pereira, J. G., \& Debbané, M. (2018). An Integrative-Relational Approach in Schizophrenia: From Philosophical Principles to Mentalization-Based Practice. In Hipolito, I., Goncalves, J., Pereira, J. (Eds.) Schizophrenia and Common Sense (pp. 193-207). Cham, Switzerland: Springer.

Pinkham, A. E., Penn, D. L., Perkins, D. O., \& Lieberman, J. (2003). Implications for the neural basis of social cognition for the study of schizophrenia. American Journal of Psychiatry, 160(5), 815824.

Read, J., Fosse, R., Moskowitz, A., \& Perry, B. (2014). The traumagenic neurodevelopmental model of psychosis revisited. Neuropsychiatry, 4(1), 65.

Ridenour, J., Knauss, D., \& Hamm, J. A. (2019). Comparing metacognition and mentalization and their implications for psychotherapy for individuals with psychosis. Journal of Contemporary Psychotherapy, 49(2), 79-85.

Selten, J. P., van der Ven, E., Rutten, B. P., \& Cantor-Graae, E. (2013). The social defeat hypothesis of schizophrenia: an update. Schizophrenia bulletin, 39(6), 1180-1186.

Semerari A., Carcione A., Dimaggio G., Falcone M., Nicolò G., Procacci M., et al. (2003). How to evaluate metacognitive functioning in psychotherapy? The metacognition assessment scale and its applications. Clinical Psychological Psychotherapy, 10(4), 238-61.

Sprong, M., Schothorst, P., Vos, E., Hox, J., \& Van Engeland, H. (2007). Theory of mind in schizophrenia: meta-analysis. The British Journal of Psychiatry, 191(1), 5-13.

Sroufe, L. A. (2005). Attachment and development: A prospective, longitudinal study from birth to adulthood. Attachment \& human development, 7(4), 349-367. 
Stumbo, S. P., Yarborough, B. J. H., Paulson, R. I., \& Green, C. A. (2015). The impact of adverse child and adult experiences on recovery from serious mental illness. Psychiatric rehabilitation journal, 38(4), 320.

Thomas, E. C., Muralidharan, A., Medoff, D., \& Drapalski, A. L. (2016). Self-efficacy as a mediator of the relationship between social support and recovery in serious mental illness. Psychiatric rehabilitation journal, 39(4), 352.

Torre, J. B., \& Lieberman, M. D. (2018). Putting feelings into words: Affect labeling as implicit emotion regulation. Emotion Review, 10(2), 116-124.

Trémeau, F. (2006). A review of emotion deficits in schizophrenia. Dialogues in clinical neuroscience, 8(1), 59.

Varese, F., Smeets, F., Drukker, M., Lieverse, R., Lataster, T., Viechtbauer, W., ... \& Bentall, R. P. (2012). Childhood adversities increase the risk of psychosis: a meta-analysis of patientcontrol, prospective-and cross-sectional cohort studies. Schizophrenia bulletin, 38(4), 661671.

Velthorst, E., Nieman, D. H., Linszen, D., Becker, H., de Haan, L., Dingemans, P. M., ... \& Heinz, A. (2010). Disability in people clinically at high risk of psychosis. The British Journal of Psychiatry, 197(4), 278-284.

Weijers, J., ten Kate, C., Eurelings-Bontekoe, E., Viechtbauer, W., Rampaart, R., Bateman, A., \& Selten, J. P. (2016). Mentalization-based treatment for psychotic disorder: protocol of a randomized controlled trial. BMC psychiatry, 16(1), 191.

Weijers, J., Fonagy, P., Eurelings-Bontekoe, E., Termorshuizen, F., Viechtbauer, W., \& Selten, J. P. (2018). Mentalizing impairment as a mediator between reported childhood abuse and outcome in nonaffective psychotic disorder. Psychiatry research, 259, 463-469.

White C., Stirling J., Morris J., Montague L., Tantam D., Lewis S. (2009). Predictors of 10-year outcome of first-episode psychosis. Psychological Medicine, 39, 1447-1456. 



\section{CHILDHOOD ABUSE AND PSYCHOSIS}





\section{REPORTED CHILDHOOD ABUSE AND STRESS REACTIVITY IN PSYCHOSIS:}

\section{A CONCEPTUAL}

REPLICATION AND AN EXPLORATION OF STATISTICAL APPROACHES

J.G. Weijers, W.V. Viechtbauer, E.H.M

Eurelings-Bontekoe, J.-P.C.J. Selten 


\begin{abstract}
A previous study observed that reported childhood abuse moderated psychotic and emotional reactivity to stress among patients with non-affective psychotic disorder. However, that study used a type of analysis unsuited for skewed data. This study aimed 1) to replicate the study and 2) to examine whether we would obtain similar results using a statistical approach better suited to skewed data. Fifty-nine patients with non-affective psychotic disorder were examined for up to six days using an intensive diary method to assess levels of negative affect, psychosis, and daily-life stress. A mixed-linear regression largely replicated earlier findings, but a two-component analysis failed to replicate the moderating effect of reported childhood abuse. These results illustrate the importance of exploring different statistical approaches to skewed data. They may also indicate that stress sensitization does not offer a complete account for the effect of reported childhood abuse on psychotic symptom severity.
\end{abstract}

Keywords: Experience sampling method, psychosis, childhood abuse, stress reactivity, non-normally distributed data.

\title{
Introduction
}

A growing body of evidence indicates that childhood abuse plays a role in the etiology of nonaffective psychotic disorder (NAPD; Matheson, Shepherd, Pinchbeck, Laurens \& Carr, 2013; Varese et al., 2012; Morgan \& Fisher, 2007; van Dam et al., 2015). It has been suggested that an increased reactivity to stressful situations accounts for this (Myin-Germeys \& van Os, 2007; Collip, MyinGermeys \& van Os, 2008; Veling, Counotte, Pot-Kolder, van Os \& van der Gaag, 2016). According to this view, cumulative exposure to traumatic experiences during childhood results in 'behavioral sensitization', a mechanism whereby previous exposure to adversity or stress renders individuals more sensitive to stress later in life, which in turn is thought to increase the risk for psychosis (Lataster, Valmaggia, Lardinois, van Os \& Myin-Germeys, 2013; Vaessen et al., 2017; Myin-Germeys, Delespaul \& van Os, 2005). Indeed, using the 'experience sampling method' (ESM), it was shown that daily life stress is associated with the intensity of psychotic experiences in patients with NAPD (Lataster et al., 2013). ESM is especially useful for examining dynamic processes in daily life, because it involves prompting participants to report on their experiences multiple times per day for an extended period of time. In this way, ESM constitutes an ecologically valid approach for the measurement of pathological experiences and stressors in daily life. 
A number of ESM studies have shown that the severity of reported childhood abuse (RCA) can indeed affect the intensity of emotional and psychotic reactions to daily life stressors (Glaser, van Os, Portegijs \& Myin-Germeys, 2006; Cristóbal-Narváez et al., 2016; van Nierop et al., 2018; Lardinois, Lataster, Mengelers, van Os, \& Myin-Germeys, 2013; Reinghaus et al., 2016). RCA was shown to be correlated with greater negative emotional reactions or psychotic reactions to stress in nonclinical samples (Glaser et al., 2006; Cristóbal-Narváez, 2016; van Nierop et al., 2018) and, with regard to NAPD (Lardinois, Lataster, Mengelers, Van Os, \& Myin-Germeys, 2011) showed that patients with high levels of RCA reported increased psychotic and emotional reactivity to eventrelated stress (i.e., when an unpleasant event happens) and activity-related stress (i.e., when an activity's difficulty exceeds one's capability). Similar observations were made by Reininghaus et al. (2016), but they involved different types of stress, namely social stress (i.e., the unpleasantness of the participant's current social situation) and area-related stress (i.e., the unpleasantness of the participant's current neighborhood). Contrary to Lardinois et al. (2011), however, Reininghaus et al. (2016) did not find evidence that the relationship between event stress and negative affect or psychotic experiences was moderated by RCA.

Thus, the previous studies are in overall support of the hypothesis of behavioral sensitization to stress due to childhood abuse. However, it remains uncertain whether RCA specifically moderates the relationship between event-related stress and negative affect or psychotic experiences, as the findings of Reininghaus (2016) and Lardinois (2011) are in contradiction. Additionally, the finding by Lardinois et al. (2011) concerning activity-related stress has not been replicated in an NAPD sample. In our view, this is important, since scientific claims can only be given credence in accordance with the reproducibility of their supporting evidence (Open Science Collaboration, 2012). Lastly, and most importantly, all studies concerning RCA and stress reactivity so far have employed mixed-effects linear regression models. Concerns may be raised about these analyses, since the outcome variables (i.e., negative affect and psychotic experiences) are rarely normally distributed and tend to be right-skewed (Terluin, de Boer \& de Vet, 2016), possibly violating normality assumptions underlying the models (with respect to the residuals and random effects). In light of this, mixed-effects linear regression analyses may not be suitable (Terluin, de Boer \& de Vet, 2016).

The current study sought to replicate and improve upon the study by Lardinois et al. (2011) in several ways. First and foremost, we explored two statistical approaches for the analysis of the data: next to a mixed-linear regression, which mirrors the original study, we added a secondary analysis more suitable for the analysis of skewed outcomes to examine the sensitivity of the 
conclusions to the modeling approach used. Second, we used a semi-structured, observer-rated instrument to measure RCA, as opposed to the self-report questionnaire used in the previous study. This offered the opportunity to get an in-depth account of childhood experiences, while simultaneously providing a less subjective rating of the severity of abuse. Cristobal-Navaez et al. (2016) suggest that interviews relying on objective definitions of adversity like the 'Childhood Experience of Care and Abuse' (CECA) instrument allow for a more precise assessment. Third, the current study treated RCA as a continuous variable as opposed to the earlier studies that dichotomized RCA using a somewhat arbitrary cut-off point (e.g., van Nierop et al., 2018, Lardinois et al., 2011; Reininghaus et al., 2016). Many authors have argued against the artificial dichotomization of variables, as this can lead to a loss of information and power, lower reliability, inflated type I and type II errors, and potential bias (Irwin \& McClelland, 2003; Royston, Altman \& Sauerbrei, 2006; Whisman \& McClelland, 2005). Fourth, some authors (Stone, Shiffman, Schwartz, Broderick \& Hufford, 2002) have cast doubt on the reliability of the pen-and-paper experience sampling method used in the study by Lardinois and colleagues, preferring the use of electronic devices like the one used in the current study.

Specifically, the aim of this study is to test whether: 1) activity-related stress and eventrelated stress are related to negative affect and psychotic experiences and 2) whether the severity of RCA moderates the emotional and psychotic reactivity to activity-related stress and eventrelated stress.

\section{Materials and methods}

Sample and procedure. This study is part of a larger one (Weijers et al., 2016) for which ninety patients with NAPD were recruited from community treatment teams at regional mental health care institutes in the Netherlands (the Rivierduinen Institute for Mental Health Care located in Leiden, Voorhout, and Zoetermeer, and the Altrecht Institute for Mental Health Care in Zeist). Diagnoses were established by psychiatrists prior to participation and included schizophrenia, schizoaffective disorder, schizophreniform disorder, brief psychotic disorder, delusional disorder, or psychotic disorder not otherwise specified. Their diagnosis was confirmed by researchers using the Comprehensive Assessment of Symptoms and History (CASH; Andreasen, Flaum \& Arndt, 1992). Only patients with a clinician diagnosis in the NAPD spectrum, were interviewed with the CASH for eligibility. Using the CASH it was revealed that all of the eligible participants who had been given a clinician diagnosis in the NAPD spectrum, also had NAPD according to the CASH. However, specific DSM-IV diagnoses (i.e. schizophrenia or schizo-affective disorder) could differ between 
clinicians and researchers. A reliability analysis revealed that there was an acceptable rate of agreement between clinicians and researchers with regard to specific NAPD diagnoses (Cronbach's alpha $=0.713$ ). Further inclusion criteria were: 1 ) at least 18 years of age, 2) fluent command of the Dutch language, and 3) the start of their treatment for psychotic disorder had to be between 6 months and 10 years ago. Exclusion criteria were 1) intellectual disability, 2) illiteracy, or 3) substance addiction that necessitates detoxification. Treatment staff scanned their caseloads for possibly eligible patients. The researchers contacted these patients by telephone and invited them for an information consult and screening for in- and exclusion criteria.

Measures. The current study used an intensive diary method almost identical to the original study. Like the study by Lardinois et al. (2011), participants were prompted by a signal (beep) ten times a day to fill out a questionnaire for a up to six days. Please refer to the original study for more detailed information about this method (Lardinois et al., 2011). The current study only diverged from the previous one by using an electronic diary device (called the 'PsyMate') to collect the responses to the questions (instead of digital wristwatches and paper booklets).

As in previous studies (e.g., Glaser et al., 2006; Lardinois et al., 2011), stress reactivity was conceptualized as an increase in negative affect or psychotic experiences due to two types of stressful situations: activity stress and event stress. Activity-related stress was assessed by three items concerning the activity participants were engaging in when the beep was emitted. In particular, participants rated how unskilled they felt at the current activity ("I am not skilled to do this activity"), how difficult their current activity was ("This activity is difficult"), and to what degree they would rather engage in some other activity ("I would rather do something else"). The average of the three items was used as an indicator of activity-related stress. Event-related stress was assessed by a single item, asking participants to rate the pleasantness of the most important event preceding the current beep. The item was rated on a -3 (very unpleasant) to 3 (very pleasant) scale and was reverse scored before the analysis. Negative affect was assessed at each beep based on the average score of fives items: feeling insecure, lonely, guilty, down, and anxious. Psychotic experiences comprised the average score of seven items: feeling unreal, feeling disliked, feeling suspicious, fearing that one might be hurt by others, fearing to lose control, hearing voices, and experiencing that one's thoughts are being influenced by others. All of these items were rated on 7point Likert scales.

For the ESM items measuring activity stress ( 3 items), negative affect ( 5 items), and psychotic experiences (7 items), we computed Cronbach's alpha values for the person-level means and the within-person mean centered values (to obtain information about the reliability of the 
items at the person and at the beep level). For activity stress, this yielded values of $\alpha=.71$ and $\alpha=.46$ for the person and beep levels, respectively. For negative affect, we found $\alpha=.93$ and $\alpha=.69$, respectively. Finally, for psychotic experiences, we obtained $\alpha=.91$ and $\alpha=.70$.

The 'Childhood Experience of Care and Abuse' (CECA) instrument was used to assess RCA. The CECA is a retrospective, semi-structured interview that allows researchers to rate the severity of possible abuse at age $0-16$ years based on patients' accounts. The CECA has been found to be reliable and valid (Bifulco, Brown \& Harris, 1994). A later study corroborated the validity of the CECA by comparing sisters' accounts of parental abuse, finding overall strong agreement between those accounts, even when only one sister had experienced the form of abuse reported (Brown, Craig, Harris, Handly \& Harvey, 2007).

Childhood abuse comprised four types of maltreatment: psychological abuse, physical abuse, sexual abuse, and parental conflict. Psychological abuse comprised extreme criticism, rejection, humiliation, or terrorizing. Physical abuse was defined as bodily harm that resulted in at least bruising. Sexual abuse was defined as the participant's report of any unwanted sexual incident, including sexual assault. Parental conflict was defined as the amount of fighting between the caregivers and/or the child. Each type of abuse was scored for both frequency and intensity. Frequency of abuse was rated on a five-point Likert-scale: 0 (never), 1 (rarely: once or twice), 2 (incidentally: more than two times, but not monthly), 3 (regularly: monthly or more often), or 4 (often: weekly or more often). Intensity of abuse was rated on a four-point Likert scale: 0 (none), 1 (some), 2 (moderate), or 3 (marked), with the exception of parental conflict, which was scored on a five-point scale that also included 4 (violence). The severity score for each type of abuse was the product of intensity and frequency. The total score, ranging from 0 to 52 , was the sum of the severity scores for each subtype of abuse. For the analyses, we rescaled the variable by dividing the total score by 5 to avoid overly small coefficients. Hence, a one-unit increase on the rescaled RCA variable represents a 5-point increase on the original CECA total score.

Data analysis. As in the previous study, the data have a multilevel structure: multiple observations (level 1) are nested within subjects (level 2). Generally, observations within a subject are related and hence the residuals are not independent and the assumption of statistical independence required for regular regression analyses is violated. Hierarchical linear modeling is therefore required (Glaser et al., 2006; Hox, 1998). Mixed-effects (multilevel) linear regression models were used to test the hypothesis that event- and activity-related stress are related to negative affect and psychotic experiences. Intercepts and slopes for the stress variable were allowed to vary across subjects, with an unstructured variance-covariance matrix for the random 
effects. Next, we fitted models that included the stress variable, RCA, and their interaction to test whether RCA moderates stress reactivity to daily life stress.

The modeling approach described above constitutes the primary analysis, which is similar to the one carried out by Lardinois and colleagues (2011). This analysis only deviated from the original one by not dichotomizing the RCA variable and allowing slopes to vary across subjects (only random intercepts were used in the original study; personal communication). Adding random slopes to the model is important to avoid inflated Type I error rates and overly narrow confidence intervals (Gurka, Edwards \& Muller, 2011; Schielzeth \& Forstmeier, 2008).

With regard to the secondary analysis, examination of the data distribution indicated that a gamma distribution could provide an adequate fit to the data, but only when considering the subset of assessments where negative affect or psychotic experiences were actually present (i.e., when outcome $>1$ ). Therefore we decided to carry out a secondary analysis using a two-part or mixeddistribution model (e.g., see Olsen \& Shafer, 2001). After rescaling the outcomes (i.e., negative affect and psychotic experiences) to a 0 to 6 range (i.e., $y=$ outcome -1 ), we conducted a mixed-effects logistic regression model for the presence vs. absence of any negative affect / psychotic experience (i.e., $\mathrm{y}>0$ vs. $\mathrm{y}=0$ ) and a mixed-effects gamma regression model with a log link for the intensity of negative affect / psychotic experiences when negative affect / psychotic experiences were actually present (i.e., if $y>0$ ). The two-part models were fitted using maximum likelihood estimation with Gauss-Hermite quadrature (either with 5 or 7 integration points). Correlated random intercepts and slopes were included for each component, but correlations across components (e.g., for the random intercepts of the logistic and gamma parts) were not allowed due to model convergence problems. The two-part model provides insights into two psychological mechanisms: How stress (and its interaction with RCA) is related to exhibiting any negative affect / psychotic experiences and how stress (and its interaction with RCA) is related to the intensity of negative affect / psychotic experiences when these experiences are actually present. Results are reported in terms of the estimated coefficients and corresponding 95\% confidence intervals (CIs) and $p$-values. The fit of the standard mixed-effects model and the two-part model was compared by computing the difference in AIC values. Analyses were carried out with SPSS 23, R 3.4.0 using the 'nlme' (Pinheiro \& Bates, 2002) and 'Ime4' (Bates, Machler, Bolker \& Walker, 2014) packages, and SAS/STAT software 9.2, using the 'proc glimmix' and 'proc nlmixed' procedures.

Lastly, we examined potential violations of statistical assumptions specific to mixed-effects models, namely the assumption of homoscedasticity and multicollinearity. Firstly, the assumption of homoscedasticity is relevant for any kind of regression analysis. Like the standard mixed-effects 
model used by Lardinois et al. (2011), the assumption of homoscedasticity of residuals of the mixed-effects model used in the current study, was highly likely to be violated due to the bounded nature of the outcome variables (negative affect and psychotic experiences). An examination of a plot of the fitted values against the Pearson residuals for the current standard mixed-effects model, shows that this is clearly the case (lower variability for low fitted values, higher variability for higher fitted values). On the other hand, in the two-part model, we do not assume homoscedasticity to begin with, since the logistic and gamma parts of the model do not make such an assumption. Secondly, multicollinearity is also an issue for any kind of regression analysis. In the present case, the only predictors are the stress and the childhood abuse (CECA) variables. We examined the correlations between the subject-level means of the activity and event stress and the CECA variables. The correlations were equal to .27 and .42 , respectively, which were not viewed to be particularly worrisome particularly worrisome.

\section{Results}

Sample characteristics. Of the 90 patients who entered the study, nine participants refused to fill out any PsyMate questionnaire. One participant refused to answer questions concerning sexual abuse and was excluded. Lastly, 21 patients failed to fill out at least 20 questionnaires and as in previous studies (Lardinois et al., 2011, Reininghaus et al., 2016) were excluded from the analyses. The final sample used for the analyses therefore included 59 participants, providing responses to a total of 1926 beeps (on average, 32.6 responses per subject; $S D=8.6$; range: 20-58). Demographic variables as well as the mean scores of the dependent and independent variables of the sample are shown in Table 1.

\section{Primary analyses.}

Main effects. Both activity stress $(b=0.14,95 \% \mathrm{CI}[0.08,0.20], p<0.001)$ and event stress $(b$ $=0.08,95 \% \mathrm{CI}[0.03,0.12], p=0.001)$ were positively and significantly associated with negative affect. Activity stress $(b=0.10,95 \%$ CI $[0.06,0.14], p<0.001)$ was also associated with the intensity of psychotic experiences, while event stress just failed to be significant $(b=0.03,95 \% \mathrm{CI}[-0.00$, 0.05], $p=0.06$ ).

Reported childhood abuse and emotional stress reactivity. Two analyses were conducted with negative affect as the outcome variable. In the first analysis, RCA, activity stress, and their interaction were added as predictors. The second analysis substituted activity stress for event stress. Results showed that RCA significantly moderated the relationship between activity stress 
and negative affect $(b=0.03,95 \% \mathrm{CI}[0.01,0.06], p=0.02)$, but not the relationship between event stress and negative affect $(b=0.02,95 \%$ CI [0.00, 0.03], $p=0.07)$.

Reported childhood abuse and psychotic stress reactivity. Two additional analyses similar to the ones above were conducted with psychotic experiences as the outcome variable. Results showed that RCA significantly moderated the association between activity stress and psychotic experiences $(b=0.02,95 \% \mathrm{CI}[0.00,0.04], p=0.03)$, and between event stress and psychotic experiences $(b=0.01,95 \% \mathrm{CI}[0.00,0.02], p=0.03)$. 
Table 1. Demographic and clinical characteristics of 59 patients with non-affective psychotic disorder who completed electronic diaries and reported on stress reactivity.

\begin{tabular}{ll}
\hline Age [Mean (SD), range] & $31.83(9.40), 19-57$ \\
Sex [M/F (\%)] & $34 / 25(57.6 \% / 42.4 \%)$ \\
CASH DSM-IV diagnosis [n (\%)] & $34(57.6 \%)$ \\
$\quad$ Schizophrenia & $10(16.9 \%)$ \\
$\quad$ Psychotic Disorder NOS & $10(16.9 \%)$ \\
$\quad$ Schizoaffective Disorder & $3(5.1 \%)$ \\
$\quad$ Brief Psychotic Disorder & $2(3.4 \%)$ \\
$\quad$ Delusional Disorder & $5.61(4.07), 1-22$ \\
Mean (SD), range & $10.1(11.3), 0-43$ \\
Years since onset of psychosis & Mean $(S D)$, range \\
RCA $\quad$ & $2.17(1.16), 1-7$ \\
\hline ESM Variables: & \\
$\quad$ nonmissing) observations & $1.82(1.00), 1-7$ \\
Negative Affect & \\
$\quad$ 1908 & $3.25(1.43), 1-7$ \\
Psychotic Experiences & \\
$\quad$ 1893 & $2.80(1.25), 1-7$ \\
Event-related stress & \\
1878 & \\
$\quad$ 1891 &
\end{tabular}

Note: CASH = Comprehensive Assessment of Symptoms and History; CECA = Childhood Experience of Care and Abuse instrument; ESM = Experience Sampling Method; RCA = Reported Childhood Abuse

Secondary analyses. The secondary analyses using the two-part models indicated that neither activity nor event stress was significantly related to the chance of the participant reporting any negative affect (i.e., any score above 0 ); neither was event stress related to the chance of the participant reporting any psychotic experience (all $p$ 's $\geq 0.20$; see Table 2 for full results). However, activity stress was related to the chance of the participant reporting any psychotic experience $(b=$ $0.39,95 \%$ CI $[0.09,0.70], p=0.01)$. RCA did not significantly moderate the relationships between activity stress or event stress, and the presence of any negative affect or psychotic experience (all $p$ 's $\geq 0.12$; see Table 3 for full results).

On the other hand, both activity and event stress were significantly and positively related to the intensity of negative affect and psychotic experiences if present (all $p$ 's $\leq 0.01$; see Table 2 for full results). However, there was no evidence to suggest that RCA moderated the relationships between activity stress / event stress and the intensity of negative affect / psychotic experiences if present (all $p$ 's $\geq 0.22$; see Table 2 for full results). 
Based on the AIC values, the two-part model always provided a better fit than the standard mixed-effects model. Across all 8 models fitted, the difference in AIC values was at least 74 points in favor of the two-part model.

Table 2. Results of the two-part analysis of main and interaction effects on negative affect and psychotic experiences.

\begin{tabular}{|c|c|c|c|c|}
\hline $\begin{array}{l}\text { Independent } \\
\text { variable } \\
\text { or interaction }\end{array}$ & Dependent variable & Estimate & CI (95\%) & $\begin{array}{l}P- \\
\text { value }\end{array}$ \\
\hline activity stress & Any negative affect (i.e. $y=0$ vs. $y>0$ ) & 0.60 & $-0.33-1.53$ & 0.20 \\
\hline event stress & Any negative affect (i.e. $y=0$ vs. $y>0$ ) & -0.00 & $-0.25-0.24$ & 0.98 \\
\hline activity stress & $\begin{array}{l}\text { Any psychotic experience (i.e. } y=0 \text { vs. } \\
y>0)\end{array}$ & 0.39 & $0.09-0.70$ & 0.01 \\
\hline event stress & $\begin{array}{l}\text { Any psychotic experience (i.e. } y=0 \text { vs. } \\
y>0 \text { ) }\end{array}$ & -0.01 & $-0.20-0.19$ & 0.95 \\
\hline activity stress & $\begin{array}{l}\text { Intensity of negative affect when } \\
\text { present } \\
\text { (i.e. if } y>0 \text { ) }\end{array}$ & 0.12 & $0.07-0.17$ & $<0.01$ \\
\hline event stress & $\begin{array}{l}\text { Intensity of negative affect when } \\
\text { present (i.e. if } y>0 \text { ) }\end{array}$ & 0.06 & $0.03-0.10$ & $<0.01$ \\
\hline activity stress & $\begin{array}{l}\text { Intensity of psychotic experience when } \\
\text { present (i.e. if } y>0 \text { ) }\end{array}$ & 0.12 & $0.06-0.18$ & $<0.01$ \\
\hline event stress & $\begin{array}{l}\text { Intensity of psychotic experience when } \\
\text { present (i.e. if } y>0 \text { ) }\end{array}$ & 0.06 & $0.02-0.12$ & 0.01 \\
\hline RCA*activity stress & Any negative affect (i.e. $y=0$ vs. $y>0$ ) & 0.14 & $-0.03-0.30$ & 0.12 \\
\hline RCA*event stress & Any negative affect (i.e. $y=0$ vs. $y>0$ ) & 0.04 & $-0.09-0.17$ & 0.57 \\
\hline RCA*activity stress & $\begin{array}{l}\text { Any psychotic experience (i.e. } y=0 \text { vs. } \\
y>0 \text { ) }\end{array}$ & 0.07 & $-0.04-0.19$ & 0.21 \\
\hline RCA*event stress & $\begin{array}{l}\text { Any psychotic experience (i.e. } y=0 \text { vs. } \\
y>0 \text { ) }\end{array}$ & 0.00 & $-0.06-0.07$ & 0.89 \\
\hline RCA*activity stress & $\begin{array}{l}\text { Intensity of negative affect when } \\
\text { present (i.e. if } y>0 \text { ) }\end{array}$ & 0.02 & $-0.01-0.04$ & 0.22 \\
\hline RCA*event stress & $\begin{array}{l}\text { Intensity of negative affect when } \\
\text { present (i.e. if } y>0 \text { ) }\end{array}$ & 0.01 & $-0.01-0.03$ & 0.36 \\
\hline RCA*activity stress & $\begin{array}{l}\text { Intensity of psychotic experience when } \\
\text { present } \\
(\text { i.e. if } y>0)\end{array}$ & 0.01 & $-0.02-0.03$ & 0.59 \\
\hline RCA*event stress & $\begin{array}{l}\text { Intensity of psychotic experience when } \\
\text { present } \\
\text { (i.e. if } y>0 \text { ) }\end{array}$ & 0.00 & $-0.01-0.02$ & 0.61 \\
\hline
\end{tabular}

Note $:$ RCA = Reported Childhood Abuse 


\section{Discussion}

Lardinois and colleagues (2011) previously observed that patients with NAPD reported increased negative affect and psychotic experiences in response to both activity- and event-related stress. Moreover, they observed that RCA moderated these relationships, such that high levels of RCA were related to more intense emotional and psychotic reactivity to stress. The current study did not unequivocally replicate these findings. While the first analysis, mirroring the statistical approach of the original study, did replicate most findings - the main effects as well as most of the moderation effects - the two-component analysis failed to replicate the moderation effects. Main effects of stress on negative affect and psychotic experiences were not replicated in the mixed-effects logistic regression, but were replicated in the mixed-effects gamma-regression.

Methodological differences between these studies may account for some of the divergence. First, the current study used the CECA, which is an interview-based measure, while the original study used the CTQ, a questionnaire. This may have influenced participant response. Moreover, the CECA does not include a subscale for physical and emotional neglect. Perhaps these subscales accounted for some amount of the original effect. We also observed that more participants failed to fill out the required number of questionnaires $(n=21)$, compared to the original study $(n=3)$. A difference in the workload between the two studies is likely to account for this: the current study is part of a larger project, involving significantly more testing than the original study (see Weijers et al. 2016 for the tests used). One could argue that such drop-out may have been selective, thus influencing results. However, post-hoc logistic regression revealed that neither severity of psychotic symptoms as measured by the Positive and Negative Syndrome Scale (Kay, Fiszbein \& Opfer, 1987) nor RCA predicted dropout from the ESM study ( $p$ 's > .18).

Another possible limitation is that our sample is fairly heterogeneous, including patients with a first-episode psychosis as well as long-term treated patients. Future research concerning stress reactivity in NAPD should attend to these different subtypes and to illness duration. A recent study has shown that age at illness onset has a significant impact on some of the outcomes of schizophrenia (Immonen, Jääskeläinen, Korpela, \& Miettunen, 2017), which also may have impacted the current results. Also, stress may have divergent effects on different subtypes of NAPD. However, we feel that it is beyond the scope of the current study to examine the impact of these factors; its main aim was to replicate the study by Lardinois et al. (2011) and the amount of heterogeneity of both studies is fairly similar. Patients in Lardinois et al.'s (2011) study received between 1 month and 10 years of treatment prior to the study, and were between 17 and 45 years 
old. In our study patients received between 6 months and 10 years of prior treatment, and were between 19 and 57 years old.

Despite the observed differences, we would also like to underscore that we did replicate findings using a similar statistical approach. Even main and interaction effect-sizes were roughly replicated, suggesting that the two studies are not that dissimilar. In our view, the main question here is why there is a lack of statistical support for main effects in the mixed-effects logistic regression as opposed to the mixed-effects gamma regression and why there is a lack of evidence for moderation in the entire two-component analysis as opposed to the standard mixed-effects model. First, the absence of statistical evidence for main effects in the mixed-effects logistic regression and the presence of statistical evidence in the mixed-effects gamma regression may indicate that stress rather influences the intensity of psychotic symptoms and negative affect than their actual development. Second, concerning the lack of statistical evidence for the moderation effects in the entire two-component analysis, one could argue that the results of the two-component analyses may reflect a lack of power. Out of necessity, to analyze the clumped and right-skewed data, we dichotomized the outcome for the binary logistic analyses. For the gamma models, only data with psychotic experiences or negative affect actually being present was taken into consideration. By breaking down the data in this manner, we may have lost information and therefore power. More participants may be needed to find existing effects with such an approach.

Lastly, a more straightforward interpretation of the data is that such moderation may not actually exist. Stress sensitization is perhaps an incomplete or oversimplified account of the effect of RCA on psychotic symptoms. Perhaps other factors, such as genetic liability (van Winkel, Stefanis \& Myin-Germeys, 2008), outsider status (Selten \& Cantor-Graae, 2014), or insecure attachment style (Sitko, Bentall, Shevlin, \& Sellwood, 2014) may ultimately determine whether abusive experiences in childhood result in psychosis. The significant moderation effects of our primary analysis then may reflect Type I errors caused by violations of assumptions of linearity and normality, which may also account for previous contradictory findings (Lardinois et al., 2011; Reininghaus et al., 2016). Of course, this does not necessarily mean that the original findings (Lardinois et al., 2011) are reflective of Type I error as well. However, given that in the original study negative affect and psychotic experiences averaged 1.80 and 1.51 respectively on a scale of 1 to 7 - suggestive of heavy right-skewness - a mixed-effects linear regression is unlikely to have been an optimal fit for the data. In defense of the original study, though, we should mention that the analysis of multilevel data is constantly in development. Accounting for violation of normality in 
hierarchically structured data has only very recently been brought to attention (Terluin, de Boer \& de Vet, 2016) and the violation is complex to address.

In conclusion, the current findings replicated some but not all findings by Lardinois et al. (2011). The relationship between stress and the intensity of negative affect / psychotic experiences (when present) seems robust, but the moderating effects of RCA on stress reactivity less so. By using two statistical approaches, this study has furthermore illustrated the importance of exploring the effects of assumption violation on multilevel data. We think that the findings of the present study are of clinical relevance. Multiple authors have argued that it may be important to tailor NAPD interventions towards the observed heightened emotional reactivity to daily stressors (Cristóbal-Narváez et al., 2016; van Nierop et al., 2018; Reininghaus et al., 2016). Indeed, stress seems robustly related to the severity of psychotic experiences and negative affect, at least if already present. This may mean that interventions targeting reactivity to stress are of benefit to patients with NAPD. Interventions such as mentalization based treatment, which is aimed at improving emotion regulation, may be fruitful in this regard (Brent, 2009). However, the current results also increase uncertainty about the pathogenic model put forth by previous articles. There is still uncertainty about whether the relation between stress and the severity of psychotic experiences and negative affect can actually be attributed to childhood abuse. Therefore, interventions aimed at reducing stress reactivity may not affect psychotic experiences attributable to childhood abuse. In our view, it is important to ascertain whether previous results do not reflect Type I errors. Previous findings involving standard mixed-effects models with similar outcomes may need re-analysis. Lastly, future research should determine whether such assumption violations actually lead to different interpretations in sufficiently large samples.

\section{Ethics statement}

Research was conducted according with the provisions of the World Medical Association Declaration of Helsinki. This study is part of a larger study for which ethical approval was given by the Medical Research Ethics Committee of the University Hospital Maastricht and Maastricht University (13-3-066.5/ab). Written informed consent was obtained from all subjects.

\section{Author's contributions}

JW developed the study concept and wrote the first draft. JW was also responsible for testing and data collection. WV and JW performed data analysis. WV, EE, and JPS provided critical revisions. All authors approve of the final version of the paper for submission. 


\section{Conflicts of interest}

The authors declare no conflicts of interest with respect to the authorship or the publication of this article.

\section{Funding}

This work received no third-party funding, neither did the authors have financial relationships with commercial interests.

\section{Acknowledgments}

None.

\section{References}

Andreasen, N.C., Flaum, M., \& Arndt, S. (1992). The Comprehensive Assessment of Symptoms and History (CASH): an instrument for assessing diagnosis and psychopathology. Archives of general psychiatry, 49(8), 615-623.

Bifulco, A., Brown, G.W., \& Harris, T.O. (1994). Childhood Experience of Care and Abuse (CECA): a retrospective interview measure. Journal of Child Psychology and Psychiatry, 35(8), 14191435.

Bates, D., Mächler, M., Bolker, B., \& Walker, S. (2014). Fitting linear mixed-effects models using lme4. Journal of Statistical Software, preprint arXiv:1406.5823.

Brent, B. (2009). Mentalization-based psychodynamic psychotherapy for psychosis. Journal of clinical psychology, 65(8), 803-814.

Brown, G.W., Craig, T.K., Harris, T.O., Handley, R.V., \& Harvey, A.L. (2007). Validity of retrospective measures of early maltreatment and depressive episodes using the Childhood Experience of Care and Abuse (CECA) instrument-A life-course study of adult chronic depression-2. Journal of affective disorders, 103(1-3), 217-224.

Cristóbal-Narváez, P., Sheinbaum, T., Ballespí, S., Mitjavila, M., Myin-Germeys, I., Kwapil, T.R., \& Barrantes-Vidal, N. (2016). Impact of adverse childhood experiences on psychotic-like symptoms and stress reactivity in daily life in nonclinical young adults. Focus, 14(3), 387-395.

Glaser, J.-P., Van Os, J., Portegijs, P.J., \& Myin-Germeys, I. (2006). Childhood trauma and emotional reactivity to daily life stress in adult frequent attenders of general practitioners. Journal of psychosomatic research, 61(2), 229-236. 
Gurka, M.J., Edwards, L.J., \& Muller, K.E. (2011). Avoiding bias in mixed model inference for fixed effects. Statistics in medicine, 30(22), 2696-2707. Collip, D., Myin-Germeys, I., Van Os, J. (2008). Does the concept of "sensitization" provide a plausible mechanism for the putative link between the environment and schizophrenia? Schizophrenia bulletin, 34(2), 220-225.

Hox, J. (1998).Multilevel modeling: When and why. Classification, data analysis, and data highways. Heidelberg: Springer.

Immonen, J., Jääskeläinen, E., Korpela, H., \& Miettunen, J. (2017). Age at onset and the outcomes of schizophrenia: A systematic review and meta-analysis. Early intervention in psychiatry, 11(6), 453-460.

Irwin, J.R., \& McClelland, G.H. (2003). Negative consequences of dichotomizing continuous predictor variables. Journal of Marketing Research, 40(3), 366-371.

Lardinois, M., Lataster, T., Mengelers, R., Van Os, J., \& Myin-Germeys, I. (2011). Childhood trauma and increased stress sensitivity in psychosis. Acta Psychiatrica Scandinavica, 123(1), 28-35.

Lataster, T., Valmaggia, L., Lardinois, M., Van Os, J, \& Myin-Germeys, I. (2013). Increased stress reactivity: a mechanism specifically associated with the positive symptoms of psychotic disorder. Psychological Medicine, 43(7), 1389-1400.

Kay, S.R., Fiszbein, A., Opfer, L.A. (1987). The positive and negative syndrome scale (PANSS) for schizophrenia. Schizophrenia bulletin, 13(2), 261-276.

Matheson, S.L., Shepherd, A.M., Pinchbeck, R.M., Laurens, K.R., \& Carr, V.J. (2013). Childhood adversity in schizophrenia: a systematic meta-analysis. Psychological medicine, 43(2), 225-238.

Morgan, C., \& Fisher, H. (2007). Environment and schizophrenia: environmental factors in schizophrenia: childhood trauma-a critical review. Schizophrenia bulletin, 33(1), 3-10.

Myin-Germeys, I., Delespaul, P., \& Van Os, J. (2005). Behavioural sensitization to daily life stress in psychosis. Psychological medicine, 35(5), 733-741.

Myin-Germeys, I., \& van Os, J. (2007). Stress-reactivity in psychosis: evidence for an affective pathway to psychosis. Clinical psychology review, 27(4), 409-424.

Olsen, M.K., \& Schafer, J.L. (2001). A two-part random-effects model for semicontinuous longitudinal data. Journal of the American Statistical Association, 96(454), 730-745.

Open Science Collaboration. (2012). An open, large-scale, collaborative effort to estimate the reproducibility of psychological science. Perspectives on Psychological Science, 7(6), 657-660.

Pinheiro, J.C., \& Bates, D.M. (2002). Linear mixed-effects models: basic concepts and examples. Mixedeffects models in $S$ and S-Plus. New York: Springer. 
Reininghaus, U., Kempton, M.J., Valmaggia, L., Craig, T.K., Garety, P., Onyejiaka, A., ..., \& Dazzan, P. (2016). Stress sensitivity, aberrant salience, and threat anticipation in early psychosis: an experience sampling study. Schizophrenia bulletin, 42(3), 712-722.

Royston, P., Altman, D.G., \& Sauerbrei, W. (2006). Dichotomizing continuous predictors in multiple regression: a bad idea. Statistics in medicine, 25(1), 127-141.

Selten, J.P., \& Cantor-Graae, E. (2014). Childhood trauma and the treatment for psychotic disorder. Acta Psychiatrica Scandinavica, 129(6), 479-480.

Schielzeth, H., \& Forstmeier, W. (2008). Conclusions beyond support: overconfident estimates in mixed models. Behavioral Ecology, 20(2), 416-420.

Sitko, K., Bentall, R.P., Shevlin, M., \& Sellwood, W. (2014). Associations between specific psychotic symptoms and specific childhood adversities are mediated by attachment styles: an analysis of the National Comorbidity Survey. Psychiatry research, 217(3), 202-209.

Stone, A.A., Shiffman, S., Schwartz, J.E., Broderick, J.E., \& Hufford, M.R. (2002). Patient non-compliance with paper diaries. British Medical Jorunal, 324(7347), 1193-1194.

Terluin, B., de Boer, M.R., \& de Vet, H.C. (2016). Differences in Connection Strength between Mental Symptoms Might Be Explained by Differences in Variance: Reanalysis of Network Data Did Not Confirm Staging. PloS one, 11(11).

Vaessen, T., van Nierop, M., Decoster, J., Delespaul, P., Derom, C., de Hert, M., ... \& van Os, J. (2017). Is sensitivity to daily stress predictive of onset or persistence of psychopathology? European Psychiatry, 45, 167-173.

Van Dam, D.S., van Nierop, M., Viechtbauer, W., Velthorst, E., van Winkel, R., Bruggeman, R., ... \& MyinGermeys, I. (2015). Childhood abuse and neglect in relation to the presence and persistence of psychotic and depressive symptomatology. Psychological Medicine, 45(7), 1363-1377.

van Nierop, M., Lecei, A., Myin-Germeys, I., Collip, D., Viechtbauer, W., Jacobs, N., Derom, C., Thiery, E., van Os, J., \& van Winkel, R. (2018). Stress reactivity links childhood trauma exposure to an admixture of depressive, anxiety, and psychosis symptoms. Psychiatry research, 1(260), 451457.

van Winkel, R., Stefanis, N.C., \& Myin-Germeys, I. (2008). Psychosocial stress and psychosis. A review of the neurobiological mechanisms and the evidence for gene-stress interaction. Schizophrenia bulletin, 34(6), 1095-1105.

Varese, F., Smeets, F., Drukker, M., Lieverse, R., Lataster, T., Viechtbauer, W., . . \& Bentall, R.P. (2012). Childhood adversities increase the risk of psychosis: a meta-analysis of patient-control, prospective-and cross-sectional cohort studies. Schizophrenia bulletin, 38(4), 661-671. 
- Chapter Three

Veling, W., Counotte, J., Pot-Kolder, R., van Os, J., \& van der Gaag, M. (2016). Childhood trauma, psychosis liability and social stress reactivity: a virtual reality study. Psychological medicine, 46(16), 3339-48.

Weijers, J., ten Kate, C., Eurelings-Bontekoe, E., Viechtbauer, W., Rampaart, R., Bateman, A., \& Selten, J.-P. (2016). Mentalization-based treatment for psychotic disorder: protocol of a randomized controlled trial. BMC psychiatry, 16(191).

Whisman, M.A., \& McClelland, G.H. (2005). Designing, testing, and interpreting interactions and moderator effects in family research. Journal of Family Psychology, 19(1), 111-120. 




\section{THE RELATIONSHIP BETWEEN CHILDHOOD ABUSE AND SEVERITY OF PSYCHOSIS IS MEDIATED BY LONELINESS: AN EXPERIENCE SAMPLING STUDY}

L. Steenkamp, J.G. Weijers, J. Gerrmann,

E.H.M Eurelings-Bontekoe, J.-P.C.J. Selten

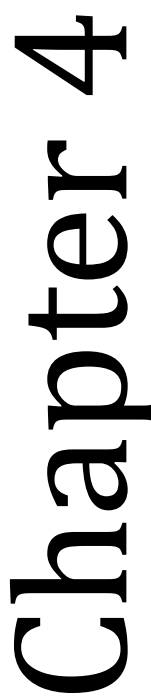




\section{Abstract}

Background. This study tested the hypotheses that (i) the relationship between a history of childhood abuse and severity of psychosis is mediated by loneliness; (ii) the relationship between loneliness and psychosis is mediated by within-person fluctuations in depressive and anxious feelings.

Methods. Fifty-nine individuals with non-affective psychotic disorder rated the intensity of loneliness, positive symptoms, and depressive and anxious feelings during repeated moments in daily life (Experience Sampling Method). Childhood abuse was assessed retrospectively using the 'Childhood Experience of Care and Abuse' interview. To test the mediation hypotheses, a multilevel structural equation modeling paradigm was used.

Results. As predicted, the relationship between severity of childhood abuse and positive symptoms was mediated by loneliness ( $b=0.08,95 \% \mathrm{CI}[0.02,0.13], p=0.005)$. In turn, the relationship between loneliness and positive symptoms was mediated by within-person fluctuations in both depressive $(b=0.04,95 \% \mathrm{CI}[0.02,0.06], p<0.001)$ and anxious $(b=0.02,95 \% \mathrm{CI}[0.01,0.03], \mathrm{p}=$ 0.002 ) symptomatology. Depression was a stronger mediator than anxiety $(b=0.02,95 \% \mathrm{CI}[0.00$, $0.04], p=0.027$ ).

Conclusions. Our findings highlight the role of childhood abuse and loneliness in the severity of psychosis in daily life.

Keywords: Childhood trauma; experience sampling method; social defeat; depression; anxiety; nonaffective psychotic disorder.

\section{Introduction}

Childhood abuse is related to an increased risk for psychosis (Arseneault et al., 2011; Bendall, Jackson, Hulbert, \& McGorry, 2008; Matheson, Shepherd, Pinchbeck, Laurens, \& Carr, 2013; Varese et al., 2012). There is also considerable evidence for a dose-response relationship, indicating that cumulative exposure to abuse is related to increased psychosis likelihood (Larkin \& Read, 2008; Longden, Sampson, \& Read, 2016) and severity of symptoms of psychosis, such as hallucinations, delusions, and paranoia Read, van Os, Morrison \& Ross, 2005; van Nierop et al., 2014). The social defeat hypothesis posits that this relationship may be explained by the sensitization of the mesolimbic dopamine system (Selten \& Cantor-Graae, 2005; Selten, van der Ven, Rutten, \& CantorGraae, 2013). Indeed, two studies have shown dopamine sensitization in psychotic and non- 
psychotic individuals who reported a history of childhood abuse (Egerton et al., 2016; Oswald et al., 2014).

Loneliness is thought to represent a consequence of social defeat that may account for the pathway from childhood abuse to psychosis (Shevlin, McElroy \& Murphy, 2015; van Nierop et al., 2014). Studies have shown that abuse during childhood is associated with feelings of loneliness in adulthood (Gibson \& Hartshorne, 1996; Merz \& Jak, 2013; Murphy, Shevlin, Adamson, \& Houston, 2013) and that patients with psychosis have a six-fold increase in feelings of loneliness compared to healthy individuals (Meltzer et al., 2013). Furthermore, a recent meta-analysis demonstrated a robust positive association between loneliness and severity of positive symptoms (Michalska, Rhodes, Vasilopoulou \& Hutton, 2017).

While loneliness previously was mainly interpreted to be a consequence of psychosis, researchers are now shifting towards the idea that loneliness may also be a causal factor in the development of psychosis (Gayer-Anderson \& Morgan, 2013; Michalska et al., 2017; van der Werf, van Winkel, van Boxtel, \& van Os, 2010). This is supported by the findings that social isolation precedes the onset of psychosis (Hoffman, 2007) and that patients themselves perceive loneliness as causal to their psychosis rather than consequential (Angermeyer \& Klusmann, 1988; Zafar et al., 2008). Perhaps due to sensitization of the mesolimbic dopamine system, a victim of childhood abuse may become more sensitive to subsequent experiences of social defeat, such as loneliness, and reacts with heightened positive symptoms.

Only a few studies have examined loneliness as a mediating factor in the association between childhood abuse and psychosis. One study demonstrated that loneliness mediated the relationship between childhood abuse and diagnoses of several psychiatric disorders, including psychosis (Shevlin et al., 2015). In patients with sub-clinical psychosis, loneliness was found to mediate the relationship between childhood abuse and positive symptoms (Boyda \& McFeeters, 2015).

In turn, the relationship between loneliness and psychosis may be explained by depressive and anxious feelings (Jaya, Hillmann, Reininger, Gollwitzer, \& Lincoln, 2016; Sündermann, Onwumere, Kane, Morgan, \& Kuipers, 2014). This is supported by prospective studies showing that loneliness is a risk factor for depressive and anxious symptomatology (Cacioppo, Hawkley, \& Thisted, 2010; Cacioppo, Hughes, Waite, Hawkley, \& Thisted. 2006; Kramer et al., 2013; Lim, Rodebaugh, Zyphur, \& Gleeson, 2016) and that symptoms of psychosis are predicted by depressive and anxious feelings (Delespaul, de Vries, \& van Os, 2002; Fowler et al., 2011; Freeman et al., 2005; Häfner et al., 2005; Kramer et al., 2014; Startup, Freeman, \& Garety, 2007). 
Here, we test the hypotheses (i) that loneliness in patients with non-affective psychotic disorder mediates the relationship between a history of childhood abuse and severity of psychosis; (ii) that the relationship between loneliness and psychosis is mediated by within-person fluctuations in depressive and anxious feelings.

Feelings such as loneliness, fear, or sadness are by definition momentary state-like experiences the fluctuating nature of which cannot be fully captured by studying between-person data. We therefore employed the Experience Sampling Method (ESM), an intensive repeatedmeasures diary technique that allows for the investigation of psychopathology in daily life (Hektner, Schmidt, \& Csikszentmihalyi, 2007; Myin-Germeys, Delespaul, \& Van 0s, 2005).

\section{Material and Methods}

Subjects. This study is part of a larger research project, see Weijers et al., 2016 for which 90 patients with a non-affective psychotic disorder (NAPD) were recruited from community treatment teams in the Netherlands (Leiden, Voorhout, Zoetermeer, and Zeist). All subjects gave written informed consent to participate. Diagnoses of subjects included schizophrenia, schizoaffective disorder, schizophreniform disorder, brief psychotic disorder, delusional disorder, and psychotic disorder not otherwise specified (NOS). Diagnoses were established by psychiatrists prior to participation and were confirmed by researchers using the Comprehensive Assessment of Symptoms and History (Andreasen, Flaum \& Arndt, 1992).

We included subjects of at least 18 years old who were fluent in the Dutch language. The first treatment for psychosis was required to have started between 6 months and 10 years ago. Exclusion criteria were (1) illiteracy, (2) intellectual disability, and (3) substance addiction that necessitated detoxification.

Design. The present study used the ESM, an intensive diary method in which subjects are repeatedly asked to fill out questionnaires in their daily life. We used an electronic device (the 'PsyMate') to collect the responses. Subjects were prompted by a signal ten times a day to fill out (identical) questionnaires on the PsyMate for a up to six days. Previous research has demonstrated the feasibility, reliability, and validity of ESM in individuals with psychotic disorders (Delespaul, de Vries, \& van Os, 2002; Kimhy et al., 2006; Thewissen et al., 2011).

\section{Materials.}

Childhood Experience of Care and Abuse (CECA): We used the 'Childhood Experience of Care and Abuse' (CECA) interview to measure childhood abuse retrospectively (Bifulco, Brown, \& Harris, 1994). The CECA is a semi-structured interview that assesses the severity of childhood abuse 
before the age of 17 years. The CECA includes four types of childhood abuse: parental conflict, psychological abuse, sexual abuse, and physical abuse. Abuse was assessed on both frequency and intensity. Frequency was rated on a five-point Likert-scale: never (0), rarely (1), incidentally (2), regularly (3), and often (4). Intensity was rated on a four-point Likert scale: none (0), some (1), moderate (2), and marked (3), with the exception of parental conflict, which was scored on a fivepoint scale that also included violence (4). The severity of each type of abuse was calculated by multiplying frequency with intensity. The sum of the severity scores for the four types of abuse results in a possible total score ranging from 0 to 52 . The possible scores for psychological abuse, sexual abuse, and physical abuse range from 0 to 12 and for parental conflict from 0 to 16 . For our analyses, the total severity score was divided by five in order to avoid overly small coefficients. Thus, a one-unit increase in the rescaled severity score resembles a five-unit increase in the actual severity score.

ESM measures: All items were rated on a 7-point Likert scale. The severity of positive symptoms consisted of the average score of seven items that assessed various positive symptoms (hearing voices, feeling unreal, feeling suspicious, being afraid to do something uncontrolled, feeling that others want to hurt him/her, feeling disliked, and thinking that one's thoughts are being controlled by others). Depressive and anxious feelings were assessed by the single items "I feel down" and "I feel anxious". Loneliness was assessed by the single item "I feel lonely", which is a common approach in studies to loneliness (Boyda \& McFeeters, 2015; Rook, 1987; Sündermann et al., 2014) and is comparable to more comprehensive measures of loneliness in establishing the relationship with positive symptoms (Michalska, Rhodes, Vasilopoulou, \& Hutton, 2017). Each ESM variable had a possible score ranging from 1-7.

Statistical Analyses. Statistical analyses were performed using Mplus (version 8). All tests were 2 -tailed with an alpha $=.05$. The ESM data have a multilevel structure: multiple observations (Level 1) are nested within subjects (Level 2). Childhood abuse was assessed at Level 2 while the remaining variables were assessed at Level 1 (ESM observations). Traditional methods for assessing mediation are therefore inappropriate, primarily because the assumption of statistical independence of residuals is violated, resulting in underestimated standard errors and inflated Type I errors. In order to take into account the multilevel structure of the data, we used a multilevel structural equation modeling (MSEM) paradigm (Preacher, Zyphur, \& Zhang, 2010). Advantages of MSEM are the ability to separate between- and within-subject effects, no required assumption of normality, and the use of robust maximum likelihood estimation that can accommodate unbalanced clusters. 
Intraclass correlations (ICCs) were calculated to determine eligibility for the proposed mediational models. The ICC resembles the proportion of the between-subject variance relative to the total variance. A 2-1-1 model with random slopes (Preacher et al., 2010) was tested to investigate whether loneliness mediates the relationship between childhood abuse and positive symptoms (see Figure 1). Next, two 1-1-1 models with random slopes (Preacher et al., 2010) were tested to investigate whether depressive and anxious feelings mediate the relationship between loneliness and positive symptoms. The lower level mediation models allow for the investigation of both between- and within-subject effects because all variables were assessed at Level 1 (ESM observations). The between-subject level reflects the average of symptoms between individuals while the within-subject level resembles the fluctuations of symptoms within individuals.

Depressive and anxious feelings were also tested in a 1-(1-1)-1 multiple mediator model (Preacher et al., 2010) (see Figure 2) in order to assess independence and compare the strength of the mediating effects.

\section{Figure 1.}

Level 2: Subjects

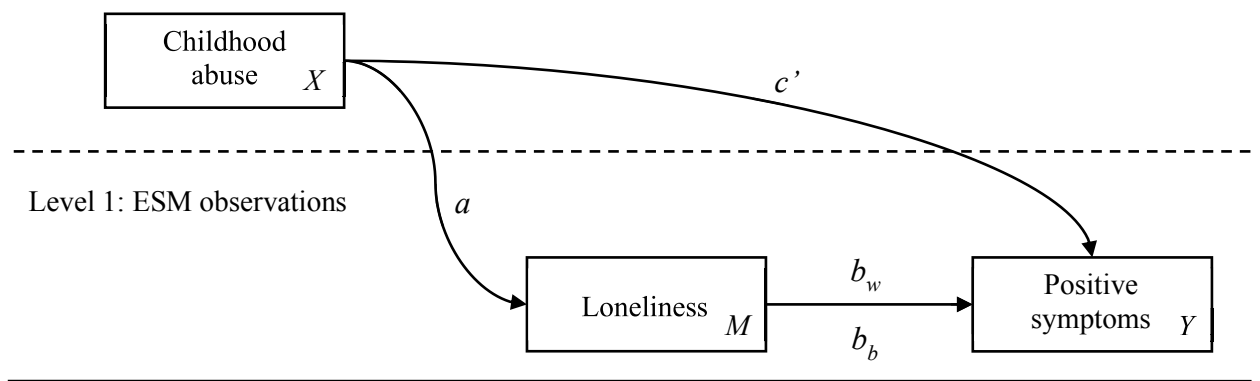

Figure 1. Illustration of the 2-1-1 multilevel mediation model predicting positive symptoms from childhood abuse via loneliness. $\mathrm{X}=$ independent variable, $\mathrm{M}=$ mediator, $\mathrm{Y}=$ dependent variable; $\mathrm{a}=$ between-subject effect path $a ; c^{\prime}=$ between-subject direct effect; $b_{w}=$ within-subject effect path $b$; $b_{b}=$ between-subject effect path b.

\section{Figure 2}


Level 2: Subjects

Level 1: ESM observations

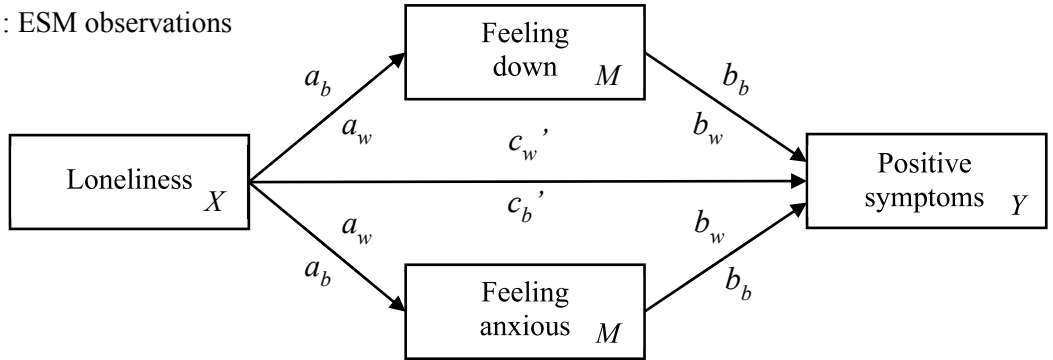

Figure 2. Illustration of the 1-(1-1)-1 multilevel mediation model predicting positive symptoms from loneliness via depressive and anxious feelings. $X=$ independent variable, $M=$ mediator, $Y=$ dependent variable; $a_{b}=$ between-subject effect path $a ; c_{b}{ }^{\prime}=$ between-subject direct effect; $c_{w}{ }^{\prime}=$ within-subject direct effect; $b_{w}=$ within-subject effect path $b ; b_{b}=$ between-subject effect path $b$.

\section{Results}

Sample. Of the 90 subjects recruited, 9 subjects were excluded because they refused or failed to fill out any PsyMate questionnaire and 21 subjects were excluded because they filled out fewer than 20 PsyMate questionnaires, similar to prior studies (Glaser, Van Os, Portegijs \& MyinGermeys, 2006; Lardinois, Mengelers, Van Os, \& Myin-Germeys, 2011). In addition, one subject was excluded because she refused to answer questions about sexual abuse. Therefore, the final sample consisted of 59 subjects.

There were some missing values for the ESM variables loneliness (20 missing; 1.0\%), depression (29 missing; 1.5\%), anxiety (18 missing; 0.9\%), and positive symptoms (31 missing; $1.6 \%$ ). We excluded ESM observations that had missing values on at least one variable. After excluding 31 ESM observations, the final data sample consisted of $1896(1927-31=1896)$ ESM observations.

Table 1 shows the characteristics of the study sample. In total, 43 subjects $(72.9 \%)$ reported some type of childhood abuse; 34 subjects (57.6\%) experienced parental discord, 15 subjects (25.4\%) experienced physical abuse, 15 subjects (25.4\%) experienced psychological abuse, and 7 subjects (11.9\%) experienced sexual abuse. Table 2 depicts the means, standard deviations, ICC's, and intercorrelations for all study variables.

Table 1. Characteristics of the study sample $(\mathrm{N}=59)$. 


\begin{tabular}{ll}
\hline Age, $M(S D)$, range & $31.8(9.4), 19-57$ \\
Sex, $n$ men (\%) & $34(57.6 \%)$ \\
CASH DSM-IV diagnosis, $n(\%)$ & \\
Schizophrenia & $34(57.6 \%)$ \\
Psychotic Disorder NOS & $10(16.9 \%)$ \\
Schizoaffective Disorder & $10(16.9 \%)$ \\
Brief Psychotic Disorder & $3(5.1 \%)$ \\
Delusional Disorder & $2(3.4 \%)$ \\
Years since onset of psychotic disorder, $M(S D)$, range & $5.6(4.1), 1-22$ \\
Childhood abuse severity, $M(S D)$, range & $10.1(11.3), 0-43$ \\
$\quad$ Parental discord & $5.4(5.9), 0-16$ \\
Physical abuse & $1.7(3.5), 0-12$ \\
Psychological abuse & $1.9(3.7), 0-12$ \\
Sexual abuse & $0.3(0.8), 0-3$ \\
\hline
\end{tabular}

Note. Possible ranges for childhood abuse scores: total 0-52, parental discord 0-16, physical abuse 0-12, psychological abuse $0-12$, and sexual abuse $0-12$.

Table 2. Characteristics, intraclass correlation coefficients, and intercorrelations of the study variables.

\begin{tabular}{|c|c|c|c|c|c|c|}
\hline Variable & ICC & Mean (SD), range & Loneliness & $\begin{array}{c}\text { Positive } \\
\text { symptoms }\end{array}$ & $\begin{array}{c}\text { Depressive } \\
\text { feelings }\end{array}$ & $\begin{array}{l}\text { Anxious } \\
\text { feelings }\end{array}$ \\
\hline $\begin{array}{l}\text { Childhood } \\
\text { abuse }\end{array}$ & $\mathrm{n} / \mathrm{a}$ & 2.01 (2.24), 0-8.6 & 0.32 & 0.28 & 0.40 & 0.26 \\
\hline Loneliness & $\begin{array}{c}0.4 \\
1\end{array}$ & 2.36 (1.59), 1-7 & - & 0.71 & 0.76 & 0.67 \\
\hline $\begin{array}{l}\text { Positive } \\
\text { symptoms }\end{array}$ & $\begin{array}{c}0.7 \\
7\end{array}$ & $1.82(0.99), 1-6.3$ & 0.22 & - & 0.68 & 0.73 \\
\hline $\begin{array}{l}\text { Depressiv } \\
\text { e feelings }\end{array}$ & $\begin{array}{c}0.5 \\
0\end{array}$ & 2.41 (1.57), 1-7 & 0.33 & 0.36 & - & 0.81 \\
\hline $\begin{array}{l}\text { Anxious } \\
\text { feelings }\end{array}$ & $\begin{array}{c}0.5 \\
2\end{array}$ & 1.91 (1.33), $1-7$ & 0.24 & 0.30 & 0.32 & - \\
\hline
\end{tabular}

Note. The within-subject correlations $(N=1896)$ are displayed below the diagonal. The between-subject correlations $(N=59)$ are displayed above the diagonal. ICC = intraclass correlation coefficient. Total childhood abuse scores were divided by 5 in order to avoid overly small coefficients. Possible range for childhood abuse score is $0-10.4$; for ESM variables 1-7. 
The mediating role of loneliness. The ICC for the outcome variable positive symptoms indicated that $77.3 \%$ of the variance in positive symptoms was attributable to between-subject differences, providing support for the investigation of the 2-1-1 model and between-subject mediational effects. Subjects who experienced more severe childhood abuse reported higher levels of loneliness ( $a=0.15,95 \% \mathrm{CI}[0.05,0.24], p=0.002$ ). In turn, subjects with higher levels of loneliness reported more severe positive symptoms $\left(b_{b}=0.54,95 \% \mathrm{CI}[0.37,0.72], p<\right.$ 0.001). Moreover, within-subject levels of loneliness were positively related to severity of positive symptoms $\left(b_{w}=0.08,95 \% \mathrm{CI}[0.05,0.12], p<0.001\right)$. A test of mediation revealed evidence of an indirect effect of childhood abuse on positive symptoms through loneliness $(a b=$ $0.08,95 \% \mathrm{CI}[0.02,0.13], p=0.005)$. While controlling for the indirect effect, the direct effect of childhood abuse on positive symptoms was no longer present $\left(c^{\prime}=-0.01,95 \% \mathrm{CI}[-0.11,0.09], p\right.$ $=0.824)$.

The mediating role of depressive and anxious symptomatology. The results of the mediation models for depressive and anxious symptomatology are displayed in Table 3. The ICC for the independent variable loneliness indicated that $41.2 \%$ of the variance in loneliness was attributable to between-subject differences and 58.8\% to within-subject differences, providing support for the investigation of a 1-1-1 multilevel mediation model and both within- and between-subject mediational effects.

Table 3. Multilevel mediation models predicting positive symptoms from loneliness via depressive and anxious symptomatology.

\begin{tabular}{|c|c|c|c|c|c|c|}
\hline & \multicolumn{3}{|c|}{ Depression as mediator } & \multicolumn{3}{|c|}{ Anxiety as mediator } \\
\hline & Estimate & $S E$ & $95 \% \mathrm{CI}$ & Estimate & $S E$ & $95 \% \mathrm{CI}$ \\
\hline \multicolumn{7}{|l|}{ Within-subject level } \\
\hline Path $a_{w}$ & $0.30^{* * *}$ & 0.04 & $0.22,0.37$ & $0.19 * * *$ & 0.03 & $0.12,0.26$ \\
\hline Path $b_{w}$ & $0.13^{* * *}$ & 0.02 & $0.10,0.17$ & $0.12^{* * *}$ & 0.03 & $0.06,0.17$ \\
\hline Path $c_{w}{ }^{\prime}$ & $0.04^{* *}$ & 0.02 & $0.01,0.07$ & $0.06^{* * *}$ & 0.02 & $0.03,0.10$ \\
\hline $\begin{array}{l}\text { Path } a b_{w} \text { (= indirect } \\
\text { effect) }\end{array}$ & $0.04^{* * *}$ & 0.01 & $0.02,0.06$ & $0.02^{* *}$ & 0.01 & $0.01,0.03$ \\
\hline $\begin{array}{l}\text { Path } a b_{w 1 / w 2} \text { in } 1-(1-1)- \\
1 \text { model }\end{array}$ & $0.04^{* * *}$ & 0.01 & $0.02,0.05$ & $0.02^{*}$ & 0.01 & $0.00,0.03$ \\
\hline \multicolumn{7}{|l|}{ Between-subject level } \\
\hline Path $a_{b}$ & $0.81^{* * *}$ & 0.12 & $0.57,1.05$ & $0.62^{* * *}$ & 0.118 & $0.39,0.85$ \\
\hline Path $b_{b}$ & 0.15 & 0.19 & $\begin{array}{l}-0.22 \\
0.56\end{array}$ & 0.38 & 0.276 & $-0.17,0.92$ \\
\hline Path $c_{b}{ }^{\prime}$ & $0.30 *$ & 0.13 & $0.05,0.55$ & 0.26 & 0.154 & $-0.04,0.56$ \\
\hline $\begin{array}{l}\text { Path } a b_{b} \text { (= indirect } \\
\text { effect })\end{array}$ & 0.12 & 0.16 & $\begin{array}{l}-0.19 \\
0.44\end{array}$ & 0.23 & 0.181 & $-0.12,0.59$ \\
\hline $\begin{array}{l}\text { Path } a b_{b 1 / b 2}(=\text { indirect } \\
\text { effect) in 1-(1-1)-1 model }\end{array}$ & 0.02 & 0.12 & $\begin{array}{l}-0.22 \\
0.26\end{array}$ & 0.15 & 0.121 & $-0.09,0.39$ \\
\hline
\end{tabular}


Within-subject effects. Higher levels of loneliness were related to more depressive and anxious feelings ( $p$ s $<0.001$; see Table 3, path $a_{w}$ ). In turn, more depressive and anxious feelings were related to more severe positive symptoms ( $p s<0.001$, see Table 3 , path $b_{w}$ ). Tests of mediation revealed indirect within-subject effects of loneliness on positive symptoms through depressive feelings ( $\left.a b_{w}=0.04,95 \% \mathrm{CI}[0.02,0.06], p<0.001\right)$, and anxious feelings $\left(a b_{w}=0.02\right.$, 95\% CI [0.01, 0.03], $p=0.002$ ). There were still within-subject direct effects of loneliness on positive symptoms while controlling for the indirect effect of depressive feelings $\left(c_{w}{ }^{\prime}=0.04\right.$, $95 \% \mathrm{CI}[0.01,0.07], p=0.005)$ and anxious feelings $\left(c_{w}{ }^{\prime}=0.06,95 \% \mathrm{CI}[0.03,0.10], p<0.001\right)$. Analyzing depressive and anxious feelings in a multiple mediator model revealed that both depressive feelings $\left(a b_{w 1}=0.04,95 \% \mathrm{CI}[0.02,0.05], p<0.001\right)$ and anxious feelings $\left(a b_{w 2}=\right.$ $0.02,95 \% \mathrm{CI}[0.00,0.03], p=0.012$ ) were independent mediators in the relationship between loneliness and positive symptoms. Depression was a stronger mediator than anxiety $\left(a b_{w 1}-a b_{w 2}\right.$ $=0.02,95 \% \mathrm{CI}[0.00,0.04], p=0.027)$.

Between-subject effects. On average, subjects with higher levels of loneliness reported more depressive and anxious feelings ( $p s<0.001$; see Table 3, path $a_{b}$ ). In turn, subjects with relatively more depressive and anxious feelings reported more severe positive symptoms, but this did not reach significance ( $p s>0.05$; see Table 3, path $b_{b}$ ). A formal test of mediation showed no significant between-subject indirect effect of loneliness on positive symptoms through depressive or anxious feelings ( $p$ s $>0.05$; see Table 3, path $a b_{b}$ ).

\section{Discussion}

The present ESM study aimed to identify mediational pathways to daily life positive symptoms in individuals with NAPD. Our findings demonstrate that the severity of childhood abuse was associated with increased levels of loneliness and positive symptoms. As hypothesized, loneliness mediated the relationship between childhood abuse and positive symptoms. In addition, to the best of our knowledge, this is the first study to reveal that within-person fluctuations in depressive and anxious symptomatology mediate the relationship between loneliness and positive symptoms. More specifically, when individuals were lonelier than their average level of loneliness, they tended to report more severe positive symptoms through increased depressive and anxious feelings (the within-subject indirect effects). Depression was a significantly stronger mediator than anxiety. However, individuals who showed above average levels of loneliness in general did not appear to show above average levels of positive symptoms through depressive or anxious feelings (the between-subject indirect effects).

Comparison to previous findings. Our findings are in line with prior research demonstrating that loneliness mediates the relationship between childhood abuse and a 
diagnosis of psychosis (Shevlin et al., 2015) and sub-clinical psychotic experiences (Boyda \& McFeeters, 2015). The findings support an emerging consensus that individuals with a history of abuse have an increased risk to develop psychosis (Arseneault et al., 2011; Bendall et al., 2008; Matheson, Shepherd, Pinchbeck, Laurens, \& Carr, 2013; Varese et al., 2012) and are prone to become lonely in adulthood (Gibson \& Hartshorne, 1996; Merz \& Jak, 2013; Murphy et al., 2013), and confirm the recently established positive association between loneliness and psychotic symptoms (Michalska et al., 2017). Importantly, our study extends previous findings by identifying loneliness as a mediating factor in the context of daily life.

Our results also support previous findings which suggested that loneliness affects psychosis through depression and anxiety (Jaya et al., 2016; Sündermann et al., 2014). However, this effect was not found on a between-person level, which is likely due to reduced power by relying on mean symptom levels. The low accuracy involved in between-person measurements may yield mixed results or conceal effects, whereas within-person analyses take into account fluctuations and individual differences, revealing subtle underlying patterns (Molenaar \& Campbell, 2009). We believe that the within-person approach is more appropriate when studying symptoms or emotions, as these are by definition momentary fluctuating experiences. In fact, there is a growing recognition for the importance of within-person data in the field of psychology, especially because most psychological theories postulate intraindividual processes (Collins, 2006; Curran \& Bauer, 2011; Hamaker, 2012; Molenaar, 2004). Using a within-person approach, we were able to detect a relative effect of loneliness - the effect that occurred when people started to feel more lonely than their "baseline" - that would not have been revealed using a between-person approach.

Our results provide support for the social defeat hypothesis of psychosis aetiology (Selten et al., 2013). Investigating loneliness in the context of dopamine sensitization may be a fruitful venue for future research, as various other social adversities, including childhood abuse (Egerton et al., 2016), hearing impairment (Gevonden et al., 2014), and migration (Egerton et al., 2017) have been related to a sensitized mesolimbic dopamine system. Likewise, as predicted by the social defeat hypothesis, the contribution of loneliness to psychosis may biologically be explained by the sensitization of the mesolimbic dopamine system (Howes \& Murray, 2014).

Strengths and limitations. The main strength of our study is the use of momentary and ecologically valid data. Measuring symptoms as they occur in daily life circumvents recall bias and improves generalizability (Myin-Germeys et al., 2009). Another strength is the use of MSEM, a state-of-the-art framework for assessing multilevel mediation (Preacher et al., 2010). This allowed us to separate between- and within-person mediated effects in a robust and unbiased manner. Particularly our focus on within-person processes is a powerful addition to typical 
between-person research paradigms as we were able to assess how underlying processes unfold within individuals.

Several potential limitations also need to be considered. First, our study depended on retrospective recall of childhood abuse, making it susceptible to recall bias (Newbury et al., 2018). Because of this, some researchers dispute the causal role of childhood abuse in psychosis (Susser \& Widom, 2012). However, it seems rather unlikely that recall bias alone would explain the robust association between childhood abuse and psychosis (Cutajar et al., 2010; Kelleher et al., 2013; Morgan \& Gayer-Anderson, 2016; Varese et al., 2012). Second, the cross-sectional nature of our analyses precludes time ordering of the variables. This means that it cannot be concluded that, for example, loneliness leads to future increases of positive symptoms. Third, the present study employed self-report instruments. Their validity depends upon the patients' ability to accurately identify and report experiences. A lack of awareness and poor insight may have influenced the validity of self-report scores in some patients (Bell, Fiszdon, Richardson, Lysaker, \& Bryson, 2007).

Conclusion. The findings of the present study strongly suggest (i) that loneliness mediates the relationship between childhood abuse and severity of positive symptoms in patients with NAPD; (ii) that the relationship between loneliness and positive symptoms is mediated by within-person fluctuations in depressive and anxious symptomatology.

\section{References}

Andreasen, N.C., Flaum, M., \& Arndt, S. (1992). The Comprehensive Assessment of Symptoms and History (CASH): an instrument for assessing diagnosis and psychopathology. Archives of general psychiatry, 49(8), 615-623.

Angermeyer, M.C., \& Klusmann, D. (1988). The causes of functional psychoses as seen by patients and their relatives. European Archives of Psychiatry and Clinical Neuroscience, 238(1), 47-54.

Arseneault, L., Cannon, M., Fisher, H.L., Polanczyk, G., Moffitt, T.E., \& Caspi, A. (2011). Childhood trauma and children's emerging psychotic symptoms: a genetically sensitive longitudinal cohort study. American Journal of Psychiatry, 168(1), 65-72.

Bell, M., Fiszdon, J., Richardson, R., Lysaker, P., \& Bryson, G. (2007). Are self-reports valid for schizophrenia patients with poor insight? Relationship of unawareness of illness to psychological self-report instruments. Psychiatry research, 151(1), 37-46.

Bendall, S., Jackson, H.J., Hulbert, C.A., \& McGorry, P.D. (2008). Childhood trauma and psychotic disorders: a systematic, critical review of the evidence. Schizophrenia bulletin, 34(3), 568-579. 
Bifulco, A., Brown, G.W., \& Harris, T.O. (1994). Childhood Experience of Care and Abuse (CECA): a retrospective interview measure. Journal of Child Psychology and Psychiatry, 35(8), 1419-1435.

Boyda, D., \& McFeeters, D. (2015). Childhood maltreatment and social functioning in adults with sub-clinical psychosis. Psychiatry research, 226(1), 376-382.

Cacioppo, J.T., Hawkley, L.C., \& Thisted, R.A. (2010). Perceived social isolation makes me sad: 5year cross-lagged analyses of loneliness and depressive symptomatology in the Chicago Health, Aging, and Social Relations Study. Psychology and aging 25(2), 453.

Cacioppo, J.T., Hughes, M.E., Waite, L.J., Hawkley, L.C. \& Thisted, R.A. (2006). Loneliness as a specific risk factor for depressive symptoms: cross-sectional and longitudinal analyses. Psychology and aging, 21(1), 140.

Collins, L.M. (2006). Analysis of longitudinal data: The integration of theoretical model, temporal design, and statistical model. Annual Review of Psychology, 57, 505-528.

Curran, P.J., \& Bauer, D.J. (2011). The disaggregation of within-person and between-person effects in longitudinal models of change. Annual review of psychology, 62, 583-619.

Cutajar, M.C., Mullen, P.E., Ogloff, J.R., Thomas, S.D., Wells, D.L., \& Spataro, J. (2010).

Schizophrenia and other psychotic disorders in a cohort of sexually abused children. Archives of general psychiatry, 67(11), 1114-1119.

Delespaul, P., de Vries, M., \& van Os, J. (2002). Determinants of occurrence and recovery from hallucinations in daily life. Social psychiatry and psychiatric epidemiology, 37(3), 97-104.

Egerton, A., Howes, O.D., Houle, S., McKenzie, K., Valmaggia, L.R., Bagby, M.R., Tseng, H.-H., Bloomfield, M.A., Kenk, M., \& Bhattacharyya, S. (2017). Elevated Striatal Dopamine Function in Immigrants and Their Children: A Risk Mechanism for Psychosis. Schizophrenia bulletin 43(2), 293-301.

Egerton, A., Valmaggia, L.R., Howes, O.D., Day, F., Chaddock, C.A., Allen, P., Winton-Brown, T.T., Bloomfield, M.A., Bhattacharyya, S., \& Chilcott, J. (2016). Adversity in childhood linked to elevated striatal dopamine function in adulthood. Schizophrenia research, 176(2), 171176.

Fowler, D., Hodgekins, J., Garety, P., Freeman, D., Kuipers, E., Dunn, G., Smith, B., \& Bebbington, P.E. (2011). Negative cognition, depressed mood, and paranoia: a longitudinal pathway analysis using structural equation modeling. Schizophrenia bulletin, sbr019.

Freeman, D., Garety, P.A., Bebbington, P., Slater, M., Kuipers, E., Fowler, D., Green, C., Jordan, J., Ray, K., \& Dunn, G. (2005). The psychology of persecutory ideation II: a virtual reality experimental study. The Journal of nervous and mental disease, 193(5), 309-315.

Gayer-Anderson, C., \& Morgan, C. (2013). Social networks, support and early psychosis: a systematic review. Epidemiology and Psychiatric Sciences, 22(02), 131-146. 
- Chapter Four

Gevonden, M., Booij, J., van den Brink, W., Heijtel, D., van Os, J., \& Selten, J.-P. (2014). Increased release of dopamine in the striata of young adults with hearing impairment and its relevance for the social defeat hypothesis of schizophrenia. JAMA psychiatry, 71(12), 1364-1372.

Gibson, R.L., \& Hartshorne, T.S. (1996). Childhood sexual abuse and adult loneliness and network orientation. Child Abuse \& Neglect, 20(11), 1087-1093.

Glaser, J.-P., Van Os, J., Portegijs, P.J., \& Myin-Germeys, I. (2006). Childhood trauma and emotional reactivity to daily life stress in adult frequent attenders of general practitioners. Journal of psychosomatic research, 61(2), 229-236.

Häfner, H., Maurer, K., Trendler, G., an der Heiden, W., Schmidt, M., \& Könnecke, R. (2005). Schizophrenia and depression: challenging the paradigm of two separate diseases-a controlled study of schizophrenia, depression and healthy controls. Schizophrenia research, 77(1), 11-24.

Hamaker, E. (2012). Why researchers should think "within-person": A paradigmatic rationale. Handbook of research methods for studying daily life, 43-61.

Hektner, J.M., Schmidt, J.A., \& Csikszentmihalyi, M. (2007). Experience sampling method: Measuring the quality of everyday life. Thousand Oakes, CA: Sage.

Hoffman, R.E. (2007). A social deafferentation hypothesis for induction of active schizophrenia. Schizophrenia bulletin, 33(5), 1066-1070.

Howes, O.D., \& Murray, R.M. (2014). Schizophrenia: an integrated sociodevelopmental-cognitive model. The Lancet, 383(9929), 1677-1687.

Jaya, E.S., Hillmann, T.E., Reininger, K.M., Gollwitzer, A., \& Lincoln, T.M. (2016). Loneliness and psychotic symptoms: The mediating role of depression. Cognitive Therapy and Research, $1-11$.

Kelleher, I., Keeley, H., Corcoran, P., Ramsay, H., Wasserman, C., Carli, V., Sarchiapone, M., Hoven, C., Wasserman, D., \& Cannon, M. (2013). Childhood trauma and psychosis in a prospective cohort study: cause, effect, and directionality. American Journal of Psychiatry, 170(7), 734-741.

Kimhy, D., Delespaul, P., Corcoran, C., Ahn, H., Yale, S., \& Malaspina, D. (2006). Computerized experience sampling method (ESMc): assessing feasibility and validity among individuals with schizophrenia. Journal of psychiatric research, 40(3), 221-230.

Kramer, I., Simons, C.J., Wigman, J.T., Collip, D., Jacobs, N., Derom, C., Thiery, E., van Os, J., MyinGermeys, I., \& Wichers, M. (2013). Time-lagged moment-to-moment interplay between negative affect and paranoia: new insights in the affective pathway to psychosis.

Schizophrenia bulletin, 40(2), 278-286. 
Kramer, I., Simons, C.J., Wigman, J.T., Collip, D., Jacobs, N., Derom, C., Thiery, E., van Os, J., MyinGermeys, I., \& Wichers, M. (2014). Time-lagged moment-to-moment interplay between negative affect and paranoia: new insights in the affective pathway to psychosis. Schizophrenia bulletin, 40(2), 278-286.

Lardinois, M., Lataster, T., Mengelers, R., Van Os, J., \& Myin-Germeys, I. (2011). Childhood trauma and increased stress sensitivity in psychosis. Acta Psychiatrica Scandinavica, 123(1), 2835.

Larkin, W., \& Read, J. (2008). Childhood trauma and psychosis: evidence, pathways, and implications. Journal of postgraduate medicine, 54(4), 287.

Lim, M.H., Rodebaugh, T.L., Zyphur, M.J., \& Gleeson, J.F. (2016). Loneliness over time: The crucial role of social anxiety. Journal of abnormal psychology, 125(5), 620.

Longden, E., Sampson, M., \& Read, J. (2016). Childhood adversity and psychosis: generalised or specific effects? Epidemiology and psychiatric sciences, 25(04), 349-359.

Matheson, S., Shepherd, A., Pinchbeck, R., Laurens, K., \& Carr, V. (2013). Childhood adversity in schizophrenia: a systematic meta-analysis. Psychological medicine, 43(2), 225.

Meltzer, H., Bebbington, P., Dennis, M.S., Jenkins, R., McManus, S., \& Brugha, T.S. (2013). Feelings of loneliness among adults with mental disorder. Social Psychiatry and Psychiatric Epidemiology, 48(1), 5-13.

Merz, E.-M., \& Jak, S. (2013). The long reach of childhood. Childhood experiences influence close relationships and loneliness across life. Advances in life course research, 18(3), 212-222.

Michalska, D.R.B., Rhodes, S., Vasilopoulou, E., \& Hutton, P. (2017). Loneliness in Psychosis: A Meta-analytical Review. Schizophrenia bulletin.

Molenaar, P.C. (2004). A manifesto on psychology as idiographic science: Bringing the person back into scientific psychology, this time forever. Measurement, 2(4), 201-218.

Molenaar, P.C., \& Campbell, C.G. (2009). The new person-specific paradigm in psychology. Current directions in psychological science, 18(2), 112-117.

Morgan, C., \& Gayer-Anderson, C. (2016). Childhood adversities and psychosis: evidence, challenges, implications. World Psychiatry, 15(2), 93-102.

Murphy, J., Shevlin, M., Adamson, G., \& Houston, J.E. (2013). From sexual abuse to psychosis: a pilot study exploring the social deafferentation hypothesis and the mediating role of avoidance. Psychosis, 5(1), 36-47.

Myin-Germeys, I., Delespaul, P., \& van Os, J. (2003). The experience sampling method in psychosis research. Current Opinion in Psychiatry, 16, 33-38.

Myin-Germeys, I., Oorschot, M., Collip, D., Lataster, J., Delespaul, P., \& van Os, J. (2009).

Experience sampling research in psychopathology: opening the black box of daily life. Psychological medicine, 39(9), 1533. 
Newbury, J.B., Arseneault, L., Moffitt, T.E., Caspi, A., Danese, A., Baldwin, J.R., \& Fisher, H.L. (2018). Measuring childhood maltreatment to predict early-adult psychopathology: Comparison of prospective informant-reports and retrospective self-reports. Journal of psychiatric research, 96, 57-64.

Oswald, L.M., Wand, G.S., Kuwabara, H., Wong, D.F., Zhu, S., \& Brasic, J.R. (2014). History of childhood adversity is positively associated with ventral striatal dopamine responses to amphetamine. Psychopharmacology, 231(12), 2417-2433.

Preacher, K.J., Zyphur, M.J., \& Zhang, Z. (2010). A general multilevel SEM framework for assessing multilevel mediation. Psychological methods, 15(3), 209.

Read, J., van Os, J., Morrison, A.P., \& Ross, C.A. (2005). Childhood trauma, psychosis and schizophrenia: a literature review with theoretical and clinical implications. Acta Psychiatrica Scandinavica, 112(5), 330-350.

Rook, K.S. (1987). Social support versus companionship: Effects on life stress, loneliness, and evaluations by others. Journal of personality and social psychology, 52(6), 1132.

Selten, J.-P., \& Cantor-Graae, E. (2005). Social defeat: risk factor for schizophrenia? The British Journal of Psychiatry, 187(2), 101-102.

Selten, J.-P., van der Ven, E., Rutten, B.P., \& Cantor-Graae, E. (2013). The social defeat hypothesis of schizophrenia: an update. Schizophrenia bulletin, 39(6), 1180-1186.

Shevlin, M., McElroy, E., \& Murphy, J. (2015). Loneliness mediates the relationship between childhood trauma and adult psychopathology: evidence from the adult psychiatric morbidity survey. Social psychiatry and psychiatric epidemiology, 50(4), 591-601.

Startup, H., Freeman, D., \& Garety, P.A. (2007). Persecutory delusions and catastrophic worry in psychosis: developing the understanding of delusion distress and persistence. Behaviour research and therapy, 45(3), 523-537.

Sündermann, O., Onwumere, J., Kane, F., Morgan, C., \& Kuipers, E. (2014). Social networks and support in first-episode psychosis: exploring the role of loneliness and anxiety. Social psychiatry and psychiatric epidemiology, 49(3), 359-366.

Susser, E., \& Widom, C.S. (2012). Still searching for lost truths about the bitter sorrows of childhood. Schizophrenia bulletin, 38(4), 672-675.

Thewissen, V., Bentall, R.P., Oorschot, M., J, A.C., van Lierop, T., van Os, J., \& Myin-Germeys, I. (2011). Emotions, self-esteem, and paranoid episodes: an experience sampling study. British Journal of Clinical Psychology, 50(2), 178-195.

van der Werf, M., van Winkel, R., van Boxtel, M., \& van Os, J. (2010). Evidence that the impact of hearing impairment on psychosis risk is moderated by the level of complexity of the social environment. Schizophrenia research, 122(1), 193-198. 
van Nierop, M., Lataster, T., Smeets, F., Gunther, N., van Zelst, C., de Graaf, R., ten Have, M., van Dorsselaer, S., Bak, M., \& Myin-Germeys, I. (2014). Psychopathological mechanisms linking childhood traumatic experiences to risk of psychotic symptoms: analysis of a large, representative population-based sample. Schizophrenia bulletin, 40(2), 123-130.

Varese, F., Smeets, F., Drukker, M., Lieverse, R., Lataster, T., Viechtbauer, W., Read, J., van Os, J., \& Bentall, R.P. (2012). Childhood adversities increase the risk of psychosis: a metaanalysis of patient-control, prospective-and cross-sectional cohort studies. Schizophrenia bulletin, sbs050.

Weijers, J., ten Kate, C., Eurelings-Bontekoe, E., Viechtbauer, W., Rampaart, R., Bateman, A., \& Selten, J.-P. (2016). Mentalization-based treatment for psychotic disorder: protocol of a randomized controlled trial. BMC psychiatry, 16(1), 191.

Zafar, S.N., Syed, R., Tehseen, S., Gowani, S.A., Waqar, S., Zubair, A., Yousaf, W., Zubairi, A.J., \& Naqvi, H. (2008). Perceptions about the cause of schizophrenia and the subsequent help seeking behavior in a Pakistani population-results of a cross-sectional survey. $B M C$ psychiatry, 8(1), 56. 



\section{MENTALIZING IMPAIRMENT AS A MEDIATOR BETWEEN REPORTED CHILDHOOD ABUSE AND OUTCOME IN NONAFFECTIVE PSYCHOTIC DISORDER}

J.G. Weijers, P. Fonagy, E.H.M. Eurelings-Bontekoe, F. Termorshuizen, W.V. Viechtbauer, J.-P.C.J. Selten 
- Chapter Five

\begin{abstract}
Reported childhood abuse has been linked to the severity of clinical symptoms and social dysfunction in non-affective psychotic disorder. Impaired mentalizing ability may be one of the mechanisms accounting for this effect. This study examined whether impaired mentalizing mediates the effect of reported childhood abuse on positive symptoms, negative symptoms, and social dysfunction. Eighty-seven patients with non-affective psychotic disorder were examined. Reported childhood abuse was measured using the Childhood Experience of Care and Abuse interview. Additionally, the Social Functioning Scale and the Positive and Negative Syndrome Scale were used. The Hinting Task was used to measure mentalizing impairment. Reported childhood abuse was significantly related to the severity of positive and negative symptoms, not to social dysfunction. Reported childhood abuse was also related to mentalizing impairment. Mentalizing impairment was related to negative symptoms, but not to positive symptoms or social dysfunction. Mentalizing impairment accounted for $40 \%$ of the association between reported childhood abuse and negative symptoms, indicating partial mediation. A sensitivity analysis revealed that the mediating effect was only observed in those who reported fairly severe childhood abuse.
\end{abstract}

Keywords. Mentalization; psychosis; positive symptoms; negative symptoms; social functioning.

\title{
Introduction
}

Patients with non-affective psychotic disorder are almost three times as likely as nonpsychiatric controls to report a history of abuse in childhood (Varese et al., 2012). Moreover, reported childhood abuse is associated with the severity of positive and negative symptoms (Longden, Sampson, \& Read, 2015; Schenkel, Spaulding, DiLillo, \& Silverstein, 2005; Spauwen, Krabbendam, Lieb, Wittchen \& Van Os, 2006; Van Dam et al., 2015), and there is some evidence for an association with social dysfunction as well (Alameda et al., 2015; Stain et al., 2013). However, little is known about the underlying mechanisms. Recently, it has been proposed that one such mechanism is an impaired ability to mentalize (van Os et al., 2010). Mentalizing has been defined as the capacity to understand one's own and others' behaviour in terms of mental states, such as intentions, wishes, beliefs, and emotions (Bateman \& Fonagy, 2012). Patients with non-affective psychotic disorder have been shown to perform poorly on different dimensions of mentalizing, such as 'theory of mind' (i.e. the ability to infer mental states from other's behavior; Sprong, Schothorst, Vos, Hox, \& Van Engeland, 2007), identifying and describing their own emotional states (O’Driscoll, Laing \& Mason, 2014) and recognizing others' emotional states (Trémeau, 2006). 
No study to date has examined the possible mediating role of impaired mentalizing in the relation between reported childhood abuse and the outcome of non-affective psychotic disorder, even though it is a plausible underlying mechanism. Abuse in childhood has been related to impaired or delayed development of mentalizing (Cicchetti, Rogosch, Maughan, Toth, \& Bruce, 2003; Pears \& Fisher, 2005; Ensink et al., 2015) and poor understanding or discrimination of emotions (Rogosch, Cicchetti \&Aber, 1995; Camras, Sachs-Alter, \& Ribordy, 1996; Shipman \& Zeman, 1999; Pollak et al., 2000; Edwards, Shipman \& Brown, 2005).

Parental abuse is considered to be particularly detrimental to the development of mentalizing, because the groundwork of mentalizing is laid through day-to-day interactions with primary caregivers (Fonagy, Gergely, \& Jurist, 2004). By labelling the child's mental states, caregivers help the child understand his/her own mental states (Kim, 2015), which may be viewed as a prerequisite for the ability to infer the mental states of others (Brüne, 2005). In contrast, parental abuse can be viewed as reflecting an inability on the part of the caregiver to mentalize the inner experiences of the child, thereby depriving the child of a good role model for mentalizing (Kim, 2015). Additionally, parental abuse has been argued to impede mentalizing by inducing a lessened motivation to mentalize in the child, or even phobic avoidance of mentalizing, because reflecting on a caregiver's malevolent or uncaring mental states is overwhelmingly painful (Chiesa \& Fonagy, 2014).

Another line of research suggests that an impaired ability to represent mental states may contribute to the severity of positive and negative symptoms in non-affective psychotic disorder (Frith, 2004). For instance, an inability to identify one's own intentions may contribute to the experience that one's actions are caused or influenced by an outside force (i.e., delusions of control). Moreover, verbal hallucinations and the experience of thought insertion could arguably be viewed as the incorrect representation of one's own thoughts. Delusions of persecution and reference, by definition, involve the misrepresentation of another person's intentions. Concerning negative symptoms, the inability to represent what others think, intend, or desire is likely to complicate social interactions, in turn increasing the tendency to withdraw from such situations. Similarly, the inability to use gestures, facial expressions, and tone of voice to express emotions - commonly referred to as 'flattened affect' - may be exacerbated by an inability to understand the particular mental states conveyed by such communicational cues. Lastly, failing to identify one's own goals may contribute to avolition.

Partial support for this theory comes from a number of studies that have consistently associated impaired mentalizing ability with negative symptoms (Doody, Götz, Johnstone, Frith, \& Owens, 1998; Greig, Bryson, \& Bell, 2004; Sergi et al., 2007) and social dysfunction (Couture et al., 2006; Fett et al., 2011). However, support for an association between impaired mentalizing ability and positive symptoms is weaker. Some studies have found such an 
association (Corcoran, Mercer, \& Frith, 1995; Frith \& Corcoran, 1996), but a majority of reviewed studies failed to do so (Garety \& Freeman, 1999).

We do not presume that impaired mentalizing is the sole mechanism whereby childhood abuse can affect psychopathology of adult patients. A few mechanisms have already been suggested, including dopamine sensitization (Selten, van der Ven, Rutten, \& Cantor-Graae, E. 2013), insecure attachment (Read \& Gumley, 2010), poorer emotional regulation (Lincoln, Marin, \& Jaya, 2017), higher emotional reactivity to stress (Lardinois, Lataster, Mengelers, Van Os, \& Myin-Germeys, 2011), and cognitive impairment (Grant \& Beck, 2009). Such pathways interact with impaired mentalizing. For example, an insecure attachment style has been related to mentalizing impairment in a sample of patients with psychotic disorder (Macbeth et al., 2011). Attachment-related stress has also been implicated in poorer performance on mentalizing tasks (Nolte et al., 2013).

In the current study, we explored [1] whether reported childhood abuse is related to the severity of positive and negative symptoms and the level of social dysfunction; [2] whether reported childhood abuse is related to mentalizing impairment; [3] whether mentalizing impairment is related to the severity of positive symptoms, negative symptoms, and level of social dysfunction; and [4] whether impaired mentalizing explains at least part of the association between reported childhood abuse and these outcome variables.

\section{Methods}

Participants and procedure. Ninety outpatients with non-affective psychotic disorder were recruited from community treatment teams at regional mental health care institutes in the Netherlands (the Rivierduinen Institute for Mental Health Care located in Leiden, Voorhout, and Zoetermeer, and the Altrecht Institute for Mental Health Care in Zeist). The intervention teams were asked to refer any patients eligible for the study. Those referred to the study were contacted to assess their interest in participating and were screened regarding in- and exclusion criteria. Patients had to be at least 18 years old, have a non-affective psychotic disorder diagnosis from a psychiatrist, and be in treatment for a period between 6 months and 10 years to be eligible for inclusion. The diagnosis of non-affective psychotic disorder was also confirmed by researchers using the Comprehensive Assessment of History and Symptoms interview (Andreasen, Flaum \& Arndt, 1992). Participants with intellectual disabilities, illiteracy, or lack of mastery of the Dutch language were excluded from participation. All participants provided written informed consent after the procedures had been fully explained and before testing. The tests were administered by trained researchers with at least a bachelor degree in (applied) psychology. The current study is part of a larger research project for which 
ethical approval was given by the Medical Research Ethics Committee of the University Hospital Maastricht and Maastricht University (13-3-066.5/ab).

Measures. The Childhood Experience of Care and Abuse (CECA; Bifulco, Brown, \& Harris, 1994), a semi-structured interview, was used to assess childhood abuse (at age 0-16 years). Childhood abuse comprised four types of maltreatment: psychological abuse, physical abuse, sexual abuse, and parental conflict. Based on theory, the link with impaired mentalizing is likely to be strongest for parental abuse (Chiesa \& Fonagy, 2014; Kim, 2015). Therefore, only abuse perpetrated by caregivers was taken into account. Psychological abuse comprised extreme criticism, rejection, humiliation, or terrorizing by a caregiver. Physical abuse was defined as bodily harm inflicted by a caregiver that resulted in at least bruising. Sexual abuse was defined as the participant's report of any unwanted sexual incident perpetrated by a caregiver. Parental conflict was defined as the amount of fighting between the caregivers and/or with the child. Each type of abuse was scored for both frequency and intensity. Intensity of abuse was rated on a four-point Likert scale: 0 (none), 1 (some), 2 (moderate), 3 (marked), with the exception of parental conflict, which was scored on a five-point scale that also included 4 (violence). Frequency of abuse was rated on a five-point Likert-scale: 0 (never), 1 (rarely: once or twice), 2 (incidentally: more than two times, but not monthly), 3 (regularly: monthly or more often), 4 (often: weekly or more often). The severity score for each type of abuse was the product of intensity and frequency. The total reported childhood abuse score, ranging from 0 to 52 , was the sum of the severity scores for each subtype of abuse.

The ability to mentalize was operationalized as the capacity to attribute intentions to others. This was measured using the Hinting Task (HT; Corcoran, Mercer, \& Frith, 1995), in which participants read extracts that describe an interaction between two characters. In each case, one of the characters says something with an implicit message. To infer the implicit message from the literal one, an understanding of the character's beliefs or feelings is needed. If the participant infers the message correctly, 2 points are scored. If a hint is needed in order to infer the message correctly, a score of 1 is given. If the answer is incorrect or the participant does not know, 0 points are scored. There are 10 passages, so participants can score up to 20 points. For ease of interpretation the HT was reverse coded, so that higher scores reflected greater mentalizing impairment.

The Positive and Negative Syndrome Scale (PANSS; Kay, Fiszbein, \& Opfer, 1987), an observer-rated instrument, was used to assess the severity of positive and negative symptoms during the 2 weeks preceding measurement. The positive syndrome scale comprises delusions, conceptual disorganization, hallucinations, excitement, grandiosity, suspiciousness, and hostility, rated on a seven-point Likert scale. The negative symptoms are represented by flattened affect, emotional withdrawal, poor rapport, passive social withdrawal, difficulty in 
abstract thinking, lack of spontaneity, and stereotyped thinking. Both scales have a range of 7 to 49. Interrater reliability was assessed by means of a videotaped interview, rated independently by all raters. Inter-rater reliability was high for the average of PANSS items (ICC $=.91$ ).

Social dysfunction was measured using the Social Functioning Scale (SFS), a self-report questionnaire (Birchwood, Smith, Cochrane, Wetton, \& Copestake, 1990). The SFS contains seven dimensions (social withdrawal, interpersonal communication, independence (competence), independence (performance), recreational activities, social activities, and employment) and has been found to be reliable, valid, sensitive, and responsive to change (Birchwood et al., 1990). The overall social functioning score is determined by averaging all subdomains, resulting in a potential range from 59.7 to 134.9. Again, for ease of interpretation the scale was reverse coded, so that higher a score on the SFS indicated greater dysfunction.

Statistical analyses. Three mediator models were tested, one for each outcome variable (positive symptoms, negative symptoms, and social dysfunction), with reported childhood abuse as the independent variable and mentalizing impairment as the mediator in each model. SPSS version 22 combined with Hayes's PROCESS macro (Hayes \& Preacher, 2013) was used for the mediation analyses. The process macro uses non-parametric bootstrapping, which involves random resampling of observations with replacement to obtain confidence intervals for the indirect effect (and functions thereof). The bootstrap confidence intervals were based on 10000 resamples. Effects are considered significant if the confidence interval does not contain 0 . Mediation is present if the indirect effect ( $a$ and $b$ ) of the independent variable (reported childhood abuse) through the mediator (mentalizing impairment) on the outcome variables (positive symptoms, negative symptoms, and social dysfunction) is significant (i.e., the confidence interval does not contain 0 ) and the direct effect of the dependent variable on the outcome variable while accounting for the mediator $\left(c^{\prime}\right)$ is smaller than the total effect $(c)$ (figure 1). 

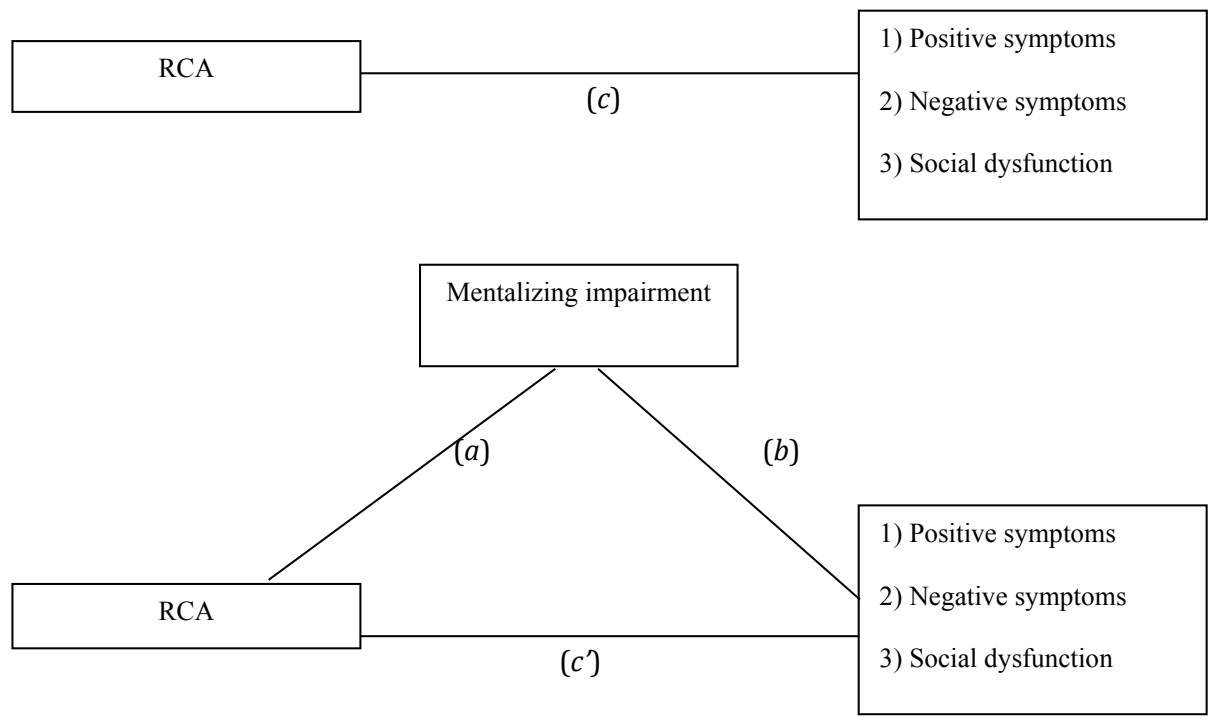

Figure 1: Mediational model with reported childhood abuse (RCA) as independent variable, mentalizing impairment as mediator, and positive symptoms, negative symptoms, and social dysfunction as dependent variables.

\section{Results}

Sample characteristics. Two participants dropped out of the study before completing all questionnaires, and another participant refused to answer questions regarding childhood experiences. They were excluded from analysis. The following results were obtained from analyses with the remaining 87 patients. Of these participants, $36.8 \%(n=32)$ reported no abuse, $63.2 \%(n=55)$ reported at least mild forms of abuse in one or more categories, and 37.9 $\%(n=33)$ reported at least marked forms of abuse in one or more categories. Other descriptive statistics are presented in Table 1. 
Table 1. Sociodemographic characteristics of sample $(\mathrm{N}=87)$.

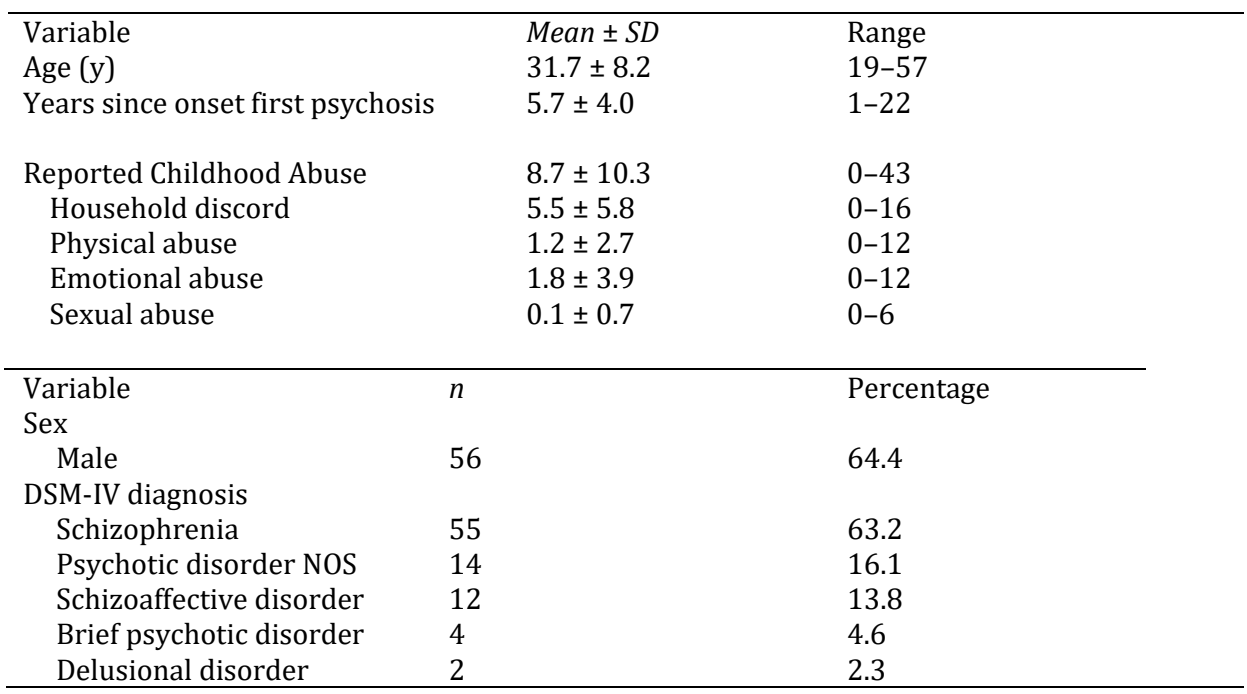

Main effects. Reported childhood abuse was significantly related to the severity of positive symptoms ( $b=0.11,95 \%$ confidence interval $[0.02,0.20], p=0.014)$ and negative symptoms $(b=0.17,95 \%$ confidence interval $[0.06,0.28], p=0.004)$, but not to social dysfunction ( $b=0.05,95 \%$ confidence interval $[-0.10,0.20], p=0.517)$. Furthermore, reported childhood abuse was related to mentalizing impairment $b=0.06,95 \%$ confidence interval $[0.01,0.11], p=0.027)$. Mentalizing impairment was not associated with the severity of positive symptoms ( $b=0.15,95 \%$ confidence interval [-0.20, 0.50], $p=0.395$ ), but it was associated with severity of negative symptoms ( $b=1.20,95 \%$ confidence interval $[0.82,1.58], p<0.001)$, and there was a positive, but not a significant association between mentalizing impairment and social dysfunction $(b=0.55,95 \%$ confidence interval $[-0.05,1.14], p=0.073)$. Interpretation of these results did not change when we added the other outcome variables as covariates to each separate analysis.

Mediation. In the case of negative symptoms only, the prerequisites of mediation - a significant association between independent variable, dependent variable, and mediator - were met. There was a significant indirect effect of reported childhood abuse on negative symptoms through mentalizing impairment, path a through $\mathrm{b}$ in figure $1(b=0.07,95 \%$ confidence interval [0.002, 0.17], $p=0.039$ ), indicative of a mediation effect. The total effect of childhood abuse on negative symptoms path $\mathrm{c}$ in figure $1(b=0.17,95 \%$ confidence interval $[0.06,0.28], p=0.004)$ 
was reduced by about $40 \%$ when mentalizing impairment was accounted for, path c' in figure 1 ( $b=0.10,95 \%$ confidence interval $[0.003,0.20], p=0.043)$, indicating partial mediation.

Sensitivity analysis. The above analysis assumes that all variables are related in a linear fashion, however curve estimations revealed that a quadratic term may be a better fit for the relation between reported childhood abuse and negative symptom severity $\left(R^{2}=0.180, p<\right.$ $.001)$, than a linear one $\left(R^{2}=0.095, p=.004\right)$. A quadratic term also better fitted the relation between reported childhood abuse and impaired mentalizing $\left(R^{2}=0.082, p=0.027\right)$, instead of a linear one $\left(R^{2}=0.056, p=.027\right)$. Both negative symptoms and mentalizing impairment increase exponentially as reported childhood abuse increases.

The use of a traditional mediation analysis in this case may be problematic, because it calculates the significance of one single indirect effect, assuming that the relationship between the independent variable, mediator and dependent variable is linear. However, in the current case the indirect effect is unlikely to be identical for each level of reported childhood abuse. We therefore also calculated the indirect effect using a mediation analysis that accounts for quadratic relationships, using the MEDCURVE macro (Hayes \& Preacher, 2010). "Instantaneous indirect effects" were generated at different levels of reported childhood abuse (one standard deviation above and below the sample mean) as suggested by Hayes \& Preacher (2010). Results showed, that only in the subgroup reporting relatively high childhood abuse (CECA $\geq 19$ ), there was a significant indirect effect of childhood abuse $(\theta=0.09,95 \%$ confidence interval [0.01, $0.22])$. This model predicted about $40 \%\left(R^{2}=0.394, p<.001\right)$ of the variance in negative symptom severity.

\section{Discussion}

Discussion of the results. This study tested the hypothesis that mentalizing impairment constitutes a pathway through which parental abuse affects clinical and functional outcomes in non-affective psychotic disorder. The majority of non-affective psychotic disorder patients in our sample reported experiencing parental abuse during their childhood. The severity of this abuse was associated with the levels of positive and negative symptoms and with mentalizing impairment, but not with social dysfunction. Mentalizing impairment, in turn, showed a significant relationship to the severity of negative symptoms, but no such relationship to positive symptoms or social dysfunction. Lastly, the relationship between reported childhood abuse and negative symptoms was partly mediated by mentalizing impairment, accounting for approximately $40 \%$ of the effect. A sensitivity analysis, which treated the relations between reported childhood abuse, negative symptoms and mentalizing impairment as quadratic, revealed that the mediating role of mentalizing impairment was only significant in the case of fairly severe abuse. 
Comparison to previous findings. The current results replicate previous findings regarding the relationship of reported childhood abuse to clinical outcome (Schenkel, Spaulding, DiLillo, \& Silverstein, 2005; Spauwen, Krabbendam, Lieb, Wittchen \& Van Os, 2006; Longden, Sampson, \& Read, 2015; Van Dam et al., 2015) and support the theory that parental abuse is related to mentalizing impairment (Chiesa \& Fonagy, 2014; Kim, 2015). While the findings do not support the idea that impaired mentalizing is related to positive symptoms, they do provide evidence of such a relationship to negative symptoms, in line with many previous studies (Garety \& Freeman, 1999; Doody et al., 1998; Mitchley et al., 1998; Greig et al., 2004; Sergi et al., 2007). Positive symptoms may not reflect an overall impaired ability to represent mental states, but rather a tendency to excessively do so, or to 'hypermentalize' (Abu-Akel \& Bailey, 2000; Clemmensen et al., 2016). Such a tendency has also been suggested to be state-like in nature, occurring only in specific circumstances (Walston et al., 2000; Charlton, 2003), which would explain the normal mentalizing performances of patients with predominantly positive symptoms in most studies (Garety \& Freeman, 1999). Interestingly, the current results also seem to echo recent observations that loneliness mediates the relation between social adversity and negative, but not positive symptoms (Jaya, Ascone, \& Lincoln, 2016). This may not come as a surprise as loneliness has been related to attachment-related stress (e.g. Wei et al., 2005), which in turn has been linked to impaired mentalizing (Nolte et al., 2013). Whatever the case may be, the current results support the notion that adversity may be related to negative and positive symptoms through different pathways, as Bentall and colleagues have recently suggested (2014).

Unexpectedly, we did not replicate the previously established relationship between reported childhood abuse and social functioning (Lysaker et al., 2004; Stain et al., 2013; Alameda et al., 2015). A possible explanation for this discrepancy may be the amount of time since onset of psychosis. Previous studies observed such associations either before (Spauwen et al., 2006; Tikka et al., 2013), or shortly after (Stain et al., 2013; Alameda et al., 2015) onset of psychosis. The current sample consisted of patients who, on average, experienced their first psychotic episode more than 5 years ago. Social functioning deteriorates most in the first 5 years after onset of psychosis; the rate of this deterioration is influenced by factors such as drug abuse, lack of social support, and symptom distress (Birchwood, Todd, \& Jackson, 1998). Possibly, social functioning is affected by a history of childhood abuse up to and around the onset of psychosis, but that other factors account for its decline afterwards. Alternatively, the effect of childhood abuse on social functioning may occur only in certain subgroups. For example, Boyette et al. (2014) found that the impact of reported childhood abuse on social dysfunction partly depends on the personality of the patient, whereas Lysaker et al. (2004) found that survivors of sexual abuse specifically showed poorer vocational outcome. 
Furthermore, the positive relationship between mentalizing impairment and social dysfunction, although in the expected direction, was not significant. The relation between mentalizing and functional outcome likely depends on the specific subdomains examined, as Couture, Penn and Roberts (2006) have suggested.

Clinical implications. This study provides initial support for the theory that impaired mentalizing ability is a potential pathway through which parental abuse affects the severity of negative symptoms in non-affective psychotic disorder. Although more research is needed to come to causal conclusions about the potentially pathogenic role of impaired mentalizing, it may be fruitful to examine the usefulness of targeting mentalizing ability as a treatment strategy for non-affective psychotic disorder. For example, mentalization based treatment (Brent, Holt \& Keshavan, 2014; Weijers et al., 2016) and metacognitive therapy (van Donkersgoed et al., 2014) both target mentalizing by helping the patient to become aware and elaborate on their own affective states as well as those of others. Alternatively, mentalization based treatment could potentially be implemented as a preventive therapy focusing on those at risk for psychosis (Debbané et al., 2016). Furthermore, the results underscore the importance of taking into account the possibility of patients having experienced abuse in childhood and their level of mentalizing impairment, as these factors negatively contribute to outcome in different ways (Selten \& Cantor-Graae, 2014).

Limitations and conclusions. Naturally, some limitations apply. First, childhood abuse scores were based on patient accounts. Some may argue this to be problematic since the validity of retrospective reports, especially by psychiatric patients has been questioned (Susser \& Widom, 2013). However, reports of abuse by psychiatric patients, including those with psychosis, have generally been found to be reliable (see Read,, van Os,, Morrison, \& Ross, 2005 for an overview). Further, a prospective study of young people very likely to have been exposed to sexual abuse clearly showed an increased risk of schizophrenia (Cutajar et al., 2010).

Second, different forms of childhood abuse were pooled into a single severity score, because the relatively small sample size precluded sufficiently powered sub-group analyses. Future studies, involving larger sample sizes, should consider the effects of each subtype of abuse separately, as different types of abuse may contribute to different dimensions of symptomatology (Bentall et al., 2014).

Third, it is important to stress that evidence of mediation does not establish causality (Maxwell, Cole \& Mitchell, 2011). A prospective study would therefore be preferable in order to make more robust claims concerning causality.

Fourth, only one type of mentalizing deficit was accounted for in this study. The ability to infer mental states of others, as measured by the hinting task, is a cognitive, other-oriented form of mentalizing and is only a partial indicator of the total construct of mentalizing. A 
number of dimensional axes have been proposed to underlie mentalizing, including cognitiveaffective, implicit-explicit, and self-other oriented axes (Fonagy \& Luyten, 2012). Specific mentalizing deficits may affect specific clinical symptoms differently, as has recently been argued (Debbané et al., 2016). Indeed, the severity of positive symptoms seems especially susceptible to deficits in self-oriented mentalizing (i.e. the ability to be aware of and identify self-generated mental events; e.g. Brunelin et al., 2007). Future studies should take different forms of mentalizing into account.

This study integrated two lines of research: one that highlights the role of impaired mentalizing regarding clinical and functional outcome in non-affective psychotic disorder (Frith, 2014) and another that underscores the developmental nature of mentalizing ability (Fonagy et al., 2004). Although recent research has increasingly focused on the role of mentalizing in nonaffective psychotic disorder, so far it has largely ignored the developmental origins of mentalizing ability. The current findings offer initial evidence that impaired mentalizing may constitute a pathway whereby childhood abuse affects adult negative symptoms, although such an effect is only likely to be observed when childhood abuse is fairly severe. Based on these findings, we believe that an understanding of the origins of impaired mentalizing may offer more insight into the pathogenesis of non-affective psychotic disorder.

\section{Funding}

This research did not receive any specific grant from funding agencies in the public, commercial, or not-for-profit sectors. Peter Fonagy was in part supported by the National Institute for Health Research (NIHR) Collaboration for Leadership in Applied Health Research and Care (CLAHRC) North Thames at Barts Health NHS Trust and is in receipt of NIHR Senior Investigator Award (ref. NF-SI-0514-10157). The views expressed are those of the author(s) and not necessarily those of the NHS, the NIHR or the Department of Health.

\section{Contributors}

Author JW designed the study and wrote the first draft. PF edited the manuscript. All authors reviewed, commented on and have approved the final manuscript.

Abbreviations. CECA: Childhood Experience of Care and Abuse; HT: Hinting Task; SFS: Social Functioning Scale; PANSS: Positive and Negative Syndrome Scale 


\section{Disclosure of interest}

The authors declare that they have no competing interest.

\section{Acknowledgements}

None

\section{References}

Abu-Akel, A., \& Bailey, A.L. (2000). Letter. Psychological medicine, 30(3), 735-738.

Addington, J., Saeedi, H., \& Addington, D. (2006). Facial affect recognition: a mediator between cognitive and social functioning in psychosis? Schizophrenia research, 85(1), 142-150.

Alameda, L., Ferrari, C., Baumann, P., Gholam-Rezaee, M., Do, K., \& Conus, P. (2015). Childhood sexual and physical abuse: age at exposure modulates impact on functional outcome in early psychosis patients. Psychological medicine, 45 (13), 2727-2736.

Andreasen, N.C., Flaum, M., \& Arndt, S. (1992). The Comprehensive Assessment of Symptoms and History (CASH): an instrument for assessing diagnosis and psychopathology. Archives of general psychiatry, 49(8), 615-623.

Bateman, A.W., \& Fonagy, P. (2012). Handbook of mentalizing in mental health practice. Arlington, VA: American Psychiatric Publishing, Inc.

Bentall, R.P., de Sousa, P., Varese, F., Wickham, S., Sitko, K., Haarmans, M., \& Read, J. (2014). From adversity to psychosis: Pathways and mechanisms from specific adversities to specific symptoms. Social Psychiatry and Psychiatric Epidemiology, 49(7), 1011-1022.

Bifulco, A., Brown, G.W., \& Harris, T.O. (1994). Childhood Experience of Care and Abuse (CECA): a retrospective interview measure. Journal of Child Psychology and Psychiatry, 35(8), 1419-1435.

Birchwood, M., Smith, J., Cochrane, R., Wetton, S., \& Copestake, S. (1990). The Social Functioning Scale. The development and validation of a new scale of social adjustment for use in family intervention programmes with schizophrenic patients. The British Journal of Psychiatry, 157 (6), 853-859.

Birchwood, M., Todd, P., \& Jackson, C. (1998). Early intervention in psychosis: the critical-period hypothesis. International Clinical Psychopharmacology, 13, 31-40.

Boyette, L.-L., van Dam, D., Meijer, C., Velthorst, E., Cahn, W., de Haan, L., Kahn, R., van Os, J., Wiersma, D., \& Bruggeman, R. (2014). Personality compensates for impaired quality of life and social functioning in patients with psychotic disorders who experienced traumatic events. Schizophrenia bulletin, 40(6), 1356-1365.

Brent, B.K., Holt, D.J., Keshavan, M.S., Seidman, L.J., \& Fonagy, P. (2014). Mentalization-based treatment for psychosis: linking an attachment-based model to the psychotherapy for 
impaired mental state understanding in people with psychotic disorders. The Israeli Journal of Psychiatry and Related Sciences, 51(1), 17-24.

Brüne, M. (2005). "Theory of mind" in schizophrenia: a review of the literature. Schizophrenia bulletin, 31(1), 21-42.

Brunelin, J., d'Amato, T., Brun, P., Bediou, B., Kallel, L., Senn, M., Poulet, E., \& Saoud, M. (2007). Impaired verbal source monitoring in schizophrenia: an intermediate trait vulnerability marker? Schizophrenia research, 89(1), 287-292.

Camras, L.A., Sachs-Alter, E., \& Ribordy, S.C. (1996). Emotion understanding in maltreated children: Recognition of facial expressions and integration with other emotion cues. In M. Lewis \& M. W. Sullivan (Eds.), Emotional development in atypical children (pp. 203225). Hillsdale, NJ: Lawrence Erlbaum Associates.

Charlton, B.G. (2003). Theory of mind delusions and bizarre delusions in an evolutionary perspective: psychiatry and the social brain. The social brain-Evolution and pathology. New York, NY: John Wiley \& Sons.

Chiesa, M., \& Fonagy, P. (2014). Reflective function as a mediator between childhood adversity, personality disorder and symptom distress. Personality and mental health, 8(1), 52-66.

Cicchetti, D., Rogosch, F.A., Maughan, A., Toth, S.L., \& Bruce, J. (2003). False belief understanding in maltreated children. Development and psychopathology, 15(4), 1067-1091.

Clemmensen, L., van Os, J., Drukker, M., Munkholm, A., Rimvall, M., Væver, M., Rask, C.U., BartelsVelthuis, A., Skovgaard, A., \& Jeppesen, P. (2016). Psychotic experiences and hypertheory-of-mind in preadolescence-a birth cohort study. Psychological medicine, 46(1), 87-101.

Corcoran, R., Mercer, G., \& Frith, C.D. (1995). Schizophrenia, symptomatology and social inference: investigating "theory of mind" in people with schizophrenia. Schizophrenia research, 17(1), 5-13.

Couture, S.M., Penn, D.L., \& Roberts, D.L. (2006). The functional significance of social cognition in schizophrenia: a review. Schizophrenia bulletin, 32(1), 44-63.

Cutajar, M.C., Mullen, P.E., Ogloff, J.R., Thomas, S.D., Wells, D.L., \& Spataro, J. (2010). Psychopathology in a large cohort of sexually abused children followed up to 43 years. Child abuse \& neglect, 34(11), 813-822.

Debbané, M., Salaminios, G., Luyten, P., Badoud, D., Armando, M., Tozzi, A.S., Fonagy, P., \& Brent, B.K. (2016). Attachment, neurobiology, and mentalizing along the psychosis continuum. Frontiers in Human Neuroscience, 10(406), 1-22.

Doody, G., Götz, M., Johnstone, E., Frith, C., \& Owens, D.C. (1998). Theory of mind and psychoses. Psychological medicine, 28(2), 397-405. 
Edwards, A., Shipman, K., \& Brown, A. (2005). The socialization of emotional understanding: A comparison of neglectful and nonneglectful mothers and their children. Child maltreatment, 10(3), 293-304.

Ensink, K., Normandin, L., Target, M., Fonagy, P., Sabourin, S., \& Berthelot, N. (2015). Mentalization in children and mothers in the context of trauma: an initial study of the validity of the Child Reflective Functioning Scale. British Journal of Developmental Psychology, 33(2), 203-217.

Fett, A.-K.J., Maat, A., \& Group Investigators. (2011). Social cognitive impairments and psychotic symptoms: what is the nature of their association? Schizophrenia bulletin, 35, 573-588.

Fonagy, P., Gergely, G., \& Jurist, E.L. (2004). Affect regulation, mentalization and the development of the self. London, UK: Karnac books

Fonagy, P., \& Luyten, P. (2012). The multidimensional construct of mentalization and its relevance to understanding borderline personality disorder. In: From the Couch to the Lab: Trends in Psychodynamic Neuroscience. Oxford, UK: Oxford University Press.

Frith, C.D. (2014). The cognitive neuropsychology of schizophrenia. Hove, UK: Psychology Press,. Frith, C.D., \& Corcoran, R. (1996). Exploring 'theory of mind' in people with schizophrenia. Psychological medicine, 26(3), 521-530.

Garety, P.A., \& Freeman, D. (1999). Cognitive approaches to delusions: a critical review of theories and evidence. British journal of clinical psychology, 38(2), 113-154.

Grant, P.M., \& Beck, A.T. (2009). Defeatist beliefs as a mediator of cognitive impairment, negative symptoms, and functioning in schizophrenia. Schizophrenia Bulletin, 35(4), 798-806.

Greig, T.C., Bryson, G.J., \& Bell, M.D. (2004). Theory of mind performance in schizophrenia: diagnostic, symptom, and neuropsychological correlates. The Journal of nervous and mental disease, 192(1), 12-18.

Hayes, A. F., \& Preacher, K. J. (2010). Quantifying and testing indirect effects in simple mediation models when the constituent paths are nonlinear. Multivariate behavioral research, 45(4), 627-660.

Hayes, A.F., \& Preacher, K.J. (2013). Conditional process modeling: Using structural equation modeling to examine contingent causal processes. In: Structural equation modeling: A second course, 217-264.

Jaya, E.S., Ascone, L., Lincoln, \& T.M. (2016). Social adversity and psychosis: the mediating role of cognitive vulnerability. Schizophrenia bulletin, 43(3), 557-565.

Kay, S.R., Fiszbein, A., \& Opfer, L.A. (1987). The positive and negative syndrome scale (PANSS) for schizophrenia. Schizophrenia bulletin, 13(2), 261-276. 
Kim, S. (2015). The mind in the making: Developmental and neurobiological origins of mentalizing. Personality Disorders: Theory, Research, and Treatment, 6(4), 356-365.

Lardinois, M., Lataster, T., Mengelers, R., Van Os, J., \& Myin-Germeys, I. (2011). Childhood trauma and increased stress sensitivity in psychosis. Acta Psychiatrica Scandinavica, 123(1), 2835.

Lincoln, T.M., Marin, N., \& Jaya, E.S. (2017). Childhood trauma and psychotic experiences in a general population sample: A prospective study on the mediating role of emotion regulation. European Psychiatry, 42, 111-119.

Longden, E., Sampson, M., \& Read, J. (2015). Childhood adversity and psychosis: generalised or specific effects? Epidemiology and psychiatric sciences, 25, 349-359.

Lysaker, P.H., Nees, M.A., Lancaster, R.S., \& Davis, L.W. (2004). Vocational function among persons with schizophrenia with and without history of childhood sexual trauma. Journal of traumatic stress, 17(5), 435-438.

MacBeth, A., Gumley, A., Schwannauer, M., \& Fisher, R. (2011). Attachment states of mind, mentalization, and their correlates in a first-episode psychosis sample. Psychology and Psychotherapy: Theory, Research and Practice, 84(1), 42-57.

Maxwell, S.E., Cole, D.A., \& Mitchell, M.A. (2011). Bias in cross-sectional analyses of longitudinal mediation: Partial and complete mediation under an autoregressive model. Multivariate Behavioral Research, 46(5), 816-841.

Mitchley, N.J., Barber, J., Gray, J.M., Brooks, D.N., \& Livingston, M.G. (1998). Comprehension of irony in schizophrenia. Cognitive Neuropsychiatry, 3(2), 127-138.

Nolte, T., Bolling, D.Z., Hudac, C.M., Fonagy, P., Mayes, L., \& Pelphrey, K.A. (2013). Brain mechanisms underlying the impact of attachment-related stress on social cognition. Frontiers in human neuroscience, 7(816), 1-12.

O'Driscoll, C., Laing, J., \& Mason, O. (2014). Cognitive emotion regulation strategies, alexithymia and dissociation in schizophrenia, a review and meta-analysis. Clinical psychology review, 34(6), 482-495.

Pollak, S.D., Cicchetti, D., Hornung, K., \& Reed, A. (2000). Recognizing emotion in faces: Developmental effects of child abuse and neglect. Developmental psychology, 36(5), 679.

Pears, K., \& Fisher, P.A. (2005). Developmental, cognitive, and neuropsychological functioning in preschool-aged foster children: Associations with prior maltreatment and placement history. Journal of Developmental \& Behavioral Pediatrics, 26(2), 112-122.

Read, J., van Os, J., Morrison, A. P., \& Ross, C.A. (2005). Childhood trauma, psychosis and schizophrenia: a literature review with theoretical and clinical implications. Acta Psychiatrica Scandinavica, 112(5), 330-350. 
Read, J., \& Gumley, A. (2010). Can attachment theory help explain the relationship between childhood adversity and psychosis. Telling stories, 51-94.

Revheim, N., \& Medalia, A. (2004). Verbal memory, problem-solving skills and community status in schizophrenia. Schizophrenia research, 68(2), 149-158.

Rogosch, F. A., Cicchetti, D., \& Aber, J. L. (1995). The role of child maltreatment in early deviations in cognitive and affective processing abilities and later peer relationship problems. Development and psychopathology, 7(4), 591-609.

Schenkel, L.S., Spaulding, W.D., DiLillo, D., \& Silverstein, S.M. (2005). Histories of childhood maltreatment in schizophrenia: relationships with premorbid functioning, symptomatology, and cognitive deficits. Schizophrenia research, 76(2), 273-286.

Selten, J.P., van der Ven, E., Rutten, B.P., \& Cantor-Graae, E. (2013). The social defeat hypothesis of schizophrenia: an update. Schizophrenia bulletin, 39(6), 1180-1186.

Selten, J.P., \& Cantor-Graae, E. (2014). Childhood trauma and the treatment for psychotic disorder. Acta Psychiatrica Scandinavica, 129(6), 479-480.

Sergi, M.J., Rassovsky, Y., Widmark, C., Reist, C., Erhart, S., Braff, D.L., Marder, S.R., \& Green, M.F. (2007). Social cognition in schizophrenia: relationships with neurocognition and negative symptoms. Schizophrenia research, 90(1), 316-324.

Shipman, K.L., \& Zeman, J. (1999). Emotional understanding: A comparison of physically maltreating and nonmaltreating mother-child dyads. Journal of Clinical Child Psychology, 28(3), 407-417.

Spauwen, J., Krabbendam, L., Lieb, R., Wittchen, H.-U., \& Van Os, J. (2006). Impact of psychological trauma on the development of psychotic symptoms: relationship with psychosis proneness. The British Journal of Psychiatry, 188(6), 527-533.

Sprong, M., Schothorst, P., Vos, E., Hox, J., \& Van Engeland, H. (2007). Theory of mind in schizophrenia. The British Journal of Psychiatry, 191(1), 5-13.

Stain, H.J., Brønnick, K., Hegelstad, W.T., Joa, I., Johannessen, J.O., Langeveld, J., Mawn, L., \& Larsen, T.K. (2013). Impact of interpersonal trauma on the social functioning of adults with first-episode psychosis. Schizophrenia bulletin, 40, 1491-1498.

Susser, E., Widom, C.S. (2012). Still searching for lost truths about the bitter sorrows of childhood. Schizophrenia bulletin, 38(4), 672-675.

Tikka, M., Luutonen, S., Ilonen, T., Tuominen, L., Kotimäki, M., Hankala, J., \& Salokangas, R.K. (2013). Childhood trauma and premorbid adjustment among individuals at clinical high risk for psychosis and normal control subjects. Early intervention in psychiatry, 7(1), 5157.

Trémeau, F. (2006). A review of emotion deficits in schizophrenia. Dialogues in clinical neuroscience, 8(1), 59-70. 
- Chapter Five

van Dam, D., van Nierop, M., Viechtbauer, W., Velthorst, E., van Winkel, R., Bruggeman, R., Cahn, W., De Haan, L., Kahn, R., \& Meijer, C. (2015). Childhood abuse and neglect in relation to the presence and persistence of psychotic and depressive symptomatology. Psychological medicine, 45(7), 1363-1377.

Van Donkersgoed, R.J., De Jong, S., Van der Gaag, M., Aleman, A., Lysaker, P.H., Wunderink, L., \& Pijnenborg, G.H.M. (2014). A manual-based individual therapy to improve metacognition in schizophrenia: protocol of a multi-center RCT. BMC psychiatry, 14(1), 14-27.

van Os, J., Kenis, G., \& Rutten, B.P.F. (2010). The environment and schizophrenia. Nature, 468(7321), 203-212.

Varese, F., Smeets, F., Drukker, M., Lieverse, R., Lataster, T., Viechtbauer, W., Read, J., van Os, J., \& Bentall, R.P. (2012). Childhood adversities increase the risk of psychosis: a metaanalysis of patient-control, prospective-and cross-sectional cohort studies. Schizophrenia bulletin, 38(4), 661-671.

Vauth, R., Rüsch, N., Wirtz, M., \& Corrigan, P.W. (2004). Does social cognition influence the relation between neurocognitive deficits and vocational functioning in schizophrenia? Psychiatry research, 128 (2), 155-165.

Walston, F., Blennerhassett, R.C., \& Charlton, B.G. (2000). "Theory of mind”, persecutory delusions and the somatic marker mechanism. Cognitive Neuropsychiatry, 5(3), 161-174.

Wei, M., Shaffer, P.A., Young, S.K., \& Zakalik, R.A. (2005). Adult attachment, shame, depression, and loneliness: The mediation role of basic psychological needs satisfaction. Journal of Counseling Psychology, 52(4), 591.

Weijers, J., ten Kate, C., Eurelings-Bontekoe, E., Viechtbauer, W., Rampaart, R., Bateman, A., \& Selten, J.-P. (2016). Mentalization-based treatment for psychotic disorder: protocol of a randomized controlled trial. BMC psychiatry, 16(1), 191. 




\section{MENTALIZATION}

\section{BASED TREATMENT \\ FOR PSYCHOTIC \\ DISORDER}

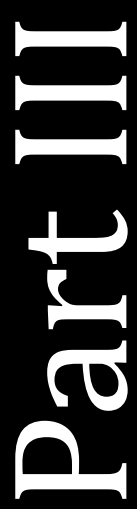





\section{MENTALIZATION- BASED TREATMENT FOR PSYCHOTIC DISORDER: PROTOCOL OF A RANDOMIZED CONTROLLED TRIAL}

J.G. Weijers, C. ten Kate, E.H.M. Eurelings-Bontekoe, W.V. Viechtbauer, L.J.A. Rampaart, A.W. Bateman, J.-P.C.J. Selten
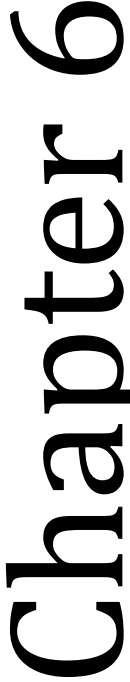
- Chapter Six

\section{Abstract}

Background: Many patients with a non-affective psychotic disorder suffer from impairments in social functioning and social cognition. To target these impairments, mentalization-based treatment for psychotic disorder, a psychodynamic treatment rooted in attachment theory, has been developed. It is expected to improve social cognition, and thereby to improve social functioning. The treatment is further expected to increase quality of life and the awareness of having a mental disorder, and to reduce substance abuse, social stress reactivity, positive symptoms, negative, anxious and depressive symptoms.

Methods/design: The study is a rater-blinded randomized controlled trial. Patients are offered 18 months of therapy and are randomly allocated to mentalization-based treatment for psychotic disorders or treatment as usual. Patients are recruited from outpatient departments of the Rivierduinen mental health institute, the Netherlands, and are aged 18 to 55 years and have been diagnosed with a non-affective psychotic disorder. Social functioning, the primary outcome variable, is measured with the social functioning scale. The administration of all tests and questionnaires takes approximately 22 hours. Mentalization-based treatment for psychotic disorders adds a total of 60 hours of group therapy and 15 hours of individual therapy to treatment as usual. No known health risks are involved in the study, though it is known that group dynamics can have adverse effects on a psychiatric disorder.

Discussion: If Mentalization-based treatment for psychotic disorders proves to be effective, it could be a useful addition to treatment.

Trial registration: Dutch Trial Register: NTR4747. Trial registration date 08-19-2014.

Keywords: Mentalization, Treatment, Schizophrenia, Psychosis, Social functioning, Social cognition, Psychotherapy

\section{Background and rationale}

Non-affective psychotic disorders (NAPD) like schizophrenia are accountable for a substantial part of the total burden of disease, constituting the fifth and sixth leading cause of disability in the world, for men and women respectively (Mathers, Fat \& Boerma, 2008). A major contributor to this high level of disability is thought to be the decline in social functioning associated with NAPD. Patients with NAPD experience difficulty communicating (Bellack, Morrisson, Wixted \& Mueser, 2002), and tend to have poor social problem-solving skills (Addington, Saeedi \& Addington, 2006). These social deficits are predictive of poor vocational outcome (Bell, Tsang, Greig, \& Bryson, 2009) and poor quality of life (Perlick, Stastny, Mattis \& Teresi, 1992). It is surprising, therefore, that few treatments have been developed to effectively target them.

Social cognition - defined as "the ability to construct representations of the relation between oneself and others, and to use those representations flexibly to guide social behavior" 
(Adolphs, 2001) has been identified as one of the strongest predictors of social functioning in patients with NAPD (Brüne, 2005). Examples of social cognitive impairments in NAPD include difficulties recognizing emotions (Kohler, Walker, Martin, Healy \& Moberg, 2010), empathizing (Bora \& Pantelis, 2009), taking another person's perspective (Montag, Heinz, Kunz \& Gallinat, 2007) and understanding social hints (Mizrahi, Korostil, Starkstein, Zipursky \& Kapur, 2007).

In recent years just a few treatments, mostly rooted in cognitive/behavioral theory (Moritz \& Woodward, 2007; Roberts \& Penn, 2009; Combs et al., 2007), have been developed that target social cognition. Results, are preliminary, but do suggest that impaired social cognitive deficits are targetable by psychosocial interventions (Roberts \& Penn, 2009; Combs et al., 2007; Rocha \& Queirós, 2013).

Mentalization-based treatment for psychotic disorder (MBTp) is based on a manualized psychodynamic treatment for Borderline Personality Disorder (BPD; Bateman \& Fonagy, 2006). Recent prospective studies suggest that psychodynamic therapy may improve global functioning in NAPD (Rosenbaum et al., 2006; Rosenbaum et al., 2012), although randomized controlled trials should be conducted to substantiate this claim. Also, metacognitive psychotherapy (Donkersgoed et al., 2014) - which is closely related to MBT (Brent \& Fonagy, 2014) - holds promise as a treatment for patients with schizophrenia (Lysaker, Buck \& Ringer, 2006). MBT- was developed to specifically improve social functioning by targeting the social cognitive process called 'mentalizing'. Gergely and colleagues (2002) describe mentalizing as "the process by which we implicitly and explicitly interpret the actions of ourselves and others as meaningful on the basis of intentional mental states".

MBT adheres to a few important principles: (i) The therapist focuses on the current mental state of the patient to practice making representations of internal states; (ii) the therapist focuses on the present as opposed to the past; (iii) the therapist avoids talking about mental states that are not linked to subjectively felt reality; (iv) the therapist avoids talking about complex mental states; (v) the therapist focuses on recovering mentalizing, not creating insight (Bateman \& Fonagy, 2006).

This approach was found to reduce symptoms and interpersonal distress, and improve social functioning in patients with BPD (Bateman \& Fonagy, 1999). Although BPD and NAPD may seem qualitatively different disorders, early views assumed borderline psychopathology occupied an area between neurosis and psychosis (e.g. Kernberg, 1986) and could involve transient psychotic episodes. Since then, evidence has substantiated psychosis proneness in BPD. Psychotic symptoms, including hallucinatory experiences and delusions, occur regularly in patients with BPD, often persist over time, and are for a large part already present in early childhood (Yee, Korne, McSwiggan, Meares \& Stevenson, 2006). In a recent study that included patients with either BPD or Schizophrenia, $17 \%$ of participants met the criteria for both 
disorders (Kingdon, Ashcroft, Bhandari, Gleeson, Warikoo \& Symons, 2010). Additionally, some NAPD and BPD patients share a tendency to excessively attribute incorrect intentions to others, or to "hypermentalize" (Clemmensen et al., 2014; Sharp et al., 2011; Abu-Akel \& Bailey, 2000). Furthermore, disturbances in self-awareness and self-representation have been suggested to play an important role in both disorders (Auerbach \& Blatt, 1996). Lastly, childhood trauma has been established as an important factor in the origins of both disorders (Varese et al. 2012). Thus, as has been suggested earlier (Brent \& Fonagy, 2014; Brent, 2009), MBT may be a similarly suitable treatment for NAPD.

\section{Research aims and hypotheses}

Primary research aim. The primary aim of this study is to establish whether mentalization-based treatment for psychotic disorder (MBTp) improves self-reported social functioning in patients with NAPD. We hypothesize that patients who receive MBTp will show greater improvements in social functioning compared to patients who have had treatment as usual (TAU) only. We also expect that any difference observed will still be present at a 6-month follow-up.

Secondary research aims. Other outcome measures were chosen with previous research regarding MBT in mind. According to Fonagy and Bateman (2006), MBT's mechanism of change is improving patients' mentalizing capacities. We therefore aim to establish whether MBTp indeed increases mentalizing capacity, measuring several dimensions of social cognition, and whether this increase mediates a potential treatment effect. Furthermore, in earlier studies, Bateman and Fonagy (1999) reported a reduction of anxious and depressive symptoms and of substance abuse. We expect similar results regarding NAPD patients. Given the strong relation between social functioning and quality of life, we assume that patients receiving MBTp will report a higher quality of life. Additionally, based on previous research (Konstantakopoulos et al., 2014), we predict that improvement of social cognitive capacity will also lead to an increased awareness of having a mental disorder. Furthermore, as Bateman and Fonagy (2006) describe that MBT was designed to improve emotion regulation in situations of attachment related, i.e., social, stress. Based on this, we assert that patients will have less aversive emotional reactions to situations of social stress as a result of MBTp. If MBTp can reduce patients' emotional reactivity to social stress, they may also become less prone to develop positive psychotic symptoms, as social stress reactivity may be an affective pathway to psychosis (MyinGermeys \& van Os, 2007). Lastly, because social functioning and mentalizing ability have been found to be strongly related to negative symptoms, we will examine whether MBTp reduces negative symptoms (Corcoran, Mercer \& Frith, 1995; Greig, Bryson \& Bell, 2004; Sergi et al., 2007). 
Covariates. Certain potential effect modifiers will be taken into account. First, adverse childhood experiences such as neglect or physical, psychological, and sexual abuse have been associated with social dysfunction later in life (Silverma, Reinherz \& Giaconia, 1996). Second, personality organization (PO) has been shown to impact psychotherapy treatment response (Koelen et al., 2012) and the level of social cognition (Eurelings-Bontekoe, Luyten, \& Snellen, 2009). Five levels of personality organization (PO) are identified, each characterized by different levels of anxiety tolerance and different capacities for impulse inhibition or 'control': Neurotic PO (good anxiety tolerance, over-control); Borderline PO (moderate to poor anxiety tolerance, differing levels of control); Narcissistic Borderline PO (good anxiety tolerance, undercontrol); Latent Psychotic PO (moderate anxiety tolerance, weak control); and Manifest Psychotic PO (poor anxiety tolerance, weak control). Third, the awareness of bodily sensations has been regarded as the first level of emotional awareness (Nentjens, Meijer, Bernstein, Arntz \& Medendorp, 2013), which is an essential part of social cognition (Green, 1996).

Psychopathology usually is accompanied by (vague) physical complaints, called "somatization". A failure to report physical complaints while suffering (severe) psychopathology may be indicative of an absence of bodily awareness and therefore an impaired social cognitive capacity. Fourth, medication use can affect social functioning in patients with NAPD, therefore the type of medication is registered and adherence to medication is measured. Fifth, MBT attendance is taken into account, because it is expected that those who attend more sessions will profit more. Sixth, baseline measurements of the outcome variables will be accounted for. Seventh, the duration of illness, because of its negative impact on functioning; and eighth, adherence to the MBT model by therapists, because it is likely to influence treatment outcome.

\section{Methods/design}

Trial design/setting. This study is a rater-blinded, randomized controlled trial. Patients referred to outpatient sites of the Rivierduinen mental health institute are randomly assigned to Treatment as Usual (TAU) plus MBTp or TAU only. The Rivierduinen mental health institute provides in- and outpatient treatment to thousands of patients with psychiatric disorders in the Dutch province of South-Holland (e.g., Leiden, Gouda). The investigator and patients are aware of treatment allocation, but all measurements are performed by researchers blind to treatment allocation. Social functioning at baseline $(\mathrm{t} 0)$ and after treatment $(\mathrm{t} 2)$ will be compared for both treatment conditions. The patients are blind to this primary aim.

Participants. Participants in the study are patients with NAPD (DSM-IV criteria (APA, 2000)): schizophrenia, schizophreniform, or schizoaffective disorder (295.x), delusional disorder (297.1), brief psychotic disorder (298.8), or psychotic disorder not otherwise specified (298.9). At least 80 participants will be included from the Rivierduinen mental health institute. 
- Chapter Six

Inclusion criteria are:

- At least 6 months of prior treatment.

- No more than 10 years of treatment for NAPD.

- Between 18 and 55 years of age.

Exclusion criteria are:

- Intellectual disability and/or illiteracy.

- A lack of mastery of the Dutch language.

- Substance abuse to such an extent that it necessitates inpatient detoxification. After

successful detoxification the patient is still eligible for participation in the study.

Patients cannot participate in a session while under the influence of drugs.

Sample size calculation. The estimated effect size of the current study is based on two previous studies. A study examining the effect of MBT on BPD (Bateman \& Fonagy, 1999) showed moderate to large reductions of problems relating to interpersonal distress $(d=$ 0.95 ; $95 \%$; CI: $0.59-1.30)$ and social functioning $(d=0.72 ; 95 \% \mathrm{CI} 0.37-1.06)$. A study concerning Social Cognition and Interaction Training (SCIT) - a treatment for patients with schizophrenia that shares elements with MBT - showed large effects on social engagement $(d$ $=1.77)$ and interpersonal communication $(d=1.57)$ on the Social Functioning Scale (Roberts \& Penn, 2009). Based on these results, we expect to find a moderate to large effect of MBTp on social cognition (i.e., a Cohen's $d$ of at least 0.7 ).To calculate the required sample size, G*Power (Faul, F., Erdfelder, E., Buchner, A., \& Lang, A., 2009) was used. To obtain a significant difference with power equal to .80 with an independent samples t-test (for a true effect size of .7 and alpha $=.05$ ), 68 participants are needed. However, because repeated measurements (baseline and post-treatment) increase the power - depending on the test-retest reliability of the outcome measure - a smaller sample size is required. A formula has been devised (Morgan \& Chase, 2013) to account for the increased power when using multiple measurements: $\mathrm{N}$ repeated measures $=(1-\rho 2) * \mathrm{~N}_{\mathrm{t} \text {-test }}$; where $\rho$ is the test-retest reliability of the scale used. Previous research has shown that the test-retest reliability of the social functioning scale after two and a half years is $\rho=.40$ (Addington \& Addington, 2000). Thus we need: (1-0.42) $68 \approx 58$ participants to have $80 \%$ power to find a significant difference. It is difficult to predict the amount of drop-out in the study. In an unpublished pilot study, conducted at the Rivierduinen mental health institute, the drop-out rate of MBTp within a period of 1 year was $10 \%$. Since the current RCT combines treatment and measurements, we estimate that the drop-out rate will be higher. Therefore, to be sure, we will recruit at least 40 (TAU) $+40($ TAU plus MBTp) $=80$ 
individuals. Even if $25 \%$ of those initial patients (i.e., 20) drop out, there will be 60 patients left to detect an effect. Because patients in the MBTp condition receive therapy in groups of up to eight persons, five groups will be formed in order to recruit 40 patients in the MBTp condition.

\section{Procedure}

Psychiatrists, psychologists, or psychiatric nurses will check their caseload for patients who meet the requirements for participation and ascertain whether they are interested in participating. If this is the case, the researcher will provide an information letter. The patient will be given seven days to read the letter and to decide whether he/she wants to participate. At a second appointment, the researcher will check whether the patient has understood the information in the letter. Subsequently, both parties sign an informed consent form in twofold. Randomization is performed by an independent external agency.

Measurements and instruments. There are four moments of assessment over the course of 2 years. The baseline assessment takes place before MBTp is started. Furthermore, there will be an assessment after 9 months (halfway MBTp), after 18 months (directly after MBTp has ended), and after 24 months (6 months after MBTp has ended). See Table 1 for the specific instruments that are used at each assessment.

Diagnosis. All patients are diagnosed according to DSM-IV criteria (APA, 2000) by a psychiatrist. Prior to participation, this diagnosis will also be verified using the Comprehensive Assessment of Symptoms and History (CASH). The CASH is a semistructured interview that documents signs, symptoms, and history of psychotic, manic and depressive syndromes as well as substance abuse. The instrument has been extensively tested concerning interrater reliability, test-retest reliability and validity (Andreasen, Flaum \& Arndt, 1992).

Social functioning. Social functioning is measured using the Social Functioning Scale (SFS), a self-report questionnaire. The SFS has been found to be reliable, valid, sensitive, and responsive to change (Birchwood, Smith, Cochrane, Wetton \& Copestake, 1990). The scale contains seven dimensions of global social functioning that are especially pertinent to patients suffering from psychotic disorders. The dimensions are: social withdrawal, interpersonal communication, independence (competence), independence (performance), recreational activities, social activities, and employment.

Social cognitive or 'mentalizing' capacity. It has been pointed out that there is to date no agreement on the assessment of social cognition, but there is a broad consensus that it is a multifaceted construct (Boyette et al., 2014). In the current study, social cognition is therefore assessed with two instruments that measure different aspects of social cognition: the Thematic Apperception Test (TAT) and the hinting task (HT). The TAT (Murray, 1943), scored with the Social Cognition and Object Relations System (SCORS; Westen, 1991), is used to assess four 
dimensions of social cognition: complexity of representations of people and understanding of social causality, which comprise cognitive aspects of social cognition, and the affect-tone of relationships and the capacity for emotional investment, comprising affective aspects of social cognition. Each dimension is scored on a 5-point scale, with higher scores representing higher social cognitive functioning in that dimension. Six pictures of the TAT are used. TAT responses are recorded and transcribed verbatim. TAT responses, when analyzed with the SCORS, have been found to be a valid and reliable way to measure social cognition and object relations (Meyer, 2004; Hibbard, Mitchell \& Porcerelli, 2001). According to Luyten and colleagues (Luyten, Fonagy, Lowyck \& Vermote, 2012), the TAT is one of the few tests that takes almost all aspects of mentalization into account, including affective and cognitive aspects.

The HT (Corcoran, Mercer \& Frith, 1995) is used to measure the ability to infer intentions from others, or 'Theory of Mind' (ToM). Patients read extracts that describe an interaction between two characters in which one character says something with an implicit message. If the patient infers the implicit message correctly, two points are scored. If a hint is needed, a score of 1 is given. When the answer is incorrect or the participant does not know, 0 points are scored. The test comprises ten short passages. The Hinting Task has very recently been reviewed (Pinkham, Penn, Green \& Harvey, 2015) regarding test-retest reliability, utility as a repeated measure, relation to functional outcome, and internal consistency and was one of two tests shown with strong psychometric properties across all evaluation criteria.

Social stress reactivity. Emotional reactivity to stress in social situations is measured with an electronic diary using the 'Experience Sampling Method' (ESM; Myin-Germeys et al., 2006). ESM is a repeated self-assessment technique with great ecological validity. Participants carry around an ESM device, which facilitates the monitoring of daily life experiences and behavior. Ten times daily on five consecutive days, it generates an audible signal (beep) at unpredictable moments of the day which participants answer by using the touch screen of the device. Participants are asked whether they are alone or in company of others. Then, both the level of social stress and negative/positive affect are assessed. Social stress is measured with items such as: "I would rather be alone" and "I like the present company" (reverse coded). Negative affect is the averaged score of the mood items "anxious", "lonely", "insecure", "irritated", "down", "guilty", and "gloomy". Positive affect will be measured with the items "happy", "satisfied", "cheerful", "relaxed", and "enthusiastic". All items are scored on a 7-point Likert Scale.

Quality of life. Using the Manchester Short Assessment of quality of life (MANSA; Priebe, Huxley, Knight \& Evans, 1999), changes in overall quality of life are measured. The MANSA is a 16-item, 7-point Likert scale self-rating instrument. 
Psychotic symptom severity. Interviewers use the Positive and Negative Syndrome Scale (PANSS) (Kay, Fiszbein \& Opfer. 1987) to assess positive (subscale P), negative (subscale N), anxious (item G2), and depressive symptoms (item G4). The PANSS is a 30-item, 7-point Likertscale rating instrument developed for the assessment of phenomena associated with schizophrenia. A Dutch version is used (Wolthaus, Dingemans \& Schene, 2000).

Additionally, the ESM diary is used to measure momentary psychotic experiences. Seven ESM items are used: 'I feel suspicious', 'I am afraid of losing control', 'I feel that others don't like me', 'I feel that others want to hurt me', 'My thoughts are influenced by other people', 'I feel unreal', and 'I hear voices'. Awareness of having a mental disorder. The PANSS (item G12) is used to assess awareness of having a mental disorder.

Substance abuse. Patients are asked to report substance use on the ESM device at each beep using categorical questions. Patients will report whether they have used any substance since the last beep, including: (1) caffeine, (2) nicotine, (3) medication, (4) alcohol, (5) cannabis, (6) other drugs, or (7) none.

Personality organization/somatization of psychopathology. Assessment of personality organization and the tendency to somatize severe psychopathology is conducted using theory driven profiles of the Dutch short Form of the MMPI (DSFM; Luteijn \& Kok, 1985), an 83-item self-assessment questionnaire. The DSFM measures personality traits on 5 scales: Extraversion, Psychopathology, Shyness, Somatization, and Negativism. Using the theory driven profile approach to the DSFM (Eurelings-Bontekoe \& Koelen, 2007; Eurelings-Bontekoe, Luyten, IJssennagger, Van Vreeswijk \& Koelen, 2010; Eurelings-Bontekoe, Luyten, Remijsen \& Koelen, 2010; Eurelings-Bontekoe, Peen, Noteboom, Alkema \& Dekker, 2012; Eurelings-Bontekoe, Koelen, Thijssen, de Ridder \& Kerkhof, 2014), five levels of Personality Organization (PO) are distinguished: Neurotic PO, Borderline PO, Narcissistic Borderline PO, Latent Psychotic PO and Manifest Psychotic PO. To measure bodily awareness, the DSFM "Somatization" subscale (20 items) will be used. This subscale measures the amount and degree of experienced bodily symptoms, and hence, the ability to subjectively report, and be aware of bodily sensations. As described (Eurelings-Bontekoe et al., 2014) affect regulation through somatization will be expressed as the relative position of scores on the subscale somatization to that on the severe psychopathology subscale.

Childhood trauma. The Childhood Experience of Care and Abuse (CECA; Bilfulco, Brown \& Harris, 1994) is a semi-structured interview that aims to assess details and the time-sequence of traumatic childhood experiences. It assesses lack of care (neglect, antipathy), physical abuse, sexual abuse, and psychological abuse.

Drug treatment: Each patient's medical record is consulted to ascertain the pharmacotherapy prescribed at $\mathrm{t} 0, \mathrm{t} 1, \mathrm{t} 2$, and $\mathrm{t} 3$. 
- Chapter Six

Adherence to the prescribed medication is measured with the Medication Adherence Questionnaire (MAQ; Morisky, Green, Levine \& 1986).

Adherence to the MBT-model. Adherence to the MBT model by therapists is rated by an experienced MBT therapist according to the MBT adherence and competence scale (Karterud, et al., 2013), using footage of therapy sessions. Therapists are judged on 17 items that characterize proper MBT treatment.

Duration of illness. Assessed using the CASH, refers to the period since first psychosis.

General demographics. The general demographic questionnaire (GDQ) is a standard instrument used in all ESM studies conducted at Maastricht University. It documents treatment history, socio-economic status, educational level, and urbanicity of the place of residence.

Table 1 Overview of the different instruments at each measurement moment

\begin{tabular}{|c|c|c|c|c|c|}
\hline & Intake & $\begin{array}{l}\text { T0: Baseline } \\
\text { measurement } \\
(0 \text { months })\end{array}$ & $\begin{array}{l}\text { T1: Halfway } \\
\text { Measurement } \\
\text { (9 months) }\end{array}$ & $\begin{array}{l}\text { T3: End of } \\
\text { Treatment } \\
\text { (18 months) }\end{array}$ & $\begin{array}{l}\text { T4: } \\
\text { Follow-up } \\
\text { (24 months) }\end{array}$ \\
\hline CASH & $x$ & & & & \\
\hline SFS & & $x$ & & $x$ & $x$ \\
\hline TAT & & $x$ & & $x$ & $x$ \\
\hline ESM & & $x$ & $x$ & $x$ & $x$ \\
\hline HT & & $x$ & & $x$ & $x$ \\
\hline MANSA & & $x$ & & $x$ & $x$ \\
\hline MAQ & & $x$ & $x$ & $x$ & $x$ \\
\hline DSFM & & $x$ & & & \\
\hline PANSS & & $x$ & & $x$ & $x$ \\
\hline GDQ & & $x$ & & & \\
\hline CECA & & $x$ & & & \\
\hline
\end{tabular}

\section{Treatment.}

TAU. All patients in the current study receive a multifaceted treatment based on the 'Flexible Assertive Community Treatment' (FACT) model. FACT teams consist of psychiatric nurses, welfare workers, psychologists, and at least one psychiatrist. The intervention consists of pharmacotherapy, case-management, psychoeducation, and in some cases cognitive behavioral therapy (CBT). CBT interventions for psychosis usually take around 20 sessions and are based on the work of van der Gaag (van der Gaag, Valmaggia, van Meer \& Slooff, 2005; van der Gaag, Nieman \& van den Berg, 2013). Whether or not patients have received CBT, and how many sessions, will be registered and taken into account. Furthermore, all patients will receive supportive structuring therapy. Sessions focus on problems patients may encounter in their 
social network, work, daily activities, or medication adherence. Patients meet with a mental health professional for an average of 30 mine very 2 weeks, with a minimum of 1 meeting of 30 min per month, over 18 months. The total number of individual sessions is estimated to be around 30 (15 h of individual therapy). Adherence to treatment sessions is monitored by registering patients' presence in the sessions.

MBTp. Patients in the TAU plus MBTp condition receive the same treatment mentioned above in combination with individual and group MBTp. The key elements of MBT, shortly described below, provided the basis for MBTp (Bateman \& Fonagy, 2006).Therapeutic stance MBT is characterized by the 'not knowing stance' in which the therapist admits to not knowing what the patient experiences. By actively asking questions the therapist cultivates an attitude of sincere interest in the patient. This gives the patient the experience of being 'kept in mind' by someone, but also stimulates curiosity in the patient towards his own mental states.

Interventions. When applying interventions, it should always be kept in mind that arousal tends to diminish the capacity to mentalize. Four stages of intervention can be used in a step-wise manner, depending on the level of arousal. At the first level, interventions are aimed at downregulating arousal in the patient. These include empathic validation of the patient's feelings and complimenting good mentalizing. At the second stage the therapist asks for clarification of a situation or elaboration on the patient's feelings and thoughts. Often the therapist stops or rewinds the patient's narrative to investigate an aspect of the dialogue. This stage is about making implicit mentalizing explicit. Often details are investigated that seem to affect the patient, or should affect the patient, but do not. This then leads to the next stage, called 'mentalized affectivity', which is the activity of reflecting on emotions, while simultaneously experiencing them. Itis considered to be a crucial aspect of emotion regulation. The explicit mentalizing of a primary affective experience gives the patient the opportunity to express (or inhibit) emotions in a non-automatic manner. At the last stage, the relationship between therapist and patient or between patients is mentalized. In this stage, both patient and therapist reflect on and share their affective experience to become aware how their relationship is affecting them. Care should be taken applying this stage of intervention, as it requires a robust level of mentalizing.

Duration and dose. Compared to original MBT, the length of MBTp, has remained unchanged: 18 months. However, the frequency and length of sessions has been reduced. In our experience, based on a pilot MBTp intervention, NAPD is associated with more severe mentalizing deficits than BPD, as has also been suggested elsewhere (Miti \& Chiala, 2003). Given, the danger of overwhelming NAPD patients with mentalizing interventions, group therapy is limited to weekly 1 -hour sessions, while individual therapy takes place in biweekly 
half-hour sessions. We feel this approach is justified by the low drop-out rate of $10 \%$ in the pilot intervention.

Psycho-education. MBTp starts with two to four sessions of psycho-education, in which patients are told about the key aspects of MBT, including the meaning of mentalizing and its sensitivity to arousal.

Individual therapy. Individual therapy provides an opportunity for intensive practice in mentalizing. The focus is on establishing a secure relationship that acts as a safe base from which failures in mentalizing can be explored. Treatment goals on the basis of five problem areas are developed and routinely reviewed with the patient, including: commitment to treatment, psychiatric symptoms, social interaction/relationships, destructive behavior, and community functioning.

Group therapy. Since patients with NAPD tend to experience a great deal of stress in social situations, group therapy provides an opportunity to practice mentalizing in a stressevoking setting. Group therapy can also generate a sense of belonging and attachment that help foster mentalizing. The group size is a maximum of eight patients and there will be one MBTp therapist and one co-therapist present at each session.

Therapists. Group therapists are experienced and registered MBT therapists. Individual therapists are mental health professionals (psychologists, psychiatric nurses or psychiatrists) who receive training to become MBTp therapists. Supervision is provided in weekly sessions of up to $1 \mathrm{~h}$, during which therapists reflect on their interventions and whether they are faithful to the MBT model.

\section{Statistical analysis}

Main effect. The main purpose of the statistical analysis is to compare the overall effect of treatment condition on social functioning. For this, an ANCOVA will be used with treatment condition as between-subjects variable, posttreatment social functioning as dependent variable, and baseline social functioning as a covariate. Other potential covariates include childhood trauma, level of PO, somatization of psychopathology, medication use, and attendance of MBTp sessions, duration of illness and adherence to the MBT-model by therapists. Similar analyses will be conducted for the secondary outcome measures (social cognition, quality of life, awareness of having a mental disorder, anxious, depressive, negative and positive symptoms and substance abuse). Since drop-out will undoubtedly result in missing data, the possibility of attrition-bias is a cause of concern (Leon et al., 2006). For example, it is conceivable that those who fare the worst in therapy tend to drop out, thus creating a biased sample. Following the advice of Altman (2009), the analyses will therefore be conducted on the basis of 'intention to treat' (ITT), meaning that they will include all patients who sign up, regardless of actual 
participation in the entire program. Missing data will be handled by means of multiple imputation (MI; Schafer, 1999). In the current case missingness is most likely to be caused by participants dropping out of their respective treatment programs. Since certain variables have been found to influence drop-out rates in patients with NAPD, we cannot assume that the data are missing at random. A review (Nose, Barbui \& Tansella, 2003) identified a lack of insight, poor social functioning, positive symptoms, young age, male gender, a history of drug abuse, and unemployment as key predictors of treatment program drop out. Thus, in the current study, these variables will be used to predict missingness. Additionally, treatment condition will be used as a predictor as well, because the time investment differs between conditions. For each analysis, a total of 5 imputed datasets will be created using a fully conditional Markov chain Monte Carlo (MCMC) approach, which will be combined using standard procedures (Preacher \& Hayes, 2013).

Mediation. We also aim to examine whether changes in various social cognitive dimensions mediate the potential increase in social functioning. In order to test this mediational model, we will carry out a multi-mediator analysis (Preacher \& Hayes, 2004). This allows for a parallel testing of the indirect effects of several social cognitive dimensions, namely: theory of mind, complexity of representations, affect-tone of relationships, capacity for emotional investment and understanding of social causality (Fig. 1).

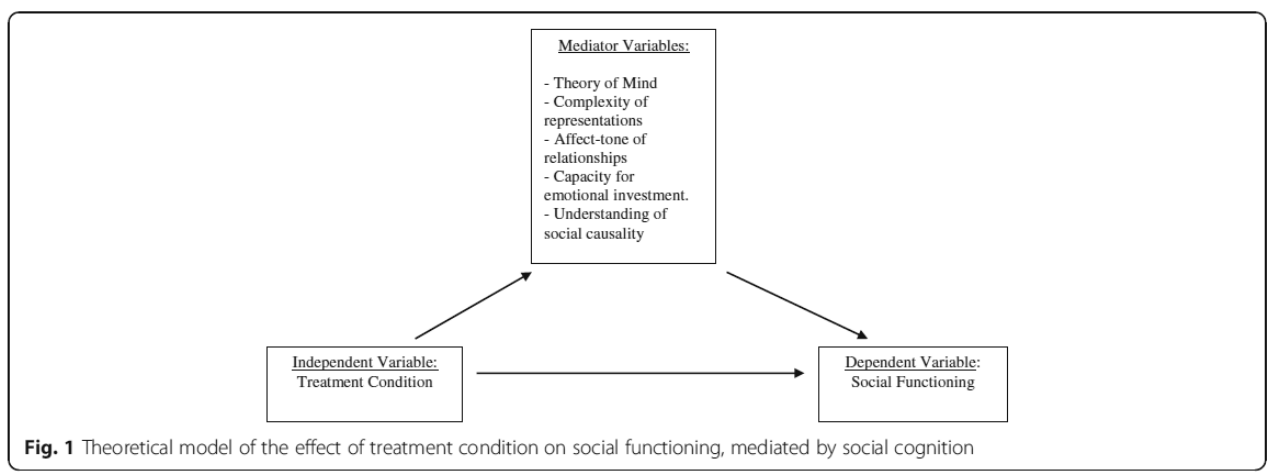

Multilevel analysis. Social stress reactivity is measured by ESM. This method generates data with a multilevel structure because there are multiple measurements per day for up to six days at a time for each patient. Since observations within patients tend to be more similar than observations from different patients, they are not independent. This necessitates different (i.e., multilevel) analysis than the one used for the other outcome measures. Similar to MyinGermeys and colleagues (2001), differences in social stress reactivity between groups will be analyzed using mixed-effects regression models with treatment condition, the amount of stress during social situations, and their interaction term as independent variables, and positive and 
- Chapter Six

negative affect as dependent variables. The model will include random intercepts and random slopes for the stress predictor at the patient level, which allows for differences in overall levels of positive and negative affect across patients and for differences in the strength of the relationship between stress and these outcomes.

\section{Discussion}

There is evidence that MBT improves, among others, social functioning and interpersonal distress in patients with BPD (e.g. Bateman \& Fonagy, 1999; Bateman \& Fonagy, 2009) and that these effects remain at follow-up (Bateman \& Fonagy, 2001). Given the similarities in both origins and symptoms of BPD and NAPD, it has previously been suggested that MBT could be a useful treatment for NAPD (Brent \& Fonagy, 2014; Brent, 2009). This randomized controlled trial, will be the first to examine the effectiveness of MBT as an adjunct therapy for patients with NAPD.

\section{Acknowledgement}

Rivierduinen Institute for Mental Health Care is funding the costs for this trial for at least 4 years. The costs include participation fees for up to 80 participants, treatment given, organizational costs and the salaries of principal investigator Jean-Paul Selten and local investigator Jonas Weijers.

This funding source has no role in the design of this study and will not have any role during its execution, analyses, interpretation of the data, or decision to submit results. The protocol was not peer-reviewed by this funding body.

\section{Availability of data and materials}

Non applicable.

\section{Authors' contributions}

CtK drafted the first version of the manuscript. JW completed the manuscript with advice from CtK, LEB, WV, RR, AB, and JPS and is the lead author. JW is also responsible for the collection of data. JPS is principal investigator and responsible for the coordination of the study. All authors provided comments, read and approved the final manuscript.

\section{Competing interests}

The authors declare that they have no competing interests. 


\section{Consent for publication}

Consent to publish results and store data and materials for a maximum of 15 years will be obtained from all participants. Consent to share raw data with outside parties will not be obtained. Reporting of data once obtained will adhere to the CONSORT guidelines (Moher, Schulz \& Altman, 2001).

\section{Ethics approval and consent to participate}

The Medical Research and Ethics Committee (MREC) of Maastricht University in The Netherlands has approved this study, registered under NL47236 068/METC 13-03-066. Consent to participate will be obtained from all participants. If no consent is given, the participant will be considered a drop-out. Administrative information Protocol identifier: Version 4, date: 02-06-2016 Sponsor: Maastricht University, the Netherlands. Correspondence: D. Op 't Eijnde, P.O. Box 616 (VIJV1), 6200 MD Maastricht T +31 4338838 69. Funder: Rivierduinen Institute for Mental Health Care, the Netherlands, Sandifortdreef 19, $2333 \mathrm{ZZ}$ Leiden. Trial registration database: Dutch Trial Register Trial registration:

NTR4747Registration date: 08-19-2014

\section{Abbreviations}

(Z)MLK, Abbreviation for the Dutch term '(zeer) moeilijk lerende kinderen' meaning: children with (severe) learning disabilities; BPD, borderline personality disorder; $\mathrm{CASH}$, comprehensive assesment of symptoms and history; CBT, cognitive behavioral therapy; CECA, childhood experiences of care and abuse; DSFM, Dutch short form of the Minnesota Multiphasic personality inventory; ESM, experience sampling method; GDQ general demographic questionnaire; HT, hinting task; ITT, Intention to treat; MANSA, Manchester short assessment $\mathrm{f}$ quality of life; MAQ, medication adherence questionnaire; MBT, mentalization-based treatment (for borderline personality disorder); MBTp, mentalization based treatment for psychotic disorders; MCMC, markov chain monte carlo; MI, multiple imputation; MMRM, mixed model for repeated measures; MREC/METC, medical research ethics committee (MREC); in Dutch: medisch ethische toetsing commissie (METC); NAPD, nonaffective psychotic disorder; PANSS, positive and negative syndrome scale; PO, personality organization; SCORS, social cognition and object relations system; SFS, social functioning scale; TAT, thematic apperception test; TAU, treatment as usual.

\section{References}

Abu-Akel, A., \& Bailey, A.L. (2000). The possibility of different forms of theory of mind. Psychological Medicine, 30, 735-738. 
- Chapter Six

Addington, J., \& Addington, D. (2000). Neurocognitive and social functioning in schizophrenia: a 2.5 year follow-up study. Schizophrenia research, 44(1), 47-56.

Addington, J., Saeedi, H., \& Addington, D. (2006). Influence of social perception and social knowledge on cognitive and social functioning in early psychosis. British Journal of Psychiatry,189, 373-378.

Adolphs, R. (2001). The neurobiology of social cognition. Current Opinion in Neurobiology,11, 231-9.Bateman, A., \& Fonagy, P. (2009). Randomized controlled trial of outpatients, mentalization based treatment versus structured clinical management for borderline personality disorder. American Journal of Psychiatry, 166, 1355-1364.

American Psychiatric Association. Diagnostic and statistical Manual of Mental disorders, (4th ed.). (2000). Washington, DC: American Psychiatric Association.

Andreasen, N.C., Flaum, M., \& Arndt, S. (1992). The Comprehensive Assessment of Symptoms and History (CASH): an instrument for assessing diagnosis and psychopathology. Archives of General Psychiatry, 49(8), 615-23.

Altman, D.G. (2009). Missing outcomes in randomized trials: addressing the dilemma. Open Medicine, 3(2), 51-53.

Auerbach, J.S., \& Blatt, S.J. (1996). Self-representation in severe psychopathology: The role of reflexive self-awareness. Psychoanalytical Psychology, 13(3), 297.

Bateman, A., \& Fonagy, P. (1999). Effectiveness of partial hospitalization in the treatment of borderline personality disorder: a randomized controlled trial. American Journal of Psychiatry, 156, 1563-1569.

Bateman, A., \& Fonagy, P. (2001). Treatment of borderline personality disorder with psychoanalytically oriented partial hospitalization: an 18-month follow-up. American Journal of Psychiatry, 158, 244-251.

Bateman, A., \& Fonagy, P. (2006). Mentalisation based treatment: a practical guide. Oxford: Oxford University Press.

Bateman, A., \& Fonagy, P. (2012). Handbook of mentalizing in mental health practice. Washington: American Psychiatric Publishing, Inc.

Bell, M., Tsang, H.W., Greig, T.C., \& Bryson, G.J. (2009). Neurocognition, social cognition, perceived social discomfort, and vocational outcomes in schizophrenia. Schizophrenia Bulletin, 35(4), 738-747.

Bellack, A.S., Morrisson, R., Wixted, J.T., \& Mueser, K. (1990). An analysis of social competence in schizophrenia. British Journal of Psychiatry, 156, 809-818.

Bifulco, A., Brown, G.W., \& Harris, T.O. (1994). Childhood Experience of Care and Abuse (CECA): A retrospective interview measure. Journal of Child Psychology and Psychiatry, 35, 14191435. 
Birchwood, M., Smith, J., Cochrane, R., Wetton, S., \& Copestake, S. (1990). The Social Functioning Scale. The Development and validation of a new scale of social adjustment for use in family intervention programmes with schizophrenic patients. British Journal of Psychiatry, 157(6), 853-859.

Bora, E.Y.M., \& Pantelis, C. (2009). ,Theory of mind impairment in schizophrenia: meta-analysis. Schizophrenia Researc, 109(1), 1-9.

Boyette, L.-L., van Dam, D., Meijer, C., Velthorst, E., Cahn, W., \& de Haan, L., et al. (2014).

Personality compensates for impaired quality of life and social functioning in patients with psychotic disorders who experienced traumatic events. Schizophrenia Bulletin, 40(6), 1356-1365.

Brent, B. (2009). Mentalization-Based Psychodynamic Psychotherapy for Psychosis. Journal of Clinical Psychology, 65(8), 803-814.

Brent, B.K., \& Fonagy, P. (2014). A mentalization-based approach to disturbances of social understanding in schizophrenia. Social cognition and metacognition in schizophrenia. Waltham: Academic, pp. 245-257.

Brüne, M. (2005). "Theory of mind” in schizophrenia: a review of the literature. Schizophrenia Bulletin, 31(1), 21-42.

Clemmensen, L., van Os, J., Skovgaard, A.M., Væver, M., Blijd-Hoogewys, E.M., Bartels-Velthuis, A.A., et al. (2014). Hyper-theory-of-mind in children with psychotic experiences. PLoS One, 9(11), e113082.

Combs, D.R., Adams, S.D., Penn, D.L., Roberts, D., Tiegreen, J., \& Stem, P. (2007). Social Cognition and Interaction Training (SCIT) for inpatients with schizophrenia spectrum disorders: preliminary findings. Schizophrenia Research, 91(1), 112-116.

Corcoran, R., Mercer, G., \& Frith, C.D. (1995). Schizophrenia, symptomatology and social inference: Investigating "theory of mind" in people with schizophrenia. Schizophrenia Research, 17, 5-13.

Donkersgoed, R.J.M., De Jong, S., van der Graag, M., Aleman, A., Lysaker, P.H., Wunderink, L., et al. (2014). A manual-based individual therapy to improve metacognition in schizophrenia: protocol of a multi-center RCT. BMC Psychiatry, 14, 27.

Eurelings-Bontekoe, E.H.M., \& Koelen, J.A. (2007). De Somatisatie-Ernstige Psychopathologie combinatie binnen de theoriegestuurde profielinterpretatie van de NVM: Somatisatie als affectregulator en maat voor sociale (in)competentie. Tijdschrift Klinische Psychologie. $37(2), 107-122$.

Eurelings-Bontekoe, E.H.M., Luyten, P., \& Snellen, W.M. (2009). Validation of the theory driven profile interpretation of the Dutch Short form of the MMPI using the TAT Social 
- Chapter Six

Cognition and Object relations Scale (SCORS). Journal of Personality Assessment, 91, 15565.

Eurelings-Bontekoe, E.H.M., Luyten, P., IJssennagger, M., Van Vreeswijk, M., \& Koelen, J.A. (2010).

Relationship between personality organization and Young's cognitive model of personality pathology. Personality and Individual Differences, 49, 198-203.

Eurelings-Bontekoe, E.H.M., Luyten, P., Remijsen, M., \& Koelen, J.A. (2010). Association between personality organization as assessed by theory driven profiles of Dutch Short Form of MMPI and self-reported structural personality pathology. Journal of Personality Assessment, 92(6), 599-609.

Eurelings-Bontekoe, E.H.M., Peen, J., Noteboom, A., Alkema, M., \& Dekker, J. (2012). Differential treatment response of subtypes of patients with borderline personality organization, as assessed with theory-driven profiles of the Dutch short form of the MMPI: a naturalistic follow-up study. Journal of Personality Assessment, 94(4), 380-392.

Eurelings-Bontekoe, E., Koelen, J., Thijssen, M., de Ridder, P., \& Kerkhof, G. (2014). The impact of level of personality organization and somatization on psychological distress, worrying, and coping among patients with sleep disorders. Journal of Sleep Disorders: Treatment and Care, 33.

Faul, F., Erdfelder, E., Buchner, A., \& Lang, A. (2009). Statistical power analyses using G*Power 3.1: Tests for correlation and regression analyses. Behavior Research Methods, 41(4), 1149-1160.

Fonagy, P., \& Bateman, A. (2006). Mechanisms of change in mentalization-based treatment of BPD. Journal of Clinical Psychology, 62, 411-430.

Gergely, G., Fonagy, P., Jurist, E., \& Target, M. (2002). Affect regulation, mentalization, and the development of the self. London: Karnac Books.

Green, M.F. (1996). What are the functional consequences of neurocognitive deficits in schizophrenia? American Journal Psychiatry, 153, 321-30.

Greig, T.C., Bryson, G.J., \& Bell, M.D. (2004). Theory of mind performance in schizophrenia: diagnostic, symptom, and neuropsychological correlates. Journal of Nervous Mental Disease, 192(1), 12-18.

Hall, R.C. (1995). Global assessment of functioning: a modified scale. Psychosomatics, 36(3), 267-75.

Hibbard, S., Mitchell, D., \& Porcerelli, J. (2001). Internal consistency of the object relations and social cognition scales for the thematic apperception test. Journal of Personality Assessment, 77(3), 408-419. 
Leon, A.C., Mallinckrodt, C.H., Chuang-Stein, C., Archibald, D.G., Archer, G.A., \& Chartier, K. (2006). Attrition in randomized controlled clinical trials: methodological issues in psychopharmacology. Biological Psychiatry, 59, 1001-1005.

Karterud, S., Pedersen, G., Engen, M., Johansen, M.S., Johansson, P.N., Schlüter, C., et al. (2013). The MBT Adherence and Competence Scale (MBT-ACS): development, structure and reliability. Psychotherapy Research, 23(6), 705-717.

Kay, S.R., Fiszbein, A., \& Opfer, L.A. (1987). The positive and negative syndrome scale (PANSS) for schizophrenia. Schizophrenia Bulletin, 13(2), 261.

Kernberg. O. (1986). Borderline Personality Organization. In: Stone MH. Essential papers on borderline disorders: One hundred years at the border. New York: NYU Press.

Kingdon, D.G., Ashcroft, K., Bhandari, B., Gleeson, S., Warikoo, N., \& Symons, M., et al. (2010). Schizophrenia and borderline personality disorder: similarities and differences in the experience of auditory hallucinations, paranoia, and childhood trauma. Journal of Nervous and Mental Disease, 198(6), 399-403.

Koelen, J.A., Luyten, P., Eurelings-Bontekoe, L.H., Diguer, L., Vermote, R., Lowyck, B., et al. (2012). The impact of level of personality organization on treatment response: A systematic review. Psychiatry, 75(4), 355-74.

Kohler, C.G., Walker, J.B., Martin, E.A., Healy, K.M., \& Moberg, P.J. (2010). Facial emotion perception in schizophrenia: a meta-analytic review. Schizophrenia Bulletin, 36(5), 109119.

Konstantakopoulos, G., Ploumpidis, D., Oulis, P., Patrikelis, P., Nikitopoulou, S., Papadimitriou, G.N., et al. (2014). The relationship between insight and theory of mind in schizophrenia. Schizophrenia Research, 152(1), 217-222.

Luteijn, F., \& Kok, A.R. (1985). NVM, Nederlandse Verkorte MMPI, handleiding, herziene versie. Lisse: Swets \& Zeitlinger.

Luyten, P., Fonagy, P., Lowyck, B., \& Vermote, R. (2012). Assessment of mentalization. Handbook of mentalizing in mental health practice. pp. 43-65.

Lysaker, P.H., Buck, K.D., \& Ringer, J. (2007). The recovery of metacognitive capacity in schizophrenia across 32 months of individual psychotherapy: A case study. Psychotherapy Research, 17(6), 713-720.

Mathers, C., Fat, D.M., \& Boerma, J.T. (2008.) The global burden of disease: 2004 update. Geneva: World Health Organization.

Meyer, G.J. (2004). The reliability and validity of the Rorschach and Thematic Apperception Test (TAT) Compared to other Psychological and Medical procedures: An analysis of systematically gathered evidence. Comprehensive handbook of psychological assessment. Hoboken, NJ: Wiley and Sons, pp. 315-342. 
- Chapter Six

Miti, G., \& Chiaia, E. (2003). Patterns of attachment and the etiology of dissociative disorders and borderline personality disorder. Journal of Trauma Practice, 2(2), 19-35.

Mizrahi, R., Korostil, M., Starkstein, S., Zipursky, R.B., \& Kapur, S. (2007). The effect of antipsychotic treatment on theory of mind. Psychological Medicine, 37, 595-601.

Moher, D., Schulz, K.F., \& Altman, D.G. (2001). The CONSORT statement: revised recommendations for improving the quality of reports of parallel group randomized trials. BMC Medical Research and Methodology, 1(1), 2.

Montag, C., Heinz, A., Kunz, D. \& Gallinat, J. (2007). ,Self-reported empathic abilities in schizophrenia. Schizophrenia Research, 92, 85-89.

Morgan, T. M., \& Case, L. D. (2013). Conservative sample size determination for repeated measures analysis of covariance. Annals of biometrics \& biostatistics, 1(1).

Moritz, S., \& Woodward, T.S. (2007). Metacognitive training in schizophrenia: from basic research to knowledge translation and intervention. Current Opinion in Psychiatry, 20(6), 619-625.

Morisky, D.E., Green, L.W., \& Levine, D.M. (1986). Concurrent and predictive validity of a SelfReported Measure of Medication Adherence. Medical Care, 24(1), 67-74.

Murray, H.A. (1943). Thematic Apperception Test. Cambridge, MA: Harvard University Press.

Myin-Germeys, I., \& van Os, J., Schwartz, J.E., Stone, A.A., Delespaul, P.A. (2001). Emotional reactivity to daily life stress in psychosis. Archives General Psychiatry, 58, 1137-1144.

Myin-Germeys, I., \& van Os, J. (2007). Stress-reactivity in psychosis: Evidence for an affective pathway to psychosis. Clinical Psychology Review, 27, 409-424.

Myin-Germeys, I., Oorschot, M., Collip, D., Lataster, J., Delespaul, P., \& van Os, J. (2009). Experience sampling research in psychopathology: opening the black box of daily life. Psychological Medicine, 39(09), 1533-1547.

Nentjens, L., Meijer, E., Bernstein, D., Arntz, A., \& Medendorp, W. (2013). Brief Communication: Investigating the Relationship Between Psychopathy and Interoceptive Awareness. Journal of Personality Disorders, 27(5), 617-24.

Nosé, M., Barbui, C., \& Tansella, M. (2003). How often do patients with psychosis fail to adhere to treatment programmes? A systematic review. Psychological Medicine, 33(07), 11491160.

Perlick, D., Stastny, P., Mattis, S., \& Teresi, J. (1992). Contribution of family, cognitive and clinical dimensions to long-term outcome in schizophrenia. Schizophrenia Research, 6, 257-65.

Pinkham, A.E., Penn, D.L., Green, M.F., \& Harvey, P.D. (2015). Social cognition psychometric evaluation: Results of the initial psychometric study. Schizophrenia Bulletin, doi: 10.1093/schbul/sbv056. 
Preacher, K.J., \& Hayes, A.F. (2004). SPSS and SAS procedures for estimating indirect effects in simple mediation models. Behavior Research Methods, Instruments and Computers, 36(4), 717-731.

Preacher, K., \& Hayes, A. (2013).Introduction to mediation, moderation, and conditional process analysis: A regression-based approach. New York: Guilford Press;

Priebe, S., Huxley, P., Knight, S., \& Evans, S. (1999). Application and results of the Manchester Short Assessment of Quality of Life (MANSA). International Journal of Social Psychiatry, 45(1), 7-12.

Roberts, D.L., \& Penn, D.L. (2009). Social cognition and interaction training (SCIT) for outpatients with schizophrenia: A preliminary study. Psychiatry Research, 166, 141-147.

Rocha, N.B., \& Queirós, C. (2013). Metacognitive and social cognition training (MSCT) in schizophrenia: a preliminary efficacy study. Schizophrenia Research, 150(1), 64-68.

Rosenbaum, B., Valbak, K., Harder, S., Knudsen, P., Køster, A., Lajer, M., et al. (2006). Treatment of patients with first-episode psychosis: two-year outcome data from the Danish National Schizophrenia project. World Psychiatry, 5(2), 100-103.

Rosenbaum, B., Harder, S., Knudsen, P., Køster, A., Lindhardt, A., Lajer, M., et al. (2012). Supportive psychodynamic psychotherapy versus treatment as usual for first-episode psychosis: two-year outcome. Psychiatry, 75(4), 331-341.

Schafer, J.L. (1999). Multiple imputation: a primer. Statistical Methods in Medical Research, 8(1), 3-15.

Sergi, M.J., Rassovsky, Y., Widmark, C., Reist, C., Erhart, S., Braff, D.L., et al. (2007). Social cognition in schizophrenia: relationships with neurocognition and negative symptoms. Schizophrenia Research, 90(1), 316-24.

Sharp, C., Pane, H., Ha, C., Venta, A., Patel, A.B., Sturek, J., et al. (2011). Theory of mind and emotion: regulation difficulties in adolescents with borderline traits. Journal of the American Academy of Child and Adolescent Psychiatry, 50(6), 563-574.

van der Gaag, M., Valmaggia, L.R., van Meer, C.R., \& Slooff, C.J. (2005). Gedachten uitpluizen: Vaardigheden oefenboek. Cognitieve gedragstherapie bij achterdocht en stemmen. Oegstgeest: Stichting Cognitie en Psychose.

van der Gaag, M., Nieman, D., \& Van den Berg, D. (2013). CBT for Those at Risk of a First Episode Psychosis: Evidence-based Psychotherapy for People with an 'at Risk Mental State. New York: Routledge.

Varese, F., Smeets, F., Drukker, M., Lieverse, R., Lataster, T., Viechtbauer, W., et al. (2012). Childhood adversities increase the risk of psychosis: a meta-analysis of patient-control, prospective- and cross-sectional cohort studies. Schizophrenia Bulletin, 38, 661-671. 
- Chapter Six

Westen, D. (1991). Clinical assessment of object relations using the TAT. Journal of Personality Assessment, 56, 56-74.

Wolthaus, J.E., Dingemans, P.M., \& Schene, A.H. (2000). Component structure of the Positive and Negative Syndrome Scale (PANSS) in patients with recent onset schizophrenia and spectrum disorders. Psychopharmacology, 150, 399-403.

Yee, L., Korner, A.J., McSwiggan, S., Meares, R.A., \& Stevenson, J. (2005). Persistent hallucinosis in borderline personality disorder. Comprehensive Psychiatry, 46(2), 147-154. 




\section{MENTALIZATION BASED TREATMENT FOR PSYCHOTIC DISORDER: A RATER-BLINDED, MULTI-CENTER, RANDOMIZED CONTROLLED TRIAL}

J. G. Weijers, C. ten Kate, W.V. Viechtbauer,

L.J.A. Rampaart, E.H.M. Eurelings-Bontekoe, J.-P. C.J. Selten
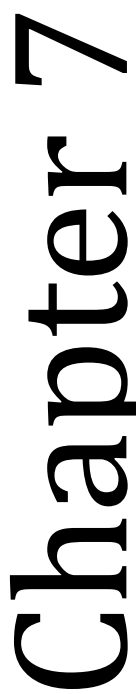
- Chapter Seven

\author{
Abstract \\ Background. Impaired mentalizing ability - an impaired ability to understand one's own and \\ other people's behavior in terms of mental states - is associated with social dysfunction in non- \\ affective psychotic disorder (NAPD). We tested whether adding Mentalization Based Treatment \\ for Psychotic disorder (MBTp) to treatment as usual (TAU) results in greater improvement in \\ social functioning.
}

Methods. Multicenter, rater-blinded, randomized controlled trial. Eighty-four patients with NAPD were assigned to TAU or MBTp plus TAU. Patients in the MBTp group received 18 months of MBTp, consisting of weekly group sessions and one individual session per two weeks. Social functioning was measured using the Social Functioning Scale. We conducted ANCOVAs to examine the difference between treatment conditions directly after treatment and at 6-month follow-up and performed moderation and mediation analyses.

Results. Intention-to-treat analyses showed no significant differences between groups posttreatment ( $p=.31$ ) but revealed the MBTp-group to be superior to TAU at follow-up ( $p=.03)$. Patients in the MBTp group also seemed to perform better on measures of mentalizing ability, although evidence of a mediation effect was limited $(p=.06)$. Lastly, MBTp treatment was less effective in chronic patients than in recent onset patients $(p=.049)$ and overall symptoms at baseline were mild, which may have reduced overall effectiveness of the intervention.

Conclusion. The results suggest that MBTp plus TAU may lead to more robust improvements in social functioning compared to TAU, especially for patients with a recent onset of psychosis.

\title{
Introduction
}

Non-affective psychotic disorder (NAPD) is often accompanied by a significant reduction in social functioning, the causes of which are still poorly understood. Impaired mentalizing, defined as the imaginative mental activity that lets us perceive and interpret human behavior in terms of intentional mental states (Bateman \& Fonagy, 2004) - is a potential candidate. Deficits in several dimensions of mentalizing have been widely observed in NAPD, such as an impaired ability to infer others' mental states, i.e. 'Theory of Mind' (Sprong et al., 2007; Bechi et al., 2020), and to identify and describe one's own and others' emotional states (O'Driscoll, Laing \& Mason, 2014;Trémeau, 2006; Kohler, Walker, Martin, Healy, Moberg, 2010). Next to mentalizing impairments (see Fett et al. 2011 for an overview), impaired metacognition, a construct largely overlapping with mentalization, has also been identified as a major contributor to social dysfunction (e.g., see Arnon-Ribenfeld 2017 for an overview; Gagen et al., 2019; Bröcker et al., 2020), particularly deficits in specific sub-components of meta-cognition such as empathic perspective taking and self-reflectivity (see Brüne, Lysaker and Dimaggio, 2011 for a review). 
Mentalization Based Treatment (MBT) is an evidence-based treatment for Borderline Personality Disorder (Bateman \& Fonagy, 1999), associated with a long-lasting decrease of depressive symptoms, suicidal and para-suicidal behavior, number of days hospitalized and improvements in social and interpersonal functioning. Interestingly, Bateman and Fonagy (2001; 2008) found that treatment effects had further increased both at 18 months and five years after treatment termination. Later studies also revealed that MBT can improve mentalizing (Rossouw et al. 2012; de Meulemeester et al., 2018). This has sparked interest in MBT as a treatment for NAPD (Brent \& Fonagy, 2014; Weijers et al., 2016; Weijers et al., 2020) and its prodromal states (Debbané et al., 2016).

The current study is a randomized, controlled trial examining whether patients who receive mentalization based treatment for psychotic disorder (MBTp) show a greater improvement in social functioning than patients who receive treatment as usual (TAU) only. If so, we hypothesized that the effect of MBTp on social functioning was at least partially mediated by mentalizing ability. Additionally, patients who receive MBTp were expected to fare better on the following outcomes: quality of life; positive, negative, anxious, and depressive symptoms; insight; drug use; psychotic experiences; negative and positive affect; social stress; and social stress reactivity (i.e., the affective and psychotic reaction to social stress).

\section{Methods}

A protocol for this study was registered prior to implementation of the study (Dutch Trial Register: Trial NL4588), approved by the Medical Ethics Committee of Maastricht University and published. The present paper provides essential information only. See the supplemental material and Weijers et al. (2016) for more details.

Participants and procedure. Clinicians of community treatment teams at two mental health care facilities in the Netherlands (GGZ Rivierduinen and Altrecht) scanned their caseloads for patients eligible to participate. Inclusion criteria were: at least 6 months, but no more than 10 years of treatment for NAPD; between 18 and 55 years of age. Exclusion criteria were: intellectual disability and/or illiteracy; insufficient knowledge of the Dutch language; addiction to such an extent that it necessitated inpatient detoxification.

Eligible patients $(n=162)$ received written information about the trial and were given at least seven days to decide whether to participate. After the baseline measurements, an independent research coordinator randomly assigned the patients to either the TAU condition or the TAU plus MBTp condition. The authors and patients were aware of treatment allocation, but the raters were blind to this. Before each measurement, patients were instructed not to reveal the treatment condition they were randomized to. If rater blindness still was broken, for example because the participant misspoke, the assessment was aborted and taken over by 
another investigator blind to the patient's treatment allocation. In three cases blindness was broken and measurements were taken over to a second research assistant who still was blind to treatment condition. All patients were diagnosed according to DSM-IV criteria (APA, 2000) by a psychiatrist prior to participation. This diagnosis was also verified by research assistants using the Comprehensive Assessment of Symptoms and History (CASH; Andreasen et al., 1982.)

Randomization, treatment allocation and rater blindness: Patients were assigned at random to TAU plus MBTp or TAU by an independent research coordinator. Randomization followed consent, enrollment and baseline assessment by the local research assistant. Using a coin toss, each time two patients were simultaneously randomized and allocated to treatment condition. The investigator informed patients of their assignment. As it was important that the research assistants who performed follow-up measurements remained blind to treatment allocation, they were not informed of the participants' allocation and participants were instructed not to reveal what condition they were allocated to. If rater blindness was broken, for example because a participant misspoke, the research assistant was instructed to stop the assessment. The entire assessment was then redone by a second research assistant.

\section{Therapy.}

Treatment as usual. Patients received treatment according to the Dutch multidisciplinary guideline for schizophrenia (van Alphen et al. 2012) and according to the so-called 'Flexible Assertive Community Treatment' (FACT) model. FACT-teams consist of nurses, psychologists, and psychiatrists.

MBTp. MBT consists of individual and group psychotherapy. MBT aims to improve mentalizing capacity, especially under stressful conditions and, by doing so, is expected to reduce psychopathology and improve functioning (Fonagy \& Bateman, 2006). The current study used the original treatment manual for BPD, with therapists focusing on affect, the establishment of a secure treatment relationship, balancing the complexity of mentalization interventions and stress, and adopting a 'not-knowing' therapeutic stance. The length of therapy - 18 months - remained unchanged, but the intensity of the original program was significantly reduced to a one-hour group session per week and a half-hour individual session once per two weeks. At the start of treatment, around four sessions were provided to educate patients about key aspects of mentalizing. The individual therapy sessions provided the opportunity to explore difficulties encountered during group sessions or in daily life based on five global areas: commitment to treatment, psychiatric symptoms, social interaction, destructive/avoidant behavior, and community functioning.

MBT therapists. Group sessions were given by two therapists, who were either psychiatrists $(n=3)$, psychologists $(n=2)$, or nurses $(n=3)$ with an average of five years of prior experience with MBT. The professionals who provided individual therapy were either 
psychologists $(n=1)$ or nurses $(n=11)$. All involved clinicians followed a two-day MBT-training program led by a certified MBT supervisor trainer in The Netherlands (CtK). To ensure treatment fidelity and adherence to the treatment manual, experienced and registered MBT supervisors provided weekly supervision. During supervision, interventions were discussed where possible using video-taped sessions - and reflected upon, particularly regarding their adherence to the MBT treatment model and their contribution to mentalizing. A registered MBT supervisor rated four randomly selected video-taped sessions, using the MBT adherence scale (Karterud et al., 2013), and found the therapist's competence and adherence to the MBT model to be 'good enough' (4), 'good' (5, n=2) and 'very good' (6). Note that in Karterud et al.'s (2013) scale an overall score is attributed to both adherence and competence. The score is a global assessment, not an arithmetic average.

Assessment. All outcomes mentioned below were obtained at three points in time: at baseline (T0), after 18 months, immediately post-treatment (T2), and at a 6-month follow-up (T3). Only the ESM questionnaires (see below) were also filled out at 9 months (T1).

Diagnosis. Table 1 shows the DSM-IV-TR diagnoses (APA, 2000) established by psychiatrists prior to participation. The researchers assessed all patients before participation using the Comprehensive Assessment of Symptoms and History (CASH; Andreasen et al. 1992), a diagnostic interview. Participants who had been given a diagnosis in the NAPD spectrum also had NAPD according to information derived from the CASH, although specific DSM-IV diagnoses could differ between clinicians and researchers, with an acceptable rate of agreement (Cohen's $\kappa=0.6)$.

\section{Primary outcome.}

Social functioning. Social functioning was measured using the Social Functioning Scale (SFS; Birchwood et al. 1990), an observer rated interview that measures seven dimensions of social functioning: social engagement, interpersonal behavior/communication, independencecompetence, independence-performance, recreational activities, pro-social activities, and employment/occupation. Subscale scores were averaged to create an overall social functioning score, with higher scores representing higher social functioning (possible range: 59.7 to 134.9). The SFS is often referred to as 'behaviorally anchored' because it uses concrete examples to rate social functioning (e.g., the number of friends or time spent alone) avoiding the need for normative judgment and evaluative decisions. The scale has been found to be reliable, responsive to change, and to have a good construct validity (Birchwood et al. 1990).

\section{Secondary outcomes.}

Mentalizing ability was assessed with the Thematic Apperception Test (TAT; Murray, 1938) and scored with the Social Cognition and Object Relations System (SCORS; Westen, 1991). 
Four dimensions of social cognition were scored: complexity of representations of people (i.e., the ability to distinguish between one's own and another's perspective), understanding of social causality (i.e., the ability to construct a logical and psychologically minded explanation of others' behavior), affect tone of relationships (i.e., the degree to which social interaction is viewed to be basically benign or malevolent), and capacity for emotional investment (i.e., the degree to which moral standards have been developed and others are treated as ends rather than means). Each dimension is scored on a five-point scale, with higher scores representing higher mentalizing ability.

Theory of mind was assessed using the Hinting Task (Corcoran et al. 1995), scored on a 20-point scale, with higher scores representing better theory of mind.

Positive symptoms / Negative symptoms / Depression / Anxiety / Lack of insight were measured using the Dutch translation (Wolthaus et al.2000) of the Positive and Negative Syndrome Scale (PANSS; Kay et al. 1987) on seven-point Likert scales. Subscales P and N each comprised the average of 7 items (see Weijers et al. 2016 for more details).

Quality of life was measured with the Manchester Short Assessment of Quality of Life (Priebe et al. 1999).

Experience sampling variables. Participants received a digital diary - the 'PsyMate' - to facilitate the sampling of experiences in daily life, i.e., the Experience Sampling Method (ESM). At T0, T1, T2, and T3, for six days, the Psymate beeped ten times a day at irregular intervals to prompt participants to fill out digital questionnaires. At each beep, patients rated how much positive affect (an average score of "happy", "satisfied", "cheerful", "relaxed", and "enthusiastic"), negative affect ("anxious", "lonely", "insecure", "irritated”, "down”, "guilty”, and "gloomy"), psychotic symptoms ('I feel suspicious', 'I am afraid of losing control', 'I feel that others don't like me', 'I feel that others want to hurt me', 'My thoughts are influenced by other people', 'I feel unreal', and 'I hear voices'), and social stress ("I would rather be alone" and "I like the present company" (reverse coded)) they experienced. All items were rated on 7-point Likert scales. In order to measure drug use, at each beep patients were asked whether they had used cannabis or other drugs since the last beep, coded 0 or 1 (for any drug use).

\section{Moderators.}

Personality organization and somatization of psychopathology. Assessment of personality organization and the tendency to somatize severe psychopathology was measured using theory driven analysis (Eurelings-Bontekoe et al., 2012) of the results on the Dutch short Form of the MMPI (DSFM; Luteijn \& Kok, 1985). Four levels of Personality Organization (PO) are distinguished: Neurotic, Borderline, Narcissistic, and Psychotic.

The DSFM Somatization subscale measures the ability to be aware of and to report bodily sensations, while the Psychopathology subscale measures the degree of severe 
psychopathology. Favorable affect regulation through somatization will be expressed as the relative position of scores on the subscale somatization to that on the psychopathology subscale (Eurelings-Bontekoe \& Koelen, 2007).

Childhood trauma. The Childhood Experience of Care and Abuse (CECA; Bifulco et al.1994) is a semi-structured interview that aims to assess details and the time-sequence of traumatic childhood experiences. It assesses lack of care (neglect, antipathy), physical abuse, sexual abuse, and psychological abuse.

Adherence to pharmacological treatment. Adherence to the prescribed medication was measured with the Medication Adherence Questionnaire (MAQ; Morisky et al. 1986).

Duration of illness. This was defined and measured based on the number of years since the onset of the first psychotic episode.

\section{Statistical analyses.}

Main analyses. First, repeated measures analyses on the basis of the intention-to-treat principle - with social functioning at T0 and either T2 or T3 - were used to determine change over time in social functioning for both the TAU and MBTp groups. Second, for all primary and secondary outcomes, ANCOVAs - with treatment condition as between-subjects variable, and the performance on the variables at either $\mathrm{T} 2$ or $\mathrm{T} 3$ as dependent variables - were used, adjusted for baseline levels. According to the European Medicines Agency guidelines (2017), dividing outcomes into primary and secondary outcomes is a way to control the Type I error rate. However, in this way, secondary outcomes can only be considered as indications - not evidence - of potential treatment effects.

Handling of missing data. The analyses of the primary and secondary outcomes were carried out with imputed data, allowing for the use of a proper 'intention-to-treat' analysis. Missing data were handled by multiple imputation (Schafer, 1999) using independent variables that were likely to predict drop-out: a lack of insight, positive symptoms, age, gender, a history of drug abuse, unemployment, treatment allocation, and poor social functioning at T0 (see Nose et al. 2003 for an overview). For each analysis, 5 imputed datasets were created using a fully conditional Markov chain Monte Carlo (MCMC) approach. Results from analyses conducted with the imputed datasets were combined using Rubin's rules.

Mediation analyses. To test whether the effect of treatment condition on social functioning was mediated by mentalizing ability, we conducted mediation analyses with any of the scales of the SCORS or the hinting task as mediators, provided they were significantly affected by treatment condition. SPSS version 22 combined with Hayes's PROCESS macro (Preacher \& Hayes, 2004) was used for the mediation analyses. The process macro uses nonparametric bootstrapping, which involves random resampling of observations with replacement to obtain confidence intervals for the indirect effect (and functions thereof). The bootstrap 
confidence intervals were based on 5000 resamples. Mediation effects are considered significant if the confidence interval does not contain 0 . All mediation analyses included treatment condition as independent variable, social functioning at either T2 or T3 as dependent variables, mentalization at $\mathrm{T} 2$ or $\mathrm{T} 3$ as a mediator and baseline social functioning as a covariate.

Moderation analyses. As described in Weijers et al. (2016), we also sought to examine potential modifiers of the treatment effect, including: severity of childhood trauma, type of personality organization (PO), the degree of somatization of psychopathology, adherence to pharmacological treatment, total number of hours of attended MBTp sessions, and duration of illness. Moderation analyses included treatment condition as independent variable, the moderator and its interaction with treatment condition as independent variables, social functioning at T0 as covariate, and social functioning at T2 or T3 as dependent variable. Since PO is a categorical variable, it was dummy-coded creating four new dichotomous variables (for neurotic, borderline, psychotic, and narcissistic PO). Additionally, since social functioning deteriorates most in the first 5 years after onset of illness (Birchwood \& Macmillan, 1993) and the first five years of NAPD are considered a crucial period for intervention (Birchwood \& Macmillan, 1993; McGorry et al. 2010), duration of illness was dichotomized (<= 5 years or $>5$ years). Somatization of psychopathology is a dichotomous score representing an either favorable (relatively high degree of somatization with high psychopathology) or unfavorable personality characteristic (relatively low somatization with high degree of psychopathology).

Multilevel analyses. The hierarchically structured measurements collected with ESM necessitate a multilevel analysis, because there are multiple measurements per day, for up to six days for each patient. In particular, for each subject, up to 60 measurements were available for each outcome of interest at each time point and hence up to 240 measurements overall. All available measurements were included in these analyses. However, as in previous ESM studies (e.g., Snippe et al. 2017), participants were included in these analyses only if they had filled out at least 20 questionnaires at baseline. We used the same criterion for follow-up measurements. Differences in changes between treatment conditions over time (i.e., across the different measurement periods) regarding social stress, psychotic experiences, negative affect, and positive affect were analyzed using mixed-effects regression models. Differences in changes between treatment conditions over time regarding illicit drug use were analyzed using a binomial logistic mixed-effects regression model. The models included treatment condition, time (coded as 0 to 3 for $\mathrm{T} 0$ through T3, respectively), and their interaction term as predictors, with either psychotic experiences, social stress, negative affect, positive affect, or drug use as dependent variables and random intercepts and random slopes for time at the subject level. Interest was focused on the condition $\mathrm{x}$ time interaction (i.e., Did the outcome of interest change differentially for the two groups over the course of the four measurement occasions?). 
Reactivity to social stress was conceptualized as the association between social stress (predictor) and negative affect, positive affect, or psychotic experiences (outcomes). Analyses of treatment effect on stress reactivity included treatment condition, time, social stress, and their two- and three-way interaction terms as predictors, with either psychotic experiences, negative affect, or positive affect as dependent variables. These models included random intercepts and random slopes for time and social stress at the subject level. Here, we were specifically interested in the three-way interaction (i.e., Did the association between an outcome of interest and social stress change differentially for the two groups over the course of the four measurement occasions?).

Comparison of medication type and dosage. To compare medication type, all medication was classified as either first generation antipsychotic (coded 1), second generation antipsychotic (coded 2) or clozapine (coded 3). Multinomial regression analyses were conducted with treatment condition as independent variable and medication type at T0, T2 or T3 as dependent variables. Dosages were compared by first calculating dose equivalents with Chlorpromazine (100 mg) as a baseline comparator, according to the guidelines of Andreasen et al. (2010). Then, for each measurement period (T0, T2, T3) AN(C)OVAs were conducted with dose equivalent as dependent variable and treatment condition as independent variable. In the analyses regarding $\mathrm{T} 2$ and $\mathrm{T} 3$, dose equivalent at $\mathrm{T} 0$ was added as a covariate.

\section{Results}

Demographics and patient characteristics. Written informed consent was obtained from 90 participants. Two participants failed to complete the baseline measurement, one patient dropped out before randomization and did not want his data stored. Three other patients were excluded during the trial: two participants were diagnosed with substance use disorders during the trial and were unwilling to enter inpatient detoxification programs, and one patient turned out to be too old (57 years). They were excluded from the study. Consequently, intention-to-treat analyses were conducted with 84 patients.

There were no significant differences between groups on any of the demographic variables or baseline measurements, except for anxiety and depression ( $p=.049$ for both), which were higher in the MBTp group. See Table 2. In the MBTp group a total of 21 patients had received Cognitive Behavioral Therapy (CBT) at some point before the trial, opposed to 23 patients in the TAU group. One patient in the MBTp group received CBT during the trial, as opposed to seven participants in the TAU group. There were no significant differences between groups in antipsychotic medication adherence (all $p$ 's >.31), type (all $p$ 's $>.27$ ) or dosage (all $p$ 's $>$.25) at either T0, T2 or T3. 
- Chapter Seven

Table 1. Demographics and clinical characteristics of patients at baseline participating in a randomized trial to test the effectiveness of mentalization-based treatment for psychotic disorder.

\begin{tabular}{|c|c|c|c|c|c|}
\hline Variable & TAU, mean (SD) & $\mathbf{N}$ & MBT-P, mean (SD) & $\mathbf{N}$ & $p^{*}$ \\
\hline Age in years & $31.88(9.43)$ & 42 & $31.21(7.80)$ & 42 & .73 \\
\hline Age of onset & $26.71(9.11)$ & 42 & $25.76(7.51)$ & 42 & .60 \\
\hline Duration of illness & $5.17(3.32)$ & 42 & $5.45(3.54)$ & 42 & .70 \\
\hline Gender & & & & & .12 \\
\hline Male, \# & & 30 & & 23 & \\
\hline Female, \# & & 12 & & 19 & \\
\hline Diagnosis (DSM-IV-TR) & & & & & .76 \\
\hline Schizophrenia & & 28 & & 26 & \\
\hline Schizoaffective disorder & & 4 & & 7 & \\
\hline Psychotic disorder N.O.S. & & 6 & & 7 & \\
\hline Brief Psychotic Disorder & & 2 & & 2 & \\
\hline Delusional Disorder & & 2 & & 0 & \\
\hline Personality Organization & & & & & .65 \\
\hline Neurotic & & 4 & & 2 & \\
\hline Borderline & & 25 & & 28 & \\
\hline Narcissistic & & 10 & & 6 & \\
\hline Psychotic & & 3 & & 5 & \\
\hline
\end{tabular}

* Based on independent samples t-tests for continuous variables and chi-square tests for categorical ones.

Drop-out and non-compliance. See Figure 1. Patients in the MBTp condition followed an average of 29.9 group sessions (range: $0-68$ ) and an average of 8.6 hours of individual therapy (range: 0-20). 


\section{CONSORT 2010 Flow Diagram}

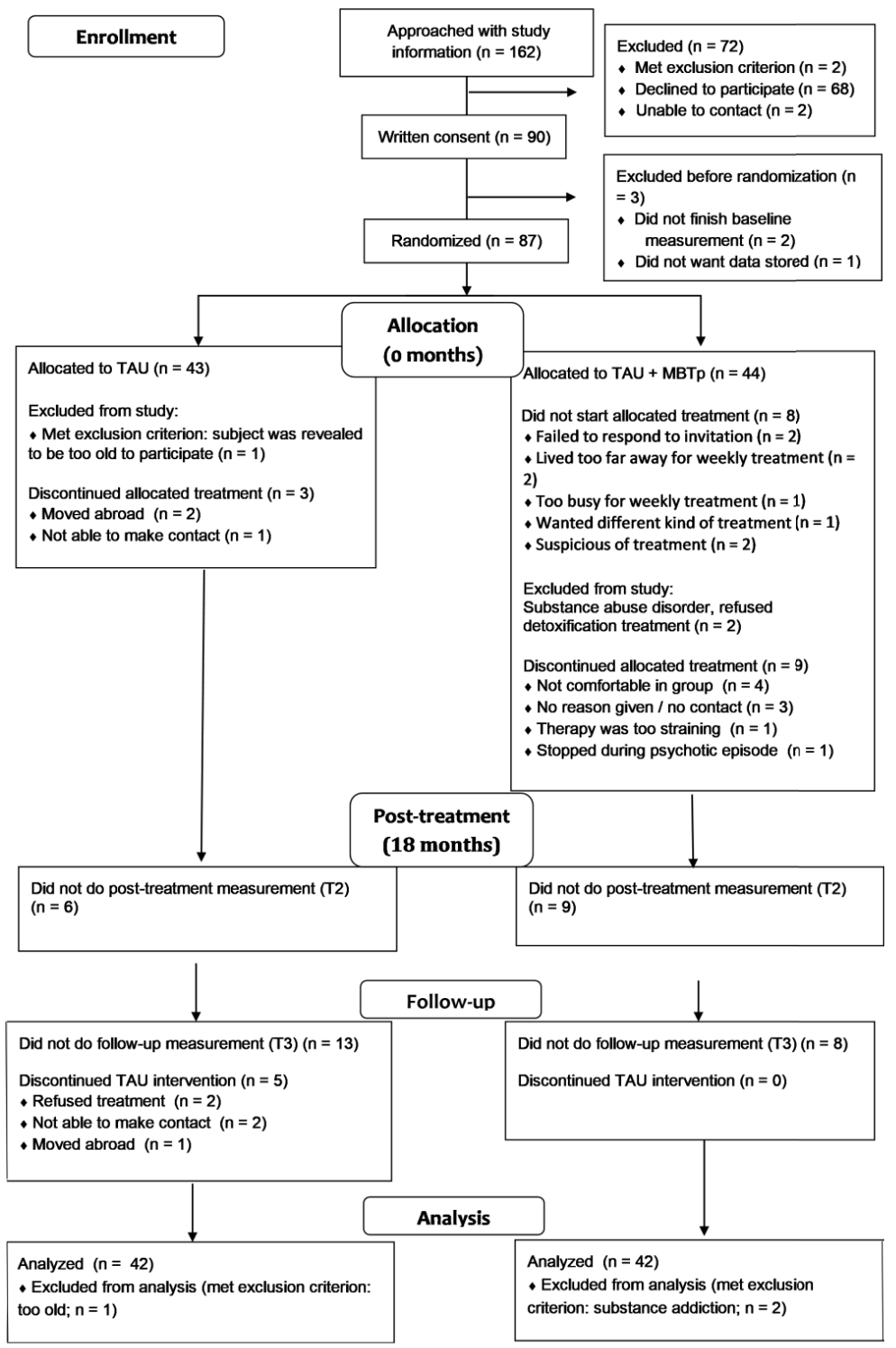

Figure 1. Diagram of participant flow.

Safety. Following the regulations of the Medical-Ethics Committee of Maastricht University, serious adverse events such as hospitalization were registered. Among those patients allocated to MBTp, six patients were hospitalized due to exacerbations of symptoms. Of 
- Chapter Seven

those only one was actively following MBTp at the time of hospitalization. From the TAU group, a total of seven patients were hospitalized.

\section{Main Analyses.}

Primary outcome. Repeated measures analyses on the basis of the intention-to-treat principle with imputed data revealed that patients in both the MBTp group $\left(F(1,41)=21.52, \eta_{\mathrm{p}}^{2}\right.$ $\left.=.34, p_{\text {pooled }}<.001\right)$ and in the TAU group showed significant improvements in social functioning at T2 $\left(F(1,41)=7.47, \eta_{\mathrm{p}}^{2}=.15, p_{\text {pooled }}=.01\right)$. Based on the benchmarks established by Cohen $(1988 ; .01=$ small; $.06=$ moderate, $.14=$ large $)$, these effects can be considered large. At T3, however, the effect in the TAU group was no longer significant $\left(F(1,41)=2.25, \eta_{\mathrm{p}}^{2}=.05, p_{\text {pooled }}=\right.$ .14), while the MBTp group continued to show a large effect $\left(F(1,41)=20.99, \eta_{\mathrm{p}}^{2}=.34, p_{\text {pooled }}<\right.$ .001). ANCOVAs on the basis of the intention-to-treat principle with imputed data revealed that the improvement in the MBTp group was not significantly greater than in the TAU group at T2 $\left(t(80)=1.01, \eta_{\mathrm{p}}^{2}=.03, p_{\text {pooled }}=.32\right)$, but was significantly greater at $\mathrm{T} 3\left(t(80)=2.17, \eta_{\mathrm{p}}^{2}=.06\right.$, $p_{\text {pooled }}=.03$ ).

Secondary outcomes. Please see Table 2 for treatment effects on the secondary outcome variables. 
Table 2. Results of the intention-to-treat ANCOVAs* comparing the effectiveness of mentalization-based treatment for psychotic disorder (MBT-p) with treatment as usual (TAU).

\begin{tabular}{|c|c|c|c|c|c|c|c|}
\hline Outcome variable & TAU & $\mathbf{N}$ & MBT-p & $\mathbf{N}$ & $\boldsymbol{F}$ & $\eta_{p}^{2}$ & $\boldsymbol{p}$ \\
\hline \multicolumn{8}{|l|}{ Social Functioning } \\
\hline Baseline (T0) & $110.01(7.09)$ & 42 & $108.41(7.94)$ & 42 & 0.96 & .01 & .33 \\
\hline Post-treatment (T2) & $112.10(7.34)$ & 42 & 112.54 (7.28) & 42 & 1.01 & .03 & .31 \\
\hline Follow-up (T3) & $111.44(6.97)$ & 42 & $113.95(6.86)$ & 42 & 2.17 & .06 & .03 \\
\hline \multicolumn{8}{|l|}{ Positive symptoms } \\
\hline Baseline (T0) & $10.86(4.36)$ & 42 & $12.26(4.39)$ & 42 & 2.17 & .03 & .14 \\
\hline Post-treatment (T2) & $11.23(4.56)$ & 42 & $11.20(3.90)$ & 42 & 1.40 & .02 & .29 \\
\hline Follow-up (T3) & $11.73(4.41)$ & 42 & $10.94(3.55)$ & 42 & 4.61 & .05 & .07 \\
\hline \multicolumn{8}{|l|}{ Negative symptoms } \\
\hline Baseline (T0) & $11.67(5.24)$ & 42 & $12.45(6.13)$ & 42 & 0.40 & .005 & .53 \\
\hline Post-treatment (T2) & $11.55(4.11)$ & 42 & $11.40(4.87)$ & 42 & 0.30 & .004 & .69 \\
\hline Follow-up (T3) & $11.29(3.70)$ & 42 & $10.97(4.97)$ & 42 & 0.41 & .005 & .60 \\
\hline \multicolumn{8}{|l|}{ Anxiety } \\
\hline Baseline (T0) & $2.00(1.21)$ & 42 & $2.60(1.50)$ & 42 & 4.01 & .05 & .049 \\
\hline Post-treatment (T2) & $2.45(1.24)$ & 42 & $2.88(1.31)$ & 42 & 1.88 & .02 & .50 \\
\hline Follow-up (T3) & $2.43(1.25)$ & 42 & $2.27(1.07)$ & 42 & 1.13 & .01 & .41 \\
\hline \multicolumn{8}{|l|}{ Depression } \\
\hline Baseline (T0) & $1.90(1.34)$ & 42 & $2.50(1.31)$ & 42 & 4.23 & .05 & .049 \\
\hline Post-treatment (T2) & $1.87(1.10)$ & 42 & $2.43(1.31)$ & 42 & 1.84 & .02 & .19 \\
\hline Follow-up (T3) & $2.06(1.29)$ & 42 & $1.99(1.16)$ & 42 & 0.91 & .01 & .39 \\
\hline \multicolumn{8}{|l|}{ Lack of insight } \\
\hline Baseline (T0) & $1.62(1.27)$ & 42 & $1.67(1.14)$ & 42 & 0.03 & $>.001$ & .86 \\
\hline Post-treatment (T2) & $1.91(1.20)$ & 42 & $1.41(0.71)$ & 42 & 6.62 & .08 & .03 \\
\hline Follow-up (T3) & $1.91(0.94)$ & 42 & $1.50(1.10)$ & 42 & 5.32 & .06 & .03 \\
\hline \multicolumn{8}{|l|}{ Theory of mind } \\
\hline Baseline (T0) & $16.50(2.67)$ & 42 & $17.52(2.42)$ & 42 & 3.39 & .40 & .07 \\
\hline Post-treatment (T2) & $17.78(1.78)$ & 42 & $18.87(1.30)$ & 42 & 7.49 & .08 & .02 \\
\hline Follow-up (T3) & $17.70(2.09)$ & 42 & $18.90(1.52)$ & 42 & 7.38 & .08 & .02 \\
\hline \multicolumn{8}{|l|}{ Complexity } \\
\hline Baseline (T0) & $11.74(1.61)$ & 42 & $12.19(1.15)$ & 42 & 2.19 & .03 & .14 \\
\hline Post-treatment (T2) & $11.61(0.92)$ & 42 & $11.99(1.03)$ & 42 & 2.90 & .03 & .14 \\
\hline Follow-up (T3) & $11.47(0.97)$ & 42 & $12.25(1.40)$ & 42 & 9.16 & .10 & .03 \\
\hline \multicolumn{8}{|l|}{ Understanding Social } \\
\hline \multicolumn{8}{|l|}{ Causality } \\
\hline Baseline (T0) & $11.57(2.00)$ & 42 & $12.12(2.23)$ & 42 & 1.40 & .02 & .24 \\
\hline Post-treatment (T2) & $10.36(1.82)$ & 42 & $11.68(1.85)$ & 42 & 10.00 & .11 & .006 \\
\hline Follow-up (T3) & $10.66(1.86)$ & 42 & $12.71(2.44)$ & 42 & 17.85 & .18 & $>.001$ \\
\hline \multicolumn{8}{|l|}{ Affect-tone } \\
\hline Baseline (T0) & $18.60(2.13)$ & 42 & $18.00(2.44)$ & 42 & 1.42 & .02 & .24 \\
\hline Post-treatment (T2) & $18.73(2.79)$ & 42 & $18.88(3.58)$ & 42 & 0.87 & .01 & .58 \\
\hline Follow-up (T3) & $19.38(2.55)$ & 42 & $20.15(2.94)$ & 42 & 2.43 & .03 & .14 \\
\hline \multicolumn{8}{|l|}{ Emotional Investment } \\
\hline Baseline (T0) & $10.98(2.96)$ & 42 & $10.64(2.83)$ & 42 & 0.28 & .003 & .60 \\
\hline Post-treatment (T2) & $8.72(2.85)$ & 42 & $9.42(3.05)$ & 42 & 2.30 & .03 & .29 \\
\hline Follow-up (T3) & $8.63(2.01)$ & 42 & $9.50(2.24)$ & 42 & 3.95 & .05 & .06 \\
\hline \multicolumn{8}{|l|}{ Quality of Life } \\
\hline Baseline (T0) & $3.51(0.59)$ & 42 & $3.59(0.56)$ & 42 & 0.46 & .006 & .50 \\
\hline Post-treatment (T2) & $3.78(0.62)$ & 42 & $3.69(0.56)$ & 42 & 0.35 & .019 & .37 \\
\hline Follow-up (T3) & $3.80(0.48)$ & 42 & $3.84(0.54)$ & 42 & 0.20 & $>.001$ & .55 \\
\hline
\end{tabular}

*Post-treatment and follow-up analyses were adjusted for baseline performance. 
Mediation analyses. Only regarding the follow-up measurement (T3) did treatment condition have a significant effect on social functioning. Additionally, treatment condition only had a significant effect on understanding of social causality and on theory of mind. Mediation analyses were therefore only conducted for these two mediators and only at T3. Bootstrapped mediation analyses in turn revealed that social functioning at T3 was significantly predicted by theory of mind $\left(b=0.79, p_{\text {pooled }}=.04\right)$, but not by understanding of social causality $(b=0.39$, $p_{\text {pooled }}=.25$ ). Lastly, while accounting for theory of mind, the effect of treatment condition on social functioning became nonsignificant ( $b=1.51, p_{\text {pooled }}=.27$ ), suggesting the presence of mediation. However, the confidence interval of the mediation effect contained 0 (95\% CI [$0.002,0.33])$.

Moderation analyses. Moderation analyses did not reveal moderation effects of medication adherence, total hours of MBTp attendance, personality organization, somatization, or childhood trauma on treatment effect at T2 or T3 (all $p$ 's > .07). However, duration of illness significantly moderated the treatment effect on social functioning at $\mathrm{T} 3(\Delta F(1,58)=4.05, p=$ $.049, \Delta R 2=.05)$, but not at T2 ( $p=.38)$. Relatively recent onset patients ( $<=5$ years) in the MBTp group showed significantly higher levels of social functioning $\left(F(1,33)=10.50, \eta_{\mathrm{p}}^{2}=.17, p\right.$ $=.02)$ at $\mathrm{T} 3(M=116.58, S D=7.17)$ than the more chronic patients ( $>5$ years) in the MBTp condition $(M=109.95, S D=6.04)$ and the relatively recent onset patients in the TAU group $(M=$ $\left.111.40, S D=6.71 ; F(1,34)=6.48, \eta_{\mathrm{p}}^{2}=.17, p=.02\right)$.

Multilevel analysis. For social stress, treatment condition interacted significantly with the time variable, with patients in the MBTp condition showing a greater decrease in reported social stress over the course of four time points ( $b=-0.32,95 \%$ CI $[-0.58,-0.059], p=.02$ ). Further analyses showed no significant differences in change over time on psychotic experiences, negative affect, positive affect, or illicit drug use between treatment conditions (all $p$ 's $>.06$ ). The interaction term of treatment condition, time, and social stress was not a significant predictor for psychotic experiences, negative affect, or positive affect (all $p$ 's > .12), meaning that there were no differences in how social stress reactivity changed over time between the two treatment conditions.

\section{Discussion}

Main findings. The current trial tested whether adding MBTp to TAU resulted in greater improvement in social functioning than TAU alone. Intention-to-treat analyses revealed that patients in both the TAU and MBTp conditions showed large, significant improvements on social functioning post-treatment. There was no significant difference between MBTp and TAU at this point in time. However, the improvements were more robust in the MBTp group and superior to TAU, remaining significant at a 6-month follow-up. Additionally, evidence suggests that duration 
of illness moderated the treatment effect at follow-up, implying that results may be especially robust in patients with a relatively recent onset of illness.

Interpretation and comparison to previous findings. It may not come as a surprise that patients who received TAU, provided according to the FACT-model, showed improvement in social functioning post-treatment, since FACT-teams include several professionals specialized in helping patients to structure their social lives. This also corroborates earlier findings (Drukker et al. 2013). The addition of individual placement and support - an evidence-based intervention that consists of targeted support in employment or education - may have further contributed to social functioning (Hoffman et al. 2012; Pos et al. 2019). Still, functional recovery appeared to be more robust in the MBTp group, which may be attributed to the 'sleeper effect' observed in previous studies concerning the long-term effects of MBT. Bateman and Fonagy (2001) argued that improved mentalizing enabled patients to better cope with the stresses of everyday life in the long run.

However, the lack of difference between the conditions post-treatment and the significant difference at follow-up may also have different origins. First, more patients in the TAU group ( $n=7$ ) received CBT between the pre- and post-treatment measurement as opposed to the MBTp group $(n=1)$. None received CBT in the follow-up period. As CBT has been show to produce a significant but non-robust effect on social functioning (Laws et al. 2018), CBT may therefore have made a contribution to the overall gain in social functioning in the TAU group between pre- and post-treatment which did not last after six months. Second, more participants in the TAU-group ( $n=5)$ than in the MBTp group $(n=0)$, discontinued FACT during the follow-up period which may have further reduced functional gains at follow-up.

Interestingly, while the evidence for MBT's proposed mechanism of change - the improvement of mentalizing ability - is still scarce (Rossouw et al. 2012), the current results suggest that patients in the MBTp group did perform better on several measures of mentalizing ability, including theory of mind, understanding of social causality, and complexity of representations. They also showed an increase in insight. However, mediation analyses offered only limited evidence that an improvement of mentalization drove this treatment effect.

Furthermore, no treatment effects were observed on the clinical symptoms of NAPD. Comparison to previous studies revealed that our sample suffered from relatively mild symptoms, which may account for the lack of observed treatment effects. Scores for clinical symptoms at baseline were similar to those for remitted patients (Češková et al. 2005; Phahladira et al. 2018). These baseline scores likely reflect a recruitment bias. During the selection procedure, treatment staff members were asked to scan their caseloads for patients who were eligible for participation. Given that only about $20 \%$ of available patients were 
referred to the intake of the trial, it is possible that staff members approached the more stable patients.

Additionally, the observed effects of MBTp on social functioning appear to be greatest in the subgroup of relatively recent onset patients. Recent patients in the MBTp group showed relatively large improvements, achieving levels of functioning $(M=116.58)$ that are between those of NAPD patients $(M=108.07)$ and healthy controls $(M=123.36)$, as established by Addington and Addington (2008). These results are in line with a growing body of literature suggesting that long duration of illness is a predictor of poor treatment response (Lieberman $e t$ al. 2013; Lincoln et al. 2014) and that the first five years of NAPD constitute a crucial period for intervention (Birchwood \& Macmillan, 1993; McGorry et al. 2010). NAPD tends to involve a multitude of problems that may complicate therapy as the disorder progresses, including cognitive decline (Wykes et al. 2011) and greater difficulty challenging long held beliefs (Lincoln et al. 2014). Consequently, the choice to include patients that had received treatment for up to ten years before enrollment in the current study may have limited the overall effect of MBTp, which may be most effectively implemented in the early stages of the disorder (Debbané et al. 2016).

Strength and limitations. The current study used a rigorous research design: randomization, taking into account baseline performance, and the use of blinded raters. Additionally, it is the first study to examine the effectiveness of MBT in NAPD and it is one of the few studies to examine whether MBT improves mentalizing ability (see Rossouw \& Fonagy, 2012, for another example). Lastly, intensive supervision was provided to ensure that professionals adhered to the MBT model.

Naturally, several limitations apply. First, the two treatment conditions cannot be deemed equal, making it difficult to determine whether observed differences were actually caused by the interventions themselves. Participants in the MBTp group received group therapy. On the other hand, participants in the TAU group received more CBT between the baseline and posttreatment measurements. Second, with a drop-out rate of around $20 \%$, the results of our study should be treated with caution. Third, the moderation analyses were likely underpowered. Fourth, except for the 'complexity of representations' dimension, we chiefly measured other-oriented, cognitive forms of mentalizing. Fifth, we are precluded from drawing conclusions about the secondary outcomes. These should be treated as indications of treatment effect. Sixth, many patients found it difficult to attend weekly sessions. This may have reduced the effectiveness of the intervention. Consequently, we think that future efforts should not be aimed at increasing the frequency of sessions, but perhaps at lengthening the duration of the treatment-period, as some patients were disappointed that they had to stop after 18 months. Seventh, the Hinting Task has been criticized for a ceiling effect, especially in high functioning 
patients (e.g., Roberts \& Penn, 2009), meaning that the pertinent results should be interpreted with caution.

\section{Conclusion}

The results of this study suggest that MBTp may lead to more robust changes in social functioning than TAU alone.

\section{Acknowledgements}

None.

\section{Financial support}

This research received no specific grant from any funding agency, commercial or not-for-profit sectors.

\section{Conflict of interest}

None.

\section{Ethical standards}

The authors assert that all procedures contributing to this work comply with the ethical standards of the relevant national and institutional committees on human experimentation and with the Helsinki Declaration of 1975, as revised in 2008.

\section{References}

Addington, J., Addington, D. (2008). Social and cognitive functioning in psychosis. Schizophrenia research, 99(1-3), 176-181.

American Psychiatric Association. (2000). Diagnostic and statistical manual of mental disorders (4th ed., Text Revision). Washington, DC: Author.

Andreasen, N.C., Flaum, M., \& Arndt S. (1992). The Comprehensive Assessment of Symptoms and History (CASH): An instrument for assessing diagnosis and psychopathology. Archives of General Psychiatry, 49(8), 615-623.

Andreasen, N.C., Pressler, M., Nopoulos, P., Miller, D., Ho, B.C. (2010). Antipsychotic dose equivalents and dose-years: a standardized method for comparing exposure to different drugs. Biological psychiatry, 67(3), 255-262.

Arnon-Ribenfeld, N., Hasson-Ohayon, I., Lavidor, M., Atzil-Slonim, D., Lysaker, P.H. (2017). The association between metacognitive abilities and outcome measures among people with schizophrenia: A meta-analysis. European Psychiatry, 46, 33-41. 
- Chapter Seven

Bateman, A.W., \& Fonagy, P. (1999). Effectiveness of partial hospitalization in the treatment of borderline personality disorder: A randomized controlled trial. American Journal of Psychiatry, 156(10), 1563-1569.

Bateman, A.W., \& Fonagy, P. (2001). Treatment of borderline personality disorder with psychoanalytically oriented partial hospitalization: An 18-month follow-up. American Journal of Psychiatry, 158(1), 36-42.

Bateman, A.W., \& Fonagy, P. (2004). Mentalization-based treatment of BPD. Journal of Personality Disorders, 18(1), 36-51.

Bateman, A.W., \& Fonagy, P. (2008). 8-year follow-up of patients treated for borderline personality disorder: Mentalization-based treatment versus treatment as usual. American Journal of Psychiatry, 165(5), 631-638.

Bechi, M., Bosia, M., Buonocore, M., Agostoni, G., Bosinelli, F., Silvestri, M.P., ... Cavallaro, R. (2019). Stability and generalization of combined theory of mind and cognitive remediation interventions in schizophrenia: Follow-up results. Psychiatric rehabilitation journal.

Bifulco, A., Brown, G.W., \& Harris, T.O. (1994). Childhood Experience of Care and Abuse (CECA): A retrospective interview measure. Journal of Childhood Psychology and Psychiatry, 35, 1419-35.

Birchwood, M., Smith, J.O., Cochrane, R., Wetton, S., \& Copestake, SONJA. (1990). The Social Functioning Scale: The development and validation of a new scale of social adjustment for use in family intervention programmes with schizophrenic patients. The British Journal of Psychiatry, 157(6), 853-859.

Birchwood, M., \& Macmillan, F. (1993). Early intervention in schizophrenia. Australian and New Zealand Journal of Psychiatry, 27(3), 374-378.

Brent, B.K., \& Fonagy, P. (2014). A mentalization-based treatment approach to disturbances of social understanding in schizophrenia. In Social cognition and metacognition in schizophrenia: Psychopathology and treatment approaches (Ed. P. H. Lysaker, G. Dimaggio, \& M. Brüne), pp. 245-259. San Diego: Elsevier Academic Press

Bröcker, A.L., Bayer, S., Stuke, F., Just, S., Bertram, G., Funcke, J., ... \& Montag, C. (2020). Levels of structural integration mediate the impact of metacognition on functioning in nonaffective psychosis: Adding a psychodynamic perspective to the metacognitive approach. Frontiers in Psychology, 11, 269.

Brüne, M., Dimaggio, G., Lysaker, P. (2011). Metacognition and social functioning in schizophrenia: Evidence, mechanisms of influence and treatment implications. Current Psychiatry Reviews, 7(3), 239-247. 
Češková, E., Přikryl, R., Kašpárek, T., \& Ondrušova, M. (2005). Psychopathology and treatment responsiveness of patients with first-episode schizophrenia. Neuropsychiatric Disease and Treatment, 1(2), 179.

Cohen, J. (1988). The effect size index: d. In: Statistical Power Analysis for the Behavioral Sciences (2nd ed.), pp. 284-288. Hillsdale: Lawrence Erlbaum Associates, Publishers.

Corcoran, R., Mercer, G., \& Frith, C.D. (1995). Schizophrenia, symptomatology and social inference: Investigating "theory of mind" in people with schizophrenia. Schizophrenia Research, 17(1), 5-13.

Debbané, M., Salaminios, G., Luyten, P., Badoud, D., Armando, M., Solida Tozzi, A. ..., \& Brent, B.K. (2016). Attachment, neurobiology, and mentalizing along the psychosis continuum. Frontiers in Human Neuroscience, 10, 406.

de Meulemeester, C., Van Steelandt, K., Luyten, P., Lowyck, B. (2018). Mentalizing as a mechanism of change in the treatment of patients with borderline personality disorder: A parallel process growth modeling approach. Personality Disorders: Theory, Research, and Treatment, 9(1), 22.

Drukker, M., Visser, E., Sytema, S., Van Os, J. (2013). Flexible assertive community treatment: Severity of symptoms and psychiatric health service use; a real life observational study. Clinical Practice \& Epidemiology in Mental Health, 9, 202-209.

Eurelings-Bontekoe, E.H., Peen, J., Noteboom, A., Alkema, M., \& Dekker, J. (2012). Differential treatment response of subtypes of patients with borderline personality organization, as assessed with theory-driven profiles of the Dutch short form of the MMPI: A naturalistic follow-up study. Journal of Personality Assessment, 94(4), 380-92.

Eurelings-Bontekoe, E.H.M., \& Koelen, J.A. (2007). De Somatisatie-Ernstige Psychopathologie combinatie binnen de theoriegestuurde profielinterpretatie van de NVM: Somatisatie als affectregulator en maat voor sociale (in)competentie. Tijdschrift Klinische Psychologie, 37(2), 107-22.

European medicines agency (2017). Guideline on multiplicity issues in clinical trials. Retrieved from https://www.ema.europa.eu/en/multiplicity-issues-clinical-trials, accessed June 102019.

Fett, A.K.J., Viechtbauer, W., Penn, D.L., van Os, J., \& Krabbendam, L. (2011). The relationship between neurocognition and social cognition with functional outcomes in schizophrenia: A meta-analysis. Neuroscience \& Biobehavioral Reviews, 35(3), 573-588.

Fonagy, P., \& Bateman, A.W. (2006). Mechanisms of change in mentalization based treatment of BPD. Journal of Clinical Psychology, 62(4), 411-430. 
- Chapter Seven

Gagen, E. C., Zalzala, A. B., Hochheiser, J., Martin, A. S., \& Lysaker, P. H. (2019). Metacognitive deficits and social functioning in schizophrenia across symptom profiles: A latent class analysis. Journal of Experimental Psychopathology, 10(1), 1-11.

Hoffmann, H., Jäckel, D., Glauser, S., Kupper, Z. (2012). A randomised controlled trial of the efficacy of supported employment. Acta Psychiatrica Scandinavica, 125(2), 157-167.

Karterud, S., Pedersen, G., Engen, M., Johansen, M.S., Johansson, P.N., Schlüter, C., et al. (2013). The MBT Adherence and Competence Scale (MBT-ACS): development, structure and reliability. Psychotherapy Research, 23(6), 705-717.

Kay, S.R., Fiszbein, A., \& Opfer, L.A. (1987). The positive and negative syndrome scale (PANSS) for schizophrenia. Schizophrenia Bulletin, 13(2), 261-276.

Kohler, C.G., Walker, J.B., Martin, E.A., Healy, K.M., Moberg, P.J. (2010). Facial emotion perception in schizophrenia: a meta-analytic review. Schizophrenia Bulletin, 36(5), 109-119.

Laws, K.R., Darlington, N., Kondel, T.K. et al. (2018). Cognitive Behavioural Therapy for schizophrenia - outcomes for functioning, distress and quality of life: a meta-analysis. BMC Psychology, 6 (32), 1-10.

Lieberman, J.A., Dixon, L.B., \& Goldman, H.H. (2013). Early detection and intervention in schizophrenia: A new therapeutic model. JAMA, 310(7), 689-690.

Lincoln, T.M., Rief, W., Westermann, S., Ziegler, M., Kesting, M.L., Heibach, E., \& Mehl, S. (2014). Who stays, who benefits? Predicting dropout and change in cognitive behaviour therapy for psychosis. Psychiatry Research, 216(2), 198-205.

Luteijn, F., Kok, A.R. (1985). NVM, Nederlandse Verkorte MMPI, handleiding, herziene versie. Lisse, the Netherlands: Swets \& Zeitlinger.

McGorry, P.D., Nelson, B., Goldstone, S., \& Yung, A.R. (2010). Clinical staging: A heuristic and practical strategy for new research and better health and social outcomes for psychotic and related mood disorders. The Canadian Journal of Psychiatry, 55(8), 486-497.

Morisky, D.E., Green, L.W., Levine, D.M. (1986). Concurrent and predictive validity of a self-reported measure of medication adherence. Medical Care, 24(1), 67-74.

Murray, H.A. (1938). Explorations in personality. New York, NY: Oxford University Press.

Nosé, M., Barbui, C., Gray, R., \& Tansella, M. (2003). Clinical interventions for treatment nonadherence in psychosis: Meta-analysis. The British Journal of Psychiatry, 183(3), 197206.

O'Driscoll, C., Laing, J., \& Mason, O. (2014). Cognitive emotion regulation strategies, alexithymia and dissociation in schizophrenia, a review and meta-analysis. Clinical Psychology Review, 34(6), 482-495. 
Phahladira, L., Asmal, L., Kilian, S., Chiliza, B., Scheffler, F., Luckhoff, H.K., ... \& Emsley, R. (2018). Changes in insight over the first 24 months of treatment in schizophrenia spectrum disorders. Schizophrenia research , 206, 394-399.

Pos, K., Franke, N., Smit, F., Wijnen, B.F., Staring, A.B., Van der Gaag, M., ... Schirmbeck, F. (2019). Cognitive behavioral therapy for social activation in recent-onset psychosis: Randomized controlled trial. Journal of consulting and clinical psychology, 87(2), 151.

Preacher, K.J., \& Hayes, A.F. (2004). SPSS and SAS procedures for estimating indirect effects in simple mediation models. Behavior Research Methods, Instruments, \& Computers, 36, 717-731.

Priebe, S., Huxley, P., Knight, S., \& Evans, S. (1999). Application and results of the Manchester Short Assessment of Quality of Life (MANSA). International Journal of Social Psychiatry, 45(1), 7-12.

Roberts, D.L., Penn, D.L. (2009). Social cognition and interaction training (SCIT) for outpatients with schizophrenia: A preliminary study. Psychiatry Research, 166, 141-147.

Rossouw, T.I., \& Fonagy, P. (2012). Mentalization-based treatment for self-harm in adolescents: A randomized controlled trial. Journal of the American Academy of Child \& Adolescent Psychiatry, 51(12), 1304-1313.

Schafer, J.L. (1999). Multiple imputation: A primer. Statistical methods in medical research, 8(1), $3-15$.

Snippe, E., Viechtbauer, W., Geschwind, N., Klippel, A., De Jonge, P., \& Wichers, M. (2017). The impact of treatments for depression on the dynamic network structure of mental states: Two randomized controlled trials. Scientific Reports, 7, 46523.

Sprong, M., Schothorst, P., Vos, E., Hox, J., \& Van Engeland, H. (2007). Theory of mind in schizophrenia: Meta-analysis. The British Journal of Psychiatry, 191(1), 5-13.

van Alphen, C., Ammeraal, M., Blanke, C., Boonstra, N., Boumans, H., \& Bruggeman, R. (2012). Multidisciplinaire richtlijn schizofrenie. Utrecht, the Netherlands: De Tijdstroom.

Weijers, J., ten Kate, C., Eurelings-Bontekoe, E., Viechtbauer, W., Rampaart, R., Bateman, A.W., \& Selten, J.P. (2016). Mentalization-based treatment for psychotic disorder: Protocol of a randomized controlled trial. BMC Psychiatry, 16(1), 191.

Weijers, J.G., ten Kate, C., Debbané, M., Bateman, A.W., de Jong, S., Selten, J.P., EurelingsBontekoe, E.H.M. (2020). Mentalization and Psychosis: A Rationale for the Use of Mentalization Theory to Understand and Treat Non-affective Psychotic Disorder. Journal of Contemporary Psychotherapy, 1-10.

Westen, D. (1991). Clinical assessment of object relations using the TAT. Journal of Personality Assessment, 56(1), 56-74. 
- Chapter Seven

Wolthaus, J.E.D., Dingemans, P.M.A.J., Schene, A.H., Linszen, D.H., Knegtering, H., Holthausen, E.A.E., ... \& Hijman, R. (2000). Component structure of the positive and negative syndrome scale (PANSS) in patients with recent-onset schizophrenia and spectrum disorders. Psychopharmacology, 150(4), 399-403.

Wykes, T., Huddy, V., Cellard, C., McGurk, S.R., \& Czobor, P. (2011). A meta-analysis of cognitive remediation for schizophrenia: Methodology and effect sizes. American Journal of Psychiatry, 168(5), 472-485. 




\section{CONCLUSION}





\section{SUMMARY AND GENERAL DISCUSSION}

J.G. Weijers 


\section{Introduction.}

In this dissertation we explored three main topics: childhood abuse, mentalization and psychosis. Childhood abuse and impaired mentalizing have received increased attention in contemporary psychosis research. A host of recent articles have underscored that childhood abuse contributes to the development and severity of psychosis (see Varese et al, 2012; Kelleher et al., 2013) and that emotion regulation difficulties (Myin-Germeys \& van Os, 2007; CristobalNavaez et al., 2016) and impaired mentalizing (Read, van Os, Morrison, \& Ross, 2005; Sprong, Schothorst, Vos, Hox, \& Van Engeland, 2007) may explain such a relationship.

Simultaneously there is an increased focus on childhood abuse and psychosis within mentalization theory (e.g. Brent \& Fonagy, 2014; Debbané et al. 2016). Mentalization theory holds that the level of security in a child's rearing environment determines how well the ability to mentalize and to regulate emotions is developed. Mentalizing ability in turn, is thought to be an important factor in the formation of psychopathology. Mentalizing deficits may contribute to the development of both positive and negative symptoms in NAPD. For example, it can be argued that delusions of persecution and reference are by definition misguided attributions of mental states to others (Frith, 1992). Additionally, negative symptoms like flattened affective expression may reflect a disorder of communication caused by an inability to understand that gestures, intonation and expression convey mental states (Frith, 1992).

Next to studying the interrelatedness of childhood trauma, mentalizing and psychosis, we also sought to determine whether mentalization based treatment (MBT) is an effective treatment to improve social functioning and mentalizing capacity. The most distinctive feature of MBT is that it centralizes the enhancement of mentalizing as a mechanism of change.

\section{Summary of Findings}

Aim I: To outline how mentalization theory may contribute to understanding and treatment of NAPD.

In chapter 2 we concurred with current conceptualizations of psychosis pathogenesis and argued that a sensitization of the mesolimbic dopaminergic system - due to constitutional vulnerability, neurodevelopmental insults and/or social adversity - contributes to the development of aberrant thoughts and perceptual experiences, characteristic of NAPD. Furthermore, using mentalization theory as a conceptual framework, we offered an argument of why aberrant experiences are interpreted in psychotic ways and why NAPD is associated with social dysfunction. As a developmental theory of psychopathology, mentalization theory proposes that the abilities to mentalize and regulate emotions are developed through secure interaction with caregivers and peers. It proposes that children as well as adults have an inner need for social relatedness to help co-regulate their emotions. If caregivers are sensitive and 
responsive to their child's emotions, this will help down-regulate emotional distress, and aids the development of a lasting trust that others can help attenuate such distress (Bowlby, 1973). Adverse childhood experiences such as abuse may undermine such trust, thus leading to difficulty in successfully co-regulating emotions. Childhood abuse, especially when perpetrated by caregivers, is seen as antithetical to a secure rearing environment. It is argued to instill a phobic fear of the imaginative exploration of other minds needed for the development of mentalizing ability. Imagining one's parent's hostile or uncaring mind-state is thought to be overwhelmingly painful and is thus avoided by the child.

Additionally, as a higher-order cognitive process, mentalizing is undermined by excess emotional arousal. During emotional dysregulation, limbic parts of the brain take control of the orchestration of brain processes at the expense of cognitive complexity, rendering individuals unable to adequately reflect on their emotions. This creates difficulty functioning in complex social situations and may lead to rejection and social withdrawal. Moreover, because social relatedness is viewed to be necessary for adequate emotional regulation, loneliness is inherently distressing, creating a vicious cycle that sensitizes the mesolimbic dopamine system.

We also argued that impaired mentalizing may be directly related to some of the positive symptoms as well. Individuals who have an impaired ability to mentalize have difficulties becoming consciously aware of sensory-affective states, making it difficult for them to critically reflect upon them. In this way they do not take into account the influence that their affective states have on their attention, thought and behavior. As such, they may equate these sensory-affective states with outer reality. For example, when one fails to become consciously aware of one's suspiciousness, one will fail to notice how this mental state influences the experience of reality, resulting in the conviction that others are deceitful and ill-meaning. To put it simply, mentalizing helps to identify feelings and to differentiate fact from feeling. We argued that this process also causes aberrant experiences to be treated as aspects of outer reality and thus to be attributed to outside sources, resulting in hallucination proper.

Lastly, we argued that a lack of epistemic trust - i.e. the ability to treat new information from others as potentially well-intentioned and personally relevant (Fonagy et al., 2017) - cuts an individual off from social learning and interpersonal meaning making. Epistemic trust theory holds that people accept new information to be true in either one of two ways. They may rely on others they trust to be well-meaning and knowledgeable to inform them. Alternatively, they can try to deduce for themselves whether new information is correct, for example through scientific experimentation (Fonagy, Luyten, Allison \& Campbell, 2017). Epistemic trust offers a clear temporal advantage, as scientific deduction is very time-consuming. Additionally, epistemic trust is important to fit in because cultural customs and values, whose functions are often opaque, cannot be acquired through experimentation (Fonagy \& Allison, 2014). 
Fonagy, Luyten, and Allison (2017) further maintain that epistemic trust between child and caregiver develops within secure attachment relationships. According to them, if a child finds itself to be accurately represented and responded to by a caregiver and being treated as a thinking and feeling intentional being this helps the child to assume that their caregivers are well-meaning and not deceitful. This is thought to engender the secure feeling that the caregiver's intentions are benign, which helps the child more readily accept shared information as true. However, children who repeatedly experience that their internal states are met with distorted or inaccurate caregiver responses may be increasingly likely to develop mistrust regarding others' messages. Given the high degree of social adversity and childhood trauma generally reported by NAPD patients (e.g. Varese et al., 2012), it seems plausible that they operate on implicit working models in which others are seen as potentially deceitful. When one adopts a general stance of distrust towards other, sometimes referred epistemic hypervigilance, this is thought to cut one off from important sources of information about the self in relation to others. Patients with NAPD often show a 'rigidity' vis-à-vis alternate viewpoints, rendering them less capable to modify beliefs pertaining to self, others, and the world. Not incidentally, the development of psychosis often coincides with a loss of socially construed meaning, and is replaced by a personal construal of meaning that makes sense to the individual, but is viewed to be idiosyncratic by others (e.g. Pereira \& Debbané, 2018).

We concluded chapter 2 by arguing that impaired mentalizing makes it difficult to treat emotions and feelings as matters of perspective, complicating psychotherapeutic intervention. Mentalization based treatment was designed to directly target these problems and thus may help overcome these obstacles in treatment.

Aim II: To test several proposed hypotheses that may explain the relationship between childhood abuse and the severity of symptoms in adult patients with NAPD.

In part II of this dissertation we examined potential pathways through which childhood abuse affects outcome of NAPD in adulthood. The studies described in part II aimed to investigate several hypotheses that may help explain the relationship between childhood abuse and the severity of symptoms in adult patients with NAPD, namely: increased stress reactivity, a tendency for loneliness and impaired mentalizing.

In chapter three we observed that stress in adulthood is related to the intensity of negative affect and psychotic symptoms once present. However, in contrast to previous studies (Lardinois, Lataster, Mengelers, Van Os, \& Myin-Germeys, 2011; Cristobal-Navaez et al., 2018), it was not unequivocally shown that a history of childhood abuse moderated this relationship. Divergent statistical approaches may account for the observed differences between studies. 
Chapter four showed that an increased proneness to loneliness is a potential mechanism by which abuse in childhood affects the severity of psychotic symptoms in adulthood and that the relation between loneliness and psychotic symptoms in turn can be explained by increased anxious and depressive feelings.

Chapter five showed that $63.2 \%$ of our participants reported having experienced some form of parental abuse during their childhood. We further observed that the severity of this reported abuse was associated with the severity of positive and negative symptoms in adulthood, and with an impaired ability to infer others' mental states. Additionally, we observed that an impaired ability to infer others' mental states may constitute a mechanism by which abuse affects the severity of negative symptoms in adulthood.

Overall, the results described in Part II support the hypothesis that childhood abuse contributes to the severity of outcome in NAPD through loneliness, dysregulated negative affect (anxiety and depression) and impaired mentalizing.

Aim III: To test whether mentalization based treatment for psychotic disorder (MBTp) is an effective addition to treatment as usual regarding social dysfunction and impaired mentalizing. In Part III, we tested whether the addition of mentalization based treatment for psychotic disorder (MBTp) to Flexible Assertive Community Treatment (FACT), would result in greater improvement of social functioning and mentalizing ability, among other outcome variables. Chapter six outlines the hypotheses and methods of our rater blinded, multicenter randomized controlled trial, whereas chapter seven describes the results of this trial.

The results suggest that MBTp leads to a more robust improvement in social functioning than FACT alone and seems especially effective if implemented in the early phases of NAPD. Patients with a relatively recent onset of psychosis, showed a greater improvement in social functioning at follow-up than more chronically ill patients. Overall, patients in the MBTp group performed better on several aspects of mentalizing ability, including understanding of social causality (i.e. the ability to construct a logical and psychologically minded explanation of others' behavior), theory of mind (i.e. the ability to infer the mental states of others), complexity of representations (i.e. the ability to distinguish between one's own and another's perspective), and insight into one's disorder (i.e. awareness of the presence and impact of symptoms and the need for treatment). They also showed a greater decrease in social stress (i.e. disliking one's present company and preferring to be alone). No significant differences were found on the other secondary outcome measures, including: positive, negative, anxious and depressive symptoms, quality of life, emotional investment in relationships, affect-tone of relationships, daily psychotic experiences, negative and positive affect, drug use, social stress reactivity. 


\section{Comparison to previous studies}

Mentalization, psychosis and childhood abuse. The results of the studies in part II add to an increasing body of evidence that childhood abuse contributes to an adverse outcome of NAPD (e.g. Varese et al., 2012). They additionally provide potential explanations for how childhood abuse affects psychotic psychopathology. The results corroborate a growing body of findings showing that childhood abuse, emotion regulation problems, social difficulty, mentalizing impairment and psychosis are interrelated. These results are in line with the view that there is an affective pathway connecting childhood abuse to psychosis (e.g., Myin-Germeys \& van Os, 2007; Cristobal-Narvaez et al., 2016). However, they also suggest that this affective pathway may not be entirely intrapsychic, but interpersonal as well, since loneliness seems to play an important, mediating role. Additionally, supporting attachment and mentalization theory, early childhood adverse experiences seem predictive of the quality of emotion regulation in adulthood, as they predict anxiety and depression in adulthood.

Furthermore, our findings suggest that impairment in cognitive, other-oriented mentalizing may constitute a pathway through which childhood abuse affects the severity of negative symptoms. This is in line with a growing body of research suggesting that an impaired mentalizing ability may be a pathway through which childhood abuse contributes to a host of psychopathology in adulthood, including depression and externalizing behavior (Ensink et al., 2017), potential for violence (Taubner, Zimmermann, Ramberg, \& Schröder, 2016), general personality pathology (Chiesa \& Fonagy, 2014), dissociation (Schimmenti et al., 2017), impaired social functioning (Macintosh et al., 2013) and schizotypal personality pathology (Berthelot, Lemieux, Garon-Bissonnette, Lacharité, \& Muzik, 2019). Regarding NAPD specifically, recent studies found that exposure to childhood abuse in patients with schizophrenia was associated with functional alterations of brain regions underlying mentalizing activity (Quidé et al., 2017) and that impaired metacognitive ability, a construct closely related to mentalizing (Ridenour et al., 2019), is strongly associated with negative symptoms as well (Trauelsen et al., 2016).

However, our findings did not corroborate previous observations that impaired mentalizing is related to positive symptoms (Corcoran, Mercer, \& Frith, 1995; Bartels-Velthuis, Blijd-Hoogewys, \& Van Os, 2011; Clemmensen, et al., 2016). As such this was in line with many other studies that did not find such a relationship either (see Garety \& Freeman, 1999 for an overview; Trauelsen et al., 2016). However, it must be underscored that most studies, including our own, featured only cognitive, other-oriented mentalizing. Impaired self-oriented, affective mentalizing, or the ability to detect and critically reflect upon one's sensory-affective experiences sometimes referred to as 'embodied mentalizing' (Debbané \& Toffel, 2019), has been suggested to be much more directly related to positive symptomatology. Indeed, so-called 
source monitoring errors have been widely related to vulnerability for hallucinatory experiences (e.g. Brookwell, Bentall \& Varese, 2013).

Mentalization based treatment for psychotic disorder. Our randomized controlled trial showed that the FACT treatment of the TAU condition in and of itself already seems successful at increasing social functioning in patients. Although improvement in the MBTp group was larger than that in the TAU group, the large improvements in the TAU group may have made the detection of statistical differences between groups more difficult. These results may not come as a surprise. FACT-teams have an array of professionals that are specialized in helping patients to structure their social lives, including social welfare workers that provide legal and social aid, individual placement and support (IPS) coaches that help patients to reintegrate into society and find employment and psychiatrists and nurses that offer psychoeducation, pharmacological treatment and supportive therapy. That the TAU condition improved social functioning corroborates some earlier findings regarding FACT (e.g. Drukker, Visser, Sytema, \& Van Os, 2013), but contradicts others (Systema, Wunderink, Bloemers, Roorda, \& Wiersma, 2007). Potentially, increased experience with the FACT model in the Netherlands (Killaspy et al., 2006), resulted in functional recovery in our trial. Moreover, the addition of IPS - an evidence based intervention that consists of targeted support in employment or education with the aim to attain as much societal reintegration as possible may have contributed to a more positive effect on social functioning as well (Hoffmann, Jäckel, Glauser, \& Kupper, 2012; Pos et al., 2019).

However, improvements in social functioning did prove to be greater in the MBTp condition, with patients showing larger improvements in social functioning six months after termination of treatment. Although the follow-up period of six months is too short to arrive at definitive conclusions, the results may mean that MBTp provides tools to sustainably and autonomously deal with social problems. Such results are not out of the ordinary, as research has shown that psychodynamic therapy often leads to sustainable or even improved recovery after termination of treatment, sometimes referred to as the 'sleeper effect'. Several metaanalyses and reviews have concluded that such sleeper effects are widely observed after psychodynamic treatments with regard to a wide range of disorders (see de Maat, de Jonghe, Schoevers, \& Dekker, 2009; Shedler, 2010; Midgley \& Kennedy, 2011; Town, et al., 2012; Brown \& Tracy, 2014; Levy, Yeomans \& Caligor, 2014; Leichsenring et al., 2015 for overviews), while the benefits of other types of treatment tend to diminish over time (Durham, Chambers, \& Power, 2005; de Maat, Dekker, Schoevers, \& de Jonghe, 2007). With regard to MBT for borderline personality disorder (BPD), it was shown that MBT was associated with a longlasting improvement in depressive symptoms, suicidal and para-suicidal behavior, number of days hospitalized and social and interpersonal functioning. Interestingly, Bateman and Fonagy 
$(2001 ; 2008)$ found that treatment effects had further increased both at 18 months and five year after treatment termination. Ultimately only $13 \%$ of patients who had received MBT, still met the diagnostic criteria for BPD as opposed to $87 \%$ of patients who had not. This consistent observation has led to the suggestion that psychodynamic therapy, including MBT, ushers in processes that continue to improve the lives of patients. However, the exact nature of this sleeper effect has not been explained satisfactorily. Several hypotheses exist, though.

Firstly, psychodynamic technique may offer an explanation. Psychodynamic therapies like MBT tend to share common aspects including: unstructured, open-ended dialogue between patient and therapist; the identification of recurring pathological patterns in a patient's experience of himself and the world; having a developmental perspective that gives meaning to a patient's affects in relation to their past; pointing out and helping the patient to confront thoughts and feelings that are perceived to be too distressing or unacceptable; and focusing on current experiences of the relationship between patient and therapist. Incidentally, these elements have been identified as drivers for therapy success in any form of psychotherapy, regardless of theoretical orientation (Blagys \& Hilsenroth, 2000). Secondly, the primary aim of psychodynamic therapy is not a reduction of symptoms, but rather the establishment of more structural and functional ways to deal with life's challenges. Compared to more symptom orientated treatments, psychodynamic treatments aim to change the implicit, automatic and reflexive - or 'unconscious' - reactions to life's stresses that are deemed dysfunctional (Shedler, 2010). This approach may be especially pertinent for patients with complex and chronic disorders who tend to have inflexible ways of interpersonal and societal functioning. Thirdly, compared to pharmacological treatments and some other forms of psychotherapy, psychodynamic therapies tend to attribute meaning to emotional distress, aiming to help patients find better ways to meet their emotional needs and thus help to regulate their emotions better (Solms, 2018). Fourthly, it should also be noted that the observed sleeper effects, ubiquitous as they are, may be the result of an artifact caused by methodological confounds such as dropout rates, the lack of intention-to-treat analyses, or receiving additional psychological treatment further down the road (Knekt et al., 2008).

Fonagy and Bateman initially proposed that the effective mechanism of change in MBT, and a potential driver of the observed sleeper effect, is the development of mentalizing capacity (Fonagy \& Bateman, 2006). Mentalizing allows a person to interpret sensory-affective experiences and integrate them into a narrative of themselves and the social world in order to devise better ways in order to meet emotional needs and function interpersonally (Bateman \& Fonagy, 2001). Indeed, recent research by Rossouw and Fonagy (2012) and Meulemeester et al. (2018) found an association between an increase in mentalizing capacity and a decrease in psychiatric symptoms. Interestingly, in chapter 7 we also found indications that patients in the 
MBTp group did perform better on several measures of mentalizing ability, and that in particular theory of mind was related to social functioning at follow-up. However, mediation analyses offered inconclusive evidence of mediation of the treatment effect by an improvement in theory of mind. This raises the question as to whether the improvement of functioning is causally linked to an improvement in mentalizing capacity. One alternative explanation for the observed results is that other forms of mentalizing, specifically self-oriented, affective forms of mentalizing, drive treatment effects. Another possible explanation is that the relatively small sample size compared to other studies (e.g. Meulemeester et al.., 2018; $N=175$ ) may have resulted in a lack of power to observe a small to moderate mediation effect. The observed marginal significance of the mediation effect $(p=.06)$ does point in this direction. Still, even if the observed effect were significant, it would only offer a partial explanation of treatment effect.

Another possibility is that mentalizing plays a different role in patient recovery than initially conceptualized. Recent developments in mentalization theory have changed and have somewhat diminished the centrality of mentalizing's hypothetical role as a driver of patient recovery. Recently, Debbané \& Toffel (2019) argued that mentalizing plays a moderating rather than a mediating role in the development of psychosis, protecting against the actual manifestation of florid psychosis in the presence of already present genetic schizotypal vulnerability. In this view, adequate mentalizing may be viewed as a resilience factor, because it allows individuals to reevaluate odd beliefs, aberrant experiences or ideas of reference (Debbané et al., 2016). Indeed, the development of theory of mind in children seems to stymie the development of delusional ideation in children with hallucinatory experiences (BartelsVelthuis, Blijd-Hoogewys \& van Os, 2011).

Furthermore, in a recent reconceptualization of MBT's mechanisms of change, Fonagy, Luyten and Allison (2017) argued that epistemic trust is an important driver of patient recovery as well. Not dissimilar to caregivers, through mentalization, the MBT therapist tries to respond contingently to the patient's emotions with marked responses, without pushing a narrative upon the patient. By doing so, the MBT therapist tries to communicate that he is well-meaning and treats the patient as an intentional agent, with meaningful experiences. Feeling attended to in this way is thought to engender a sense of security in the patient that helps him to again become flexible in his cognitive beliefs and to become more open to and learn from other perspectives about one's self in relation to his social world. In this way mentalizing may be seen as a tool to reinstate the patient's trust that others are well-meaning, have something relevant to say about their experiences, and can help co-regulate emotional distress. It is perhaps this trust that is the true driver of patient recovery. Because building such trust is difficult, yet hypothetically crucial for patient recovery, this may explain why MBT and other psychodynamic therapies are often time-consuming but tend to yield sustainable changes. In this sense it is 
interesting that two meta-analyses concluded that psychodynamic treatments tend to be equivalent to other treatment approaches in many respects, but significantly superior at improving maladaptive interpersonal relationships (Town et al., 2012) and social functioning (Steinert, Munder, Rabung, Hoyer, \& Leichsenring, 2017). In this regard MBT seems no different, significantly increasing social functioning (Bateman \& Fonagy, 1999; 2001; 2008; Jorgensen, 2013; Weijers et al., 2020) and decreasing social stress (Weijers et al., 2020).

Epistemic trust as a driver for patient recovery may also explain why we found better effects in recent onset patients. In chapter seven we observed that duration of illness was significantly related to social dysfunction and affected treatment outcome, suggesting that a patient's ability to relate to others, participate in society and benefit from treatment deteriorates as the disorder progresses. It is widely known that psychosis can be extremely damaging to interpersonal relationships and social standing. In the aftermath of a psychotic episode, patients often find their social environments drastically altered, whether due to a loss of friends, romantic relationships or employment. Research shows that social functioning deteriorates most in the first five years after onset (Birchwood \& Macmillan, 1993) and such losses can be difficult to regain, as hospitalizations, negative symptoms, cognitive decline, (self)stigma and medication side-effects constitute further obstacles to social rehabilitation (Pereira \& Debbané, 2018). Mentalization theory holds that patient recovery does not primarily depend on what happens in therapy sessions, but more importantly on what happens between sessions. Fonagy, and Allison (2014) argue that through improving mentalizing ability and rekindling epistemic trust, patients become motivated again to engage in meaningful communication with their social environment. This in turn may allow them to judge their situations more accurately and increase their willingness to modify cognitive models of themselves and the world based on feedback from others. Chronic patients with NAPD, tend to have smaller, more fragile social networks, and as a consequence may find themselves with 'less to work with'. This may also explain why chronic patients experience greater difficulty challenging long held beliefs (Lincoln et al. 2014) and show poorer treatment response (Lieberman, Dixon \& Goldman, 2013; Lincoln et al. 2014). Some authors have therefore arrived at the conclusion that the first years after onset comprise a 'critical period' for intervention (e.g. Birchwood \& Macmillan, 1993; McGorry, Nelson, Goldstone, \& Yung, 2010), and that MBTp is may be best implemented in the prodromal or early stages of NAPD (Debbané et al., 2016).

MBTp in the therapeutic landscape. To place these trial results into perspective, it is important to juxtapose MBTp against other prominent treatments for psychotic disorder. The recent decades saw the development of multiple psychological treatment modalities that aim to treat psychosis. Cognitive Behavioral Therapy (CBT), being the most studied, has arguably become the most prominent among them. CBT for psychosis (CBTp), aims to increase a patient's 
understanding of psychotic symptoms and to reduce distress and invalidation caused by such symptoms. Multiple randomized controlled trials have suggested that CBTp has beneficial effects on positive symptoms (see Zimmermann, Favrod, Trieu, \& Pomini, 2005 for an overview), trauma-related symptoms (van den Berg et al., 2015; Sin \& Spain, 2017; Brand, McEnery, Rossell, Bendall, \& Thomas, N., 2018), anxiety (see Heavens, Odgers, \& Hodgekins, 2019 for an overview), and sleep disturbance (Freeman et al., 2015). Additionally, CBT has been proven effective in halting transition into psychosis for those at ultra-high risk of developing a psychotic episode (van der Gaag, van den Berg, \& Ising, 2017).

Given the successes of CBTp, which are plentiful, one could argue that there is little need for other psychotherapeutic interventions. However, some critical notes can and should be made. Recent meta-analyses have also shown that most of the effects obtained by CBTp tend to be small in size (Jauhar et al, 2014). Additionally, some effect-sizes seem to be artificially inflated by researcher bias, as the effects of CBTp in rater-blinded trials are substantially smaller (Wykes, Steel, Everitt, \& Tarrier, 2008; Jauhar et al., 2014). Furthermore, a growing body of evidence shows that CBTp cannot treat negative symptoms effectively and does not prevent relapse (see Jauhar, Laws \& Mckenna, 2019 for an overview). Additionally, CBTp does little to improve more general patient factors, such as quality of life or social functioning in patients with psychotic disorders (see Laws, Darlington, Kondel, McKenna, \& Jauhar 2018 for an overview) or those at ultra-high risk (van der Gaag et al., 2012). Such criticism, however, may be deemed unfair, as CBT was never developed to take a 'holistic' approach to patient treatment, focusing on specific symptoms instead.

More akin to MBT, are the so called 'third wave' cognitive behavioral therapies, which aim to alter the process of cognition rather than its contents, and include Metacognitive Training (MCT; Moritz \& Woodward, 2007), mindfulness-based cognitive therapy (MBCT; e.g. Segal, Teasdale, \& Williams, 2004), social cognitive training programs (see Green \& Horan, 2019 for an overview), and Metacognitive Insight and Reflection Therapy (MERIT; de Jong et al., 2018).

MCT is a group-based training program, which aims to address cognitive biases underlying delusional beliefs, such as jumping to conclusions. Patients are educated about cognitive biases and are asked to share examples of their own biases within the supportive setting of group therapy. This is thought to help patients confront their own biases and help patients come to more accurate representations of reality. A recent meta-analysis, however, did not offer evidence of a positive effect of MCT on positive symptoms, delusions or cognitive biases, showing only small, nonsignificant effects. These effects were even further diminished when confounding factors such as publication and researcher biases were accounted for (van Oosterhout et al., 2015). It remains unclear if MCT can help ameliorate impaired social cognition and social dysfunction. 
MBCT aims to help patients develop 'mindfulness', defined as the ability to be present in the here and now and to be aware of one's thoughts and emotions without judgment. Embracing present experiences in the moment - rather than trying to avoid or suppress them - is thought to be helpful in regulating negative emotions and alleviating the distress caused by psychotic symptoms (Chadwick, Taylor, \& Abba, 2005). Little research has been done concerning the effects of MBCT on either social cognition or social functioning in psychotic disorder, although research suggests that MBCT makes patients respond more mindfully to stressful internal events (Langer, Cangas, Salcedo, \& Fuentes, B. 2012), improves overall functioning (Chadwick et al., 2005) and decreases negative symptoms (Khoury, Lecomte, Gaudiano, \& Paquin, 2013) and depression (Chadwick et al., 2016).

Arguably most akin to MBTp is MERIT, which also focuses on the development of higher order cognitive processing, or 'metacognition' in the case of MERIT. MERIT focuses on the identification and communication of mental states and helps the patient to learn to discriminate between subjective (psychotic) experience and outer reality. As a treatment, MERIT shares many aspects with MBTp such as an inquisitive therapeutic stance towards the patient, avoiding pushing a narrative upon the patient and helping the patient to integrate subjective experience into coherent and meaningful personal narrative through open dialogue. MERIT was recently examined in an RCT, and it was observed that MERIT did not substantially increase metacognition over TAU directly post-treatment (de Jong et al., 2018). However, patients in the MERIT condition did perform better on metacognition (self-reflection in particular) compared to TAU at a six month follow-up, also suggestive of a sleeper effect in the case of MERIT. No differences were observed between MERIT and TAU on theory of mind, cognitive insight, depression, psychotic symptoms and social functioning.

Lastly, recent decades have seen the development of several training programs that target specific aspects of social cognition which are thought to contribute to the formation of psychotic symptoms, including theory of mind (i.e. the ability to infer other people's mental states), facial affect recognition, emotion processing (i.e. detecting and managing emotions in order to facilitate functioning), social perception (i.e. the ability to decode and interpret social cues of others), and attributional style (i.e. the way in which people tend to attribute negative events to situational or internal factors; see Lana et al. (2017) for an overview). Diverging from MERIT or MBTp, social cognitive training programs tend to solely focus on one or two of these skills and take the form of training-sessions as opposed to open-ended, psychotherapeutic dialogue. Social cognitive training programs seem to hold some promise: they have been shown to produce moderate-to-large effects on facial affect recognition and small to-moderate effects on theory of mind, although they have negligible effects on social cue perception and attributional style. However, there is currently little evidence that social cognitive therapies 
improve social functioning, nor whether they improve social cognition sustainably (Green \& Horan, 2019), although one recent study showed that this is possible (Bechi et al., 2019).

\section{Clinical implications}

The clinical insights gained from this dissertation offer some suggestions as to how psychotherapeutic intervention for NAPD could be improved. Firstly, we believe it is fruitful for clinicians to ask about the presence of abuse in childhood, as we have shown it to impact the severity of outcome in several ways. Establishing the existence of childhood abuse may provide both patients and clinicians with more insight into the pathogenesis of the disorder and the role of past experiences therein. The presence of childhood abuse may also signal the need for specific trauma-targeted interventions such as Eye Movement Desensitization and Reprocessing Therapy or Imaginary Exposure, which have been shown to be of great benefit to traumatized patients with NAPD (van den Berg et al., 2015).

Secondly, we hold that mentalization theory enriches therapeutic practice and theory, and that specific elements of MBTp can easily be adopted by other treatments as well. For example, inquisitive listening with a nonjudgmental, not-knowing, yet challenging stance greatly helps to establish a secure bond with patients that are generally viewed to be notoriously hard to reach. At the same time, within such an 'earned secure relationship', dysfunctional beliefs can be more easily challenged. It is important for clinicians to consider that feelings of loneliness and adverse social experiences may make it difficult for patients to adequately regulate their emotions, consequently impeding their ability to mentalize and thus communicate.

Additionally, MBT may be well suited to bridge the gap between the psychodynamic and cognitive approaches to psychopathology that have divided the current landscape of mental health care. Like other psychodynamic therapies, MBT prioritizes attendance to transference and countertransference and holds that early childhood experiences play a role in a patients' current psychopathology (Allen, et al. 2012). At the same time, MBT shares important elements with CBT, such as a focusing on present emotional problems, adopting a challenging stance towards held beliefs and a time-limited, manualized approach to treatment. We believe that the synergy of these approaches, inherent to MBT, is of great benefit to patients.

Thirdly, we believe that the sustained improvements in mentalizing and social functioning yielded by MBTp are of clinical importance. Although one could reasonably argue that MBTp does not add much to TAU directly post treatment, only in the MBTp condition did improvements in social functioning prove to be robust. Previous studies have shown that sustainably improving social dysfunction is notoriously difficult with psychotherpeutic interventions (Cather et al., 2005; de Jong et al. 2018; Pos et al., 2019; Green \& Horan, 2019), and pharmacological treatment (Carbon \& Correll, 2014), often creating a gap between 
symptomatic and functional recovery (Birchwood et al., 2013). Since social dysfunction is predictive of relapse into psychosis (Couture, Penn \& Roberts, 2006), the addition of MBTp to TAU, while more labor intensive, may prove to be more cost effective. Indeed, the limited number of hospitalizations of patients participating in MBTp seems indicative of this (see Chapter 7), although more research is needed to come to definitive conclusions.

Fourthly, the observed effects in the subgroup of relatively recent onset patients seem especially relevant. Recent onset patients in the MBTp group showed great improvements, attaining levels of functioning on the Social Functioning Scale $(M=116.58$; see Chapter 7$)$ in between those of first episode psychosis patients $(M=108.07)$ and healthy controls $(M=$ 123.36), as established by Addington and Addington (2008) ${ }^{1}$. The greater treatment responses of relatively recent onset patients may mean that MBTp should be implemented sooner rather than later. This is especially pertinent, as social dysfunction often increases during the course of illness (Carbon \& Correll, 2014), and contributes to an adverse course of the disorder (FusarPoli et al., 2010).

\section{Suggestions for future research}

Future research should investigate whether the loneliness contributing to psychosis is in the eye of the beholder' or not. In other words, it should investigate whether psychosis is related to the quantity of social relations or the low experienced quality of existing relationships. Perhaps loneliness is more akin to the feeling of being misunderstood or social inferiority (Selten \& Cantor-Graae, 2005) than actual 'aloneness'. Furthermore, investigating loneliness in the context of dopamine sensitization may be a fruitful venue for future research, as the contribution of loneliness to psychosis may be biologically explained by the sensitization of the mesolimbic dopamine system (Howes \& Murray, 2014). Likewise, it may be fruitful to examine whether loneliness is related to impaired mentalizing functionality, as a recent study showed that social isolation predicts theory of mind impairment (De Sousa, Sellwood, Eldridge, \& Bentall, 2018).

Additionally, research should investigate, whether MBTp is more effective when it has a longer duration, when it is specifically tailored to psychotic patients (Sanz, 2018), when it is implemented in the prodromal phase of psychosis (Debbané et al., 2016), and whether the effects of MBTp remain beyond six months. In fact, given the wide-ranging implications of childhood abuse on severity of symptoms in adulthood, one could question whether interventions should not be implemented as early as childhood. Family- and school-targeted mentalization based interventions are currently being implemented in the United Kingdom

1 The scores reported by Addington et al. were recalculated, as their article incorrectly mentions the sum of raw sub-scores, as opposed to the average of scaled sub-scores. 
(Midgley \& Vrouva, 2013). Such interventions may help parents to better mind their children, and children to better mind their peers and themselves. It will be interesting to see whether such interventions can stymie abuse and its pathogenic consequences.

Additionally, we believe that in future trials, MBTp should be compared to other treatments for psychotic disorders such as CBTp, MBCT (Segal et al., 2004), or MERIT (de Jong et al., 2018). As mentioned earlier, many interventions are thought to be able to increase mentalizing ability. However, from the perspective of mentalization theory, mentalization enhancing techniques will be of little value "...if the patient is not helped to mentalize at the time when intense emotional states are evoked in attachment relationships" (Allen, et al., 2008). In our view, the ability to mentalize cannot and must not be isolated from the natural setting in which it is most likely to be impaired, namely in the setting of relationships. This may be especially pertinent for patients with NAPD who, like patients with BPD (Fonagy \& Luyten, 2009), seem to have an overactive mirror neuron system (McCormick et al., 2012) and experience difficulty differentiating between self and others in social contexts (Sass \& Parnas, 2003). Treatments like MBCT may contribute to improved, self-oriented mentalizing within an isolated setting, but may not necessarily improve mentalizing in in context of relationships. MERIT is much more akin to MBT in this regard, but does not provide group-therapy, which arguably is the most emotionally complex context for patients with NAPD.

\section{General strengths and limitations}

Specific strengths and limitations of each study are described in the respective chapter. However, some general strengths and limitations should be discussed. First, in the studies described in this dissertation we sought to attain a high standard of measurement quality by using instruments that measure symptoms as they occur in daily life, circumventing recall bias, or by using concrete, behaviorally anchored interviews or performance based instruments, circumventing poor insight and impaired reflective capacity. Extensive training was provided to maximize interrater reliability. Second, we made use of blinded raters to eliminate observer bias. Third, we included patients with a wide range of illness duration, and a multitude of psychotic diagnoses and comorbid diagnoses. As such, we feel our results adequately reflect general practice. Many studies make use of stringent inclusion criteria, a custom that has been criticized for impacting the generalizability of their results (Hoertel et al., 2015).

The first and foremost limitation of our studies is that they all involved the same research sample. This means that questions remain about the generalizability of our findings as the results may simply reflect characteristics specific to this sample. Given that our sample had relatively mild positive and negative symptoms at baseline (see chapter seven), our data need to be interpreted with caution. Second, the studies of chapters three, four and five did not include 
healthy control groups, making it impossible to examine whether the observed correlations are specific to patients with NAPD, or are also extant in the general population.

\section{Concluding remarks}

The inherent "un-understandability" of psychotic experiences to the layman must make psychosis a profoundly lonely experience. Tragically, as the results of this thesis suggest, loneliness in turn seems to contribute significantly to the severity of the disorder, generating a vicious cycle of pathogenesis. However, we also argued that having one's personal experiences understood as meaningful by another, is a powerful tool to overcome such a sense of social isolation. Mentalizing based treatment is thought to help people better understand themselves and others, and thus improve people's capacity to communicate with and learn from others. A mentalizing stance may thus help bridge the gap of loneliness. However improved mentalizing alone may not be enough, as true patient recovery also requires a social environment that is genuinely well-meaning and emotionally responsive. We therefore hold that it is not only important to develop a more thorough understanding of psychosis for academic purposes, but that the act of trying to understand the psychotic experience together with the patient, in and of itself, may aid recovery. In our view, this should not only be taken to heart by clinicians, but by society in general.

\section{References}

Addington, J., \& Addington, D. (2008). Social and cognitive functioning in psychosis. Schizophrenia research, 99(1-3), 176-181.

Allen, J. G., Fonagy, P., \& Bateman, A. W. (2008). Mentalizing in clinical practice. American Psychiatric Association Publishing, Washington, DC.

Bartels-Velthuis, A. A., Blijd-Hoogewys, E. M., \& Van Os, J. (2011). Better theory-of-mind skills in children hearing voices mitigate the risk of secondary delusion formation. Acta Psychiatrica Scandinavica, 124(3), 193-197.

Bateman, A., \& Fonagy, P. (1999). Effectiveness of partial hospitalization in the treatment of borderline personality disorder: a randomized controlled trial. American journal of Psychiatry, 156(10), 1563-1569.

Bateman, A., \& Fonagy, P. (2001). Treatment of borderline personality disorder with psychoanalytically oriented partial hospitalization: an 18-month follow-up. American Journal of psychiatry, 158(1), 36-42. 
Bateman, A., \& Fonagy, P. (2006). Mentalizing and borderline personality disorder. In J. G. Allen \& P. Fonagy (Eds.), The handbook of mentalization-based treatment (p. 185-200). Hoboken, NJ: John Wiley \& Sons Inc.

Bateman, A., \& Fonagy, P. (2008). 8-year follow-up of patients treated for borderline personality disorder: mentalization-based treatment versus treatment as usual. American Journal of Psychiatry, 165(5), 631-638.

Bechi, M., Bosia, M., Buonocore, M., Agostoni, G., Bosinelli, F., Silvestri, M. P., ... \& Cavallaro, R. (2019). Stability and generalization of combined theory of mind and cognitive remediation interventions in schizophrenia: Follow-up results. Psychiatric rehabilitation journal.

Berthelot, N., Lemieux, R., Garon-Bissonnette, J., Lacharité, C., \& Muzik, M. (2019). The protective role of mentalizing: Reflective functioning as a mediator between child maltreatment, psychopathology and parental attitude in expecting parents. Child Abuse \& Neglect, 95.

Birchwood, M., \& Macmillan, F. (1993). Early intervention in schizophrenia. Australian and New Zealand Journal of Psychiatry, 27(3), 374-378.

Birchwood, M., Connor, C., Lester, H., Patterson, P., Freemantle, N., Marshall, M., ... \& Everard, L. (2013). Reducing duration of untreated psychosis: care pathways to early intervention in psychosis services. The British Journal of Psychiatry, 203(1), 58-64.

Blagys, M. D., \& Hilsenroth, M. J. (2000). Distinctive features of short-term psychodynamicinterpersonal psychotherapy: A review of the comparative psychotherapy process literature. Clinical psychology: Science and practice, 7(2), 167-188.

Bowlby, J. (1973). Attachment and loss, vol. II: Separation. Basic Books, New York, NY.

Brand, R. M., McEnery, C., Rossell, S., Bendall, S., \& Thomas, N. (2018). Do trauma-focused psychological interventions have an effect on psychotic symptoms? A systematic review and meta-analysis. Schizophrenia research, 195, 13-22.

Brent, B.K., \& Fonagy, P. (2014). A mentalization-based treatment approach to disturbances of social understanding in schizophrenia. In P. H. Lysaker, G. Dimaggio, and M. Brüne (Eds.), Social cognition and metacognition in schizophrenia: Psychopathology and treatment approaches, 245-259. Elsevier Academic Press, San Diego, CA.

Brookwell, M. L., Bentall, R. P., \& Varese, F. (2013). Externalizing biases and hallucinations in source-monitoring, self-monitoring and signal detection studies: a meta-analytic review. Psychological medicine, 43(12), 2465-2475.

Carbon, M., \& Correll, C. U. (2014). Clinical predictors of therapeutic response to antipsychotics in schizophrenia. Dialogues in clinical neuroscience, 16(4), 505. 
- Chapter Eight

Cather, C., Penn, D., Otto, M. W., Yovel, I., Mueser, K. T., \& Goff, D. C. (2005). A pilot study of functional Cognitive Behavioral Therapy (fCBT) for schizophrenia. Schizophrenia Research, 74(2-3), 201-209.

Chadwick, P., Taylor, K. N., \& Abba, N. (2005). Mindfulness groups for people with psychosis. Behavioural and Cognitive Psychotherapy, 33(3), 351-359.

Chadwick, P., Strauss, C., Jones, A. M., Kingdon, D., Ellett, L., Dannahy, L., \& Hayward, M. (2016). Group mindfulness-based intervention for distressing voices: a pragmatic randomised controlled trial. Schizophrenia Research, 175(1-3), 168-173.

Chiesa, M., \& Fonagy, P. (2014). Reflective function as a mediator between childhood adversity, personality disorder and symptom distress. Personality and mental health, 8(1), 52-66.

Clemmensen, L., van Os, J., Drukker, M., Munkholm, A., Rimvall, M., Væver, M., Rask, C.U., BartelsVelthuis, A., Skovgaard, A., \& Jeppesen, P. (2016). Psychotic experiences and hypertheory-of-mind in preadolescence-a birth cohort study. Psychological medicine, 46(1), 87-101.

Couture, S. M., Penn, D. L., \& Roberts, D. L. (2006). The functional significance of social cognition in schizophrenia: a review. Schizophrenia bulletin, 32(1), 44-63.

Corcoran, R., Mercer, G., Frith, C.D., 1995. Schizophrenia, symptomatology and social inference: investigating "theory of mind" in people with schizophrenia. Schizophrenia research, 17(1), 5-13.

Cristóbal-Narváez, P., Sheinbaum, T., Ballespí, S., Mitjavila, M., Myin-Germeys, I., Kwapil, T.R., Barrantes-Vidal, N. (2016). Impact of adverse childhood experiences on psychotic-like symptoms and stress reactivity in daily life in nonclinical young adults. Focus, 14(3), 387-395.

Debbané, M., Benmiloud, J., Salaminios, G., Solida-Tozzi, A., Armando, M., Fonagy, P., \& Bateman, A. (2016). Mentalization-based treatment in clinical high-risk for psychosis: a rationale and clinical illustration. Journal of Contemporary Psychotherapy, 46(4), 217-225.

Debbané, M., Salaminios, G., Luyten, P., Badoud, D., Armando, M., Solida Tozzi, A., ... \& Brent, B. K. (2016). Attachment, neurobiology, and mentalizing along the psychosis continuum. Frontiers in human neuroscience, 10, 406.

Debbané, M., \& Toffel, E. (2019). Mentalizing through the early stages of the Psychosis Continuum. The Neurobiology-Psychotherapy-Pharmacology Intervention Triangle: The need for common sense in 21st century mental health, 141.

de Jong, S., van Donkersgoed, R. J. M., Timmerman, M. E., Aan Het Rot, M., Wunderink, L., Arends, J., ... \& Pijnenborg, G. H. M. (2019). Metacognitive reflection and insight therapy (MERIT) for patients with schizophrenia. Psychological Medicine, 49(2), 303-313. 
de Maat, S.M., Dekker, J., Schoevers, R.A. \& de Jonghe, F. (2007). Relative efficacy of psychotherapy and combined therapy in the treatment of depression: A meta-analysis. European Psychiatry, 22(1), 1-8.

de Maat, S.M., de Jonghe, F., Schoevers, R. \& Dekker, J. (2009) The effectiveness of long-term psychoanalytic therapy: A systematic review of empirical studies. Harvard Review of Psychiatry, 17(1): 1-23.

de Meulemeester, C., Vansteelandt, K., Luyten, P., \& Lowyck, B. (2018). Mentalizing as a mechanism of change in the treatment of patients with borderline personality disorder: A parallel process growth modeling approach. Personality Disorders: Theory, Research, and Treatment, 9(1), 22.

De Sousa, P., Sellwood, W., Eldridge, A., \& Bentall, R.P. (2018). The role of social isolation and social cognition in thought disorder. Psychiatry Research, 269, 56-63.

Driessen, E., Cuijpers, P., de Maat, S.C.M., Abbass, A.A., de Jonghe, F., Dekker, J.J.M. (2010). The efficacy of short-term psychodynamic psychotherapy for depression: a meta-analysis. Clinical Psychological Review, 30, 25-36.

Drukker, M., Visser, E., Sytema, S., \& Van Os, J. (2013). Flexible assertive community treatment: Severity of symptoms and psychiatric health service use; a real life observational study. Clinical Practice \& Epidemiology in Mental Health, 9, 202-209.

Durham, R.C., Chambers, J.A., Power, K.G. (2005). Long-term outcome of cognitive behaviour therapy (CBT) clinical trials in central Scotland. Health Technology Assessment, 9, 1-174.

Ensink, K., Normandin, L., Target, M., Fonagy, P., Sabourin, S., \& Berthelot, N. (2015). Mentalization in children and mothers in the context of trauma: An initial study of the validity of the Child Reflective Functioning Scale. British Journal of Developmental Psychology, 33(2), 203-217.

Fonagy, P., \& Bateman, A. W. (2006). Mechanisms of change in mentalization-based treatment of BPD. Journal of clinical psychology, 62(4), 411-430.

Fonagy, P., \& Luyten, P. (2009). A developmental, mentalization-based approach to the understanding and treatment of borderline personality disorder. Development and psychopathology, 21(4), 1355-1381.

Fonagy, P., \& Allison, E. (2014). The role of mentalizing and epistemic trust in the therapeutic relationship. Psychotherapy, 51(3), 372.

Fonagy, P., Luyten, P., Allison, E., \& Campbell, C. (2017). What we have changed our minds about: Part 2. Borderline personality disorder, epistemic trust and the developmental significance of social communication. Borderline personality disorder and emotion dysregulation, 4(1), 9. 
Freeman, D., Waite, F., Startup, H., Myers, E., Lister, R., McInerney, J., ... \& Foster, R. (2015). Efficacy of cognitive behavioural therapy for sleep improvement in patients with persistent delusions and hallucinations (BEST): a prospective, assessor-blind, randomised controlled pilot trial. The Lancet Psychiatry, 2(11), 975-983.

Frith, C. D. (1992). The cognitive neuropsychology of schizophrenia. London, UK: Psychology Press.

Fusar-Poli, P., Byrne, M., Valmaggia, L., Day, F., Tabraham, P., Johns, L., ... \& OASIS Team. (2010). Social dysfunction predicts two years clinical outcome in people at ultra-high risk for psychosis. Journal of psychiatric research, 44(5), 294-301.

Garety, P. A., \& Freeman, D. (1999). Cognitive approaches to delusions: a critical review of theories and evidence. British journal of clinical psychology, 38(2), 113-154.

Green, M. F., Horan, W. P., \& Lee, J. (2019). Nonsocial and social cognition in schizophrenia: current evidence and future directions. World Psychiatry, 18(2), 146-161.

Heavens, D., Odgers, K., \& Hodgekins, J. (2019). Cognitive behavioural therapy for anxiety in psychosis: a systematic review and meta-analysis. Psychosis, 11(3), 223-237.

Hoertel, N., López, S., Wang, S., González-Pinto, A., Limosin, F., \& Blanco, C. (2015). Generalizability of pharmacological and psychotherapy clinical trial results for borderline personality disorder to community samples. Personality Disorders: Theory, Research, and Treatment, 6(1), 81.

Hoffmann, H., Jäckel, D., Glauser, S., \& Kupper, Z. (2012). A randomised controlled trial of the efficacy of supported employment. Acta Psychiatrica Scandinavica, 125(2), 157-167.

Howes, O. D., \& Murray, R. M. (2014). Schizophrenia: an integrated sociodevelopmentalcognitive model. The Lancet, 383(9929), 1677-1687.

Jauhar, S., McKenna, P. J., Radua, J., Fung, E., Salvador, R., \& Laws, K. R. (2014). Cognitivebehavioural therapy for the symptoms of schizophrenia: systematic review and metaanalysis with examination of potential bias. The British Journal of Psychiatry, 204(1), 2029.

Jauhar, S., Laws, K. R., \& McKenna, P. J. (2019). CBT for schizophrenia: a critical viewpoint. Psychological medicine, 49(8), 1233-1236.

Jørgensen, C. R., Freund, C., Bøye, R., Jordet, H., Andersen, D., \& Kjølbye, M. (2013). Outcome of mentalization-based and supportive psychotherapy in patients with borderline personality disorder: a randomized trial. Acta Psychiatrica Scandinavica, 127(4), 305317.

Kelleher, I., Keeley, H., Corcoran, P., Ramsay, H., Wasserman, C., Carli, V., ... \& Cannon, M. (2013). Childhood trauma and psychosis in a prospective cohort study: cause, effect, and directionality. American Journal of Psychiatry, 170(7), 734-741. 
Khoury, B., Lecomte, T., Gaudiano, B. A., \& Paquin, K. (2013). Mindfulness interventions for psychosis: a meta-analysis. Schizophrenia research, 150(1), 176-184.

Killaspy, H., Bebbington, P., Blizard, R., Johnson, S., Nolan, F., Pilling, S., \& King, M. (2006). The REACT study: Randomised evaluation of assertive community treatment in north London. British Medical Journal, 332, 815-820.

Knekt, P., Lindfors, O., Härkänen, T., Välikoski, M., Virtala, E., Laaksonen, M. A., ... \& Helsinki Psychotherapy Study Group. (2008). Randomized trial on the effectiveness of long-and short-term psychodynamic psychotherapy and solution-focused therapy on psychiatric symptoms during a 3-year follow-up. Psychological medicine, 38(5), 689-703.

Langer, Á. I., Cangas, A. J., Salcedo, E., \& Fuentes, B. (2012). Applying mindfulness therapy in a group of psychotic individuals: a controlled study. Behavioural and Cognitive Psychotherapy, 40(1), 105-109.

Lardinois, M., Lataster, T., Mengelers, R., Van Os, J., \& Myin-Germeys, I. (2011). Childhood trauma and increased stress sensitivity in psychosis. Acta Psychiatrica Scandinavica, 123(1), 2835.

Laws, K. R., Darlington, N., Kondel, T. K., McKenna, P. J., \& Jauhar, S. (2018). Cognitive Behavioural Therapy for schizophrenia-outcomes for functioning, distress and quality of life: a meta-analysis. BMC psychology, 6(1), 32.

Leichsenring, F., Luyten, P., Hilsenroth, M. J., Abbass, A., Barber, J. P., Keefe, J. R., ... \& Steinert, C. (2015). Psychodynamic therapy meets evidence-based medicine: a systematic review using updated criteria. The Lancet Psychiatry, 2(7), 648-660.

Lehmann, A., Bahçesular, K., Brockmann, E. M., Biederbick, S. E., Dziobek, I., Gallinat, J., \& Montag, C. (2014). Subjective experience of emotions and emotional empathy in paranoid schizophrenia. Psychiatry research, 220(3), 825-833.

Lieberman, J. A., Dixon, L. B., \& Goldman, H. H. (2013). Early detection and intervention in schizophrenia: a new therapeutic model. JAMA, 310(7), 689-690.

Lincoln, T.M., Rief, W., Westermann, S., Ziegler, M., Kesting, M.L., Heibach, E., Mehl, S. (2014). Who stays, who benefits? Predicting dropout and change in cognitive behaviour therapy for psychosis. Psychiatry Research, 216(2), 198-205.

MacIntosh, H. B. (2013). Mentalizing and its role as a mediator in the relationship between childhood experiences and adult functioning: Exploring the empirical evidence. Psihologija, 46(2), 193-212.

McCormick, L. M., Brumm, M. C., Beadle, J. N., Paradiso, S., Yamada, T., \& Andreasen, N. (2012). Mirror neuron function, psychosis, and empathy in schizophrenia. Psychiatry Research: Neuroimaging, 201(3), 233-239. 
McGorry, P. D. (2010). Risk syndromes, clinical staging and DSM V: new diagnostic infrastructure for early intervention in psychiatry. Schizophrenia Research, 120(1-3), 4953.

Midgley, N., \& Vrouva, I. (Eds.). (2013). Minding the child: Mentalization-based interventions with children, young people and their families. Routledge, London, United Kingdom.

Moritz, S., \& Woodward, T. S. (2007). Metacognitive training in schizophrenia: from basic research to knowledge translation and intervention. Current opinion in psychiatry, 20(6), 619-625.

Myin-Germeys I, \& van Os J. (2007). Stress-reactivity in psychosis: evidence for an affective pathway to psychosis. Clinical psychology review, 27(4), 409-424.

Nordén, T., Malm, U., \& Norlander, T. (2012). Resource Group Assertive Community Treatment (RACT) as a tool of empowerment for clients with severe mental illness: a meta-analysis. Clinical practice and epidemiology in mental health: CP \& EMH, 8, 144.

Nugter, M. A., Engelsbel, F., Bähler, M., Keet, R., \& van Veldhuizen, R. (2016). Outcomes of FLEXIBLE assertive community treatment (FACT) implementation: a prospective real life study. Community mental health journal, 52(8), 898-907.

Pereira, J. G., \& Debbané, M. (2018). An Integrative-Relational Approach in Schizophrenia: From Philosophical Principles to Mentalization-Based Practice. In Hipólito, I., Gonçalves, J., Pereira, J. G. (Eds.), Schizophrenia and Common Sense, 193-207. Cham, Switzerland: Springer.

Pos, K., Franke, N., Smit, F., Wijnen, B. F., Staring, A. B., Van der Gaag, M., ... \& Schirmbeck, F. (2019). Cognitive behavioral therapy for social activation in recent-onset psychosis: Randomized controlled trial. Journal of consulting and clinical psychology, 87(2), 151.

Quidé, Y., Ong, X. H., Mohnke, S., Schnell, K., Walter, H., Carr, V. J., \& Green, M. J. (2017). Childhood trauma-related alterations in brain function during a Theory-of-Mind task in schizophrenia. Schizophrenia research, 189, 162-168.

Read, J., van Os, J., Morrison, A. P., \& Ross, C. A. (2005). Childhood trauma, psychosis and schizophrenia: a literature review with theoretical and clinical implications. Acta Psychiatrica Scandinavica, 112(5), 330-350.

Rossouw, T. I., \& Fonagy, P. (2012). Mentalization-based treatment for self-harm in adolescents: a randomized controlled trial. Journal of the American Academy of Child \& Adolescent Psychiatry, 51(12), 1304-1313.

Sanz, P. (2018). Technical adaptations from MBT to Schizophrenic Psychosis. Working on the Self Boundaries, presented at International Conference of Mentalization Based Treatment for Psychosis, Madrid, Spain. 
Sass, L. A., \& Parnas, J. (2003). Schizophrenia, consciousness, and the self. Schizophrenia Bulletin, $29,427-444$.

Schimmenti, A. (2017). The developmental roots of dissociation: A multiple mediation analysis. Psychoanalytic Psychology, 34(1), 96.

Segal, Z. V., Teasdale, J. D., \& Williams, J. M. G. (2004). Mindfulness-Based Cognitive Therapy: Theoretical Rationale and Empirical Status. In Hayes, S. C., Follette, V. M., \& Linehan, M. M. (Eds.), Mindfulness and acceptance: Expanding the cognitive-behavioral tradition, 4565. New York, NY: Guilford Press.

Selten, J. P., \& Cantor-Graae, E. (2005). Social defeat: risk factor for schizophrenia? The British Journal of Psychiatry, 187(2), 101-102.

Shedler, J. (2010). The efficacy of psychodynamic psychotherapy. American psychologist, 65(2), 98.

Sin, J., \& Spain, D. (2017). Psychological interventions for trauma in individuals who have psychosis: a systematic review and meta-analysis. Psychosis, 9(1), 67-81.

Solms, M. L. (2018). The neurobiological underpinnings of psychoanalytic theory and therapy. Frontiers in behavioral neuroscience, 12, 294.

Sprong, M., Schothorst, P., Vos, E., Hox, J., \& Van Engeland, H. (2007). Theory of mind in schizophrenia: meta-analysis. The British Journal of Psychiatry, 191(1), 5-13.

Steinert, C., Munder, T., Rabung, S., Hoyer, J., \& Leichsenring, F. (2017). Psychodynamic therapy: as efficacious as other empirically supported treatments? A meta-analysis testing equivalence of outcomes. American Journal of Psychiatry, 174(10), 943-953.

Systema, S., Wunderink, L., Bloemers, W., Roorda, L., \& Wiersma, D. (2007). Assertive community treatment in the Netherlands: A randomized controlled trial. Acta Psychiatrica Scandinavica, 116, 105-112.

Taubner, S., Zimmermann, L., Ramberg, A., \& Schröder, P. (2016). Mentalization mediates the relationship between early maltreatment and potential for violence in adolescence. Psychopathology, 49(4), 236-246.

Town, J. M., Diener, M. J., Abbass, A., Leichsenring, F., Driessen, E., \& Rabung, S. (2012). A metaanalysis of psychodynamic psychotherapy outcomes: Evaluating the effects of researchspecific procedures. Psychotherapy, 49(3), 276.

Trauelsen, A. M., Gumley, A., Jansen, J. E., Pedersen, M. B., Nielsen, H. G. L., Trier, C. H., ... \& Simonsen, E. (2016). Metacognition in first-episode psychosis and its association with positive and negative symptom profiles. Psychiatry research, 238, 14-23.

van den Berg, D. P., de Bont, P. A., van der Vleugel, B. M., de Roos, C., de Jongh, A., Van Minnen, A., $\&$ van der Gaag, M. (2015). Prolonged exposure vs eye movement desensitization and 
- Chapter Eight

reprocessing vs waiting list for posttraumatic stress disorder in patients with a psychotic disorder: a randomized clinical trial. JAMA psychiatry, 72(3), 259-267.

van der Gaag, M., Nieman, D. H., Rietdijk, J., Dragt, S., Ising, H. K., Klaassen, R. M., ... \& Linszen, D. H. (2012). Cognitive behavioral therapy for subjects at ultrahigh risk for developing psychosis: a randomized controlled clinical trial. Schizophrenia bulletin, 38(6), 11801188.

van der Gaag, M., van den Berg, D., \& Ising, H. (2017). CBT in the prevention of psychosis and other severe mental disorders in patients with an at risk mental state: a review and proposed next steps. Schizophrenia research, 88-93.

Van Oosterhout, B., Smit, F., Krabbendam, L., Castelein, S., Staring, A. B. P., \& van Der Gaag, M. (2016). Metacognitive training for schizophrenia spectrum patients: a meta-analysis on outcome studies. Psychological medicine, 46(1), 47-57.

van Veluw, S. J., \& Chance, S. A. (2014). Differentiating between self and others: an ALE metaanalysis of fMRI studies of self-recognition and theory of mind. Brain imaging and behavior, 8(1), 24-38.

Varese, F., Smeets, F., Drukker, M., Lieverse, R., Lataster, T., Viechtbauer, W., ... \& Bentall, R. P. (2012). Childhood adversities increase the risk of psychosis: a meta-analysis of patientcontrol, prospective-and cross-sectional cohort studies. Schizophrenia bulletin, 38(4), 661-671.

Weijers, J.G., ten Kate, C., Viechtbauer, W.V., Rampaart, L.J.A., Eurelings-Bontekoe, E.H.M., \& Selten, J.P. (2020). Mentalization-based treatment for psychotic disorder: a raterblinded, multi-center, randomized controlled trial. Psychological Medicine.

Wykes, T., Steel, C., Everitt, B., \& Tarrier, N. (2008). Cognitive behavior therapy for schizophrenia: effect sizes, clinical models, and methodological rigor. Schizophrenia bulletin, 34(3), 523-537. 




\section{SUMMARY IN DUTCH VALORIZATION}

\section{LIST OF PUBLICATIONS AND INVITED LECTURES}

\section{ACKNOWLEDGEMENTS CURRICULUM VITAE}

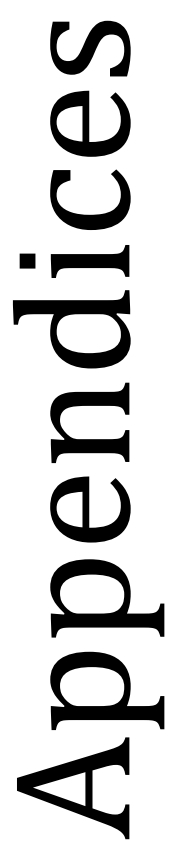




\section{Nederlandse samenvatting}

\section{Inleiding}

Dit proefschrift is het resultaat van een zes jaar lange empirische reis waarin ik onderzoek heb gedaan naar mentaliserend vermogen en kindermishandeling onder patiënten met een psychotische stoornis.

Psychose is een syndroom dat wordt gekenmerkt door een verlies van contact met de realiteit. Kenmerken van psychose zijn de aanwezigheid van idiosyncratische, soms aantoonbaar onjuiste interpretaties van de werkelijkheid, ook wel 'wanen' genoemd, en de perceptie van dingen die niet echt aanwezig zijn, 'hallucinaties' genoemd. Ongeveer $6 \%$ van de algemene bevolking heeft op enig moment in het leven één of meerdere psychotische ervaringen, maar zulke ervaringen hoeven niet noodzakelijkerwijs het dagelijks functioneren ernstig te verstoren.

Een psychotische stoornis is per definitie pathologisch en invalideert patiënten dikwijls ernstig. Binnen het spectrum van psychotische stoornissen wordt soms onderscheid gemaakt tussen affectieve psychoses, die uitsluitend voorkomen in de context van manische of depressieve episoden, en de zogenaamde 'niet-affectieve psychotische stoornis' (NAPS), die DSM-5-categorieën bevat als schizofrenie, schizo-affectieve stoornis, kortdurende psychotische stoornis en waanstoornis.

De meeste patiënten met NAPS vertonen wanen of hallucinaties (American Psychiatric Association, 2013), ook wel psychotische of 'positieve symptomen' genoemd. Traditioneel gezien ligt de nadruk van de behandeling op deze positieve symptomen. Dat is misschien ook niet zo gek omdat deze symptomen dikwijls het meest in het oog springen en daarnaast vaak adequaat behandeld kunnen worden met antipsychotische medicatie. Echter, naast de positieve symptomen, laten veel patiënten met NAPS ook een afname zien in het sociaal functioneren, zoals het vermogen om werk of relaties in stand te houden. De behandeling van dit sociaal disfunctioneren kan, ondanks recentelijk toegenomen aandacht (bijv. McCutcheon, Reis Marques, \& Howes, 2019), als ondergeschoven kindje worden beschouwd. Antispychotische medicatie is geen effectieve behandeling voor het sociaal disfunctioneren (Pinkham et al., 2003), waardoor dikwijls een grote kloof ontstaat tussen de ernst van de positieve symptomen en de mate van disfunctioneren bij patiënten met chronische NAPS (bijv. Birchwood et al., 2013). Sterker nog, in de afgelopen 100 jaar weinig vooruitgang geboekt in de behandeling van het sociaal disfunctioneren bij patiënten met NAPS (Green, Horan \& Lee, 2015). Dat is wrang, omdat de mate van sociaal disfunctioneren voorspellend is voor een terugkeer van een psychotische 
episode (Couture, Penn \& Roberts, 2006) en een slechter beloop van de stoornis (Fusar-Poli et al., 2010),

Echter, zo blijkt uit een recent overzichtsartikel, is functioneel herstel wel mogelijk (Leonhardt et al., 2017). In plaats van farmacologische factoren, lijken echter vooral sociale factoren - zoals een gevoel van verbondenheid (Eisenstadt, Monteiro, Diniz, \& Chaves. 2012) en de mate van ervaren sociale steun (Norman, Windell, Lynch \& Wachanda, 2013; Thomas, Muralidharan, Medoff , \& Drapalski, 2016) - van belang voor het functionele herstel. Daarom is er de laatste decennia meer aandacht voor de ontwikkeling van niet-farmacologische, psychosociale interventies die het sociaal functioneren verbeteren (bijv. Holthausen et al., 2007). Er zijn tot nu toe nog weinig studies geweest die laten zien dat middels psychotherapeutische interventies het sociaal functioneren duurzaam verbeterd kan worden (zie Horan \& Green, 2019 voor een overzicht), maar één enkele, recente studie gaf wel aanwijzingen dat dit mogelijk is (Bechi et al., 2019).

\section{Mentaliseren en sociaal functioneren}

Uit onderzoek blijkt dat een beperkt sociaal cognitief of 'mentaliserend' vermogen een belangrijke bijdrage levert aan het sociaal disfunctioneren van patiënten met NAPS (bijv. Fett, Viechtbauer, Penn, van Os \& Krabbendam, 2011). Mentaliseren is het vermogen om gedrag van jezelf en anderen te begrijpen in termen van mentale toestanden zoals verlangens, behoeftes, gevoelens en overtuigingen. Door te mentaliseren kunnen mensen zich een voorstelling maken van iemands binnenwereld. Vervolgens kan zo'n voorstelling gebruikt worden om het gedrag van anderen (en jezelf) te begrijpen, om het te kunnen voorspellen en om er op een adequate manier op te kunnen reageren. Er is echter wel een bepaalde mate van voorstellingsvermogen nodig om te kunnen mentaliseren, omdat het gedrag dat we bij een ander zien niet per se diens intenties reflecteert.

Patiënten met NAPS hebben op meerdere vlakken problemen met mentaliseren, zoals het kunnen interpreteren van andermans mentale toestanden (Sprong,, Schothorst, Vos, Hox, \& van Engeland, 2007), het herkennen van andermans emoties (O'Discoll, Laing \& Mason, 2014), het herkennen van de eigen emoties (Brunelin et al., 2007) en het verwoorden van hun eigen emoties (Trémeau, 2006). Het meemaken van mishandeling in de kindertijd zou één van de oorzaken voor dit beperkte mentaliserend vermogen kunnen zijn. Patiënten met NAPS zijn ongeveer driemaal vaker het slachtoffer geweest van misbruik of mishandeling in hun kindertijd dan mensen die geen psychose hebben gekregen (Varese et al., 2012). Een groot aantal artikelen suggereert zelfs dat kindermishandeling een causale rol speelt in de ontwikkeling van NAPS (Matheson, Shepherd, Pinchbeck, Laurens, \& Carr, 2013; Varese et al., 2012; Morgan \& Fisher, 2007; van Dam et al., 2015). 'Mentalisatietheorie' stelt dat de mate van 
veiligheid in de opvoedingsomgeving van een kind bepaalt hoe goed het vermogen om te mentaliseren zich ontwikkelt. Mishandeling in de kindertijd wordt gezien als diametraal tegengesteld aan een veilige opvoedingsomgeving. Het zou het ontwikkelen van het mentaliserend vermogen tegengaan omdat het representeren van de vijandige of onverschillige gemoedstoestand van de verzorger, een soort fobische angst zou opwekken, omdat dit overweldigend pijnlijk is voor het kind.

Sommige onderzoekers hebben ook geopperd dat een beperkt mentaliserend vermogen op haar beurt kan bijdragen aan de klinische symptomen van NAPS (Debbané \& Toffel, 2019). Er kan bijvoorbeeld worden betoogd dat achtervolgings- en betrekkingswanen per definitie onjuiste opvattingen zijn over de mentale toestanden van anderen (Frith, 1992). Daarnaast weerspiegelen negatieve symptomen, zoals afgevlakte affectieve expressie, mogelijk een communicatiestoornis die wordt veroorzaakt door een onvermogen om te begrijpen dat gebaren, intonatie en gezichtsuitdrukking mentale toestanden overbrengen (Frith, 1992).

\section{Doelen van dit proefschrift}

Op basis van al deze voorkennis was een volgende logische stap om onderzoek te doen naar de verwevenheid van kindermishandeling, mentaliserend vermogen en psychose. Daarnaast hebben we onderzocht of Mentaliseren Bevorderende Therapie voor Psychotische stoornissen (MBTp) een effectieve behandeling is om het sociaal functioneren en het mentaliserend vermogen van patiënten te verbeteren. $0 m$ dat te doen heb ik de volgende doelen opgesteld.

\section{Doel I: Schetsen hoe mentalisatietheorie kan bijdragen aan het begrijpen en behandelen} van NAPS. Deel I van dit proefschrift vormt het theoretissche raamwerk van het proefschrift. In hoofdstuk 1 geven we een algemene inleiding op het proefschrift. In hoofdstuk twee beschrijven we een theoretisch model van NAPS gebaseerd op de mentalisatietheorie. Daarin leggen we uit hoe kindermishandeling, onveilige hechting, sociaal disfunctioneren, slechte emotieregulatie, een gebrek aan 'epistemisch vertrouwen' en verminderd mentaliseren met elkaar samenhangen en hoe deze factoren kunnen bijdragen aan psychose. Daarnaast wordt besproken hoe MBTp kan worden ingezet om patiënten met NAPS te behandelen.

Doel II: Het toetsen van verschillende hypothesen die de relatie tussen kindermishandeling en de ernst van symptomen bij volwassen patiënten met NAPS kunnen verklaren. De studies die in deel II van dit proefschrift beschreven zijn, hadden tot doel om verschillende hypothesen te toetsen die kunnen helpen bij het verklaren van het verband tussen mishandeling in de kindertijd en de ernst van de symptomen in de volwassenheid.

In hoofdstuk drie onderzochten we of een verhoogde 'stressreactiviteit' het verband tussen kindermishandeling en psychotische symptomen in de volwassenheid kan verklaren, 
zoals eerder is gesuggereerd (Myin-Germeys \& van Os, 2007; Veling, Counotte, Pot-Kolder, van Os \& van der Gaag, 2016). Volgens deze opvatting resulteert cumulatieve blootstelling aan traumatische ervaringen tijdens de kindertijd in een verhoogde emotionele respons op stress. In andere woorden, de vroege blootstelling aan kindermishandeling zou personen op latere leeftijd gevoeliger maken voor stress (Glaser, van Os, Portegijs \& Myin-Germeys, 2006; Cristóbal-Narváez et al ., 2016; van Nierop et al., 2018; Lardinois, Lataster, Mengelers, van Os, \& Myin-Germeys, 2013; Reininghaus et al., 2016). Kindermishandeling bleek in eerder onderzoek inderdaad samen te hangen met grotere negatieve emotionele en psychotische reacties op stress (Glaser et al., 2006; Cristóbal-Narváez, 2016; van Nierop et al., 2018, Lardinois et al. 2011), maar de statistische analyse die gehanteerd werd in die studies was mogelijk niet optimaal voor het analyseren van niet-normaal verdeelde data. Het doel van hoofstuk drie was daarom om te testen of: 1) stress gerelateerd is aan de intensiteit van negatieve emotie en psychotische ervaringen in patiënten met NAPS; 2) de ernst van mishandeling in de kindertijd deze stressreactiviteit vergroot en 3 ) een statistische analyse die geschikt is voor niet-normaal verdeelde data, dezelfde resultaten zou opleveren.

In hoofdstuk vier onderzochten we of mishandeling in de kindertijd gerelateerd is aan meer eenzaamheid in de volwassenheid en of eenzaamheid op haar beurt weer meer symptomen in het dagelijks leven zou voorspellen. Vervolgens onderzochten we of de relatie tussen mishandeling in de kindertijd en psychotische symptomen in het dagelijks leven verklaard zou kunnen worden door eenzaamheid en of de relatie tussen psychotische symptomen en eenzaamheid verklaard kan worden door angstige en depressieve gevoelens.

In hoofdstuk vijf onderzochten we of een verminderd mentaliserend vermogen de relatie kan verklaren tussen kindermishandeling en de mate van sociaal disfunctioneren en de ernst van klinische symptomen bij volwassen patiënten met NAPS.

Doel III: Testen of Mentaliseren Bevorderende Therapie voor psychotische stoornis (MBTp) een effectieve aanvulling is op de gebruikelijke behandeling met betrekking tot sociaal disfunctioneren en beperkt mentaliserend vermogen. In Deel III hebben we getest of de toevoeging van MBTp aan Treatment as Usual (TAU) zou leiden tot een grotere verbetering op gebied van sociaal functioneren en mentaliserend vermogen (naast andere uitkomstvariabelen).

\section{Belangrijkste meetinstrumenten van het proefschrift}

\section{Sociaal functioneren.}

De mate van sociaal functioneren werd gemeten aan de hand van de Social Functioning Scale (SFS), een zelfrapportage-vragenlijst (Birchwood, Smith, Cochrane, Wetton \& Copestake, 1990) die zeven dimensies van sociaal functioneren meet, te weten: terugtrekking uit sociale situaties, interpersoonlijke communicatie, vermogen tot autonoom functioneren, daadwerkelijk 
autonoom functioneren, recreatieve activiteiten, sociale activiteiten en werk. De SFS maakt gebruik van concrete voorbeelden om het sociaal functioneren te beoordelen (bijvoorbeeld de hoeveelheid vrienden of de tijd die per dag alleen doorgebracht wordt) zodat subjectieve oordelen zoveel mogelijk vermeden kunnen worden. Onderzoek heeft aangetoond dat de SFS betrouwbaar en valide is en daarnaast gevoelig genoeg om veranderingen door de tijd heen op te pikken (Birchwood et al., 1990). De algemene score voor sociaal functioneren wordt bepaald door het gemiddelde te nemen van alle dimensies.

\section{Meting van mentaliserend vermogen}

Het meten van mentaliserend vermogen staat nog in de kinderschoenen. Er is tot nu toe weinig consensus over hoe mentaliserend vermogen het best kan worden gemeten. Het meten van het vermogen om te mentaliseren op basis van zelfrapportageinstrumenten is moeilijk, omdat het enig mentaliserend vermogen vereist om te begrijpen waar het eigen mentaliserend vermogen tekortschiet. Aan de andere kant zijn veelgebruikte niet-zelfrapportageinstrumenten erg verschillend en hebben dikwijls slechte psychometrische eigenschappen. Ze zijn bijvoorbeeld niet betrouwbaar of meten niet wat ze beogen te meten (Green et al, 2008; Horan \& Green, 2019). De instrumenten voor het meten van mentaliserend vermogen die in dit proefschrift worden gebruikt, verdienen dus enige aandacht.

In een recent grootschalig onderzoek naar de psychometrische eigenschappen van veelgebruikte instrumenten om het mentaliserend vermogen te meten, werd de Hinting Task (HT; Corcoran, Mercer, \& Frith, 1995) als een van de weinige instrumenten 'goed genoeg' bevonden voor gebruik in klinisch onderzoek (Pinkham et al., 2013). De HT bevat tien korte passages, waarbij elke passage een interactie tussen twee personages weergeeft die door de respondent moet worden geïnterpreteerd. De personages bedoelen in deze passages iets anders dan dat zij letterlijk zeggen. Om te kunnen begrijpen wat de personages in de passages bedoelen, moeten respondenten zich in de personage kunnen verplaatsen. Een voorbeeld:

Peter komt het kantoor van Annet binnen na een lange zware reis. Annet begint direct te vertellen over een aantal zakelijke ontwikkelingen. Peter onderbreekt Annet met een: “Tjonge, jonge, dat was me een lange zware reis". Wat bedoelde Peter werkelijk toen hij dit zei? (Corcoran, Mercer, \& Frith, 1995).

De HT meet dus het vermogen om een idee te vormen over wat er omgaat in andermans geest, ook wel 'Theory of Mind' genoemd. In feite gaat het hier om een cognitief, op anderen georiënteerd aspect van mentaliseren. De HT toonde voldoende test-hertestbetrouwbaarheid, slechts kleine leereffecten, een sterke relatie met sociaal functioneren en ook voldoende 
gevoeligheid om NAPS patiënten te kunnen onderscheiden van mensen zonder NAPS (Pinkham et al., 2013). De HT wordt echter ook bekritiseerd omdat hij te makkelijk zou zijn, wat kan leiden tot 'plafondeffecten' (bijv. Roberts \& Penn, 2009). De HT wordt gescoord op een 20puntsschaal, waarbij hogere scores een betere Theory of Mind vertegenwoordigen.

Het tweede instrument dat we hebben gebruikt voor het meten van mentaliserend vermogen is de Social Cognition and Object-Relations Scale (SCORS), die gebruikt kan worden om narratieven van patiënten te analyseren en te beoordelen. Om narratieven te genereren is gebruik gemaakt van de Thematische Apperceptie-Test (TAT; Murray, 1943). De TAT is een zogenaamde 'projectieve' taak die bestaat uit zwart-wit foto's van ambigue, veelal sociale situaties zoals mensen in een landschap. In totaal zijn er zes platen gebruikt. Respondenten worden daarbij onder andere gevraagd om te beschrijven wat er gebeurt op de plaat, wat er omgaat in de personen op de plaat, wat er vooraf is gegaan aan de plaat en hoe de situatie op de plaat afloopt. Het is vaak niet helemaal duidelijk wat de situaties precies voorstellen en de platen kunnen dus op meerdere manieren geïnterpreteerd worden. De patiënt moet dus zelf invulling geven aan hetgeen dat afgebeeld wordt. Met behulp van de SCORS kan vervolgens ontleed worden in welke mate patiënten een 'psycho-logisch' verhaal kunnen vertellen over de platen.

In het systeem van SCORS worden vier dimensies van sociaal cognitief vermogen onderscheidden: het vermogen om een beeld te vormen van de psychologische drijfveren van anderen en het vermogen om op basis daarvan een logische en geloofwaardige verklaring voor gedrag te kunnen geven (ook wel 'begrip van sociale causaliteit genoemd'); het vermogen onderscheid te kunnen maken tussen het eigen perspectief en dat van de ander (de 'complexiteit van representaties'); de mate waarin sociale interactie als goedaardig gezien wordt (de 'affect-toon van relaties') en in hoeverre er sprake is van morele standaarden waarbij de ander gezien wordt als een doel op zich en niet als een middel (het 'vermogen tot emotioneel investeren'). Deze vier dimensies van mentaliserend vermogen werden gescoord op een vijfpuntsschaal, waarbij hogere scores ook hogere sociale cognitieve capaciteiten vertegenwoordigen.

De SCORS wordt minder vaak gebruikt vanwege zijn tijdrovende en projectieve aard en wordt daarom vaak overgeslagen bij beoordelingen van meetinstrumenten (zie bijv. Pinkham et al., 2013; Horan, \& Green 2019). Dit is jammer omdat het goed bestudeerde en voldoende adequate psychometrische eigenschappen bezit. Onderzoek wijst uit dat het een valide en betrouwbaar instrument is om sociale cognitie te meten (Meyer, 2004) met een goede interne consistentie tussen platen (Hibbard, Mitchell \& Porcerelli, 2001) en een goede (Hibbard et al., 2001) tot uitstekende (Meyer, 2004) betrouwbaarheid tussen beoordelaars van narratieven. Belangrijk is ook om te vermelden dat volgens Luyten, Fonagy, Lowyck en Vermote (2012) de 
SCORS een van de weinige testen is die vrijwel alle aspecten van het mentaliserend vermogen meet, zowel de cognitieve aspecten (gemeten door complexiteit van representaties en begrip van sociale causaliteit) als de affectieve aspecten (gemeten door affect-toon van relaties en vermogen tot emotioneel investeren).

\section{Mishandeling in de kindertijd}

De Childhood Experience of Care and Abuse (CECA; Bilfulco, Brown \& Harris, 1994) is een retrospectief, semi-gestructureerd interview waarmee onderzoekers de ernst van mogelijk misbruik en mishandeling op de leeftijd van 0-16 jaar kunnen beoordelen. De CECA brengt de mate van ouderlijk conflict, fysieke mishandeling, seksueel misbruik en psychologische mishandeling in kaart. Fysieke mishandeling werd daarbij gedefinieerd als fysiek geweld met lichamelijk letsel tot gevolg. Seksueel misbruik werd gedefinieerd als een seksueel incident dat door de participant als ongewenst werd ervaren. Ouderlijk conflict werd gedefinieerd als de hoeveelheid ruzies tussen de zorgverleners (mogelijk inclusief het kind). Psychologische mishandeling werd gedefinieerd als extreme kritiek, afwijzing, of vernedering.

Van elk type mishandeling werd zowel intensiteit als frequentie in kaart gebracht. De frequentie van mishandeling werd beoordeeld op een vijfpuntsschaal: 0 (nooit), 1 (zelden: één of twee keer), 2 (incidenteel: meer dan twee keer, maar niet maandelijks), 3 (regelmatig: maandelijks of vaker) of 4 (vaak: wekelijks of vaker). De intensiteit van misbruik werd beoordeeld op een vierpuntsschaal: 0 (geen), 1 (enigszins), 2 (matig) of 3 (ernstig), met uitzondering van ouderlijk conflict, dat werd gescoord op een vijfpuntsschaal die ook 4 (geweld) bevatte. Het product van intensiteit en frequentie samen bepaalde de totaalscore van mishandeling in de kindertijd, en varieerde tussen de 0 en 52 , waarbij hogere scores ernstiger vormen van mishandeling vertegenwoordigden. De CECA is betrouwbaar en valide bevonden door de ontwikkelaars (Bifulco, Brown \& Harris, 1994).

\section{Klinische symptomen en ziekte-inzicht}

De Positive and Negative Syndrome Scale (PANSS; Kay, Fiszbein, \& Opfer, 1987) is gebruikt om de klinische symptomen en ziekte-inzicht in kaart te brengen. Het is een semi-gestructureerd interview dat veel gebruikt in onderzoek naar NAPS omdat het goede psychometrische kwaliteiten, bezit (Peralta \& Cuesta, 1994). We hebben de PANSS specifiek gebruikt om de ernst van positieve symptomen, negatieve symptomen, depressie, angst en gebrek aan ziekte-inzicht in kaart te brengen. In dit instrument bevatten de dimensies 'positieve symptomen' en 'negatieve symptomen' elk zeven items (zie Weijers et al. 2016 voor meer informatie). Angst, depressie en gebrekkig ziekte-inzicht werden alle met één item gemeten. Elk item werd gemeten met zevenpuntsschalen, waarbij 1 de afwezigheid van het symptoom 
vertegenwoordigde en 7 een zeer ernstige mate. Voor dit proefschrift is gebruik gemaakt van een Nederlandse versie (Wolthaus, Dingemans \& Schene, 2000).

\section{Experience Sampling: psychotische ervaringen, negatief en positief affect, eenzaamheid,} middelengebruik, verscheidene types stress en stressreactiviteit.

In dit proefschrift hebben we tevens gebruik gemaakt van een intensieve dagboekmethode, de 'Experience Sampling Method' (ESM). Gevoelens en psychiatrische symptomen zoals eenzaamheid, angst of het horen van stemmen zijn per definitie tijdelijke toestanden die, afhankelijk van de context, kunnen fluctueren gedurende de dag. We hebben daarom een elektronisch dagboek, de 'PsyMate' gebruikt om ervaringen van participanten in hun dagelijks leven vast te leggen. Tijdens vier meetperiodes verspreid over twee jaar, werd aan patiënten gevraagd om de PsyMate gedurende zes dagen bij zich te houden. Tien keer per dag genereerde de PsyMate een geluidssignaal (een piep) op onvoorspelbare momenten. Daarop moesten participanten antwoorden geven op verscheidene vragen over hun gemoedstoestand. Eerder onderzoek heeft aangetoond dat ESM een betrouwbare en valide methode is voor metingen bij personen met psychotische stoornissen (Delespaul, de Vries, \& van Os, 2002; Kimhy et al., 2006; Thewissen et al., 2011). Omdat proefpersonen herhaaldelijk gevraagd worden om vragenlijsten in te vullen in hun natuurlijke omgeving, is ESM meer ecologisch valide dan de meeste meetinstrumenten die vaak in een instelling of universiteit worden afgenomen. Hieronder beschrijven we enkele variabelen die gemeten zijn met behulp van de PsyMate en die aan bod komen in dit proefschrift. Alle vragen of stelling, voortaan 'items' genoemd, werden gemeten op een zevenpuntsschaal ( 1 = helemaal niet, 7 = heel erg), tenzij anders aangegeven.

Psychotische ervaringen. Aan participanten werd gevraagd om de ernst van hun psychotische ervaringen op dat moment te beoordelen met de volgende zeven items: 'Ik voel me achterdochtig', 'Ik ben bang om de controle te verliezen', 'Ik voel dat anderen me niet mogen', 'Ik voel dat anderen me pijn willen doen', 'Mijn gedachten worden beïnvloed door andere mensen',' Ik voel me onwerkelijk'en' Ik hoor stemmen'. De gemiddelde score van deze items bepaalde de totale score van psychotische ervaringen.

Depressieve en angstige gevoelens. De mate van van depressieve en angstige gevoelens. werden beoordeeld door de afzonderlijke items 'Ik voel me neerslachtig' en 'Ik voel me angstig'.

Eenzaamheid. De mate van eenzaamheid werd gemeten met het item 'Ik voel me eenzaam'.

Middelengebruik. Bij elke piep werd met behulp van categorische items uitgevraagd of participanten sinds de laatste piep middelen hadden gebruikt, waaronder: (1) cafeïne, (2) nicotine, (3) medicatie, (4) alcohol, (5) cannabis, (6) andere drugs, of (7) geen. 
Sociale stress. Participanten werd gevraagd in te vullen of ze alleen waren of in gezelschap van anderen. Wanneer zij in het gezelschap van anderen verkeerden werd sociale stress vervolgens gemeten met de items: 'Ik zou liever alleen zijn' en 'Ik het gezelschap waarin ik momenteel verkeer prettig' (omgekeerd gecodeerd).

Activiteit-gerelateerde stress. De mate van activiteit-gerelateerde stress werd beoordeeld aan de hand van drie items met betrekking tot de activiteit die participanten op dat moment ondernamen. In het bijzonder beoordeelden participanten hoe bekwaam ze zich voelden in het doen van hun huidige activiteit ('Ik ben niet bekwaam om deze activiteit te doen'), hoe moeilijk hun huidige activiteit was ('Deze activiteit is moeilijk'), en in welke mate ze liever bezig zouden zijn met een andere activiteit ('Ik zou liever iets anders doen'). Het gemiddelde van de drie items werd gebruikt als een indicator voor activiteit-gerelateerde stress.

Gebeurtenis-gerelateerde stress. De mate van gebeurtenis-gerelateerde stress werd beoordeeld door participanten te vragen om aan te geven hoe aangenaam de belangrijkste voorgaande gebeurtenis was geweest. Deze score werd omgekeerd gecodeerd als indicator voor gebeurtenis-gerelateerde stress.

Negatief affect. De mate van negatief affect werd gedefinieerd als de gemiddelde score van de volgende stemmingsitems: 'Ik voel me angstig', 'Ik voel me eenzaam', 'Ik voel me onzeker', 'Ik voel me geïrriteerd', 'Ik voel me neerslachtig', 'Ik voel me schuldig' en 'Ik voel me somber'.

Positief affect. De mate van positief affect werd gedefinieerd als de gemiddelde score van de volgende stemmingsitems: 'Ik voel me gelukkig', 'Ik voel me tevreden', 'Ik voel me vrolijk', 'Ik voel me ontspannen' en 'Ik voel me enthousiast'.

Stressreactiviteit. De mate van stressreactiviteit werd berekend als de associatie tussen stress (dat kon zowel activiteit-, gebeurtenis-gerelateerde of sociale stress zijn) en negatief affect of psychotische ervaringen.

\section{Bevindingen}

Deel I, Hoofdstuk 2.

In hoofdstuk 2 stelden we, overeenkomstig de huidige opvattingen over het ontstaan van non-affectieve psychose (bijv. Howes \& Murray, 2014), dat een sensitisatie van het mesolimbische dopaminerge systeem in belangrijke mate bijdraagt aan het ontstaan van de vreemde ervaringen die kenmerkend zijn voor psychoses. Verder gebruikten we mentalisatietheorie als een conceptueel raamwerk om te beargumenteren waarom zulke vreemde ervaringen vaak op psychotische wijze geïnterpreteerd worden. Personen met een verminderd vermogen om te mentaliseren, vertonen moeite om zich bewust te worden van hun subjectieve gemoedstoestanden en ervaringen, wat het bemoeilijkt om daar kritisch op te 
reflecteren. Op deze manier houden zij minder rekening met de invloed die hun subjectieve gemoedstoestanden hebben op hun aandacht, gedachten en gedrag. Wanneer iemand zich bijvoorbeeld niet bewust is van zijn achterdocht, zal hij niet opmerken hoe deze mentale toestand de ervaring van de werkelijkheid beïnvloedt, resulterend in de overtuiging dat anderen bedrieglijk en slecht zijn, in plaats van dat hij ze zo ervaart. Een ander voorbeeld is dat stemmen die intern gegenereerd zijn, kunnen worden toegeschreven aan externe bronnen. In feite wordt op deze manier de subjectieve ervaring gelijkgesteld aan de externe realiteit. Eenvoudig gezegd helpt mentaliseren om subjectieve beleving te identificeren en feiten van beleving te scheiden.

We betoogden verder dat een beperkt mentaliserend vermogen mogelijk ook verband houdt met het beperkte sociaal functioneren dat geobserveerd wordt bij patiënten met NAPS. Als 'hoger cognitief proces' wordt mentaliseren ondermijnd door overmatige emotionele stress. Tijdens emotionele ontregeling nemen limbische delen van de hersenen de controle over de hersenprocessen op zich. Hierdoor reageert men sneller op zaken die acuut de aandacht vragen, zoals gevaar, maar dit proces gaat ten koste van cognitieve complexiteit. Daardoor zijn individuen minder goed in staat om adequaat op hun eigen emoties en die van anderen te reflecteren. Dit veroorzaakt problemen op gebied van functioneren in complexe sociale situaties omdat de persoon in kwestie moeite ervaart te begrijpen wat anderen denken en voelen. Mogelijk gevolgen daarvan zijn buitengesloten te worden door anderen of het zich terugtrekken uit sociale situaties.

We beargumenteerden verder dat mishandeling en een onveilige hechting in de kindertijd - vaak voorkomend bij patiënten met NAPS - bijdragen aan beperkingen in het mentaliserend vermogen. Mentalisatietheorie stelt namelijk dat het vermogen om op emoties te reflecteren en ze te reguleren wordt ontwikkeld door een veilige interactie met ouders (en later met leeftijdsgenoten). Kindermishandeling of verwaarlozing zou een fobische angst bewerkstelligen voor het reflecteren op andermans gemoedstoestand, wat de ontwikkeling van het mentaliserend vermogen bemoeilijkt (Kim, 2015).

Ten slotte hebben we betoogd dat een gebrek aan 'epistemisch vertrouwen' - dat wil zeggen, het vermogen om nieuwe informatie van anderen te behandelen als potentieel goedbedoeld en relevant (Fonagy, Luyten, Allison \& Campbell, 2017) - een persoon afsnijdt van sociaal leervermogen en interpersoonlijke betekenisgeving. Fonagy en collega's (2017) veronderstellen dat het voor mensen gemakkelijker is om iets voor waar aan te nemen, wanneer zij de bron van die informatie vertrouwen. Echter, patiënten met NAPS tonen dikwijls een algemene houding van wantrouwen ten opzichte van anderen, en wat zij te zeggen hebben, soms aangeduid als 'epistemische hypervigilantie'. Zulk wantrouwen snijdt mensen af van belangrijke bronnen van informatie over het zelf in relatie tot anderen, aldus Fonagy en Allison 
(2014). Daardoor ontwikkelen zij een 'rigiditeit' ten opzichte van het perspectief van anderen. Zodoende zijn zij minder in staat om overtuigingen over zichzelf, anderen en de wereld te wijzigen. Een sociaal geconstrueerd perspectief op de realiteit wordt dan vervangen door een persoonlijke betekenisgeving die betekenisvol is voor het individu, maar door anderen als vreemd wordt gezien (bijvoorbeeld Pereira \& Debanné, 2018).

\section{Deel II, Hoofdstuk 3.}

In hoofdstuk drie observeerden we, overeenkomstig eerder onderzoek (bijv. Lardinois, Lataster, Mengelers, Van Os, \& Myin-Germeys, 2011), dat gerapporteerde stress in het dagelijks leven gerelateerd is aan de intensiteit van negatief affect en psychotische symptomen. Eerdere studies (bijv. Lardinois et al., 2011; Cristobal-Navaez et al., 2018) stelden ook vast dat patiënten met NAPS die kindermishandeling hadden meegemaakt, een meer intense psychotische en emotionele reactie lieten zien op stress. Onze resultaten toonden echter niet eenduidig aan dat gerapporteerde mishandeling in de kindertijd de intensiteit van deze affectieve of psychotische reactie op stress in de volwassenheid vergroot. Mogelijk kunnen de verschillende statistische benaderingen die gehanteerd zijn het verschil in uitkomsten verklaren. In eerdere studies is gebruik gemaakt van een analysemethode die mogelijk ongeschikt is voor het analyseren van niet-normaal verdeelde data. Concluderend kan gesteld worden dat de relatie tussen stress en de intensiteit van negatieve affect of psychotische ervaringen (indien aanwezig) robuust lijkt. Er bestaat echter nog steeds onzekerheid over de vraag of de relatie tussen stress en de intensiteit van psychotische ervaringen en negatief affect in de volwassenheid daadwerkelijk wordt gemodereerd door een voorgeschiedenis van mishandeling in de kindertijd.

\section{Deel II, Hoofdstuk 4.}

Hoofdstuk vier toonde bij patiënten met een bestaande psychotische stoornis aan dat een verhoogde neiging tot eenzaamheid een potentieel mechanisme is waardoor mishandeling in de kindertijd de ernst van psychotische symptomen op volwassen leeftijd beïnvloedt. De relatie tussen eenzaamheid en psychotische symptomen kan op haar beurt worden verklaard door toegenomen angstige en depressieve gevoelens. Deze bevindingen ondersteunen de groeiende consensus dat personen met een verleden van mishandeling of misbruik geneigd zijn om op volwassen leeftijd eenzaam te zijn (Merz en Jak, 2013; Murphy, Shevlin, Adamson, \& Houston, 2013) en een verhoogd risico hebben om een psychose te ontwikkelen (Varese et al., 2012). Deze bevindingen zijn ook in lijn met eerder onderzoek dat aantoonde dat eenzaamheid gerelateerd is aan psychotische symptomen (Michalska, Rhodes, Vasilopoulou, \& Hutton, 2017) en biedt verdere ondersteuning voor de 'Social Defeat' theorie van psychose-etiologie, die stelt dat een ondergeschikte sociale positie of sociale buitensluiting bijdraagt aan de sensitisering 
van het mesolimbisch dopamine-systeem (Selten, van der Ven, Rutten, \& Cantor-Graae, 2013). Er is met de huidige studie ook meer bewijs gevonden voor de stelling dat eenzaamheid een deel van de relatie tussen kindermishandeling en psychotische ervaringen verklaart (Boyda \& McFeeters, 2015) en dat eenzaamheid een invloed uitoefent op psychotische symptomen middels depressie en angst (Jaya, Hillmann, Reininger, Gollwitzer, \& Lincoln, 2016; Sündermann, Onwumere, Kane, Morgan, \& Kuipers, 2014).

\section{Deel II, Hoofdstuk 5.}

Deze studie testte de hypothese dat een beperkt mentaliserend vermogen een mogelijke verklaring geeft voor de relatie tussen mishandeling door ouders in de kindertijd en de ernst van klinische symptomen of de mate van het sociaal disfunctioneren op volwassen leeftijd. Het onderzoek wees uit dat een meerderheid van de patiënten in onze steekproef meldde dat ze ouderlijk conflict, mishandeling of misbruik hadden ervaren tijdens hun kindertijd. De ernst van dit misbruik was geassocieerd met de ernst van positieve en negatieve symptomen en met de mate van beperking van het mentaliserend vermogen, maar niet met de mate van sociaal disfunctioneren. Bovendien observeerden we dat een verminderd mentaliserend vermogen ongeveer $40 \%$ van het verband tussen misbruik in de kindertijd en de ernst van negatieve symptomen in de volwassenheid verklaarde.

\section{Deel III, Hoofdstuk 6.}

Hoofdstuk 6 bevat het onderzoeksprotocol van onze studie naar de effectiviteit van Mentaliseren Bevorderende Therapie voor Psychotische stoornissen (MBTp). Dit hoofdstuk beschrijft de hypothesen en methoden in een vooraf gepubliceerd artikel. Deze studie is een gerandomiseerd, gecontroleerd onderzoek met geblindeerde beoordelaars. De primaire onderzoeksvraag van dit onderzoek was: Leidt de toevoeging van MBTp aan treatment as usual (TAU) voor NAPS tot een grotere verbetering van sociaal functioneren en mentaliserend vermogen (naast andere uitkomstvariabelen)? Hieronder geven we een kort overzicht van de methode van het onderzoek.

Participanten. Participanten die aan het onderzoek meededen waren patiënten met NAPS (DSM-IV-criteria; APA, 2000), waaronder de diagnoses schizofrenie, schizofreniforme of schizoaffectieve stoornis (295.x), waanstoornis (297.1), korte psychotische stoornis (298.8) of psychotische stoornis niet anders gespecificeerd (298.9). Inclusiecriteria waren: een NAPSdiagnose, minimaal 6 maanden in behandeling, maar niet meer dan 10 jaar; tussen de 18 en 55 jaar oud. Exclusiecriteria waren: verstandelijke beperking en/of analfabetisme; een gebrek aan beheersing van de Nederlandse taal; middelenmisbruik in dusdanige mate dat een ontwenningsbehandeling voor de patiënt noodzakelijk was (na succesvolle behandeling kwam 
de patiënt weer in aanmerking voor deelname aan het onderzoek. Patiënten werden niet toegelaten tot MBT-sessies onder invloed van middelen).

Randomisatie. Aan clinici die werkzaam waren in FACT-teams van het psychiatrische instituut Rivierduinen (Zuid-Holland) of Altrecht (Zeist), werd gevraagd hun caseload door te nemen en te bepalen wie voldeed aan de inclusiecriteria van de studie. Vervolgens werden patiënten die interesse toonden en wanneer zij daarvoor goedkeuring gaven, benaderd door een onderzoeksassistent. Patiënten kregen uitleg over het onderzoek en een week bedenktijd om te beslissen of ze wilden deelnemen. Na het ondertekenen van een toestemmingsformulier, werden zij officieel participanten en volgde de nulmeting. Om de geblindeerdheid van de beoordelaars te garanderen, werden participanten pas na de nulmeting gerandomiseerd. Een onafhankelijke onderzoekscoördinator wees vervolgens participanten willekeurig toe aan de Treatment as Usual (TAU)-conditie of de TAU plus MBTp-conditie. De onderzoeker en participanten waren gedurende het onderzoek op de hoogte van de behandeltoewijzing, maar alle metingen werden uitgevoerd door onderzoekers die blind waren voor de behandeltoewijzing.

\section{Therapie.}

$T A U$. De psychiatrische instituten Rivierduinen en Altrecht bieden klinische en poliklinische behandeling aan duizenden patiënten met psychiatrische stoornissen in respectievelijk Zuid-Holland en provincie Utrecht. Patiënten worden er behandeld volgens de Nederlandse multidisciplinaire richtlijn voor schizofrenie (van Alphen et al. 2012) en de behandelteams werkten volgens het zogenaamde 'Flexible Assertive Community Treatment' (FACT)-model waarin de behandeling wordt geïntensiveerd wanneer patiënten in een crisis verkeren, met als doel om een klinische opname te voorkomen. FACT-teams bestaan uit verpleegkundigen, psychologen en psychiaters, die psycho-educatie, farmacologische behandeling, ondersteunende therapie of cognitieve gedragstherapie (CGT) geven. FACT-teams hebben verder ook professionals die gespecialiseerd zijn in het helpen van patiënten bij het structureren van hun sociale leven, waaronder maatschappelijk werkers, die juridische en sociale hulp bieden, en Individual Placement and Support (IPS)-coaches die patiënten helpen om te re-integreren door het vinden van een baan of opleiding.

TAU plus MBT. Patiënten in de TAU plus MBTp-conditie ontvingen dezelfde hierboven beschreven behandeling, maar volgden daarnaast ook individuele en groepssessies MBTp. De belangrijkste elementen van het originele MBT-handboek (Bateman \& Fonagy, 2006) vormden tevens de leidraad voor MBTp. De therapeutische houding binnen MBT-sessies wordt gekenmerkt door de 'niet wetende houding' waarbij de therapeut actief vragen stelt en een oprechte interesse in de actuele gemoedstoestand van de patiënt cultiveert. Dit geeft de patiënt 
de ervaring door iemand gehoord te worden, maar stimuleert ook de nieuwsgierigheid van de patiënt naar diens eigen mentale toestand. Daarnaast is het belangrijk dat de therapeut rekening houdt met de mate van mentaliserend vermogen van de patiënt. Onder invloed van stress kan dat vermogen namelijk min of meer verloren gaan, waardoor de patiënt niet goed meer kan reflecteren op zijn eigen of andermans gemoedstoestand. De meeste, wat complexere, psychologische interventies hebben dan geen zin meer. Tegelijkertijd is het van belang om samen met de patiënt emotioneel beladen gedachtes en herinneringen te confronteren en bespreekbaar te maken, zodat diegene minder overspoeld raakt door zijn of haar emoties. Doel van de behandeling is dat de patiënt op een gegeven moment in staat is om te kunnen blijven reflecteren op zichzelf en de ander, zelfs als er (hevige) emoties ervaren worden.

Interventies. Bij het toepassen van interventies moet altijd worden bedacht dat stress het mentaliserend vermogen ondermijnt. Daarom wordt er bij MBT gewerkt met vier interventie-niveaus, die stapsgewijs gebruikt kunnen worden, afhankelijk van de mate van stress. Op het hevigste stressniveau zijn interventies vooral gericht op het verminderen van stress bij de patiënt. Dat kan middels steunende interventies zoals de empathische validatie van de gevoelens van de patiënt. In de tweede fase, wanneer de stress wat afgenomen is, vraagt de therapeut om opheldering van een situatie of uitleg bij de gevoelens en gedachten van de patiënt. In feite gaat de therapeut naast de patiënt zitten om samen met diegene meer duidelijkheid te krijgen over diens binnenwereld. Vaak worden details onderzocht die de patiënt emotioneel lijken te raken, of de patiënt zouden moeten beïnvloeden, maar dat niet doen. Dit leidt vervolgens tot de volgende fase, die ook wel 'gementaliseerde emotionaliteit' genoemd wordt. In deze fase is het van belang om de patiënt aan te sporen te reflecteren op emoties, terwijl deze in het hier-en-nu worden ervaren. Het expliciet mentaliseren van een primaire, affectieve ervaring geeft de patiënt de mogelijkheid om er meer afstand van te nemen, waardoor er ruimte ontstaat om andere, meer doordachte keuzes te kunnen maken. In de laatste fase wordt er expliciet gepraat over de relatie tussen therapeut en patiënt. In deze fase reflecteren zowel patiënt als therapeut op hun emotionele ervaringen om te weten te komen hoe deze door hun relatie worden beïnvloed.

Duur en frequentie. In vergelijking met de originele MBT is de lengte van MBTp ongewijzigd gebleven: 18 maanden. De frequentie en duur van sessies is echter verminderd. Onze ervaring op basis van een proef-interventie is dat NAPS geassocieerd is met ernstigere beperkingen in het mentaliserend vermogen dan bij patiënten met een Borderline Persoonlijkheidsstoornis. Gezien het gevaar van overprikkeling bij therapeutische interventies, is groepstherapie beperkt tot een wekelijkse sessies van 1 uur, terwijl individuele therapie plaatsvindt in tweewekelijkse sessies van een half uur. 
Groepstherapie. Omdat patiënten met NAPS de neiging hebben om veel stress te ervaren in sociale situaties, biedt groepstherapie bij uitstek de mogelijkheid te oefenen met mentaliseren in een stressvolle omgeving. Groepstherapie kan ook een gevoel van verbondenheid en gehechtheid genereren, dat mentaliseren bevordert. De groepen bevatten maximaal acht patiënten en werden gegeven door één ervaren MBTp-therapeut en een cotherapeut.

Individuele therapie. Naast de groepstherapie bood individuele therapie de mogelijkheid voor intensiever contact tussen patiënt en therapeut. Het hoofddoel van individuele therapie was het opbouwen van een vertrouwensband die fungeerde als een veilige basis van waaruit emotioneel beladen gedachtes en herinneringen konden worden onderzocht.

Metingen. Het onderzoek bevatte vier beoordelingsmomenten verspreid over een periode van 2 jaar. De nulmeting (T0) vond plaats voordat MBTp werd gestart. Halverwege de MBTp behandeling, na negen maanden, vond er alleen een meting plaats met de PsyMate. Na 18 maanden (direct nadat MBTp was beëindigd) en na 24 maanden (6 maanden nadat MBTp was beëindigd) vonden er uitgebreide metingen plaats met alle uitkomstmaten. De primaire uitkomstmaat, sociaal functioneren, werd bij aanvang (T0) direct na behandeling (T2) en een half jaar na het einde van de behandeling gemeten (T3).

\section{Deel III, Hoofdstuk 7.}

De resultaten van hoofstuk 7 suggereren dat patiënten in zowel de FACT-conditie als de FACT plus MBTp-conditie een grote verbetering lieten zien op gebied van sociaal functioneren. Dat patiënten alleen op basis van FACT al een grote verbetering lieten zien op het gebied van sociaal functioneren zal voor sommige kenners geen verrassing zijn. Zoals gezegd hebben FACTteams meerdere professionals die gespecialiseerd zijn in het helpen van patiënten bij het structureren van hun sociale leven, waaronder maatschappelijk werkers en IPS-coaches. Dat FACT alleen het sociaal functioneren kan verbeteren, wordt ondersteund door enkele eerdere bevindingen (bijv. Drukker, Visser, Sytema, \& Van Os, 2013), maar tegengesproken door een ander onderzoek (Systema, Wunderink, Bloemers, Roorda, \& Wiersma, 2007). Daarnaast kan de toevoeging van IPS mogelijk ook hebben bijgedragen aan een positiever effect op het sociaal functioneren, zoals eerder onderzoek impliceerde (Hoffmann, Jäckel, Glauser \& Kupper, 2012; Pos et al., 2019). Ten slotte hebben meer mensen in de FACT groep CGT genoten ( $n=6)$ dan in de MBTp groep ( $\mathrm{n}=1$ ), wat kan bijgedragen hebben aan de toename van het sociaal functioneren in de FACT-conditie.

De resultaten suggereerden verder wel dat het effect van FACT plus MBTp robuuster was dan FACT alleen en zes maanden na het einde van behandeling behouden bleef. De followup periode van zes maanden is echter veel te kort om daarover definitieve uitspraken te doen. 
Bateman en Fonagy (2001) vonden eerder dat MBT robuuste veranderingen bewerkstelligde bij patiënten met Borderline Persoonlijkheidsstoornis, die zelfs tot acht jaar na het beëindigen van de behandeling aanhielden (Bateman \& Fonagy, 2008). De oorzaak van deze robuustere verbetering schreven zij toe aan verbeteringen van het mentaliserend vermogen, dat patiënten beter in staat zou stellen om de stress van het dagelijks leven het hoofd te bieden en beter psychosociaal te functioneren.

Het is daarom interessant te noemen dat, hoewel het bewijs voor het voorgestelde veranderingsmechanisme van MBT - de verbetering van het mentaliserend vermogen - nog steeds schaars is (Rossouw \& Fonagy, 2012; de Meulemeester, Vansteelandt, Luyten, \& Lowyck, 2018), de huidige resultaten suggereren dat patiënten in de MBTp-groep beter presteerden op verschillende maten van mentaliserend vermogen. Patiënten presteerden beter op de HT, op de dimensies 'begrip van sociale causaliteit' en 'complexiteit van representaties' van de SCORS, en op het item ziekte-inzicht van de PANSS. Mediatie-analyses leverden echter slechts beperkt bewijs dat een verbetering van het mentaliserend vermogen ook echt bijdroeg aan het behandeleffect.

Verder toonde een moderatie-analyse aan dat patiënten met een kortere ziekteduur een betere behandelrespons vertoonden, overeenkomstig eerder onderzoek (bijvoorbeeld Lincoln et al. 2014). Deze resultaten stroken ook met een groeiend aantal artikelen dat suggereert dat de eerste vijf jaar van NAPS een cruciale periode voor interventie vormen (Birchwood \& Macmillan, 1993; McGorry, Nelson, Goldstone, \& Yung, 2010). Het sociaal functioneren verslechtert namelijk het meest in de eerste 5 jaar na het ontstaan van de eerste psychose (Birchwood \& Macmillan, 1993) en ziekteduur is geïdentificeerd als een belangrijke voorspeller van een slechte behandelrespons (Lieberman, Dixon, \& Goldman, 2013). NAPS veroorzaakt een grote hoeveelheid aan problemen die therapeutische interventies kunnen compliceren naarmate de stoornis vordert, waaronder cognitieve achteruitgang (Wykes, Huddy, Cellard, McGurk, \& Czobor, 2011) en grotere rigiditeit ten opzichte van de eigen overtuigingen (Lincoln et al. 2014). Daarom hebben verscheidene onderzoekers en clinici geopperd dat de behandeling van verschillende stadia van NAPS ook een verschillende benaderingen vereist (McGorry, Nelson, Goldstone, \& Yung, 2010).

We observeerden verder dat patiënten in de FACT plus MBTp conditie een grotere afname van sociale stress in het bijzijn van anderen lieten zien. We zagen echter geen grotere verbeteringen in de FACT plus MBTp conditie op kwaliteit van leven (MANSA); affect-toon van relaties en vermogen om emotioneel te investeren (SCORS); op middelengebruik, psychotische symptomen, negatief affect en stressreactiviteit in het dagelijks leven (ESM); of positieve, negatieve, angstige en depressieve symptomen (PANSS). Een mogelijk verklaring voor het gebrek aan verdere behandelresultaten is dat de patiënten in onze steekproef aan relatief milde 
symptomen leden. Scores voor positieve en negatieve symptomen bij aanvang waren vergelijkbaar met die van (deels) herstelde patiënten (Češková, Přikryl, Kašpárek, \& Ondrušova, 2005; Phahladira et al. 2018). Deze basisscores weerspiegelen waarschijnlijk een zogenaamde recruitment bias, waarbij voornamelijk relatief stabiele patiënten deelnamen aan het onderzoek. Tijdens de selectieprocedure werd aan clinici gevraagd om hun caseloads door te nemen op patiënten die mogelijk in aanmerking zouden kunnen komen voor deelname aan het onderzoek. Aangezien slechts ongeveer $20 \%$ van de beschikbare patiënten werd doorverwezen naar het intakegesprek van het onderzoek, is het mogelijk dat clinici vooral de stabielere patiënten hebben benaderd.

\section{Implicaties voor de klinische praktijk}

De klinische inzichten verkregen uit dit proefschrift geven enkele aanwijzingen voor de verbetering van psychotherapeutische interventies voor NAPS. We zijn van mening dat het voor clinici nuttig kan zijn om naar de aanwezigheid van mishandeling in de kindertijd te vragen, omdat we hebben aangetoond dat dit op verschillende manieren invloed heeft op de ernst van symptomen in de volwassenheid. Het vaststellen van de aanwezigheid van mishandeling in de kindertijd kan zowel patiënten als artsen meer inzicht geven in de pathogenese van de aandoening. Daarnaast kan kennis van de manier waarop kindermishandeling bijdraagt aan het ontstaan van psychose helpen bij het ontwikkelen van preventiestrategieën.

Verder zijn wij van mening dat de relatief robuuste verbeteringen op het gebied van sociaal functioneren en mentaliserend vermogen die zijn geobserveerd in de MBTp conditie, van klinisch belang zijn. Hoewel redelijkerwijs beargumenteerd zou kunnen worden dat MBTp niet veel toevoegt aan FACT, omdat beiden een groot effect sorteren op het gebied van sociaal functioneren, bleken die verbeteringen in de MBTp-conditie zes maanden na het einde van de behandeling in stand te blijven en robuuster te zijn dan FACT alleen. Dat is interessant voor de klinische praktijk omdat er tot nu toe weinig bewijs is geweest dat psychosociale interventies het sociaal functioneren duurzaam kunnen verbeteren (Cather et al., 2005; Laws, Darlington, Kondel, McKenna, \& Jauhar, 2018; Green \& Horan, 2019). Aangezien sociaal disfunctioneren voorspellend is voor terugval in psychose (Couture, Penn \& Roberts, 2006), zou de toevoeging van MBTp aan FACT, ondanks de arbeidsintensieve aard van de therapie, kosteneffectiever kunnen blijken. Het beperkte aantal geobserveerde ziekenhuisopnames van patiënten die actief deelnamen aan MBTp lijkt hier inderdaad voor te pleiten (zie hoofdstuk 7), hoewel meer onderzoek nodig is om hierover definitieve uitspraken te doen.

Het waargenomen effect van MBTp op sociaal functioneren, lijkt in de subgroep van relatief recente patiënten het grootst. Recente patiënten in de MBTp groep vertoonden relatief grote verbeteringen, waarbij niveaus van functioneren werden bereikt ( $M=116.58$; zie 
hoofdstuk 7) die zich bevinden tussen die van NAPS patiënten ( $M=108.07)$ en gezonde mensen $(M=123.36)$, zoals eerder is vastgesteld door Addington en Addington (2008). De grotere behandelrespons van relatief recente patiënten kan betekenen dat MBTp eerder in plaats van later zou moeten worden geïmplementeerd

\section{Maatschappelijke implicaties en toekomstig onderzoek}

Wereldwijd ontwikkelen ongeveer 7,5 per 1000 personen een psychotische stoornis gedurende hun leven (Moreno-Küstner, Martin, \& Pastor, 2018). Dat betekent dat er, gebaseerd op het huidige bevolkingsaantal (United Nations Population Division), wereldwijd naar schatting zo'n 58 miljoen mensen op een bepaald moment in hun leven een psychotische stoornis zullen ontwikkelen. Aangezien psychotische stoornissen de neiging hebben om patiënten ernstig te invalideren, leveren psychotische stoornissen een substantiële bijdrage aan de wereldwijde ziektelast, in eerste plaats voor patiënten zelf, maar ook voor samenlevingen (Mathers, Fat \& Boerma, 2008). Een belangrijke oorzaak van dit hoge niveau van invalidering is vermoedelijk de achteruitgang van het sociaal functioneren. Hoewel er in de laatste decennia verschillende psychotherapeutische interventies zijn ontwikkeld voor psychotische stoornissen blijft bewijs dat zulke interventies zorgen voor duurzame verbeteringen op gebied van sociaal functioneren of cognitie momenteel beperkt (Green, Horan \& Lee, 2019; Laws, Darlington, Kondel, McKenna, \& Jauhar, 2018).

Dit proefschrift levert een bijdrage aan de ontwikkeling van psychosociale interventies die zich richt op duurzame verbetering van het sociaal cognitief en functionerend niveau. Er zijn echter nog veel vragen over de effecten van MBTp, voordat deze als evidence based behandeling ingezet kan worden. Het blijft de vraag hoe MBTp het best geïmplementeerd kan worden, bijvoorbeeld of het effectiever zou zijn wanneer de interventie langer duurt, wanneer deze nog specifieker wordt afgestemd op psychotische patiënten (Sanz, 2018), of wanneer die wordt geïmplementeerd in de vroege fase van de stoornis (Debbané et al., 2016). Bovendien zijn we van mening dat MBTp in toekomstige studies moet worden vergeleken met andere, bij voorkeur vergelijkbare behandelingen voor psychotische stoornissen zoals CGT, Mindfulness Based Cognitive Therapy (Segal, Teasdale, \& Williams 2004) of Metacognitive Reflection Insight Therapy (de Jong et al., 2018), omdat we nu niet met zekerheid kunnen vaststellen of aspecifieke factoren zoals het toevoegen van psychotherapie of behandeling in groepsvorm aan FACT de geobserveerde effecten hebben veroorzaakt. Ook is het van belang om te onderzoeken of de effecten van MBTp langer dan zes maanden beklijven. Interventies die het sociaal functioneren van patiënten met NAPS namelijk duurzaam kunnen verbeteren, zouden in potentie miljoenen patiënten kunnen helpen een beter bestaan op te bouwen. 


\section{Algemene sterke punten en beperkingen}

Specifieke sterke punten en beperkingen van elke studie zijn eerder beschreven in de verscheidene hoofdstukken van het proefschrift. Enkele algemene sterke punten zijn de kwalitatief sterke meetinstrumenten die we hebben gebruikt. Er is daarnaast uitgebreide training gegeven aan de beoordelaars om zo de betrouwbaarheid van de metingen te maximaliseren. Ten tweede hebben we gebruik gemaakt van geblindeerde beoordelaars om mogelijke vooringenomenheid van beoordelaars te elimineren. Ten derde selecteerden we patiënten met een uitlopende lengte van ziekteduur en een veelheid aan psychotische diagnoses. Zodoende vinden wij dat onze resultaten de algemene praktijk op een adequate wijze weerspiegelen. Veel studies maken gebruik van strikte inclusiecriteria wat de generaliseerbaarheid van resultaten niet ten goede komt (Hoertel et al., 2015).

De belangrijkste beperking van onze studies is dat ze allemaal gebruik maakten van dezelfde steekproef. Dit doet af aan de generaliseerbaarheid van onze bevindingen, omdat onze resultaten ook simpelweg kenmerken kunnen weerspiegelen die specifiek zijn voor deze steekproef. Aangezien onze steekproef relatief milde positieve en negatieve symptomen had bij aanvang (zie hoofdstuk zeven), moeten onze gegevens met voorzichtigheid worden geïnterpreteerd. Ten tweede vergroot het toetsen van meerdere hypotheses binnen dezelfde steekproef, de aanwezigheid van zogenaamde 'type 1' fouten. Met elke toetsing bestaat er namelijk een kans van 5\% dat gevonden effecten binnen deze steekproef, daarbuiten niet werkelijk bestaan. Herhaalde toetsingen vergroten daarmee ook de kans op het vinden van nietbestaande effecten. Ten derde bevatten de studies van de hoofdstukken drie, vier en vijf geen gezonde controlegroepen, waardoor het onmogelijk is om te aan te geven of de waargenomen correlaties specifiek zijn voor patiënten met NAPS, of ook bestaan in de algemene bevolking.

\section{Referenties}

Addington, J., \& Addington, D. (2008). Social and cognitive functioning in psychosis. Schizophrenia research, 99(1-3), 176-181.

Bateman, A., \& Fonagy, P. (2001). Treatment of borderline personality disorder with psychoanalytically oriented partial hospitalization: an 18-month follow-up. American Journal of psychiatry, 158(1), 36-42.

Bateman, A., \& Fonagy, P. (2006). Mentalisation based treatment: a practical guide. Oxford: Oxford University Press.

Bateman, A., \& Fonagy, P. (2008). 8-year follow-up of patients treated for borderline personality disorder: mentalization-based treatment versus treatment as usual. American Journal of Psychiatry, 165(5), 631-638. 
Bechi, M., Bosia, M., Buonocore, M., Agostoni, G., Bosinelli, F., Silvestri, M. P., ... \& Cavallaro, R. (2019). Stability and generalization of combined theory of mind and cognitive remediation interventions in schizophrenia: Follow-up results. Psychiatric rehabilitation journal.

Bifulco, A., Brown, G.W., \& Harris, T.O. (1994). Childhood Experience of Care and Abuse (CECA): a retrospective interview measure. Journal of Child Psychology and Psychiatry, 35(8), 1419-1435.

Birchwood, M., Smith, J., Cochrane, R., Wetton, S., \& Copestake, S. (1990). The Social Functioning Scale. The development and validation of a new scale of social adjustment for use in family intervention programmes with schizophrenic patients. The British Journal of Psychiatry, 157 (6), 853-859.

Birchwood, M., \& Macmillan, F. (1993). Early intervention in schizophrenia. Australian and New Zealand Journal of Psychiatry, 27(3), 374-378.

Birchwood, M., Connor, C., Lester, H., Patterson, P., Freemantle, N., Marshall, M., ... \& Everard, L. (2013). Reducing duration of untreated psychosis: care pathways to early intervention in psychosis services. The British Journal of Psychiatry, 203(1), 58-64.

Bowlby, J. (1973). Attachment and loss, vol. II: Separation. New York, NY: Basic Books.

Boyda, D., \& McFeeters, D. (2015). Childhood maltreatment and social functioning in adults with sub-clinical psychosis. Psychiatry research, 226(1), 376-382.

Brent, B.K., \& Fonagy, P. (2014). A mentalization-based treatment approach to disturbances of social understanding in schizophrenia. In P. H. Lysaker, G. Dimaggio, and M. Brüne (Eds.), Social cognition and metacognition in schizophrenia: Psychopathology and treatment approaches, 245-259. San Diego, CA: Elsevier Academic Press.

Brunelin, J., d'Amato, T., Brun, P., Bediou, B., Kallel, L., Senn, M., ... \& Saoud, M. (2007). Impaired verbal source monitoring in schizophrenia: an intermediate trait vulnerability marker? Schizophrenia Research, 89(1-3), 287-292.

Češková, E., Přikryl, R., Kašpárek, T., \& Ondrušova, M. (2005). Psychopathology and treatment responsiveness of patients with first-episode schizophrenia. Neuropsychiatric Disease and Treatment, 1(2), 179.

Corcoran, R., Mercer, G., \& Frith, C.D. (1995). Schizophrenia, symptomatology and social inference: investigating "theory of mind" in people with schizophrenia. Schizophrenia research, 17(1), 5-13.

Couture, S.M., Penn, D.L., \& Roberts, D.L. (2006). The functional significance of social cognition in schizophrenia: a review. Schizophrenia bulletin, 32(1), 44-63.

Cristóbal-Narváez, P., Sheinbaum, T., Ballespí, S., Mitjavila, M., Myin-Germeys, I., Kwapil, T.R., \& Barrantes-Vidal, N. (2016). Impact of adverse childhood experiences on psychotic-like 
symptoms and stress reactivity in daily life in nonclinical young adults. Focus, 14(3), 387-395.

de Jong, S., van Donkersgoed, R. J. M., Timmerman, M. E., Aan Het Rot, M., Wunderink, L., Arends, J., ... \& Pijnenborg, G. H. M. (2019). Metacognitive reflection and insight therapy (MERIT) for patients with schizophrenia. Psychological Medicine, 49(2), 303-313.

de Meulemeester, C., Vansteelandt, K., Luyten, P., \& Lowyck, B. (2018). Mentalizing as a mechanism of change in the treatment of patients with borderline personality disorder: A parallel process growth modeling approach. Personality Disorders: Theory, Research, and Treatment, 9(1), 22.

Debbané, M., Benmiloud, J., Salaminios, G., Solida-Tozzi, A., Armando, M., Fonagy, P., \& Bateman, A. (2016). Mentalization-based treatment in clinical high-risk for psychosis: a rationale and clinical illustration. Journal of Contemporary Psychotherapy, 46(4), 217-225.

Debbané, M., \& Toffel, E. (2019). Mentalizing through the early stages of the Psychosis Continuum. The Neurobiology-Psychotherapy-Pharmacology Intervention Triangle: The need for common sense in 21st century mental health, 141.

Delespaul, P., de Vries, M., \& van Os, J. (2002). Determinants of occurrence and recovery from hallucinations in daily life. Social psychiatry and psychiatric epidemiology, 37(3), 97-104.

Drukker, M., Visser, E., Sytema, S., \& Van Os, J. (2013). Flexible assertive community treatment: Severity of symptoms and psychiatric health service use; a real life observational study. Clinical Practice \& Epidemiology in Mental Health, 9, 202-209.

Eisenstadt, P., Monteiro, V. B., Diniz, M. J., \& Chaves, A. C. (2012). Experience of recovery from a first-episode psychosis. Early intervention in psychiatry, 6(4), 476-480.

Glaser, J.-P., Van Os, J., Portegijs, P.J., \& Myin-Germeys, I. (2006). Childhood trauma and emotional reactivity to daily life stress in adult frequent attenders of general practitioners. Journal of psychosomatic research, 61(2), 229-236.

Green, M. F., Penn, D. L., Bentall, R., Carpenter, W. T., Gaebel, W., Gur, R. C., ... \& Heinssen, R. (2008). Social cognition in schizophrenia: an NIMH workshop on definitions, assessment, and research opportunities. Schizophrenia bulletin, 34(6), 1211-1220.

Green, M. F., Horan, W. P., \& Lee, J. (2015). Social cognition in schizophrenia. Nature Reviews Neuroscience, 16(10), 620.Fonagy, P., \& Allison, E. (2014). The role of mentalizing and epistemic trust in the therapeutic relationship. Psychotherapy, 51(3), 372.

Green, M. F., Horan, W. P., \& Lee, J. (2019). Nonsocial and social cognition in schizophrenia: current evidence and future directions. World Psychiatry, 18(2), 146-161.

Fett, A. K. J., Viechtbauer, W., Penn, D. L., van Os, J., \& Krabbendam, L. (2011). The relationship between neurocognition and social cognition with functional outcomes in schizophrenia: a meta-analysis. Neuroscience \& Biobehavioral Reviews, 35(3), 573-588. 
Fonagy, P., \& Allison, E. (2014). The role of mentalizing and epistemic trust in the therapeutic relationship. Psychotherapy, 51(3), 372.

Fonagy, P., Luyten, P., Allison, E., \& Campbell, C. (2017). What we have changed our minds about: Part $1 \& 2$. Borderline personality disorder, epistemic trust and the developmental significance of social communication. Borderline personality disorder and emotion dysregulation, 4(1), 9.

Frith, C. D. (1992). The cognitive neuropsychology of schizophrenia. London, United Kingdom: Psychology Press.

Fusar-Poli, P., Byrne, M., Valmaggia, L., Day, F., Tabraham, P., Johns, L., ... \& OASIS Team. (2010). Social dysfunction predicts two years clinical outcome in people at ultra-high risk for psychosis. Journal of psychiatric research, 44(5), 294-301.

Hibbard, S., Mitchell, D., \& Porcerelli, J. (2001). Internal consistency of the object relations and social cognition scales for the thematic apperception test. Journal of Personality Assessment, 77(3), 408-419.

Hoertel, N., López, S., Wang, S., González-Pinto, A., Limosin, F., \& Blanco, C. (2015). Generalizability of pharmacological and psychotherapy clinical trial results for borderline personality disorder to community samples. Personality Disorders: Theory, Research, and Treatment, 6(1), 81.

Hoffmann, H., Jäckel, D., Glauser, S., \& Kupper, Z. (2012). A randomised controlled trial of the efficacy of supported employment. Acta Psychiatrica Scandinavica, 125(2), 157-167.

Holthausen, E. A., Wiersma, D., Cahn, W., Kahn, R. S., Dingemans, P. M., Schene, A. H., van den Bosch, R. J. (2007). Predictive value of cognition for different domains of outcome in recent-onset schizophrenia. Psychiatry Research, 149, 71-80.

Horan, W. P., \& Green, M. F. (2019). Treatment of social cognition in schizophrenia: Current status and future directions. Schizophrenia research, 203, 3-11.

Howes, O. D., \& Murray, R. M. (2014). Schizophrenia: an integrated sociodevelopmentalcognitive model. The Lancet, 383(9929), 1677-1687.

Jaya, E.S., Hillmann, T.E., Reininger, K.M., Gollwitzer, A., \& Lincoln, T.M. (2016). Loneliness and psychotic symptoms: The mediating role of depression. Cognitive Therapy and Research, $1-11$.

Kay, S.R., Fiszbein, A., Opfer, L.A. (1987). The positive and negative syndrome scale (PANSS) for schizophrenia. Schizophrenia bulletin, 13(2), 261-276.

Kelleher, I., Keeley, H., Corcoran, P., Ramsay, H., Wasserman, C., Carli, V., ... \& Cannon, M. (2013). Childhood trauma and psychosis in a prospective cohort study: cause, effect, and directionality. American Journal of Psychiatry, 170(7), 734-741. 
Kim, S. (2015). The mind in the making: Developmental and neurobiological origins of mentalizing. Personality Disorders: Theory, Research, and Treatment, 6(4), 356.

Kimhy, D., Delespaul, P., Corcoran, C., Ahn, H., Yale, S., \& Malaspina, D. (2006). Computerized experience sampling method (ESMc): assessing feasibility and validity among individuals with schizophrenia. Journal of psychiatric research, 40(3), 221-230.

Lardinois, M., Lataster, T., Mengelers, R., Van Os, J., \& Myin-Germeys, I. (2011). Childhood trauma and increased stress sensitivity in psychosis. Acta Psychiatrica Scandinavica, 123(1), 2835.

Laws, K. R., Darlington, N., Kondel, T. K., McKenna, P. J., \& Jauhar, S. (2018). Cognitive Behavioural Therapy for schizophrenia-outcomes for functioning, distress and quality of life: a meta-analysis. BMC psychology, 6(1), 32.

Leonhardt, B. L., Huling, K., Hamm, J. A., Roe, D., Hasson-Ohayon, I., McLeod, H. J., \& Lysaker, P. H. (2017). Recovery and serious mental illness: a review of current clinical and research paradigms and future directions. Expert Review of Neurotherapeutics, 17(11), 1117-1130.

Lieberman, J. A., Dixon, L. B., \& Goldman, H. H. (2013). Early detection and intervention in schizophrenia: a new therapeutic model. JAMA, 310(7), 689-690.

Lincoln, T.M., Rief, W., Westermann, S., Ziegler, M., Kesting, M.L., Heibach, E., Mehl, S. (2014). Who stays, who benefits? Predicting dropout and change in cognitive behaviour therapy for psychosis. Psychiatry Research, 216(2), 198-205.

Luyten P., Fonagy P., Lowyck B., Vermote R. (2012). Assessment of mentalization. In Bateman \& Fonagy (2012). Handbook of mentalizing in mental health practice, 43-65. Washington, DC: American Psychiatric Pub.

Mathers, C., Fat, D.M., \& Boerma, J.T. (2008.) The global burden of disease: 2004 update. Geneva: World Health Organization.

McCutcheon, R. A., Marques, T. R., \& Howes, O. D. (2019). Schizophrenia-An Overview. JAMA psychiatry, 1-10.Myin-Germeys I, \& van Os J. (2007). Stress-reactivity in psychosis: evidence for an affective pathway to psychosis. Clinical psychology review, 27(4), 409424.

McGorry, P. D. (2010). Risk syndromes, clinical staging and DSM V: new diagnostic infrastructure for early intervention in psychiatry. Schizophrenia Research, 120(1-3), 4953.

Merz, E.-M., \& Jak, S. (2013). The long reach of childhood. Childhood experiences influence close relationships and loneliness across life. Advances in life course research, 18(3), 212-222.

Meyer, G. J. (2004). The reliability and validity of the Rorschach and Thematic Apperception Test (TAT) compared to other psychological and medical procedures: An analysis of 
systematically gathered evidence. Comprehensive handbook of psychological assessment, 2, 315-342.

Michalska, D.R.B., Rhodes, S., Vasilopoulou, E., \& Hutton, P. (2017). Loneliness in Psychosis: A Meta-analytical Review. Schizophrenia bulletin.

Moreno-Küstner, B., Martin, C., \& Pastor, L. (2018). Prevalence of psychotic disorders and its association with methodological issues. A systematic review and meta-analyses. PloS one, 13(4).

Morgan, C., \& Fisher, H. (2007). Environment and schizophrenia: environmental factors in schizophrenia: childhood trauma-a critical review. Schizophrenia bulletin, 33(1), 3-10.

Murphy, J., Shevlin, M., Adamson, G., \& Houston, J.E. (2013). From sexual abuse to psychosis: a pilot study exploring the social deafferentation hypothesis and the mediating role of avoidance. Psychosis, 5(1), 36-47.

Murray, H.A. (1943). Thematic Apperception Test. Cambridge, MA: Harvard University Press. Myin-Germeys I, \& van Os J. (2007). Stress-reactivity in psychosis: evidence for an affective pathway to psychosis. Clinical psychology review, 27(4), 409-424.

Nordén, T., Malm, U., \& Norlander, T. (2012). Resource Group Assertive Community Treatment (RACT) as a tool of empowerment for clients with severe mental illness: a meta-analysis. Clinical practice and epidemiology in mental health: CP \& EMH, 8, 144.

Norman, R. M., Windell, D., Lynch, J., \& Manchanda, R. (2013). Correlates of subjective recovery in an early intervention program for psychoses. Early intervention in psychiatry, 7(3), 278-284.

O'Driscoll C., Laing, J., \& Mason, O. (2014). Cognitive emotion regulation strategies, alexithymia and dissociation in schizophrenia, a review and meta-analysis. Clinical Psychology Review, 34(6), 482-495.

Peralta, V., \& Cuesta, M. J. (1994). Psychometric properties of the positive and negative syndrome scale (PANSS) in schizophrenia. Psychiatry research, 53(1), 31-40.

Pereira, J. G., \& Debbané, M. (2018). An Integrative-Relational Approach in Schizophrenia: From Philosophical Principles to Mentalization-Based Practice. In Hipólito, I., Gonçalves, J., Pereira, J. G. (Eds.), Schizophrenia and Common Sense, 193-207. Cham, Switzerland: Springer.

Phahladira, L., Asmal, L., Kilian, S., Chiliza, B., Scheffler, F., Luckhoff, H.K., ... \& Emsley, R. (2018). Changes in insight over the first 24 months of treatment in schizophrenia spectrum disorders. Schizophrenia research , 206, 394-399. 
Pinkham, A. E., Penn, D. L., Green, M. F., Buck, B., Healey, K., \& Harvey, P. D. (2013). The social cognition psychometric evaluation study: results of the expert survey and RAND panel. Schizophrenia bulletin, 40(4), 813-823.

Pos, K., Franke, N., Smit, F., Wijnen, B. F., Staring, A. B., Van der Gaag, M., ... \& Schirmbeck, F. (2019). Cognitive behavioral therapy for social activation in recent-onset psychosis: Randomized controlled trial. Journal of consulting and clinical psychology, 87(2), 151.

Read, J., van Os, J., Morrison, A. P., \& Ross, C. A. (2005). Childhood trauma, psychosis and schizophrenia: a literature review with theoretical and clinical implications. Acta Psychiatrica Scandinavica, 112(5), 330-350.

Reininghaus, U., Kempton, M.J., Valmaggia, L., Craig, T.K., Garety, P., Onyejiaka, A., ..., \& Dazzan, P. (2016). Stress sensitivity, aberrant salience, and threat anticipation in early psychosis: an experience sampling study. Schizophrenia bulletin, 42(3), 712-722.

Roberts, D.L., \& Penn, D. L. (2009). Social cognition and interaction training (SCIT) for outpatients with schizophrenia: a preliminary study. Psychiatry research, 166(2-3), 141147.

Rossouw, T.I., \& Fonagy, P. (2012). Mentalization-based treatment for self-harm in adolescents: A randomized controlled trial. Journal of the American Academy of Child \& Adolescent Psychiatry, 51(12), 1304-1313.

Sanz, P. (2018). Technical adaptations from MBT to Schizophrenic Psychosis. Working on the Self Boundaries, presented at International Conference of Mentalization Based Treatment for Psychosis, Madrid, Spain.

Segal, Z. V., Teasdale, J. D., \& Williams, J. M. G. (2004). Mindfulness-Based Cognitive Therapy: Theoretical Rationale and Empirical Status. In Hayes, S. C., Follette, V. M., \& Linehan, M. M. (Eds.), Mindfulness and acceptance: Expanding the cognitive-behavioral tradition, 4565. New York, NY: Guilford Press.

Selten, J.-P., van der Ven, E., Rutten, B.P., \& Cantor-Graae, E. (2013). The social defeat hypothesis of schizophrenia: an update. Schizophrenia bulletin, 39(6), 1180-1186.

Sprong, M., Schothorst, P., Vos, E., Hox, J., \& Van Engeland, H. (2007). Theory of mind in schizophrenia: meta-analysis. The British Journal of Psychiatry, 191(1), 5-13.

Sündermann, O., Onwumere, J., Kane, F., Morgan, C., \& Kuipers, E. (2014). Social networks and support in first-episode psychosis: exploring the role of loneliness and anxiety. Social psychiatry and psychiatric epidemiology, 49(3), 359-366.

Systema, S., Wunderink, L., Bloemers, W., Roorda, L., \& Wiersma, D. (2007). Assertive community treatment in the Netherlands: A randomized controlled trial. Acta Psychiatrica Scandinavica, 116, 105-112. 
Thewissen, V., Bentall, R.P., Oorschot, M., J, A.C., van Lierop, T., van Os, J., \& Myin-Germeys, I. (2011). Emotions, self-esteem, and paranoid episodes: an experience sampling study. British Journal of Clinical Psychology, 50(2), 178-195.

Thomas, E. C., Muralidharan, A., Medoff, D., \& Drapalski, A. L. (2016). Self-efficacy as a mediator of the relationship between social support and recovery in serious mental illness. Psychiatric rehabilitation journal, 39(4), 352.

Trémeau, F. (2006). A review of emotion deficits in schizophrenia. Dialogues in clinical neuroscience, 8(1), 59.

van Dam, D.S., van Nierop, M., Viechtbauer, W., Velthorst, E., van Winkel, R., Bruggeman, R., ... \& Myin-Germeys, I. (2015). Childhood abuse and neglect in relation to the presence and persistence of psychotic and depressive symptomatology. Psychological Medicine, 45(7), 1363-1377.

van Nierop, M., Lecei, A., Myin-Germeys, I., Collip, D., Viechtbauer, W., Jacobs, N., Derom, C., Thiery, E., van Os, J., \& van Winkel, R. (2018). Stress reactivity links childhood trauma exposure to an admixture of depressive, anxiety, and psychosis symptoms. Psychiatry research, 1(260), 451-457.

United Nations Population Division (2019), World Population Prospects: the 2019 revision. Retrieved from https://www.worldometers.info/world-population/accessed January 2 2020.

Varese, F., Smeets, F., Drukker, M., Lieverse, R., Lataster, T., Viechtbauer, W., ... \& Bentall, R. P. (2012). Childhood adversities increase the risk of psychosis: a meta-analysis of patiëntcontrol, prospective-and cross-sectional cohort studies. Schizophrenia bulletin, 38(4), 661-671.

Veling, W., Counotte, J., Pot-Kolder, R., van Os, J., \& van der Gaag, M. (2016). Childhood trauma, psychosis liability and social stress reactivity: a virtual reality study. Psychological medicine, 46(16), 3339-48.

Weijers, J., ten Kate, C., Eurelings-Bontekoe, E., Viechtbauer, W., Rampaart, R., Bateman, A., \& Selten, J.-P. (2016). Mentalization-based treatment for psychotic disorder: protocol of a randomized controlled trial. BMC psychiatry, 16(1), 191.

Wolthaus, J.E., Dingemans, P.M., \& Schene, A.H. (2000). Component structure of the Positive and Negative Syndrome Scale (PANSS) in patients with recent onset schizophrenia and spectrum disorders. Psychopharmacology, 150, 399-403.

Wykes, T., Steel, C., Everitt, B., \& Tarrier, N. (2008). Cognitive behavior therapy for schizophrenia: effect sizes, clinical models, and methodological rigor. Schizophrenia bulletin, 34(3), 523-537. 


\section{Valorization}

Maastricht university emphasizes that knowledge obtained through academic research should also be transferred back into general society to be implemented in everyday life. This transference of knowledge is sometimes referred to as 'valorization', defined as "the process of creating value from knowledge, by making this knowledge available and suitable for economic and social exploitation and to translate this knowledge into products, services, processes and new businesses" (Knowledge Transfer Office, Maastricht University).

I believe that the knowledge obtained from this dissertation offers insights that may prove to be valuable to society. With a median lifetime prevalence of 7.5 per 1000 persons (Küstner et al., 2018) an estimated total or 58 million people will develop NAPD at one point in their lives, based on the current world population (United Nations Population Division). As NAPD tends to severely invalidate patients and accounts for a substantial part of the worldwide burden of disease (Mathers, Fat \& Boerma, 2008), this presents major challenges to individuals and societies alike. A major contributor to this high level of disability is thought to be the decline in social functioning associated with NAPD, which includes difficulties with independent living, and the maintenance of relationships and employment. In turn, poor social functioning predicts relapse into psychotic episodes (Couture, Penn \& Roberts, 2006). Moreover, the last 100 years have seen little improvement in the treatment of social functioning in patients with NAPD (Green, Horan \& Lee, 2015), whether through psychosocial interventions (Cather et al., 2005; de Jong et al. 2018; Pos et al., 2019) or pharmacological treatment (Carbon \& Correll, 2014). And although the last decade has seen the rise of several interventions targeting social cognitive, or 'mentalizing', impairments in NAPD (see Lana et al., 2017 for an overview), evidence that social cognitive training programs (Green, Horan \& Lee, 2019) or cognitive behavioral therapy (Laws, Darlington, Kondel, McKenna, \& Jauhar, 2018) provide sustained improvements in social functioning or cognition is currently limited, although one recent study showed that this is possible (Bechi et al., 2019).

I therefore feel that this dissertation contributes to the current body of knowledge, as our results seem to suggest that Mentalization Based Treatment for Psychotic disorder (MBTp) produces a sustained, greater performance on instruments that measure social functioning and social cognition. Sustained improvements that prevail even after the termination of treatment often referred to as the 'sleeper effect' - have been observed widely in studies examining the long term consequences of psychodynamic treatments in general (see de Maat, de Jonghe, Schoevers, \& Dekker, 2009; Town, et al., 2012; Leichsenring et al., 2015 for overviews) and MBT specifically (Bateman \& Fonagy, 2001; 2008). While more labor intensive, the addition of MBTp 
may therefore prove to be invaluable, because its results may last after treatment termination. In turn sustained improvements in social functioning are expected to decrease invalidation, relapse, hospitalization and thereby societal costs.

However, the follow-up period of six months in the current study is far too short to arrive at any definitive conclusions. As such, this dissertation should be only be considered as a first step in the examination and development of MBTp. Many questions remain regarding MBT-P's effects and the best way to implement it. Future research should establish whether MBTp produces long-term social cognitive and functional changes. Millions of patients may benefit from interventions that lead to durable social cognitive and functional improvements.

Additionally, our results suggest that interventions early in life may prove to be crucial in the prevention and effective treatment of NAPD. Firstly, the results of this dissertation showed that childhood abuse impacts the severity of outcome of NAPD through several pathways. Knowledge of these pathways, may help to develop prevention strategies that can stymie the development of NAPD. Secondly, MBTp seems to hold greater promise for those relatively recent onset patients, which may mean that MBTp should be implemented sooner rather than later. Thus, early intervention may further help to reduce individual suffering and societal costs.

Valorization also involves the utilization and dissemination of gained knowledge. As a science-practitioner, I consider it to be my duty to communicate the importance of childhood abuse in the development of NAPD (Varese et al., 2012) and of adjunct psychotherapy in the treatment of NAPD (van den Berg et al., 2015; Zimmermann, Favrod, Trieu, \& Pomini, 2005), especially since the implementation of psychotherapeutic treatment for psychosis in the Netherlands is still considered to be sub-optimal (Timmermans, 2019). In the course of this project, I have strived to reach fellow clinicians, for example in my current community treatment team, with lectures concerning the contents of this dissertation. In the hope of impacting clinical practice, we have provided MBTp training seminars for clinicians, and have published an article detailing the practical aspects of MBT for psychotic disorders in a trade journal for psychologists (ten Kate et al., 2016).

\section{References}

Bateman, A., \& Fonagy, P. (2001). Treatment of borderline personality disorder with psychoanalytically oriented partial hospitalization: an 18-month follow-up. American Journal of psychiatry, 158(1), 36-42.

Bateman, A., \& Fonagy, P. (2008). 8-year follow-up of patients treated for borderline personality disorder: mentalization-based treatment versus treatment as usual. American Journal of Psychiatry, 165(5), 631-638. 
Bechi, M., Bosia, M., Buonocore, M., Agostoni, G., Bosinelli, F., Silvestri, M. P., ... \& Cavallaro, R. (2019). Stability and generalization of combined theory of mind and cognitive remediation interventions in schizophrenia: Follow-up results. Psychiatric rehabilitation journal.

Carbon, M., \& Correll, C. U. (2014). Clinical predictors of therapeutic response to antipsychotics in schizophrenia. Dialogues in clinical neuroscience, 16(4), 505.

Cather, C., Penn, D., Otto, M. W., Yovel, I., Mueser, K. T., \& Goff, D. C. (2005). A pilot study of functional Cognitive Behavioral Therapy (fCBT) for schizophrenia. Schizophrenia Research, 74(2-3), 201-209.

Couture, S. M., Penn, D. L., \& Roberts, D. L. (2006). The functional significance of social cognition in schizophrenia: a review. Schizophrenia bulletin, 32(1), 44-63.

de Jong, S., van Donkersgoed, R. J. M., Timmerman, M. E., Aan Het Rot, M., Wunderink, L., Arends, J., ... \& Pijnenborg, G. H. M. (2019). Metacognitive reflection and insight therapy (MERIT) for patients with schizophrenia. Psychological Medicine, 49(2), 303-313.

de Maat, S.M., de Jonghe, F., Schoevers, R. \& Dekker, J. (2009) The effectiveness of long-term psychoanalytic therapy: A systematic review of empirical studies. Harvard Review of Psychiatry, 17(1): 1-23.

Green, M. F., Horan, W. P., \& Lee, J. (2015). Social cognition in schizophrenia. Nature Reviews Neuroscience, 16(10), 620.

Green, M. F., Horan, W. P., \& Lee, J. (2019). Nonsocial and social cognition in schizophrenia: current evidence and future directions. World Psychiatry, 18(2), 146-161.

Knowledge Transfer Office, Maastricht University. (2016). Knowledge Transfer Office. Retrieved at 2019, December 12 from https://www.maastrichtuniversity.nl/about-um/otheroffices/knowledge-transfer-office.

Lana, F., Africa Cruz, M., Sola Victor, P., Marti-Bonany, J. (2017). Social Cognition Based Therapies for People with Schizophrenia: Focus on Metacognitive and Mentalization Approaches. Schizophrenia treatment. SM Groups Open access ebooks.

Laws, K. R., Darlington, N., Kondel, T. K., McKenna, P. J., \& Jauhar, S. (2018). Cognitive Behavioural Therapy for schizophrenia-outcomes for functioning, distress and quality of life: a meta-analysis. BMC psychology, 6(1), 32.

Leichsenring, F., Luyten, P., Hilsenroth, M. J., Abbass, A., Barber, J. P., Keefe, J. R., ... \& Steinert, C. (2015). Psychodynamic therapy meets evidence-based medicine: a systematic review using updated criteria. The Lancet Psychiatry, 2(7), 648-660.

Mathers, C., Fat, D.M., \& Boerma, J.T. (2008.) The global burden of disease: 2004 update. Geneva: World Health Organization. 
Moreno-Küstner, B., Martin, C., \& Pastor, L. (2018). Prevalence of psychotic disorders and its association with methodological issues. A systematic review and meta-analyses. PloS one, 13(4), e0195687.

Pos, K., Franke, N., Smit, F., Wijnen, B. F., Staring, A. B., Van der Gaag, M., ... \& Schirmbeck, F. (2019). Cognitive behavioral therapy for social activation in recent-onset psychosis: Randomized controlled trial. Journal of consulting and clinical psychology, 87(2), 151.

ten Kate, C., Weijers, J.G., \& Smit, M. (2016). Mentaliseren bevorderende therapie voor nonaffectieve psychotische stoornissen. PsyXpert, 42-50.

Timmermans, M. (2019, may 31). Zorg voor patiënten met psychoses is ondermaats. De Volkskrant, p. 1.

Town, J. M., Diener, M. J., Abbass, A., Leichsenring, F., Driessen, E., \& Rabung, S. (2012). A metaanalysis of psychodynamic psychotherapy outcomes: Evaluating the effects of researchspecific procedures. Psychotherapy, 49(3), 276.

van den Berg, D. P., de Bont, P. A., van der Vleugel, B. M., de Roos, C., de Jongh, A., Van Minnen, A., \& van der Gaag, M. (2015). Prolonged exposure vs eye movement desensitization and reprocessing vs waiting list for posttraumatic stress disorder in patients with a psychotic disorder: a randomized clinical trial. JAMA psychiatry, 72(3), 259-267.

Varese, F., Smeets, F., Drukker, M., Lieverse, R., Lataster, T., Viechtbauer, W., ... \& Bentall, R. P. (2012). Childhood adversities increase the risk of psychosis: a meta-analysis of patientcontrol, prospective-and cross-sectional cohort studies. Schizophrenia bulletin, 38(4), 661-671.

Zimmermann, G., Favrod, J., Trieu, V. H., \& Pomini, V. (2005). The effect of cognitive behavioral treatment on the positive symptoms of schizophrenia spectrum disorders: a metaanalysis. Schizophrenia research, 77(1), 1-9.

United Nations Population Division (2019), World Population Prospects: the 2019 revision. Retrieved from https://www.worldometers.info/world-population/accessed January 2 2020. 
- List of publications and invited lectures

\section{List of publications and invited lectures}

\section{Peer-reviewed journal articles}

Adriaanse, M.A., Weijers, J.G., De Ridder, D.T.D, De Witt Huberts, J., \& Evers, C. (2014). Confabulating reasons for behaving bad: The psychological consequences of unconsciously activated behaviour that violates one's standards. European Journal of Social Psychology, 44, 255-266.

Weijers, J., ten Kate, C., Eurelings-Bontekoe, E., Viechtbauer, W., Rampaart, R., Bateman, A., \& Selten, J. P. (2016). Mentalization-based treatment for psychotic disorder: protocol of a randomized controlled trial. BMC psychiatry, 16(1), 191.

Adriaanse, M. A., Kroese, F. M., Weijers, J., Gollwitzer, P. M., \& Oettingen, G. (2018). Explaining unexplainable food choices. European Journal of Social Psychology, 48(1), 15-24.

Weijers, J., Fonagy, P., Eurelings-Bontekoe, E., Termorshuizen, F., Viechtbauer, W., \& Selten, J. P. (2018). Mentalizing impairment as a mediator between reported childhood abuse and outcome in nonaffective psychotic disorder. Psychiatry research, 259, 463-469.

Weijers, J., Viechtbauer, W., Eurelings-Bontekoe, E., \& Selten, J. P. (2018). Reported Childhood Abuse and Stress Reactivity in Psychosis: A Conceptual Replication and Exploration of Statistical Approaches. Frontiers in psychiatry, 9.

Steenkamp, L., Weijers, J., Gerrmann, J., Eurelings-Bontekoe, E., \& Selten, J. P. (2019). The relationship between childhood abuse and severity of psychosis is mediated by loneliness: an experience sampling study. Schizophrenia research.

Weijers, J.G., ten Kate, C. Debbané, M., Bateman, A.W., Selten, J.-P.C.J, \& Eurelings-Bontekoe, E.H.M. (2020). Mentalization and psychosis: a rationale for the use of mentalization theory to understand and treat non-affective psychotic disorder. Journal of Contemporary Psychotherapy, 1-10.

Weijers, J.G., ten Kate, C., Viechtbauer, W.V., Rampaart, L.J.A., Eurelings, E.H.M., \& Selten, J.P. (2020). Mentalization-based treatment for psychotic disorder: a rater-blinded, multicenter, randomized controlled trial. Psychological Medicine.

\section{Trade journal article}

ten Kate, C., Weijers, J.G., Smit, M. (2016). Mentaliseren bevorderende therapie voor nonaffectieve psychotische stoornissen. PsyXpert, 42-50. 


\section{Invited lectures}

Weijers, J.G., Fonagy, P., Eurelings-Bontekoe, E., Termorshuizen, F., Viechtbauer, W, \& Selten, J.P. (2016). Mentalizing impairment as mediator between reported childhood abuse and outcome in nonaffective disorder. Presented at: International Congress on Borderline Personality Disorder and Allied Disorders, Vienna, Austria.

Weijers, J.G. (2018). Attachment processes in the development of psychosis: childhood trauma, mentalizing and loneliness. Presented at: Metacognition and psychosis symposium, Groningen, the Netherlands.

Weijers, J.G. (2018). Childhood abuse, loneliness and mentalization in non-affective psychotic disorder, presented at: International Conference of Mentalization Based Treatment for Psychosis, Madrid, Spain.

Weijers, J.G., ten Kate, C., \& Siecker, I. (2019). Mentaliseren bevorderende therapie bij psychotische stoornissen. Psychiater Expertgroep Persoonlijkheidsstoornissen, Amersfoort, the Netherlands. 


\section{Dankwoord}

Laat ik beginnen bij de belangrijkste persoon in mijn leven. Lotte, mijn lief. Dank voor jouw liefde en je eindeloze geduld met mij. Al het harde werk en de verloren zondagen dienden slechts één doel: onze toekomst, die we binnenkort met een zoontje mogen delen! Ik hou van jou het allermeest.

Natuurlijk ook veel dank aan mijn familie. Pap en mam, dank voor al jullie steun en liefde, ik hou van jullie. Jullie hebben op meerdere wijzen een cruciale bijdrage geleverd aan het dit proefschrift. Zonder jullie had ik überhaupt niet bestaan, wat de totstandkoming van dit proefschrift had gecompliceerd. Pap, jouw genuanceerde, compassievolle en kritische blik op allerhande zaken heeft mij al vroeg voorbereid op mijn werk als therapeut en wetenschapper. Mam, van jou 'erfde' ik de liefde voor de psychodynamische benadering, waarin empathie, transparantie en begrip voorop staan. Jesse en Nina, wat een geluk heb ik met zo'n lieve broer en schoonzus. Nu het proefschrift klaar is, hoop ik veel meer tijd met jullie door te kunnen brengen. En lieve Otis en Lou, wat ben ik blij dat ik jullie (peet)oom ben! Daan en Sanne, het doet me veel goed dat jullie naast mijn zwager en schoonzus ook gewoon heel fijne vrienden zijn! Zo mooi dat we ongeveer tegelijk zullen beginnen aan het ouderschap. Ik kan me geen ander koppel voorstellen met wie ik deze bijzondere tijd liever door zou willen brengen. Jos en Coby, dank voor al jullie betrokkenheid en steun. Wat bof ik met jullie als schoonouders, en wat gaat onze zoon boffen met jullie als grootouders!

Alle deelnemende patiënten mag ik natuurlijk niet overslaan; jullie zijn misschien wel de belangrijkste mensen in de totstandkoming van dit werk. Al het onderzoek draait uiteindelijk om jullie en werd gedragen door jullie. Wat ontzettend fijn en stoer dat jullie het hebben aangedurfd deel te nemen aan een experiment van twee jaar (!) en dat jullie ons jullie vertrouwen hebben willen geven. Ik heb jullie leren kennen als ongelofelijk dappere mensen die, ondanks tegenslagen in het leven, de strijd niet opgeven.

Coriene ten Kate, veel dank, veel dank. Zonder jouw visie was dit project nooit van de grond gekomen. Je hebt me geïnfecteerd met je passie voor MBT. Je bent daarnaast zeer vormend geweest in mijn ontwikkeling, niet louter de cognitieve, maar vooral ook mijn affectieve ontwikkeling.

Prof. J.P. Selten, beste Jean-Paul, ik ben jou het meest erkentelijk voor het succes waarmee we onze artikelen hebben gepubliceerd. Ik heb je ervaren als een zeer kundig en begeesterd wetenschapper die zijn eigen pad durft te bewandelen. Jouw feedback fungeerde als een slijpsteen voor de geest. Eén van de eerste commentaren die je me gaf, was dat ik moest 
leren om beknopt te leren schrijven en om hoofd van bijzaken te scheiden. Ik vrees dat ik een hardleerse leerling ben gebleken; laten we het er op houden dat het mijn "persoonlijke stijl" is. Met jouw visie heb je mijns inziens de psychosezorg ook een grote dienst bewezen. Twintig jaar geleden was het nog een zonde om te spreken van de sociale invloeden op het ontstaan van psychoses, dat was namelijk een genetische, degeneratieve hersenaandoening. Maar jij 'zondigde' hardnekkig door, ook al was dat toen niet modieus. Gelukkig heb je met je visie en onderzoek menigeen meegesleurd in jouw zondeval, want tegenwoordig weten we wel beter.

Prof. Dr. Elisabeth Eurelings-Bontekoe, beste Liesbeth, dank voor al je feedback, maar vooral ook je steun. Je combineert een scherpe geest met een warm hart, eigenschappen die denk ik essentieel zijn in de psychologie. Op belangrijke momenten waarop ik worstelde met het proces, wist jij precies de juiste dingen te zeggen om mij vooruit te helpen. Ook in voor jou zware tijden kon je er oprecht zijn voor mij. Dat vind ik zó'n mooie eigenschap. Jouw klinische blik en je tegendraadsheid zijn zeer inspirerend geweest. Ook jij hebt, in weerwil van de waan van de dag, altijd je eigen koers gevaren. Misschien komt dat omdat je je eigen werk en het commentaar daarop altijd in een breder, historisch perspectief hebt kunnen plaatsen. Dat is een houding die nog lang zal resoneren in mij. Ik ben trots om met je samengewerkt te mogen hebben.

Dr. Viechtbauer, dear Wolfgang, thank you for helping me navigate through the labyrinth that is multilevel regression analysis. Also, thank you for dispelling the persistent rumor that statisticians cannot be warm, sociable and funny.

Dear Martin Debbané, Anthony Bateman and Peter Fonagy, thank you for your collaboration on several papers. Asking for your feedback was, at times, intimidating, but your comments were always delivered with grace and lightheartedness. Your insights were invaluable, thank you for your truly inspirational work.

Natuurlijk ook dank aan alle teams die hebben bijgedragen aan het onderzoek, en met name de behandelaren die hebben meegewerkt aan het project. Wat een geluk dat ik met zulke gedreven, consciëntieuze collega's heb mogen werken. Allereerst natuurlijk dank aan het MBTteam in Voorhout en in het bijzonder dank aan Rutger Rampaart, Irma Siecker, Rosa Klaver, Yvonne Noij, Andrea Landman, Iliana Borisova, Mary Boes, en Heidi Geutjes voor hun directe bijdrage. Het VIP-team Leiden mag natuurlijk ook niet ontbreken, omdat jullie zo veel participanten bereid hebben gekregen mee te doen. In het bijzonder dank aan Leon Jansen en Willem Jan van Utrecht voor jullie bijdrage aan de therapie, maar ook voor de manier waarop jullie me welkom hebben geheten in het team. Daarnaast veel dank aan Anneke Duijn. Het was ontzettend fijn hoe je mij, als bijna vanzelfsprekend, hebt geholpen toen mijn onderzoekscontract ten einde liep. Natuurlijk ook dank aan Wijkteam Zoetermeer; wat een mooie therapiegroep draaiden jullie! In het bijzonder wil ik daarvoor Ester Schellingerhout, 
- Acknowledgements

Nandl Lokhorst, Maaike van Hooff en Karin Schoenmaker bedanken. Ten slotte wil ik FACT-team Altrecht Zeist bedanken voor hun bijdrage, met name Peter van Beek, Yolanda Licher, Erik Smid, Sonja Knecht en Sabine Werre.

Dank ook aan het onderzoeksteam van de psychoselijn bij Rivierduinen. Els wat was ik blij met jou als collega. Ik vond je ambitie inspirerend en je levenslust aanstekelijk. Bovenal prijs ik jouw stoerheid. Ik weet nog goed hoe je hoogzwanger je onderzoek over de invloed van stress tijdens zwangerschap op psychopathologie stond te verdedigen. Fabian, ik mis onze uitgebreide wetenschapsfilosofische discussies tijdens de lunch! Je combineert vakmanschap, eigenzinnigheid, en humor met compassie. Wanneer ga je ons nou eens een rondleiding langs je varkens geven? Yvonne, zo mooi om te zien hoe jij een promotietraject, moederschap en nu ook een opleiding tot verpleegkundig specialist combineert en dat zonder een krimp, zucht of klacht. Daar kunnen velen nog een puntje aan zuigen. Jori, het promoveren was uiteindelijk niet helemaal wat je ervan verwacht had en je maakte de dappere keuze om je eigen pad te bewandelen, maar dat was wel een gemis voor Yvonne en mij! Je was een zeer prettige collega en bleef ook bij tegenslag altijd empathisch. Rik, jij bent niet alleen een wetenschapper pur sang maar ook gewoon een allround intellectueel, en een zeer prettige bovendien. Gesprekken met jou konden gaan over de NASA, whiskey, de netwerktheorie van psychopathologie en Jordan Peterson. Carmen, de jongste loot aan de boom van JP, hou vol en ga zo door! Zodra je die medisch ethische goedkeuring binnen hebt gaat alles vanzelf ;-). Geloof me, ik kan het weten.

Dank aan de onderzoeksassistente en alle studenten die zo ijverig alle data hebben verzameld. Hanneke van der Werf, Latifa si Amer en Valentein Hol, jullie beten het spits af, en hoe! Mooi hoe rustig jullie te werk gingen. Floor van den Berge en Patrick Imanse, wat zijn jullie een doorzetters! Jullie waren er vanaf het begin transparant over dat onderzoek niet jullie favoriete bezigheid was, maar jullie hebben je er doorheen geslagen. Zo mooi om te zien hoe empathisch jullie met de patiënten omgingen. Jorinde Gerrmann en Lisa Steenkamp, jullie gingen ambitieus aan de slag met de nieuwste, net aangeleerde statistische methodes om zo de ingewikkeld gestructureerde data van de PsyMate te temmen. Jullie hebben prachtig onderzoek gedaan, al echt promovendus-waardig. Marleen van Pelt en Emma Deckers, wat waren jullie ijverig! Niet alleen deden jullie alle werkzaamheden uitmuntend, maar jullie schreven ook nog een heuse gids voor de volgende stagiaire (iets wat duidelijk ontbrak toen jullie bij mij begonnen). Esther van Zoen, jij was hekkensluiter van het project en erg prettig om mee te werken. Je bent een enorm compassievolle psycholoog die tegelijkertijd geheel haar eigen gang durft te gaan.

Mijn dank gaat ook uit naar iedereen die me de laatste twee jaar heeft geholpen bij het jongleren van de werkzaamheden voor mijn proefschrift en de GZ-opleiding. Ik heb de afgelopen tijd eigenlijk als relatief ontspannen ervaren. Natuurlijk wil ik daarvoor mijn opleidingsgroep 
$G Z 19 B$ bedanken. De relaxte, no-nonsense sfeer van onze groep is besmettelijk en zorgt ervoor dat ik nooit té gestrest ben over de opleiding. In het bijzonder ook dank aan Fleur van Ierschot, die langer als jaargroep-vertegenwoordiger wilde fungeren zodat ik in alle rust mijn proefschrift kon afronden. Ook dank aan mijn werkbegeleiders, supervisoren en praktijkbegeleiders: Mieke de Jong, Yvonne Verburg, Michael Holwerda, Koert Velders, en Daan Jonker. Jullie leken er stuk voor stuk naar te streven om de opleiding niet nodeloos zwaar te maken en dat is goed gelukt! Daarnaast moet ik absoluut ook mijn collega's van Wijkteam Gouda West en de Polikliniek Gouda noemen. Dank dat jullie mij zo'n prettige tijd hebben gegeven! Door de gemoedelijke sfeer heb ik me op beide locaties erg welkom gevoeld.

Ook wil ik de medewerkers van de School of Mental Health and Neuroscience van Maastricht University bedanken voor hun hulp. Debora op ' $t$ Eijnde en Truda Driesen wil ik in het bijzonder even in het zonnetje zetten. Dank voor het beantwoorden van mijn eindeloze vragen over $4 \mathrm{~d}$ en de invoer van al die bergen data! Jullie stonden altijd direct paraat om problemen op te lossen. Jullie waren een heuse lifeline.

Ik zou ook mijn dank willen uiten naar de directie van GGZ Rivierduinen voor hun financiële steun en het lef dat ze hebben getoond om met dit project aan de slag te gaan.

En last but not least, dank aan mijn vrienden die me er, waar nodig, doorheen hebben gesleept. Eddie, hoe kan zo veel talent en zo veel bescheidenheid in één persoon samenkomen? Ik zou daar een compliment over willen maken, maar volgens jouw eigen onderzoek mag dat niet. Dan ga je naast je schoenen lopen. Daarom zeg ik maar: goed bezig gozah! Dank voor je steun, en de eindeloos meanderende gesprekken. Dank ook dat je me hebt geleerd dat je als zelfrespecterend onderzoeker en psycholoog best het werk van de psychoanalytici mag bestuderen. Ik ben bevoorrecht jou mijn vriend te mogen noemen. Sjoerd, jij bent nooit, maar ook echt nooit, te beroerd om iets voor een ander te doen. Je bent zo'n fijne maat en toffe vent. Heel gaaf (en een beetje jaloersmakend) om te zien hoe jij nu met je eigen bedrijf je eigen koers trekt in het leven. Je bent daarin een voorbeeld voor me. Heel veel dank voor de prachtige cover van dit proefschrift. Roel, het zal voor mij altijd een mysterie blijven hoe iemand tegelijkertijd zo sociaal fijngevoelig kan zijn en zulke harde grappen kan maken. Je bent een onbaatzuchtige, vrijgevige en oprechte vriend. Jeroen, je bent een echte rots in de branding en stiekem gewoon het grappigste lid van onze groep. Ik mis de tijd dat je even bij ons meubilair hoorde! Die twee maanden vlogen voorbij. Kom je volgende week weer een film kijken? En wanneer gaan we Trix zien? Ralf, boyo, ik vind het mooi hoe onverschrokken en tegendraads jij in het leven staat. Je laat je niet leiden door algemene verwachtingen of 'hoe het hoort', maar door een zoektocht naar authenticiteit en echt menselijk contact. Dat verdient alle lof. Rick, ik vind het mooi hoe bewust jij je keuzes maakt en hoe je in het leven staat. Ogenschijnlijk gaat het je allemaal erg gemakkelijk af, maar je staat jezelf niet toe om al te veel achterover te leunen en blijft jezelf 
ontwikkelen. Dat is navolgenswaardig. Reinier, jij bent het levende bewijs dat een goede buur ook een naaste vriend kan zijn. Ik vind het bewonderenswaardig hoe het je lukt om zo veel energie in je vriendschappen te blijven steken. Mooi om te zien hoe jij met nuchterheid, humor, transparantie en een dappere kwetsbaarheid, de obstakels in je leven te lijf gaat. Oh en de cappucino is nog steeds heerlijk. Jaapiooooo, hoe kan iemand die zó veel geld verdient tegelijk zo empathisch zijn? Wat heb ik genoten van onze tocht door de Utrechtse heuvelrug (en de whiskey om 11 uur 's ochtends)! Wat begon als een jazzband (hoe heetten we ook alweer?!) is uitgebloeid tot een vriendschap die ik niet zou willen missen. Stefan, fijne vent en mijn oudste vriend! Het heeft mijn leven verrijkt om jou al sinds mijn vierde jaar te kennen. Je bent een oertrouwe, fijne vent. Ik zou je wel willen vragen om te stoppen met het kopiëren van mijn levenskeuzes, want het begint nu wel een beetje creepy te worden. Martin, wat begon als een goed collegiaal contact in Leiden is uitgegroeid tot een zeer gewaardeerde vriendschap. De horrornight is een roemloze dood gestorven maar de spelletjesmiddagen (D\&D!) en de zelfgebrouwen (soms ontploffende) Martinbiertjes, zijn wat mij betreft een blijvertje! Wijnand, jij hebt een onverschrokken eigenzinnige blik op het leven en de psychotherapie die mij inspireert. Ik ben zeer blij dat ik je heb leren kennen tijdens de Dag van de Psychotherapie. Moge we nog vaak wandelen langs Goudse grachten. Mieke, jouw nuchtere, grappige kijk op de wereld zorgt ervoor dat ik met mijn benen iets meer op de grond blijf staan. Ik vind je enorm dapper en stoer. Hoe jij omgaat met veranderende omstandigheden is een voorbeeld voor ons allemaal. Steven, mijn meest recente vriend. Dank dat je me op sleeptouw nam met de Metacognitie-groep in Florence! We hebben er mooie, iets te lange avonden in de kroeg doorgebracht. De bijwerkingen van die avonden neem ik je overigens niet in dank af. Ook dank voor je collaboratie bij een van de artikelen. Ik hoop dat er nog vele mogen volgen. Want zeg nou zelf, MBT en MERIT zijn toch eigenlijk hetzelfde (of toch niet?). Gijs en Femke! Samen sterrenkijken in de Eifel en schnitzels eten in een vies café behoren tot mijn leukste herinneringen uit dit rare corona tijdperk. Een oerdegelijke vakantie werd tienmaal leuker met jullie als gezelschap, want een gewone boswandeling werd plotseling een dinosafari. 


\section{Curriculum Vitae}

Jonas Gijs Weijers was born on April the 8th, 1986 in Nijmegen, the Netherlands. He attended his high school at the Stedelijk Gymnasium in Nijmegen between 1998 and 2004, after which he went to Utrecht University where he studied Clinical Psychology, Social Psychology and Philosophy. He obtained his bachelor's degree in 2009. Having discovered both a passion for scientific research and an interest in clinical practice - and being utterly unable to choose between them - he decided to attend the Social and Health Psychology and Clinical Psychology master's programs at Utrecht University. After university he started working as a junior researcher at the Self Regulation Lab of Utrecht University and as a psychologist at Altrecht Mental Health Institute. In late 2013 he was offered the opportunity to work as a PhD-student and psychologist at the Rivierduinen Mental Health Institute and Maastricht University, studying and practicing psychotherapy. In 2019, he started a two-year post-master's program to become a mental health-care psychologist, continuing his work with patients with severe mental illness in a Flexible Assertive Community Treatment team in Gouda. 
